Corroboration of the new method of obtaining dissipation
in wake flow

by

\author{
Harinder Pal Singh Virk
}

\begin{abstract}
A thesis
presented to the University of Manitoba

in fulfillment of the

thesis requirement for the degree of

Master of Science

in

The Department of Mechanical Engineering
\end{abstract}

Winnipeg, Manitoba

(c) Harinder Pal Singh Virk, 1989 
National Library

of Canada

Canadian Theses Service

Ottawa, Canada

K1A ON4
Bibliothèque nationale

du Canada

Service des thèses canadiennes
The author has granted an irrevocable nonexclusive licence allowing the National Library of Canada to reproduce, loan, distribute or sell copies of his/her thesis by any means and in any form or format, making this thesis available to interested persons.

The author retains ownership of the copyright in his/her thesis. Neither the thesis nor substantial extracts from it may be printed or otherwise reproduced without his/her permission.
L'auteur a accordé une licence irrévocable et non exclusive permettant à la Bibliothèque nationale du Canada de reproduire, prêter, distribuer ou vendre des copies de sa thèse de quelque manière et sous quelque forme que ce soit pour mettre des exemplaires de cette thèse à la disposition des personnes intéressées.

L'auteur conserve la propriété du droit d'auteur qui protège sa thèse. Ni la thèse ni des extraits substantiels de celle-ci ne doivent être imprimés ou autrement reproduits sans son autorisation.

ISBN $\quad 0-315-54874-6$ 


\title{
CORROBORATION OF THE NEW METHOD OF OBTAINING \\ DISSIPATION IN WAKE FLOW
}

BY

HARINDER PAL SINGH VIRK

\begin{abstract}
A thesis submitted to the Faculty of Graduate Studies of the University of Manitoba in partial fulfillment of the requirements of the degree of
\end{abstract}

\author{
MASTER OF SCIENCE
}

(c) 1989

\begin{abstract}
Permission has been granted to the LIBRARY OF THE UNIVERSITY OF MANITOBA to lend or sell copies of this thesis. to the NATIONAL LIBRARY OF CANADA to microfilm this thesis and to lend or sell copies of the film, and UNIVERSITY MICROFILMS to publish an abstract of this thesis.
\end{abstract}

The author reserves other publication rights, and neither the thesis nor extensive extracts from it may be printed or otherwise reproduced without the author's written permission. 
I hereby declare that I am the sole author of this thesis. I authorize the University of Manitoba to lend this thesis to other institutions or individuals for the purpose of scholarly research.

Haritlder Pal Singh Virk

I further authorize the University of Manitoba to reproduce this thesis by photocopying or by other means, in total or in part, at the request of other institutions or individuals for the purpose of scholarly research.

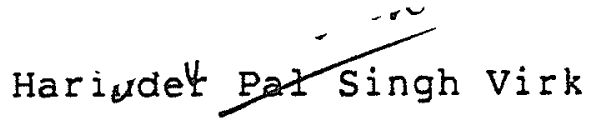


The University of Manitoba requires the signatures of all persons using or photocopying this thesis. Please sign below, and give address and date. 
A two-dimensional far wake of a circular cylinder has been investigated for the average turbulent kinetic energy equation. The wake was generated by placing a cylinder of diameter $2.77 \mathrm{~mm}$ in a free-stream velocity of $6.70 \mathrm{~m} / \mathrm{s}$ and the Reynolds number for this flow was 1160. Both analog and digital techniques of measurement were used to obtain the data with hot-wire anemometry. The dissipation term is obtained from the $\overline{\mathrm{u}^{2}}$-spectra, using the zero-length method of Azad \& Kassab (1989). This dissipation is compared with the best values of dissipation available up to date in a similar flow due to Browne et al. (1987) and it shows excellent agreement with their values. Additionally, the results of dissipation also satisfy the closure of the energy equation. It seems that this new method of obtaining dissipation is universal in nature. 


\section{ACKNOWLEDGEMENTS}

First of all I would sincerely like to thank Dr. R.S. Azad, my thesis advisor, for his excellent guidance, helpful discussions, appreciation and encouragement during this work. Thanks are also due to Dr. A.C. Trupp and Dr. E.V. Wilms for their careful review and constructive criticism of the thesis.

I am also thankful to my friend Ravi Suman for all his help and moral support during the last stages of this work and last but not the least, I appreciate the technical assistance provided by Ken Tarte.

Finally, I would like to offer special thanks to my parents, wife and sister. 
CONTENTS

\begin{abstract}
• • . . . . . . . . . . . . . . . . . • iv ACKNOWLEDGEMENTS LIST OF TABLES • LIST OF FIGURES • . . . . . . . . . . . . . . . . . ix NOMENCLATURE •. . . . . . . . . . . . . . . . . xii
\end{abstract}

\title{
Chapter
}

page

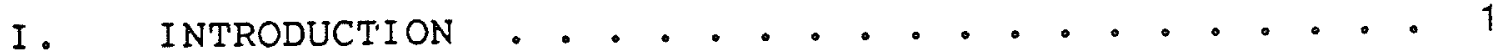

I. EXPERIMENTAL SET-UP AND PROCEDURES • • • • • • . 10

The wind tunnel facility . . . . . . . . 10

Pressure measurements . . . . . . . . . 13

Turbulence Measurements . . . . . . . . . 15

Instrumentation for turbulence measurements . . . . . . . . 15

Procedure for General turbulence measurements ........... 18

Procedure for Spectra Measurements . . . 22

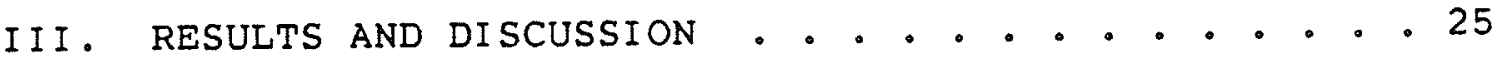

Mean-Velocities . . . . . . . . . . 26

Fluctuating velocity correlations . . . . . 29

spectral data in the self-similar wake... . 32

Energy Budget . . . . . . . . . . . . 35

$\bar{q}^{2}$ diffusion .............. . . 35

Advection............... 36

Production ............... 37

Dissipation . . . . . . . . . . . . . 38

Pressure diffusion ............ 40

Discussion of Energy Budget... . . . . 40

Dissipation by other methods... . . . . . 41

IV. CONCLUSIONS . . . . . . . . . . . . . . . 45

REFERENCES •. . . . . . . . . . . . . . . . 47 


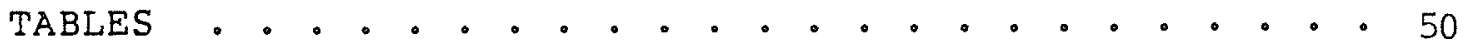

FIGURES • • • • • • • • • • • • • • • • • • • • 101

APPENDIX A 


\section{LIST OF TABLES}

Table

Page

A Summary of Experimental Conditions . . . . . . 50

B Dimensions of the Wires used for Spectra

Measurements........... 50

C. 1 Mean-velocity Profile in Cylinder Wake

at $\mathrm{x} / \mathrm{D}=220$............... 51

C.2 Mean-velocity Profile in Cylinder Wake at $x / D=270$............ 52

C.3 Mean-velocity Profile in Cylinder Wake at $\mathrm{x} / \mathrm{D}=320$...............

C.4 Mean-velocity Profile in Cylinder Wake

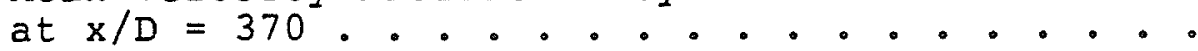

C.5 Mean-velocity Profile in Cylinder Wake at $\mathrm{x} / \mathrm{D}=420$..................

D.1 Second Order Velocity Correlations in

the Wake.......... 56

D.2 Third order Velocity Correlations in the Wake.............. 57

E.1 $\overline{u^{2}}$-Spectra Obtained with Wire 1 . . . . . . . 58

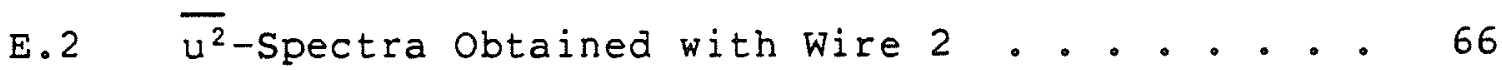

E.3 $\overline{u^{2}}$-Spectra Obtained with wire $3 . . . . . . .74$

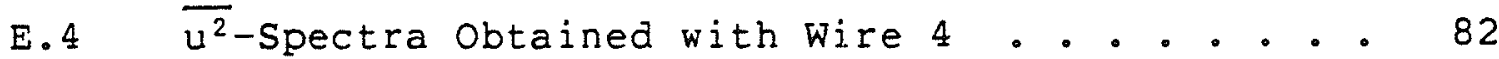

E.5 $\overline{u^{2}}$-Spectra Obtained with wire $5 \ldots 90$

F Dissipation Obtained with Different Wires and the Corresponding Zero-length Extrapolated Values . . . . . . . . . . .

G Average Turbulent Kinetic Energy Budget in the Wake .............. 99

H Values of the Factor J Across the Wake . . . 100 - viii - 


\section{LIST OF FIGURES}

\section{Figure}

Page

The wind Tunnel . . . . . . . . . 101

2 (a) The coordinate system . . . . . . . . 102

(b) Sketch of a plane turbulent wake... . . 102

3.1 Block diagram of the instruments used for analog measurements .......... 103

3.2 Block diagram of the instruments used for digital measurements........... . 104

4 Electron microscope photographs of a typical hotwire, showing, (a) the length of the wire and (b) the diameter of the wire... . . . 105

5 The coordinate system and mean-velocity defect profiles in self-preserving coordinates . . . 106

6 Variation of the wake half-width, I, along the wake............. 107

7.1 Distribution across the wake of the r.m.s. of the $x$-component of the fluctuating velocity . 108

7.2 Distribution across the wake of the r.m.s. of the $y$-component of the fluctuating velocity . 109

7.3 Distribution across the wake of the r.m.s. of the z-component of the fluctuating velocity . . 110

7.4. Distribution across the wake of the second order velocity correlation uv . . . . . . . 111

8.1 Distribution across the wake of the third

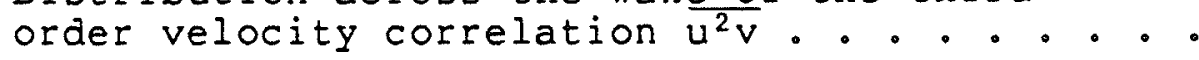

8.2 Distribution across the wake of the third

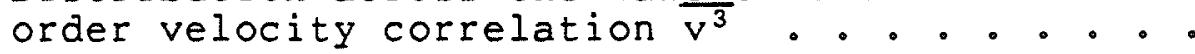

8.3 Distribution across the wake of the third order velocity correlation $\overline{\mathrm{vw}^{2}} . . . . . .$. .

9 Comparison of $\overline{\mathrm{q}^{2}}$ diffusion with Browne et al. (1987) 
10 Comparison of advection with Browne et al. $(1987)$. . . . . . . .... 116

11 Comparison of production with Browne et al. $(1987)$................. 117

12.1 Zero-length extrapolation of dissipation measured with different wires at $y=0 \mathrm{~mm}$, $\mathrm{x} / \mathrm{D}=420$

12.2 Zero-length extrapolation of dissipation measured with different wires at $y=4 \mathrm{~mm}$, $\mathrm{x} / \mathrm{D}=420$

12.3 Zero-length extrapolation of dissipation measured with different wires at $y=8 \mathrm{~mm}$, $\mathrm{x} / \mathrm{D}=420$

12.4 Zero-length extrapolation of dissipation measured with different wires at $y=12 \mathrm{~mm}$, $x / D=420$

12.5 Zero-length extrapolation of dissipation measured with different wires at $y=16 \mathrm{~mm}$, $\mathrm{x} / \mathrm{D}=420$. . . . . . . . . . . . . . . . .

12.6 Zero-length extrapolation of dissipation measured with different wires at $y=20 \mathrm{~mm}$, $\mathrm{x} / \mathrm{D}=420$. . . . . . . . . . . . . . . .

12.7 Zero-length extrapolation of dissipation measured with different wires at $y=24 \mathrm{~mm}$, $\mathrm{x} / \mathrm{D}=420$

12.8 Zero-length extrapolation of dissipation measured with different wires at $y=28 \mathrm{~mm}$, $\mathrm{x} / \mathrm{D}=420$

13 Comparison of the dissipation measured by zero-length method with the dissipation of Browne et al. (1987)

14 Comparison of the pressure diffusion term of the energy budget...............

15 Measured budget of average turbulent kinetic energy . . . . . . . . . . . . . 128

16.1 $\overline{u^{2}}$-spectra in the cylinder wake at $y=0 \mathrm{~mm}$, $\mathrm{x} / \mathrm{D}=420$. [Obtained with standard wire(\#3)] 
Figure

Page

$16.2 \quad \overline{u^{2}}$-Spectra in the cylinder wake at $y=4 \mathrm{~mm}$,
$\mathrm{x} / \mathrm{D}=420 .[$ Obtained with standard wire $(\# 3)] \quad . \quad 130$

$\begin{array}{ll}16.3 & \overline{u^{2}} \text {-Spectra in the cylinder wake at } y=8 \mathrm{~mm}, \\ \mathrm{x} / \mathrm{D}=420 . \text { [Obtained with standard wire }(\# 3)] & . \quad 131\end{array}$

$\begin{array}{ll}16.4 & \overline{u^{2}} \text {-Spectra in the cylinder wake at } y=12 \mathrm{~mm}, \\ \mathrm{x} / \mathrm{D}=420 . \text { [Obtained with standard wire }(\# 3)] & . \quad 132\end{array}$

$\begin{array}{ll}16.5 & \overline{u^{2}}-\text { Spectra in the cylinder wake at } y=16 \mathrm{~mm}, \\ \mathrm{x} / \mathrm{D}=420 . \text { [Obtained with standard wire }(\# 3)] & .133\end{array}$

$\begin{array}{ll}16.6 & \overline{u^{2}}-\text { Spectra in the cylinder wake at } y=20 \mathrm{~mm}, \\ \mathrm{x} / \mathrm{D}=420 . \text { [Obtained with standard wire }(\# 3)] & .134\end{array}$

$\begin{array}{ll}16.7 & \overline{u^{2}}-\text { Spectra in the cylinder wake at } y=24 \mathrm{~mm}, \\ \mathrm{x} / \mathrm{D}=420 .[\text { Obtained with standard wire }(\# 3)] & . \quad 135\end{array}$

$\begin{array}{ll}16.8 & \overline{u^{2}}-\text { Spectra in the cylinder wake at } y=28 \mathrm{~mm}, \\ \mathrm{x} / \mathrm{D}=420 .[\text { Obtained with standard wire }(\# 3)] & .136\end{array}$ 


\section{NOMENCLATURE}

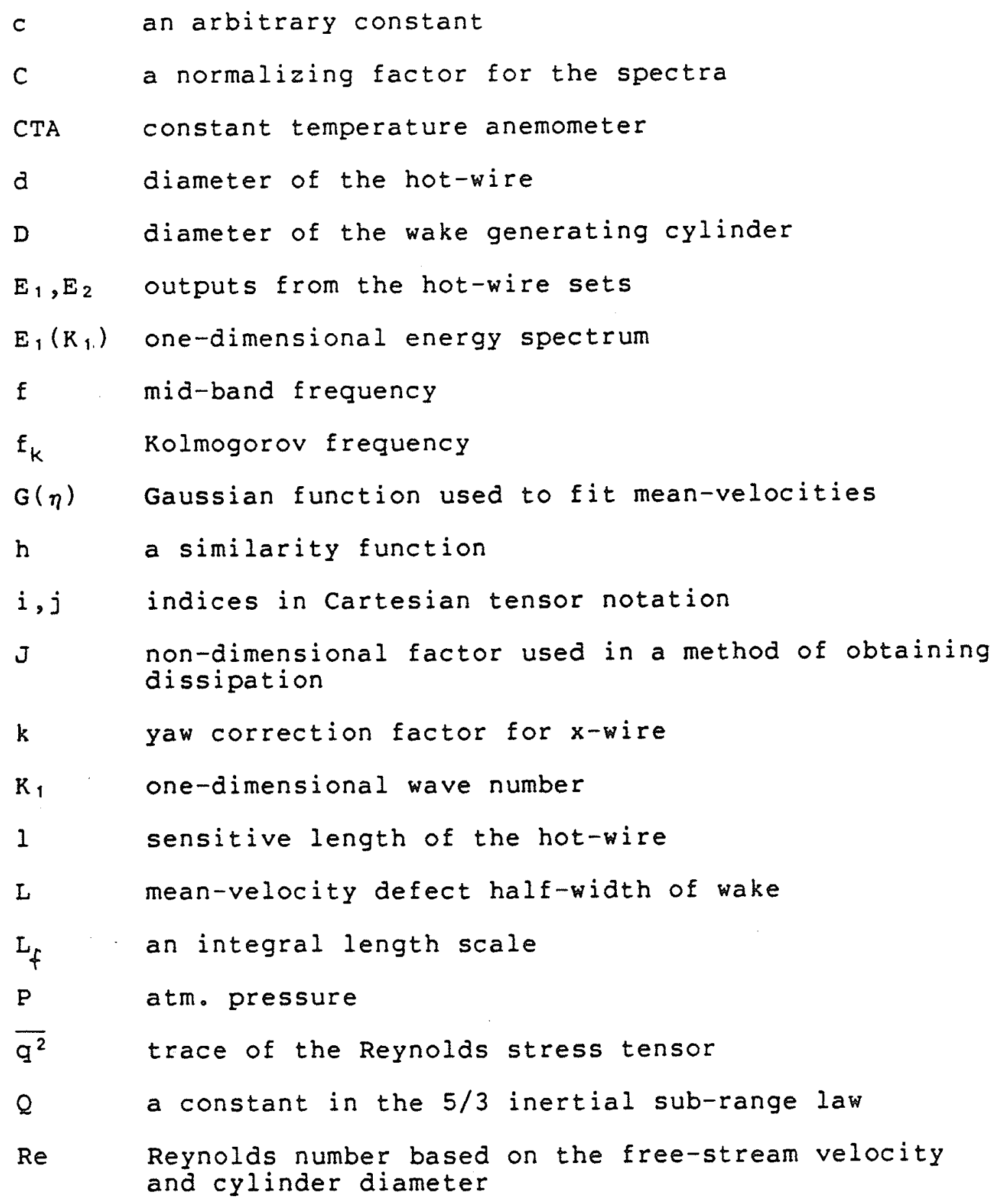




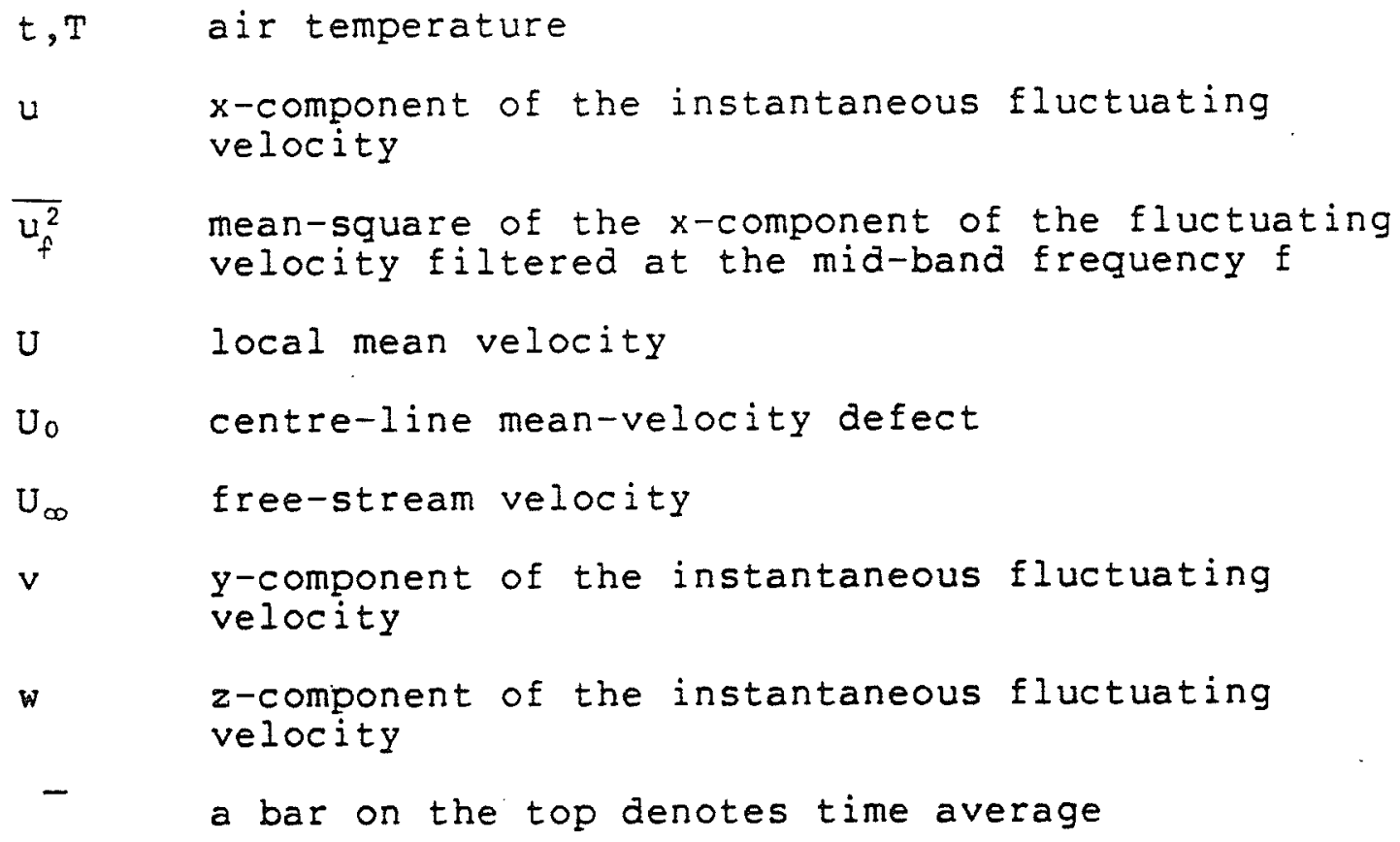

Greek Symbols

$\epsilon$ dissipation rate

$\gamma \quad$ Kolmogorov length scale, $=\left(\nu^{3} / \epsilon\right)^{1 / 4}$

$\eta \quad$ the non-dimensional distance $y / L$

$\nu \quad$ kinematic viscosity of air

$\rho$ air density 
Chapter I

I NTRODUCTION

Almost all the flows, natural or man-made, are turbulent. Examples of natural turbulent flows are, flows in earth's atmosphere; water currents in oceans; interstellar gas clouds; wake of the earth in solar winds; flow in rivers etc. and the examples of artificial turbulent flows are, flows in laboratories; flows in canals; wakes of aircraft, land vehicles, ships and submarines; and flows in turbomachinery etc. Turbulence is an irregular and most complicated fluid motion in time and space. Hinze (1959, p.1) defines turbulence as "Turbulent fluid motion is an irregular condition of flow in which the various quantities show a random variation with time and space coordinates, so that statistically distinct average values can be discerned."

Turbulent shear flows can be divided into two categories, namely, the wall bounded shear flows and the free shear flows. Some examples of the wall bounded shear flows are the flows through pipes, flows through diffusers and flows along plates. The free shear flows are the flows in jets and wakes, where no restricting walls are present. In free shear flows there is no direct effect of any fixed wall on the turbulence in the flow. In this investigation we have 
studied a wake flow from an infinite circular cylinder. The far wake of an infinite circular cylinder is two-dimensional and self-similar. The average turbulent kinetic energy equation for a self-similar plane wake can be written in the form (Townsend 1949b, Tennekes and Lumley, 1972 p.120 and Browne et al. 1987)

$$
I+I I+I I I+I V+V=0
$$

where the different terms are defined as follows:

$I:$ Advection $=U_{\infty} \frac{\partial}{\partial x}\left(\frac{1}{2} \frac{q^{2}}{2}\right)$

II : Production $=\overline{U V} \frac{\partial U}{\partial y}$

III : $\overline{q^{2}}$ or Kinetic diffusion $=\frac{\partial}{\partial y}\left(\frac{1}{\overline{2}} \overline{v q^{2}}\right)$

$I V$ : Pressure diffusion $=\frac{\partial}{\partial y}\left(\frac{\overline{p V}}{\rho}\right)$

$\mathrm{V}:$ Dissipation $=\varepsilon$

Many researchers have done a lot of extensive study about the turbulent kinetic energy budget in a self-similar wake, the most notable being Townsend (1949a, 1949b) and Browne et al. (1987). A general picture which emerges from these studies is that in a turbulent wake, the energy is extracted 
from the mean flow (represented by production term) and converted into internal heat energy by an important physical process called dissipation. The transfer terms such as advection and diffusion due to kinetic and pressure effects transfer the energy from the surplus to deficit areas where it is dissipated. At any cross-section in the flow there is always an overall energy balance between production and dissipation which is achieved with the help of the transfer terms. In order to visualize a true model of a turbulent flow field, a correct and accurate measurement of the turbulent kinetic energy equation is very essential.

The three terms, namely kinetic diffusion, advection and production can be obtained experimentally with great accuracy and relative ease. Out of the other two terms, the pressure diffusion term has been nearly impossible to obtain up to date. The dissipation is one of the major terms left in the turbulent kinetic energy buaget which is very difficult to obtain. So the key to the solution of the turbulent kinetic energy equation lies in an accurate and reliable means of measurement of the dissipation term. If this is achieved, the pressure diffusion term can be easily obtained by difference.

The total dissipation in a non-isotropic turbulent flow field can be denoted by the expression,

$$
\varepsilon=v \sqrt{\left.\frac{\partial u_{i}}{\partial x_{j}}+\frac{\partial u_{j}}{\partial x_{i}}\right] \frac{\partial_{u}}{\partial x_{i}}}
$$


as in Hinze (1959, p.398), using standard Cartesian tensor notation and summation on repeated indices. This expression expands into twelve terms (e.g. Browne et al. 1987) which are as follows:

$$
\begin{aligned}
& \varepsilon=v\left[2 \overline{\left(\frac{\partial u}{\partial x}\right)^{2}}+\overline{\left(\frac{\partial v}{\partial x}\right)^{2}}+\overline{\left(\frac{\partial w}{\partial x}\right)^{2}}+\overline{\left(\frac{\partial u}{\partial y}\right)^{2}}+\right. \\
& 2 \overline{\left(\frac{\partial v}{\partial y}\right)^{2}}+\overline{\left(\frac{\partial w}{\partial y}\right)^{2}}+\overline{\left(\frac{\partial u}{\partial z}\right)^{2}}+\overline{\left(\frac{\partial v}{\partial z}\right)^{2}}+\overline{2\left(\frac{\partial w}{\partial z}\right)^{2}}+ \\
& \text { \{5\} } \\
& \{5\} \\
& \{7\} \\
& \left.2 \overline{\left(\frac{\partial u}{\partial y}\right)\left(\frac{\partial v}{\partial x}\right)}+2 \overline{\left(\frac{\partial u}{\partial z}\right)\left(\frac{\partial w}{\partial x}\right)}+2 \overline{\left(\frac{\partial v}{\partial z}\right)\left(\frac{\partial w}{\partial y}\right)}\right]
\end{aligned}
$$

Measuring all of these twelve terms is still not possible and most of the measurable terms require very cumbersome and lengthy procedures. Until recently, only five terms, i.e. terms [1], [2], [3], [4] and [7] had been measured in the laboratory by Laufer (1954) and Wygnanski \& Fiedler (1969). Therefore, still the dissipation term could not be determined accurately. However, if the turbulence is assumed to be isotropic, the equation ( 3 ) is reduced to a very simple form,

$$
\varepsilon=15 v \overline{\left(\frac{\partial u}{\partial x}\right)^{2}}
$$


(see Hinze 1959 p.399, Townnsend 1949a, 1949b).

Townsend $(1949 a, 1949 b)$ has assumed local isotropy of flow and has obtained the dissipation term using the above relation. His experiments were done in the far wake of a cylinder at a Reynolds number $R e=8400$ and his measurement of dissipation term was believed to be the most accurate for a long period of time. But recently, Browne et al. (1987) have expressed reservations about the dissipation term of Townsend $(1949 \mathrm{~b})$ and even about the concept of assuming local isotropy to obtain the dissipation term. They argue that the Townsend's (1949b) pressure diffusion term, which was obtained by difference, is "unrealistically high, of the same order as production and dissipation near the region of maximum production" and that it did not satisfy the constraint of integration to zero across the wake.

Browne et al. (1987) have themselves conducted experiments in a cylinder wake at a Reynolds number Re=1170 and they claim to have obtained the dissipation term most accurately up to date. They have been able to measure the first nine terms of equation (3) experimentally and have assumed isotropic relations for the last three terms hoping that their magnitudes are small enough as not to affect the dissipation term critically. They even claim that the dissipation which is computed by assuming isotropic flow is smaller in magnitude than the total dissipation by about $45 \%$ on the wake centre-line and by about $80 \%$ near the wake edge. 
The dissipation measurements of Browne et al. (1987) in a self-similar cylinder wake of low Reynolds number seem to be the most accurate until now and their claim of accuracy is even justified by the fact that their pressure diffusion, obtained by difference and the kinetic diffusion terms satisfy the constraint of integration to zero across the wake, within a reasonable experimental error. But, the major shortcoming of their method is that it involves very tricky and cumbersome procedures, explained in their paper, which demand great patience and expertise on the part of the experimentalist to obtain even fairly accurate results.

A new method of measuring dissipation in a turbulent flow field using hot-wire anemometry has been introduced by Azad \& Kassab (1989). This method is called the zero-length method of dissipation measurement. A fundamental advantage of this method is that since only single-wire measurements are used in this method, the margin of error is only about $\pm 5 \%$ to $\pm 8 \%$, which in the case of $x$-wire can be as high as $\pm 15 \%$. This method takes into consideration the fact that a hotwire probe can not resolve velocity fluctuations with length scales smaller than the sensitive length (1) of the probe. If the sensitive wire length is longer than the length scale being studied, then the measured values are not the true values but rather the spatially filtered values along the wire length. The true values can only be obtained if the sensitive wire length is nearly zero. But there is always a 
limit to how small the hot-wire can be made. So the zerolength method of dissipation measurement incorporates the extrapolation of the values of dissipation measured with hot-wire probes of different sensitive lengths to the zero wire length and taking that value as the true value of dissipation. This technique is illustrated in figures 12.1 to 12.8

In the measurement of dissipation with different wires, the isotropic relation,

$$
\varepsilon=15 v \int_{0}^{\infty} K_{1}^{2} E_{1}\left(K_{1}\right) d K_{1}
$$

is used, where $E_{1}\left(K_{1}\right)$, the one dimensional energy spectrum of the longitudinal velocity fluctuation is defined by,

$$
\int_{0}^{\infty} E_{1}\left(K_{1}\right) d K_{1}=\overline{u^{2}}
$$

and is equivalent to equation (4) in spectral form (Azad \& Kassab 1989). The idea of extrapolation to zero-length assumes that the hot-wire measures through isotropic relation, the true sample of dissipation, that occurs at any location in the flow field and that these samples are linearly related to the true value of dissipation, i.e., the value of dissipation at zero-length. This method takes care of the non-isotropic behaviour of the flow field as well as the filtering effect of the finite length of the hot-wire. 
This method has been successfully used by Azad \& Kassab (1989) in boundary layer, fully developed pipe flow and diffuser flow. In the diffuser flow, they have used the required high-intensity correction due to Lumley (1965). Furthermore, Turan (1988) also concurs with this method of dissipation measurement in pipe flow and in diffuser flow. These flows represent partially or wholly wall bounded shear flows.

The objective of the present study was to test for the validity of this zero-length method to obtain dissipation in a free shear flow, i.e., in the far wake of a circular cylinder. An advantage of testing this method in a wake flow is that the corrections due to high-intensity of turbulence are not required since its magnitude is very low. The wall effects, which also need corrections, are also not present. Since the measurements of dissipation of Browne et al. (1987) were the most accurate ones available up to date hence it was decided to generate a cylinder wake similar to Browne et al. This would be helpful in the verification of the correctness of the zero-length method by the comparison of the results of the present study with those of Browne et al. (1987). Secondly, the correctness of this method could also be verified independently, from the balance of the turbulent kinetic energy equation. 
A new concept about the mean-velocity field of a selfsimilar wake has been recently used by Cimbala (1984). He has shown that the mean-velocity profiles, when properly non-dimensionalized follow the Gaussian function

$$
G(\eta)=e^{-(\ln 2) \eta^{2}}
$$

This concept is also tested in the present study and is applied towards the calculation of the production term.

The second chapter deals with the experimental set-up and also the procedures are discussed in detail here. The results are presented and discussed in the third chapter. In this chapter, an attempt has also been made to apply some other methods of dissipation measurement to the wake flow of the present study. Finally, conclusions have been made in the fourth chapter. The various tables and figures are given in the end. 
Chapter II

EXPERIMENTAL SET-UP AND PROCEDURES

\subsection{THE WIND TUNNEL FACILITY}

All the experiments for the present study were conducted in a closed-circuit, return type wind tunnel at the University of Manitoba. Figure 1 shows the sketch of the wind tunnel and the cross-sections of the lower and upper test sections. The experiments were done in the lower test section which was $0.76 \mathrm{~m}$ wide, $0.53 \mathrm{~m}$ high and $1.83 \mathrm{~m}$ long. As evident from figure 1, the cross-section is octagonal in shape, with the area gradually increasing downstream to account for the developing boundary layer on the walls of the test section. This design feature helps in maintaining a nearly zero pressure gradient along the length of the test section. Next to the lower test section is the first diffuser of area ratio $0.386 \mathrm{~m}^{2}$ to $1.05 \mathrm{~m}^{2}$ which deccelerates the flow upon approach to the fan entrance. The fans are contrarotating wooden aerofoils (type $48 \mathrm{~J} 2$ ). Downstream to the fans is the second diffuser which has an area ratio of $1.05 \mathrm{~m}^{2}$ to $1.95 \mathrm{~m}^{2}$. Next, the flow is turned $180^{\circ}$ by two sets of corner vanes. The flow then enters the $7.62 \mathrm{~m}$ long upper test section. After the upper test section is a $0.25 \mathrm{~m}$ long 
bleed which helps in maintaining the upper test section at an approximately static atmospheric pressure. The airflow is then again turned $180^{\circ}$ by the corner vanes and is passed through two fine wire mesh screens to reduce turbulence. Next, the contraction of an area ratio 5 to 1 accelerates and mixes the flow and feeds it into the lower test section.

Prior to inserting the cylinder into the flow and doing experiments, the free-stream velocity readings were taken in the test section at three stations (i.e., the front, the midale and the rear) to check for the uniformity of the flow. These readings indicated a region of uniform meanvelocity along the test section about $15 \mathrm{~cm}$ from the upper wall and about $10 \mathrm{~cm}$ from the lower wall. Since the maximum thickness of the full wake was no more than $60 \mathrm{~mm}$, the interference from the walls was practically nil on the wake. The Eree-stream turbulence intensity, $\sqrt{\overline{u^{2}}} / U_{\infty}$, was measured to be about $0.2 \%$ at the free-stream velocity $U_{\infty}=6.70 \mathrm{~m} / \mathrm{s}$.

The traversing mechanism was mounted on the upper wall of the test section. This mechanism could be set at any location along the test section and the probe could be traversed vertically across the test section with increments of as little as $0.1 \mathrm{~mm}$.

A drill rod of diameter, $D=2.77 \mathrm{~mm}$, was used as the wake generating cylinder. This idea was taken from Cimbala (1984), because the drill rod provided the required 
strength, rigidity, smoothness and uniformity of diameter. The drill rod was cleaned regularly to remove any dust build up. The drill rod was mounted horizontally in the central plane of the test section. It was $0.23 \mathrm{~m}$ downstream from the start of the test section and normal to the airflow. The drill rod was $90 \mathrm{~cm}$ long and protruded out from the holes, slightly bigger than the rod diameter, in the vertical walls of the test section. The rod was passed through a nut and bolt assembly on one wall of the test section. This nut and bolt assembly was used to keep the rod under tension so as to be perfectly horizontal at that height.

The coordinate system used in the present study is illustrated in figure 2. A cartesian coordinate system is taken with the $x$ coordinate in the free-stream direction, measuring positive downstream, with the origin at the centre of the cylinder. The $z$ coordinate is along the cylinder and the $y$ coordinate is normal to the $x$ and $z$ coordinates, measured from the horizontal centre-plane of the wake.

The experiments were conducted in a free-stream velocity, $\mathrm{U}_{\infty}$, of $6.70 \mathrm{~m} / \mathrm{s}$. A pitot-static tube was placed approximateIy half-way between the top of the test section and the central plane, downstream of the measuring station, to monitor the free-stream velocity. A thermometer was mounted flush with one of the walls of the test section to record the temperature of the airflow. The Reynolds number based on the 
cylinder diameter and the free-stream velocity was approximately 1160 .

The final measurements were done at the station $x / D=420$, the same location as Browne et al. (1987). This location was originally chosen because it was in the self-preserving region of the two-dimensional cylinder wake. Antonia \& Browne (1986) have shown that a cylinder wake becomes selfsimilar after $x / D=200$. The measurements of La Rue \& Libby (1974) taken in a cylinder wake at $x / D=400$ and 500 show self-similarity. In addition, the present measurements of mean-velocity profiles at different stations after $x / D=220$, as illustrated in figure 5, also indicate that the location $x / D=420$ is in the self-preserving region of the wake. A summary of the experimental conditions for the present experiments and those of Browne et al. (1987) is given in table A.

\subsection{PRESSURE MEASUREMENTS}

The pressure measurements were done basically to obtain the mean-velocity $U$ across the wake, at five different stations along the wake. These five stations were at $x / D=220$, $270,320,370$ and 420 , with the origin taken as the centre of the cylinder. These pressure measurements were obtained using total and static pressure tubes, which were incorporated in the same probe. These tubes were made of steel and had an outer diameter of $1 \mathrm{~mm}$ and an inner diameter of $0.6 \mathrm{~mm}$. 
The total and static pressure tubes were parallel to each other and were separated by a distance of $5 \mathrm{~cm}$ in the same horizontal plane. These probe had been designed based on potential flow theory for some earlier study in the wind tunnel. The pressure measuring device was a combist differential micro-manometer. This micro-manometer was sensitive upto $1 / 100 \mathrm{th}$ of a $\mathrm{mm}$ of water and had a range of 0 to $30 \mathrm{~mm}$ of water.

Before entering the wake, the tubes were aligned parallel to the Eree-stream velocity. Thereafter it was traversed through the wake downwards in $y$ direction, taking measurements at different $y$ locations till the free-stream was reached on the lower end of the wake. The wake centre-line was taken to be the position where the mean-velocity defect, Uo, was found to be maximum. Temperature of the air was noted during each run and the following formula,

$$
\rho=\left[\frac{1.293}{I+0.00367 t}\right] \frac{H}{76},
$$

taken from Handbook of Chemistry \& Physics (1987-88, p.F-10) was used to calculate the density of the air in order to obtain the mean-velocities. Here $t$ is the air temperature in ${ }^{\circ} \mathrm{C}$ and $\mathrm{H}$ is the pressure in $\mathrm{cm}$ of Mercury. This gives the air density in $\mathrm{g} / \mathrm{ml}$. Bernoulli's equation was used to obtain the mean-velocities. 


\subsection{TURBULENCE MEASUREMENTS}

The turbulence measurements were done both with analog as well as digital means using hot-wire anemometry. Figures 3.1 and 3.2 show the block diagrams of the instrumentation used for these measurements. In this section, first of all, the instrumentation used for the present study is described. Then the procedures for general and spectra measurements are given.

\subsubsection{Instrumentation for turbulence measurements}

All the single-wire measurements in the present study, including the spectra measurements, were made with Dantec 55P05 boundary layer type probes. These probes are goldplated at the ends, with the filament made of platinum plated tungsten and have a nominal distance of $3 \mathrm{~mm}$ between the prongs. The standard 55 P05 probes have a filament of diameter $5 \mathrm{~mm}$ and sensitive length $1.25 \mathrm{~mm}$.

Special $55 \mathrm{P} 05$ probes were used for the spectra measurements. These probes were of different lengths as required by the zero-length method. They were also of different diameters because Azad \& Kassab (1985b, 1989) recommend the use of wires with a length to diameter $1 / d \geq 200$. Gessner \& Moller (197i), Hinze (1975, pp. 119-120) and Blackwelder \& Haritonidis (1983) also report diminished sensor response for probes with lesser $1 / d$ values. For spectra measurements, 
probes free from manufacturing defects were used. The dimensions of the special probes are given in table B. Electron microscope photographs were used to determine the dimensions of the probes. These photographs were also used to eliminate probes with visible manufacturing defects such as faulty wire to prong connections and sagging wires (see Turan \& Azad 1989). An example of an electron microscope photograph showing the length and diameter of a wire is given in Eigure 4.

There was no particular reason for the choice of boundary layer type probes except that they were already available in the turbulence laboratory because most of the studies done previously involved wall bounded flows which required the use of these probes. The $x$-wire measurements were done with Dantec 55P51 type probes. These probes are also gold-plated and have the same nominal wire dimensions as the standard 55P05 single-wire probes. Both the sensors for these probes are yawed at an angle of $45^{\circ}$ with respect to the prongs.

DISA $55 \mathrm{M}$ constant temperature anemometer systems along with Disa 55D10 linearizers were used for the hot-wire measurements. The anemometers were operated at an overheat ratio of 0.75 . A higher overheat ratio increases the sensitivity of the anemometer but on the other hand it can lead to the burning out of the hot-wire sensor. The frequency response of the anemometers which was determined by the square wave 
test extended up to $30 \mathrm{kHz}$. The calibration and linearization were first done on the DISA 55D calibration system and then checked on location in the wind tunnel test section. The reason for doing the calibration seperately was that it required air at a constant velocity for long periods of time which was more convenient using the DISA 55D calibration system than the wind tunnel at a low velocity of $6.70 \mathrm{~m} / \mathrm{s}$. Although the range of the mean-velocity in the wake was from $6.34 \mathrm{~m} / \mathrm{s}$ to $6.70 \mathrm{~m} / \mathrm{s}$, the linearization was done from $4 \mathrm{~m} / \mathrm{s}$ to $9 \mathrm{~m} / \mathrm{s}$ and hence the linearization in the mean-velocity range of the wake was very good. The linearized mean-velocity outputs from the anemometers were within $\pm 0.02 \mathrm{~m} / \mathrm{s}$ of those obtained with the pitot-static tube. The linearizer constant for all type of measurements was unity (i.e., 0.01 volt $=0.01 \mathrm{~m} / \mathrm{s})$. In order to ensure the thermal stability of the electronic equipment, the anemometer and the linearizer units were left powered during the course of the experimental work, even when the instruments were not in use.

DISA 55D31 type voltmeters were used to read the linearized mean voltages from the linearizers. The 55D31 type voltmeters also incorporate integrators with a choice of time constants to average the fluctuating voltages over a desired period of time. A TM377 (Tri-Met Instruments limited) multi-function turbulence processor was used to process the fluctuating voltages. This also acted as a low-pass filter and an amplifier. A Tektronix D 1011 dual oscilloscope 
was used to monitor the electronic signals. An LS 7517 (Iinear Systems limited) multi-integrator was used to integrate the different outputs from the turbulence processor. This multi-integrator also gave a choice of different integrating times. It had five input channels with output of one channel at a time. Fluke $8050 \mathrm{~A}$ digital multimeter (accuracy \pm 0.0005 volts) was used to read the outputs from the multi-integrator. Krohn-hite 3550 filters were used at different stages. These filters acted as low-pass, band-pass and high-pass filters. DISA 55D35 R.M.S. unit was used to measure the mean-square of the longitudinal fluctuating velocity i.e., $\overline{u^{2}}$, for the analog spectra. A PDP $11 / 34$ computer was used for digital data collection and processing. The data was converted with the help of an AD11-K analog to digital converter.

\subsubsection{Procedure for General turbulence measurements}

The general turbulence measurements include the measurements of mean-squares of fluctuating velocity components $\overline{\mathrm{u}^{2}}$, $\overline{v^{2}}$, and $\overline{w^{2}}$, shear stress $\overline{U v}$ and the third order correlations $\overline{u^{2} v}, \overline{v^{3}}$ and $\overline{w^{2} v}$. These measurements involved the use of single-wire as well as $x$-wire probes. The single-wires were used to measure only $\overline{u^{2}}$ and the $x$-wires were used for all of the above quantities. Standard procedure recommended in the DISA technical literature was followed to obtain linearized signals from the single and $x$-wires. The data for these 
measurements were acquired both digitally as well as analog several times. The probes were aligned parallel to the flow by visual means as well as by monitoring the mean-velocity outputs. In the case of the $\mathrm{x}$-wire, the outputs $\overline{\mathrm{u}^{2}}, \overline{\mathrm{v}^{2}}, \overline{\mathrm{v}^{3}}$, $\overline{u v}$ and $\overline{u^{2} v}$ were obtained when the sensors were in the $x-y$ plane. The outputs $\overline{\mathrm{u}^{2}}$ and $\overline{\mathrm{w}^{2}}$ were obtained when the sensors were in the $x-z$ plane or in other words, rotated $90^{\circ}$ from the previous position. It was decided to measure the triple velocity correlation $\overline{w^{2} v}$ (which was not measured but rather calculated by Browne et al. 1987) using the method due to Townsend (1949b) and later followed by Wygnanski \& Fiedler (1969) and Irwin (1973). This method is outlined below.

The $x$-wire was placed in the flow such that its plane was parallel to the flow and at an angle of $45^{\circ}$ to the $y-$ and $z-$ axes. The outputs of the hot-wire sets thus obtained were then:

$$
E_{1} \propto u+c(v+w)
$$

and

$$
E_{2} \propto u-c(v+w)
$$

where $c$ is a constant of proportionality.

Subtracting second from the first gives

$$
\left(E_{1}-E_{2}\right) \propto(v+w) .
$$

Squaring this we get

$$
\overline{\left(E_{1}-E_{2}\right)^{2}} \propto \overline{v^{2}}+\overline{2 v w}+\overline{w^{2}}
$$


and cubing gives

$$
\overline{\left(E_{1}-E_{2}\right)^{3}} \propto \overline{v^{3}}+\overline{3 v^{2} w}+3 \overline{v w^{2}}+\overline{w^{3}} .
$$

From symmetry of the wake, the terms involving the odd powers of $w$ are zero, hence $\overline{w^{3}}, \overline{v w}$ and $\overline{v^{2} w}$ vanish.

Therefore

$$
\overline{\left(E_{1}-E_{2}\right)^{2}} \propto \overline{v^{2}}+\overline{w^{2}}
$$

and

$$
\overline{\left(E_{1}-E_{2}\right)^{3}} \propto \overline{v^{3}}+\overline{3 v w^{2}}
$$

which gives

$$
\frac{\overline{\left(E_{1}-E_{2}\right)^{3}}}{\left[\overline{\left(E_{1}-E_{2}\right)^{2}}\right]^{3 / 2}}=\frac{\overline{v^{3}}+\overline{3 v w^{2}}}{\left.\overline{\left(v^{2}\right.}+\overline{w^{2}}\right)^{3 / 2}}
$$

Using the values of $\overline{v^{3}}, \overline{v^{2}}$ and $\overline{w^{2}}$ obtained earlier, the correlation $\overline{\mathrm{Vw}^{2}}$ was calculated.

The experimental values obtained with the $x$-wire were corrected for yaw using the yaw factor $k=0.2$. This value is recommended by Jorgensen (1971) for the gold-plated type $x$-wires used in the present study. The expressions given by Vagt (1979) were used for the yaw corrections.

As seen from figure 3.1 , for single-wire analog measurements, the signal from the hot-wire goes to the DISA 55M CTA system, which is then linearized by the 55010 Iinearizer. One output from the linearizer goes to the 55D31 voltmeter to read the mean voltages and the other output goes to the input $A$ of the turbulence processor. It is low-pass filtered and amplified here. One output from the turbulence processor is in the form of $u$. This goes to the oscilloscope where it 
is monitored for proper amplification. The other output from the turbulence processor which is in the form of $\mathrm{u}^{2} / 10$ goes to the multi-integrator where it is averaged over a desired period of time and read by the digital multimeter.

In the case of $x$-wire measurements, two sets of CTA's and linearizers are used. The mean voltages are read from each Iinearizer and the second output from each linearizer goes to the two inputs $A$ and $B$ of the turbulence processor. Here the signals are low-pass filtered, amplified and processed into instantaneous outputs $\mathrm{u}^{2} / 10, \mathrm{v}^{2} / 10, \mathrm{w}^{2} / 10, \mathrm{uv} / 10$, $v^{3} / 100$ and $u^{2} v / 100$, depending upon the orientation of the probe in the flow. Each $u$ and $v$ signal is again monitored on the oscilloscope for proper amplification. The outputs from the turbulence processor are fed into the multi-integrator and read on the digital multimeter, one at a time. The integration times used on the multi-integrator were 60 and 120 seconds.

For the digital measurements the procedure is nearly the same as described above except that the instantaneous outputs of one or both the channels (single or $x$-wire) of the turbulence processor are fed into the PDP $11 / 34$ computer via the AD11-K converter. The data collection and processing was done using the software developed by Derksen (1986). The sampling rate was $25 \mathrm{KHz}$ and each record length was 2350 buffers with each buffer being equivalent to 1024 samples. 
The maximum sampling rate available was $75 \mathrm{KHz}$ for single channel and $40 \mathrm{kHz}$ for both channels. Data for all the locations for a particular run was first acquired and stored on different discs and at the end of data collection, each data disc was processed. One advantage of the digital method was that the data acquisition time was minimal (about 2 hours for each run as compared to upto 12 hours for the analog method) and hence the change in ambient conditions was negligible.

\subsubsection{Procedure for Spectra Measurements}

The spectra measurements were made only for the longitudinal fluctuating velocity component $\overline{u^{2}}$ and hence only single-wire probes were used. These probes were of five different lengths as described earlier. The spectra measurements presented in this thesis are all taken digital1y. Analog measurements were also done at a few locations for the sake of comparison. The comparison of the results of both these measurements was very good except that more noise was observed in analog results as higher frequencies were approached. One of the reasons for this could be that as higher frequencies are approached, the value of $\overline{u_{f}^{2}}$ starts decreasing and becomes very small and hence can not be resolved properly by the R.M.S. meter. 
The procedure given by Azad \& Kassab (1985a) and Kassab(1986) was followed. The low-pass cut-off frequency was set at the Kolmogorov erequency $f_{K}$, since no practically measurable energy in turbulence is available beyond $f_{K}$ due to the predominance of noise. The kolmogorov frequency is defined as $f_{X}=U /(2 \pi \gamma)$ where $U$ is the local mean velocity and $\gamma$, the kolmogorov length scale equals $\left(\nu^{3} / \epsilon\right)^{1 / 4}$. Here $\nu$ is the kinematic viscoscity of the fluid and $\epsilon$ is the dissipation rate. Kuo \& Corrsin (1971) have also used low-pass filter to cut off the highest frequencies at $f_{K}$.

Signal from the single-wire probe was fed into the CTA and this signal was linearized with 55D10 linearizers. One output from the linearizer went to the voltmeter to read mean voltage and the other went to one of the inputs of the turbulence processor. The signal was low-pass filtered and amplified here. The amplification was monitored on the oscilloscope. The u output from the turbulence processor went to a set of cascaded filters. The first filter was set in a low pass mode with cut-off at the local kolmogorov frequency and the second was used as a band-pass filter. About thirty mid-band frequencies between $2 \mathrm{~Hz}$ and $3 \mathrm{f}_{\mathrm{K}}$ were chosen for the measurement of spectra. The minimum value of $2 \mathrm{~Hz}$ was dictated by the availability of the Krohn-hite filters. These midband frequencies were equaliy spaced logarithmically so that integration of spectra could be done easily using Simpson's rule and another factor for this choice was that 
it gave equal distribution of data points on the spectral curve. The output from the band-pass filter went to the $55 \mathrm{D} 35$ R.M.S. meter to read the energy of $\overline{\mathrm{u}^{2}}$ in each band.

For the digital measurements the procedure was almost the same except that after the first low-pass filter which was set at $\mathfrak{f}_{K}$, the next filter was also set in low-pass mode but at three times the $E_{K}$. This ensured further reduction of noise. The output from the second filter went to the PDP $11 / 34$ computer for sampling. Once the data was acquired at all the $y$ locations for a particular run, it was processed on the PDP itself. Again Derksen's software was used for sampling and processing the data. The output obtained was in the form of energy of $\overline{u^{2}}$ per $\mathrm{Hz}$ in different band-widths. The data sampling rate was $25 \mathrm{Khz}$ in this case also. 
Chapter III

RESULTS AND DISCUSSION

The basic purpose of the present study was to test the validity of the zero-length method of dissipation measurement in a free shear turbulent flow, i.e., in a wake flow. Investigations were made in the wake of a circular cylinder of diameter $2.77 \mathrm{~mm}$ with a free-stream velocity of $6.70 \mathrm{~m} / \mathrm{s}$. The Reynolds number based on the cylinder diameter and the free-stream velocity was approximately 1160. In the following paragraphs, all the experimental results are presented. The turbulent kinetic energy budget is calculated from these results. Special details are given for the calculation of the dissipation term. This term was obtained with a method different than conventionally used by researchers, i.e., the zero-length method.

First, the mean-velocity results are presented and discussed in detail. Next, the different moments, upto thirdorder, of fluctuating quantities are given and discussed. The spectral data, which are of vital importance to the calculation of dissipation rate, are presented in tabular form and discussed. In section 3.4 , each term of the energy budget is presented and critically discussed. Finally some other methods of obtaining dissipation are discussed in comparison with the present method. 


\subsection{MEAN-VELOCITIES}

The profiles of mean-velocity were obtained at five stations in the range $220 \leq x / D \leq 420$, where $x$ is the distance from the centre of the cylinder, downstream and measured along the wake. The results of mean-velocity are given in tables C.1 to C.5. These results show how the wake grows as the mean-velocity defect decreases going downstream. The mean-velocity profiles are plotted in the non-dimensional form $\left(U_{\infty}-U\right) / U_{0}$ versus $\eta=y / L$ in figure 5 . Here, $U$ is the local mean-velocity, $U_{0}$ is the mean-velocity defect which is defined as the difference between the free-stream velocity and the centre-line velocity, $y$ is the distance across the wake in lateral direction measured from the centre-plane of the wake and $L$ is the mean-velocity defect half-width, which is defined as the distance from the centre-plane of the wake in $y$ direction, to the point where the mean-velocity defect becomes half (see figure 2 for details). In the present study, Uo and L are used to normalize the velocities and distances respectively. It can be seen from figure 5 that how well all the velocity profiles collapse on to a single curve defined by the function

$$
G(\eta)=e^{-(\ln 2) \eta^{2}}
$$

This function has been known to researchers for a very long time but Cimbala (1984) has used it to fit mean-velocities 
in his doctoral thesis. It is worth noting that there are three important characteristics of the Gaussian function $G(\eta)$. At $\eta=0 \quad(y=0)$, the value of $G(\eta)=1$. At $\eta=1 \quad(y=I)$, $G(\eta)=0.5$ and only at $\eta=\infty(y=\infty)$ does the value of $G(\eta)$ become zero. These characteristics agree very much with the nondimensional form $\left(U_{\infty}-U\right) / U_{0}$ of the mean-velocities and the definition of the wake half-width $L$. In a real flow the wake extends upto an infinite distance in the $y$ direction following the Gaussian curve. But there is a limit to the resolution of the measuring devices hence, as can be observed from figure 5, near the wake boundaries the measured velocities do not follow the Gaussian curve to infinity but rather tend to the zero value sooner. This projects an imaginary picture of a wake having a physical boundary which is not true in real sense. The fact that the mean-velocity profiles in their non-dimensional forms collapse so well on to a single curve illustrates the self-preserving flow of the wake in this region.

The values of $U_{0}$ and $L$ were obtained by plotting the local mean velocity U versus $y$. A smooth curve was then drawn through these points and the quantities $U_{0}$ and $L$ were measured according to their definitions. Figure 6 shows the variations of $L$ along the wake. It is observed that this variation, plotted in the form (L/D) ${ }^{2}$ vs. $x / D$, fits a straight line. The equation of the least-square-fit for this is

$$
(I / D)^{2}=0.03924(x / D)+5.6372 .
$$


This gives the relation:

$$
L / D=0.198[x / D+144]^{1 / 2} \text {. }
$$

for the present wake flow. Also, from the variations of $U_{0}$, the following relation was obtained:

$$
U_{0} / U_{\infty}=1.28[x / D+144]^{-1 / 2} \text {. }
$$

Similar relationships have been obtained by Browne et al. (1987), which are

$$
L / D=0.2[x / D+125]^{1 / 2}
$$

and

$$
\mathrm{U}_{0} / \mathrm{U}_{\infty}=1.28[\mathrm{x} / \mathrm{D}+125]-1 / 2
$$

(see Antonia \& Browne 1986).

Practically, only the constant in the parenthesis is different, i.e., in the present study it is 144 instead of 125 for Browne et al. (1987). This constant is considered to be the virtual origin of the wake (Hinze 1959, p.385). One of the reasons of this difference could be the slight difference in the cylinder diameters. But it was also noted during the formulation of equation ( 8 ) that even a small variation in the value of $L$ at any station has a large effect upon the resultant value of this constant. However this difference in the constant does not influence the calculations of the shear stress $\overline{u v}$ or the production term significantly. 


\subsection{FLUCTUATING VELOCITY CORRELATIONS}

The turbulent velocity measurements across the wake were done at the station $x / D=420$. A number of runs were done by analog as well as digital means across the full width of the wake. These measurements indicated that the wake was symmetrical about its centre-plane. Hence, the results presented in this section are shown only on one half of the wake. The best-fit values of second order velocity correlations $\overline{u^{2}}, \overline{v^{2}}$ and $\overline{w^{2}}$ and the shear stress $\overline{U V}$ are given in table D.1. Table D.2 gives the values of the third order correlations $\overline{v^{2}}, \overline{v^{3}}$ and $\overline{v^{2}}$. The distributions across the wake of these terms are illustrated in figures 7.1 to 7.4 and figures 8.1 to 8.3

Figure 7.1 shows the distribution of $\sqrt{\overline{u^{2}}}$ for the present study as well as for Browne at al. (1987). This term shows a very good agreement with the values of Browne et al. (1987). It should be noted here that $\overline{u^{2}}$ is the only term which can be measured with great accuracy with hot-wire anemometry. The next figure (7.2) shows the distributions of $\sqrt{\overline{v^{2}}}$ for both the studies. The measurement of this term requires the use of $x$-wire and therefore can have an error upto $\pm 15 \%$. Even the different runs of our own study do not match as closely as in the case of $\sqrt{u^{2}}$. But if a look is taken at the fluctuating velocity distributions of Browne et al. (1987), the scatter present there is about $10 \%$ near the wake centreline and more than $30 \%$ near the wake edges. Our values fall 
well within these scatter limits and hence compare quite well with those of Browne et al., except near the wake edges. The reason for this is that this term slowly tends to the free-stream value as it approaches the wake boundaries. The free-stream value of $\sqrt{\overline{\mathrm{v}^{2}}}$ is $0.03 \mathrm{~m} / \mathrm{s}$ approximately for the present study and is obviously higher than that of Browne et al. (1987). Figure 7.3 shows us the distributions of $\sqrt{\bar{w}^{2}}$ for both the studies. This term also is measured with the use of $x$-wire and hence is susceptible to relatively larger error. But again if the distributions of Browne et al. (1987) are observed our term compares quite well with their's within reasonable experimental error, except near the wake boundaries. The free-stream value of this term also, which is $0.34 \mathrm{~m} / \mathrm{s}$, for the present study, seems to be somewhat higher than that of Browne et al. (1987). Figure 7.4 illustrates the distributions of the shear stress $\overline{u v}$ across the wake for the present study. Browne et al. (1987) do not illustrate their distributions for this term so a comparison can not be made. But later on in this chapter the production terms, which have been obtained from $\overline{u v}$, will be compared and it will be seen how well they match for both the studies. It should be noted that in figure 7.4 , all the values of $\overline{u v}$ are shown to be positive. In fact $\overline{u v}$ is not symmetric but rather anti-symmetric about the central plane of the wake. 
Figure 8.1 shows the distributions of the triple-velocity correlation $\overline{u^{2} v}$. All the triple-velocity correlations have been presented in a non-dimensional form, normalized by $U_{0}{ }^{3}$. The maximum deviation of these correlations from the mean values of the present study and of Browne et al. (1987) is about $\pm 16 \%$ as seen in figure 8.1 . The $\overline{v^{3}}$ distributions, as shown in Eigure 8.2 match very well with those of Browne et al. (1987). In reality, it is not the triple-velocity correlations but rather the slopes of their distributions, which actually affect the $\overline{q^{2}}$ diffusion term. The third term, i.e., $\overline{v w^{2}}$ is illustrated in figure 8.3. This term has been obtained by different methods for both the studies. We have used the method introduced by Townsend (1949b) and later followed by Wygnanski \& Fiedler (1969). This method has already been outlined in Chapter II. It will not be out of way to point out that Browne et al. (1987) have scaled this correlation from the values of Fabris (1974) using the relation:

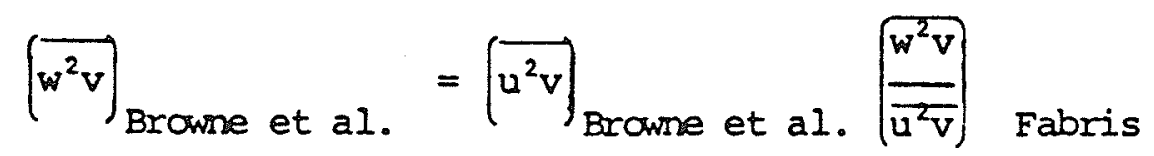

But still, taking these facts into account, the agreement of $\overline{\mathrm{VW}}{ }^{2}$ is not too far away. Also, this correlation has quite a lower magnitude as compared to the other two triple-velocity correlations and hence has lesser contribution to the kinetic diffusion term. All of these triple-velocity correlations are anti-symmetric about the central $x-z$ plane of the wake. 
Until now, the mean velocities and the fluctuating velocities of the present study have been compared with those of Browne et al. (1987). The good agreement of these quantities points towards a possibility of similar wake flows in both the cases.

\subsection{SPECTRAL DATA IN THE SELF-SIMILAR WAKE}

The method suggested by Azad \& Kassab (1985a) was followed to obtain and reduce the spectral data for the present study. At each location of measurements, the local mean-velocity $U$, the mean-square of the longitudinal velocity fluctuation $\overline{u^{2}}$ and the mean-square of the filtered longitudinal velocity fluctuation $\overline{u_{f}^{2}}$ for about thirty mid-band frequencies were obtained. As mentioned earlier, the mid-band frequencies were logarithmically equally spaced with the lowest being $2 \mathrm{~Hz}$ and the maximum upto three times the local kolmogorov frequency. These results were changed into wave-number domain by Taylor's hypothesis as $K_{1}=2 \pi f / U$ where $K_{1}$ is the one-dimensional wave number and $f$ is the mid-band frequency. This assumption is supported by the similarity evidence provided in figures $5 \& 6$. The method used to reduce the spectral data into wave-number domain is outlined below.

First of all the measured spectrum of $\overline{u^{2}}$ is normalized using the relation

$$
\overline{u^{2}}=c \int_{\min .}^{f_{\max }}\left(\overline{u_{f}^{2}} / f\right) d f
$$


or, $\overline{u^{2}}=c \int_{2 \mathrm{~Hz}}^{3 E_{k}} \overline{u_{f}^{2}} d(\ln f)$

where $C$ is the normalizing factor. The $f_{\min }$, in the present study is $2 \mathrm{~Hz}$ for all the locations. From the above expression $C$ was calculated

$$
c=\overline{u^{2}} / \int_{2 \mathrm{~Hz}}^{f_{\max }} \overline{u_{f}^{2}} d(\ln f)
$$

Simpsons's rule of integration was used to calculate the integral on the R.H.S.. The ideal value of $C$ should be unity. The smaller the interval between the mid-band frequencies, the closer the value of $c$ will be to unity. In the present study $C$ was never greater than 1.25 but Azad \& Kassab (1985a) report values of $C$ as high 8.16 . The integration limits can be changed as 0 to $\infty$ because there is practically no energy in the spectrum below $2 \mathrm{~Hz}$ and above $3 \mathrm{f}$. ThereEore

$$
\begin{aligned}
& \overline{u^{2}} \simeq c \int_{0}^{\infty}\left(\overline{u_{f}^{2}} / f\right) d f, \\
& \text { or } \overline{u^{2}}=(c * u / 2 \pi) \int_{f}^{\infty}\left(\overline{u_{f}^{2}} / f\right) d(2 \pi f / U), \\
& \text { or } \frac{u^{2}}{}=\int_{0}^{\infty}\left\{c * u * \overline{u_{f}^{2}} / 2 \pi f\right\} d(2 \pi f / U),
\end{aligned}
$$


or

$$
\overline{u^{2}}=\int_{0}^{\infty} E_{1}\left(K_{1}\right) d K_{1}
$$

because $2 \pi \mathrm{f} / \mathrm{U}$ is equal to $K_{1}$ from the Taylor's hypothesis and $\left[C * U * \overline{u_{f}^{2}} / 2 \pi f\right]$ equals the one-dimensional energy spectrum $E_{1}\left(K_{1}\right)$.

The spectra have been obtained at eight different locations across the wake from the wake centre-line to the wake boundary. This has been done five times with wires of different lengths and diameters. The values of $f, \overline{u_{f}^{2}}, K_{1}$ and $E_{1}\left(K_{1}\right)$ are given in tables E.1.1 to E.5.8. Also in these tables are given the values of $U, \overline{u^{2}}$ and the kinematic viscosity $\nu$.

The spectral data obtained with the standard hot-wire (wire \#3) are plotted in figures 16.1 to 16.8 . These figures will also be used for later discussions in other connections. The spectral data plots provide a description of the structure of turbulence and show how energy is distributed across the range of frequencies. It was also observed that the noise starts to appear at frequencies beyond $2 \mathrm{f}_{K}$. Hence to obtain dissipation, the spectra were integrated upto $2 f_{K}$ only. 


\subsection{ENERGY BUDGET}

The measurements of the different terms of the energy budget, i.e. equation (1) are systematiclly presented in this section. First of all, the three terms which were obtained by conventional methods namely the $\overline{q^{2}}$ diffusion, the advection and the production are discussed. Then the dissipation term, which in the present study was obtained using the zero-length method is presented. Finally the total budget of the average turbulent kinetic energy is calculated. There is still no reliable direct method available for the calculation of the pressure diffusion term. Therefore, as usual, it is obtained by difference from the closure of the equation of the turbulent kinetic energy.

\subsection{1 $\overline{\mathrm{g}^{2}}$ diffusion}

The diffusion of turbulence due to kinetic effects, also known as the $\overline{q^{2}}$ diffusion is the most complicated phenomenon in the physics of turbulence. In the self-similar wake flow it is given by the relation

$$
\frac{\partial}{\partial y}\left(\frac{1}{2} \overline{v q^{2}}\right)
$$

where $\overline{v q^{2}}=\overline{v u^{2}}+\overline{v^{3}}+\overline{v w^{2}}$. These triple-veiocity correlations and the methods of measuring them have been discussed earlier and were found to show good agreement with the results of Browne et al. (1987). The best fit values of these correlations, which are given in table D.2 were taken 
to obtain $\overline{\mathrm{vq}^{2}}$. The lateral derivative of $\overline{\mathrm{vq}^{2}}$ was obtained by using the data analysis software DADiSP (1987). This software fits a quadratic curve through each of three consequtive points $(n-1, n$ and $n+1)$ for the purpose of numerical differentiation. The $\overline{q^{2}}$ diffusion term is presented in figure 9, together with the same term of Browne et al. (1987) for the purpose of comparison. Figure 9 shows how well the results of both the studies match which also indicates a possibility that the wake flows studied in both the cases are similar.

\section{$3.4 .2 \quad$ Advection}

The advection term is obtained from the measurements of the mean-square of fluctuating velocities $\overline{u^{2}}, \overline{v^{2}}$ and $\overline{w^{2}}$. As can be seen from equation (1), the advection term is given by

$$
U_{\infty} \frac{\partial}{\partial x}\left(\frac{1}{2} q^{2}\right)
$$

Here $\overline{q^{2}}$ is the trace of the Reynolds stress tensor and is defined as the sum $\overline{u^{2}}+\overline{v^{2}}+\overline{w^{2}}$. This term was calculated using the method described by Browne et al. (1987). The gradient $\partial \overline{q^{2}} / \partial x$ was obtained using equations (8) \& (9) which give the streamwise variations of $L$ and $U_{0}$ and the self-preserving form $\overline{q^{2}}=U_{0}{ }^{2} h(\eta)$. We can write

$$
\frac{\partial \overline{q^{2}}}{\partial x}=U_{0}^{2}\left(\frac{d h}{d n}\right)\left(-\frac{\eta}{L}\right)\left(\frac{d L}{d x}\right)+2 h U_{0}\left(\frac{d U_{0}}{d x}\right) \text {. }
$$


Here $d h / d \eta$ was obtained from the differentiation of $\overline{\mathrm{q}^{2}} / \mathrm{U}_{0}{ }^{2}$ This differentiation again was performed with DADiSP. The derivative $d L / d x$ was derived from equation (8) and $d U_{0} / d x$ from equation (9). The advection term thus obtained is presented in figure 10 and compared with the advection of Browne et al. (1987). Both the terms are normalized with $L / U_{0}{ }^{3}$ and they compare very well with each other. Up until now the two transfer terms, advection and $\overline{q^{2}}$ diffusion of the present study agree very well with the similar terms of Browne et al. (1987).

\subsubsection{Production}

The production of the turbulent kinetic energy is given by the relation

$$
\overline{u v} \frac{\partial U}{\partial y}
$$

This consists of two terms, i.e., the shear stress $\overline{u v}$ and the lateral derivative of the mean-velocity $\partial u / \partial y \cdot \overline{U V}$ is obtained experimentally as already described. These terms can be derived from the self-similar form

$$
\left(U_{\infty}-U\right) / U_{0}=G(\eta)=e^{-(\ln 2) \eta^{2}}
$$

and equations $(8) \&(9)$ also. The reader should refer to appendix for details. An advantage of using the derived values of $\overline{u v}$, as described in the appendix, is that it is free 
of experimental errors. The results of the production term for the present study and that of Browne et al. (1987) are presented in figure 11. Again, this term is also normalised by $\mathrm{L} / \mathrm{U}_{0}{ }^{3}$. Figure 11 clearly demonstrates that both the results collapse on each other within experimental error. The production of the turbulent kinetic energy is zero at the wake centre-line, goes to maximum near $\eta=0.85$ and then again decreases to zero as the wake boundary is approached. Close agreement of this term also shows again that the wakes in both the studies are similar.

\subsubsection{Dissipation}

The present study is mainly directed towards the measurement of dissipation with the new method introduced by Azad \& Kassab (1989). Browne et al. (1987) claim the perfect.method of measuring dissipation in a self-similar wake. They have shown that all the terms of energy budget for their study balance to zero and thus they infer that their measurement of dissipation, which agrees with this assessment, has been correctly made. Till now, it has been shown that $\overline{q^{2}}$ diffusion, advection and production terms of the energy budget of the present study agree with the corresponding terms of Browne et al. (1987). This also shows that the wake flows of both the cases are similar. So if the measurement made by the zero-length method agrees with their results of dissipation, it can be concluded that this method of measurement of dissipation is a correct one. 
The zero-length method is again described here briefly. Five different wire lengths were used to measure the $\overline{u^{2}}$ spectra at different locations across the wake. The results of these spectra are presented in tables E.1.1 to E.5.8. The dissipation was obtained from these spectra by the use of equation (5), as described earlier in Chapter I. Use of Simpson's rule was made for these integrations also. The dissipation values obtained with wires of different lengths are given in table $F$. The procedure to obtain the zerolength value is illustrated in figures 12.1 to 12.8. The dissipation values are plotted against the sensitive wire length and linearly extrapolated to the zero-wire-length value. A least-square $f$ it was used for this purpose. The value of dissipation for the zero-wire-length is taken as the true value of dissipation at that particular location. The zerollength values of dissipation are also given in table F. The distribution of dissipation thus obtained across the wake is shown in figure 13, where the results of Browne et al. (1987) are also plotted. It can be seen from this figure that at the centreline the deviation from the mean value is about $\pm 4 \%$ and although the magnitude of the error band is nearly the same near the wake edges the deviation is about $\pm 39 \%$. This figure clearly demonstrates the agreement of these two results. Hence it can be concluded that the zero-length method gives the true dissipation rate of the turbulent kinetic energy in a wake flow. 


\subsubsection{Pressure diffusion}

The pressure diffusion terms for the present study and for Browne et al. (1987) are presented in Eigure 14. This term has been calculated by difference, as the closing term of the energy equation in both the cases, because there is still no direct method to obtain this term. The magnitude of this term is nearly a fifth of the other major terms of the energy budget and since it is obtained by the difference of the sum of the rest of the terms, there can be a lot of uncertainty about the accuracy of this term. Hence a good agreement of this term for both the studies cannot be expected, but the trends are similar.

\subsubsection{Discussion of Energy Budget}

The average turbulent kinetic energy budget, i.e. equation (1), for the present study is presented in its final form in figure 15. All the terms have been normalized by the factor $\mathrm{L} / \mathrm{U}_{0}{ }^{3}$. The values of the different terms at the different locations are also given in table $G$. The sum of the integrals across the wake of both the diffusion terms should be zero, i.e.,

$$
\int_{-\infty}^{\infty} \frac{\partial}{\partial y}\left(\overline{v q^{2}}\right) d y+\int_{-\infty}^{\infty} \frac{\partial}{\partial y}\left(\frac{\overline{p v}}{p}\right) d y=0 .
$$


It has been observed from the experimental results that (i) is equal to zero on its own. Hence (ii) should also be independently equal to zero. In the case of Browne et al. (1987), these constraints are satisfied within errors of $2 \%$ and $8 \%$ respectively. For the present study the corresponding errors are $2 \%$ and $4 \%$. These facts independently support the contention that the measurements of dissipation by the zerolength method for the present study is correct.

\subsection{DISSIPATION BY OTHER METHODS}

Some other possible methods of obtaining dissipation from the spectra of $\overline{u^{2}}$ are discussed in this section. The spectra of $\overline{u^{2}}$ for the present study are plotted in figures 16.1 to 16.8. These are the spectra obtained with the standard single-wire, i.e., wire\#3. The spectra obtained with other wires also present a similar picture hence they are not shown although they are given in tables E.1.1 to E.5.8. Spectral analysis provides a very good description of the structure of turbulence and it shows how the eddies of different sizes are dynamically related in the exchange of energy. The larger eddies cause low Erequency fluctuations whereas the smaller eddies cause high frequency fluctuations. The eddies lying between these two are not affected by viscosity and this region is called the inertial subrange. 
One of the methods of obtaining dissipation from the spectra called the $5 / 3$ inertial sub-range method. This method is due to kolmogorov (1941) and was experimentally examined by Bradshaw (1967). This method is explained in detail in Azad \& Kassab (1985b). Bradshaw (1967) suggests that a universal inertial range of spectrum may exist if the turbulence Reynolds number exceeds 100. The energy spectrum function in the inertial sub-range is given by

$$
E_{1}\left(K_{1}\right)=Q \epsilon^{2 / 3} K_{1}-5 / 3
$$

where $Q$ is a constant having a value of $0.50 \pm 0.05$. This method gives good results of dissipation provided an inertial sub-range exists. This inertial sub-range has been investigated for the present study by fitting the $k_{1}^{-5 / 3}$ Iine to the spectral curve as shown in figure 16.1 to 16.8. From these figures it is evident that this line can not be fitted to the spectral curve and hence the inertial sub-range does not exist. Browne et al. (1987) also report that the inertial sub-range cannot be found in their flow. Therefore this method cannot be applied to obtain dissipation for the present study.

There is another method based upon dimensional reasoning which gives the dissipation as

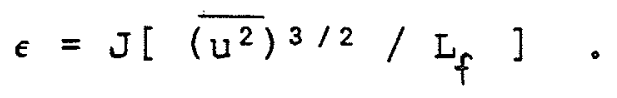

This method is also described in Azad \& Kassab (1985b). In the above equation, $J$ is a factor whose value depends upon the type of the flow and also on the turbulence Reynolds 
number although Townsend $(1980, p .61)$ gives the value of $\mathrm{J}=$ 0.8 as a constant. This method presents two practical difficulties. One is to find the real value of $\mathrm{J}$ and the other to obtain the value the integral length scale $I_{f}$. Hence a true value of dissipation can be obtained only if these two quantities are known accurately. $L_{f} c a n$ be obtained by using the expression:

$$
I_{f}=\frac{\pi E_{1}(0)}{2 \overline{u^{2}}}
$$

provided $E_{1}(0)$ is determined correctly. If a fairly straight and horizontal part of the spectrum exists near the lower frequencies, $E_{1}(0)$ can be obtained by the extrapolation to the zero-value, of a straight line running through this horizontal part of the spectral curve. This procedure is also illustrated in figures 16.1 to 16.8 and an attempt has been made to obtain a correct value $E_{1}(0)$.

Since the true value of the factor $J$ could not be known for the present study so dissipation with this method also could not be obtained. So it was decided to determine the value of $J$ by assuming the dissipation obtained by the zerolength method to be correct. Equation (13) was used to find the values of $\mathrm{J}$. The values of $\mathrm{L}_{f}$ and $\mathrm{J}$ for the present study are given in table $H$. It can be seen that the values of $J$ thus obtained vary from 1.43 to 3.55 . If the value of Townsend (1980, p.61) is taken to be the correct one, our 
values of $J$ contain a lot of error. This error, if present, is presumably due to the inability of determining the true $E_{,}(0)$. Actually if a closer look is taken at figures 16.1 to 16.8 , one can notice that even the $E_{1}(2 \mathrm{~Hz})$, i.e., the leftmost point in the spectral curve, falls lower than the horizontal extrapolation line. This gives rise to the speculation that the correct value of $E_{1}(0)$ might be lower than the one obtained by extrapolation. So it is difficult to comment about the accuracy of the values of $J$ obtained for the present study.

In a private communication, Prof. P. Bradshaw has suggested that dimensionally, the dissipation $\epsilon$ might be proportional to $I^{2}$ and not to $I$, the sensitive wire length. Or in other words, dissipation obtained by different wires, when plotted against $1^{2}$ might be 1 inear. All kinds of dimensional reasonings were tried but it could not be ascertained as to why $\epsilon$ might be proportional $1^{2}$ and not to 1 . The results of dissipation obtained with different wires were also plotted in the form $\epsilon$ vs. $1^{2}$ but they were not found to be linear. Also, the very good linearity of $\epsilon$ versus 1 as evident in figures 12.1 to 12.8 does not support this suggestion. 


\section{Chapter IV}

\section{CONCLUSIONS}

First of all, after comparing all the mean and fluctuating quantities and the various terms of the energy budget of the present study with those of Browne et al. (1987), it can be concluded without any reservation that the wake flows in both the cases are similar to each other.

The second conclusion is a major conclusion towards which the present study was mainly directed, i.e., the validity of the zero-length method of obtaining dissipation. The measurements of dissipation obtained with this method in a wake flow agree with the best measurements of dissipation available (of Browne et al. 1987) in a similar flow. This method is also corroborated independently by the satisfactory closure of the turbulent kinetic energy budget. The zerolength method of obtaining dissipation has been proved to be successful in boundary layer, fully developed pipe flow and diffuser flow with high intensity turbulence (see Azad \& Kassab 1989). Thus the zero-length method to obtain dissipation is valid in wall bounded shear flow, i.e., boundary layer, pipe flow and diffuser flow as well as in free shear flow, i.e., a wake flow. Consequently, it can be concluded that the zero-length is a universal method of obtaining dissipation. 
Thirdly, from the results of the spectra of $u^{2}$, it can be concluded that the inertial sub-range does not exist in the wake flow of present study. 


\section{REFERENCES}

Antonia, R.A. \& Browne, L.W.B. 1986 Anisotropy of the temperature dissipation in a turbulent wake. J. Fluid Mech. 163, 393-403.

Azad, R.S. \& Kassab,S.Z. 1985a spectral data in axisymmetric wall-bounded shear flow. Report METR-4, Mech. Eng. Dept., The University of Manitoba.

Azad, R.S. \& Kassab, S.Z. 1985b Dissipation of energy in turbulent flow. Report METR-9, Mech. Eng. Dept., The University of Manitoba.

Azad, R.S. \& Kassab, S.Z. 1989 New method of obtaining dissipation. Experiments in Fluids $7,81-87$.

Blackwelder, R.F. \& Haritonidis, J.H. 1983 Scaling of the bursting frequency in turbulent boundary layers. J. Fluid Mech. 132, 87-103.

Bradshaw, P. 1967 Conditions for the existence of an inertial subrange in turbulent flow. NPI Aero. Rep. No. 1220.

Browne, L.W.B., Antonia, R.A.\& Shah, D.A. 1987 Turbulent energy dissipation in a wake. J. Fluid Mech. 179, 307326 .

Cimbala, J.M. 1984 Large structure in the far wakes of twodimensional bluff bodies. Ph.D. thesis, California Institute of Technology.

DADiSP 1987 Signal analysis software worksheet manual. DSP Development Corporation.

Derksen, R.W. 1986 An experimental investigation of the fluctuating wall shear stresses in an eight degree conical diffuser. Ph.D. thesis, The University of Manitoba.

DISA 55M system with 55M10 standard bridge instruction manual. DISA Elektronik A/S.

DISA instruction and service manual for type 55D10 linearizer. DISA Elektronik A/S. 
Fabris, G. 1974 Conditionally sampled turbulent thermal and velocity fields in the wake of a warm cylinder and its interaction with an equal cool wake. Ph.D. thesis, Ilinois Institute of Technology.

Gessner, F.B. \& Moller, G.L. 1971 Response behaviour of hotwires in shear flow. J. Fluid Mech. 47, 449-468.

Handbook of Chemistry \& Physics 1987-88. 68th ed. CRC Press.

Hinze, J.O. 1959 TURBULENCE An introduction to its mechanism and theory. McGraw-Hill Book Co.

Hinze, J.O. 1975 Turbulence. 2nd Ed., McGraw-Hill Book Co.

Irwin, H.P.A.H. 1973 Measurements in a self-preserving plane wall jet in a positive pressure gradient. J. Fluid Mech. $61,33-63$.

Jorgensen, F.E. 1971 Directional sensitivity of wire and fibre film probes, an experimental study. DISA information No. 11 (May 1971), 31-37.

Kassab, S.Z. 1986 Turbulence structure in axisymmetric wallbounded shear flow. Ph.D. thesis, The University of Manitoba.

Kolmogorov, A.N. 1941 Local structure of turbulence in an incompressible viscous fluid at very high Reynolds numbers. Doklady Akad. Nauk. SSSR 30, 299-303.

Krohn-Hite Operating and Maintenance Manual. Krohn-Hite corporation.

Kuo, A.Y. \& Corrsin, S. 1971 Experiments on internal intermittency and fine-structure distribution functions in fully turbulent fluid. J. Fluid Mech. 50, 285-319.

LaRue, J.C. \& Libby, P.A. 1974 Temperature and intermittency in the turbulent wake of a heated cylinder. Phys. Fluids $17,873-878$.

Laufer, J. 1954 The structure of turbulence in fully developed pipe flow. NACA Rep. 1174.

Lumley, J.L. 1965 Interpretation of time spectra measured in high-intensity shear flows. Phys. Fluids 8, 1056-1062.

Tennekes, H. \& Iumley, J.L. 1972 A first course in turbulence. The MIT Press.

Townsend, A.A. 1949a Momentum and energy diffusion in the turbulent wake of a cylinder. Proc. Roy. Soc. A197, 124140 . 
Townsend, A.A. 1949b The fully developed turbulent wake of a circular cylinder. Austral. J. Sci. Res. 2, 451-468.

Townsend, A.A. 1980 The structure of turbulent shear flow. First paperback edition, Cambridge University Press.

Turan, 0.1988 Further study of a new method of evaluating turbulence dissipation. Ph.D. thesis, The University of Manitoba.

Turan, O. \& Azad, R.S. 1989 Effects of hot-wire probe defects on a new method of evaluating turbulence dissipation. J. Phys. E: Sci. Instrum. 22, 254-261.

Vagt, J.D. 1979 Hot-wire probes in low speed flow. Prog. Aerospace Sci. 18, 271-323.

Wygnanski, I. \& Fiedier, H. 1969 some measurements in the self-preserving jet. J. Fluid Mech. 38, 577-612. 
TABLE A

SUMMARY OF EXPERIMENTAL CONDITIONS

\begin{tabular}{|c|c|c|}
\hline & $\begin{array}{l}\text { Present } \\
\text { Expts. }\end{array}$ & $\begin{array}{l}\text { Expts. of Browne } \\
\text { et al. }(1987)\end{array}$ \\
\hline Free-stream velocity, $U_{\infty}$ & $6.70 \mathrm{~m} / \mathrm{s}$ & $6.70 \mathrm{~m} / \mathrm{s}$ \\
\hline Cylinder diameter, D & $2.77 \mathrm{~mm}$ & $2.67 \mathrm{~mm}$ \\
\hline Location in wake, $x / D$ & 420 & 420 \\
\hline $\begin{array}{l}\text { Reynolds number based } \\
\text { on } U_{\infty} \text { and } D, \text { Re }\end{array}$ & 1160 & 1170 \\
\hline Mean-velocity defect, $U_{0}$ & $0.36 \mathrm{~m} / \mathrm{s}$ & $0.36 \mathrm{~m} / \mathrm{s}$ \\
\hline $\begin{array}{r}\text { Mean-velocity defect } \\
\text { half-width, L }\end{array}$ & $13.03 \mathrm{~mm}$ & $12.3 \mathrm{~mm}$ \\
\hline
\end{tabular}

TABLE B

DIMENSIONS OF THE WIRES USED FOR SPECTRA MEASUREMENTS

\begin{tabular}{cccc}
\hline wire no. & $\begin{array}{c}\text { Sensitive length, } \\
{[\mathrm{mm}]}\end{array}$ & $\begin{array}{c}\text { Diameter, } \\
{[\mu \mathrm{m}]}\end{array}$ & $1 / \mathrm{d}$ \\
\hline 1 & 0.49 & 2.42 & 202 \\
2 & 1.04 & 3.10 & 335 \\
3 & 1.23 & 5.41 & 227 \\
4 & 1.68 & 4.40 & 382 \\
5 & 1.98 & 4.60 & 430 \\
\hline
\end{tabular}


TABLE C.I

MEAN-VELOCITY PROFILE IN CYIINDER WAKE AT $x / D=220$

$$
U_{0}=0.44[\mathrm{~m} / \mathrm{s}] \quad I=10.46[\mathrm{~mm}]
$$

\begin{tabular}{lll}
\hline$y$ & $U$ & $\frac{U U_{\infty}-U}{U_{0}}$ \\
{$[\mathrm{~mm}]$} & {$[\mathrm{m} / \mathrm{s}]$} &
\end{tabular}

\begin{tabular}{rll}
\hline 22.0 & 6.70 & \\
19.0 & 6.68 & 0.0000 \\
17.0 & 6.66 & 0.0455 \\
15.0 & 6.62 & 0.0909 \\
13.0 & 6.56 & 0.1818 \\
11.0 & 6.50 & 0.3182 \\
9.0 & 6.43 & 0.4545 \\
7.0 & 6.38 & 0.6136 \\
5.0 & 6.33 & 0.7273 \\
3.0 & 6.30 & 0.8409 \\
1.0 & 6.28 & 0.9091 \\
0.0 & 6.26 & 0.9545 \\
-1.0 & 6.28 & 1.0000 \\
-3.0 & 6.30 & 0.9545 \\
-5.0 & 6.33 & 0.9091 \\
-7.0 & 6.38 & 0.8409 \\
-9.0 & 6.43 & 0.7273 \\
-11.0 & 6.50 & 0.6136 \\
-13.0 & 6.56 & 0.4545 \\
-15.0 & 6.62 & 0.3182 \\
-17.0 & 6.66 & 0.1818 \\
-19.0 & 6.68 & 0.0909 \\
-22.0 & 6.70 & 0.0455 \\
& & 0.0000 \\
\hline
\end{tabular}


MEAN-VELOCITY PROFILE IN CYLINDER WAKE AT $x / D=270$

$$
U_{0}=0.42[\mathrm{~m} / \mathrm{s}] \quad I=11.16[\mathrm{~mm}]
$$

\begin{tabular}{rll}
\hline$Y$ & & \\
{$[\mathrm{~mm}]$} & $U$ & $\frac{U_{00}-U}{U_{0}}$ \\
& {$[\mathrm{~m} / \mathrm{s}]$} & \\
\hline & & \\
24.0 & & \\
21.0 & 6.70 & 0.0000 \\
19.0 & 6.69 & 0.0238 \\
17.0 & 6.66 & 0.0952 \\
15.0 & 6.62 & 0.1905 \\
13.0 & 6.58 & 0.2857 \\
11.0 & 6.54 & 0.3810 \\
9.0 & 6.48 & 0.5238 \\
7.0 & 6.44 & 0.6190 \\
5.0 & 6.40 & 0.7143 \\
3.0 & 6.35 & 0.8333 \\
1.0 & 6.32 & 0.9048 \\
0.0 & 6.29 & 0.9762 \\
-1.0 & 6.28 & 1.0000 \\
-3.0 & 6.29 & 0.9762 \\
-5.0 & 6.32 & 0.9048 \\
-7.0 & 6.36 & 0.8095 \\
-9.0 & 6.40 & 0.7143 \\
-11.0 & 6.45 & 0.5952 \\
-13.0 & 6.49 & 0.5000 \\
-15.0 & 6.55 & 0.3571 \\
-17.0 & 6.59 & 0.2619 \\
-19.0 & 6.63 & 0.1667 \\
-21.0 & 6.66 & 0.0952 \\
-24.0 & 6.69 & 0.0238 \\
& 6.70 & 0.0000 \\
\hline
\end{tabular}


TABLE C.3

MEAN-VELOCITY PROFILE IN CYLINDER WAKE AT $X / D=320$

$$
U_{0}=0.40[\mathrm{~m} / \mathrm{s}] \quad I=11.81[\mathrm{~mm}]
$$

\begin{tabular}{lll}
\hline & $U$ & $\frac{U_{\infty}-U}{U}$ \\
{$[m]$} & {$[m / s]$} &
\end{tabular}

\begin{tabular}{rll}
\hline & & \\
26.0 & 6.70 & 0.0000 \\
24.0 & 6.69 & 0.0250 \\
22.0 & 6.67 & 0.0750 \\
20.0 & 6.65 & 0.1250 \\
18.0 & 6.62 & 0.2000 \\
16.0 & 6.60 & 0.2500 \\
14.0 & 6.56 & 0.3500 \\
12.0 & 6.51 & 0.4750 \\
10.0 & 6.45 & 0.6250 \\
8.0 & 6.41 & 0.7250 \\
6.0 & 6.37 & 0.8250 \\
4.0 & 6.35 & 0.8750 \\
2.0 & 6.32 & 0.9500 \\
1.0 & 6.31 & 0.9750 \\
0.0 & 6.30 & 1.0000 \\
-1.0 & 6.31 & 0.9750 \\
-2.0 & 6.32 & 0.9500 \\
-4.0 & 6.35 & 0.8750 \\
-6.0 & 6.37 & 0.8250 \\
-8.0 & 6.41 & 0.7250 \\
-10.0 & 6.45 & 0.6250 \\
-12.0 & 6.51 & 0.4750 \\
-14.0 & 6.56 & 0.3500 \\
-16.0 & 6.60 & 0.2500 \\
-18.0 & 6.62 & 0.2000 \\
-20.0 & 6.65 & 0.1250 \\
-22.0 & 6.67 & 0.0750 \\
-24.0 & 6.69 & 0.0250 \\
-26.0 & 6.70 & 0.0000 \\
-12 & & \\
\hline & &
\end{tabular}


TABLE C. 4

MEAN-VELOCITY PROFILE IN CYIINDER WAKE AT $x / D=370$

$$
U_{0}=0.38[\mathrm{~m} / \mathrm{s}] \quad I=12.43[\mathrm{~mm}]
$$

\begin{tabular}{|c|c|c|}
\hline $\begin{array}{l}Y \\
{[\mathrm{~mm}]}\end{array}$ & $\begin{array}{l}U \\
{[m / s]}\end{array}$ & $\frac{U_{\infty}-U}{U_{0}}$ \\
\hline $\begin{array}{r}28.0 \\
26.0 \\
24.0 \\
22.0 \\
20.0 \\
18.0 \\
16.0 \\
14.0 \\
12.0 \\
10.0 \\
8.0 \\
6.0 \\
4.0 \\
2.0 \\
0.0 \\
-2.0 \\
-4.0 \\
-6.0 \\
-8.0 \\
-10.0 \\
-12.0 \\
-14.0 \\
-16.0 \\
-18.0 \\
-20.0 \\
-22.0 \\
-24.0 \\
-26.0 \\
-28.0\end{array}$ & $\begin{array}{l}6.70 \\
6.69 \\
6.68 \\
6.65 \\
6.63 \\
6.60 \\
6.58 \\
6.54 \\
6.50 \\
6.47 \\
6.43 \\
6.39 \\
6.36 \\
6.34 \\
6.32 \\
6.34 \\
6.36 \\
6.39 \\
6.43 \\
6.47 \\
6.50 \\
6.54 \\
6.58 \\
6.60 \\
6.63 \\
6.65 \\
6.68 \\
6.69 \\
6.70\end{array}$ & $\begin{array}{l}0.0000 \\
0.0263 \\
0.0526 \\
0.1316 \\
0.1842 \\
0.2632 \\
0.3158 \\
0.4211 \\
0.5263 \\
0.6053 \\
0.7105 \\
0.8158 \\
0.8947 \\
0.9474 \\
1.0000 \\
0.9474 \\
0.8947 \\
0.8158 \\
0.7105 \\
0.6053 \\
0.5263 \\
0.4211 \\
0.3158 \\
0.2632 \\
0.1842 \\
0.1316 \\
0.0526 \\
0.0263 \\
0.0000\end{array}$ \\
\hline
\end{tabular}


TABLE C. 5

MEAN-VELOCITY PROFILE IN CYLINDER WAKE AT $X / D=420$

$$
U_{0}=0.36[\mathrm{~m} / \mathrm{s}] \quad I=13.03[\mathrm{~mm}]
$$

\begin{tabular}{rll}
\hline & & \\
$Y$ & $U$ & $U_{00}-U$ \\
{$[\mathrm{~mm}]$} & {$[\mathrm{m} / \mathrm{s}]$} & \\
& & \\
\hline & & \\
30.0 & 6.70 & 0.0000 \\
28.0 & 6.69 & 0.0278 \\
26.0 & 6.67 & 0.0833 \\
24.0 & 6.66 & 0.1111 \\
22.0 & 6.65 & 0.1389 \\
20.0 & 6.64 & 0.1667 \\
18.0 & 6.60 & 0.2778 \\
16.0 & 6.56 & 0.3889 \\
14.0 & 6.53 & 0.4722 \\
12.0 & 6.51 & 0.5278 \\
10.0 & 6.48 & 0.6111 \\
8.0 & 6.44 & 0.7222 \\
6.0 & 6.41 & 0.8056 \\
4.0 & 6.39 & 0.8611 \\
2.0 & 6.36 & 0.9444 \\
1.0 & 6.35 & 0.9722 \\
0.0 & 6.34 & 1.0000 \\
-1.0 & 6.35 & 0.9722 \\
-2.0 & 6.36 & 0.9444 \\
-4.0 & 6.39 & 0.8611 \\
-6.0 & 6.41 & 0.8056 \\
-8.0 & 6.44 & 0.7222 \\
-10.0 & 6.47 & 0.6389 \\
-12.0 & 6.51 & 0.5278 \\
-14.0 & 6.53 & 0.4722 \\
-16.0 & 6.56 & 0.3889 \\
-18.0 & 6.60 & 0.2778 \\
-20.0 & 6.62 & 0.2222 \\
-22.0 & 6.65 & 0.1389 \\
-24.0 & 6.66 & 0.1111 \\
-26.0 & 6.67 & 0.0278 \\
-28.0 & 6.69 & \\
-30.0 & 6.70 & \\
\hline & & \\
\hline
\end{tabular}


TABLE D.I

SECOND ORDER VELOCITY CORRELATIONS IN THE WAKE

\begin{tabular}{|c|c|c|c|c|c|}
\hline $\begin{array}{c}y \\
{[\mathrm{~mm}]}\end{array}$ & $\begin{array}{l}\overline{u^{2}} \times 10^{2} \\
{\left[\mathrm{~m}^{2} \mathrm{~s}^{-2}\right]}\end{array}$ & $\begin{array}{l}\overline{v^{2}} \times 10^{2} \\
{\left[\mathrm{~m}^{2} \mathrm{~s}^{-2}\right]}\end{array}$ & $\begin{array}{l}\overline{w^{2}} \times 10^{2} \\
{\left[\mathrm{~m}^{2} \mathrm{~s}^{-2}\right]}\end{array}$ & $\begin{array}{l}\overline{\mathrm{q}^{2}} \times 10^{2} \\
{\left[\mathrm{~m}^{2} \mathrm{~s}^{-2}\right]}\end{array}$ & $\begin{array}{l}\overline{u v} \times 10^{3} \\
{\left[\mathrm{~m}^{2} \mathrm{~s}^{-2}\right]}\end{array}$ \\
\hline 0 & 1.000 & 0.810 & 0.723 & 2.533 & 0.250 \\
\hline 1 & 1.020 & 0.810 & 0.723 & 2.553 & 1.100 \\
\hline 3 & 1.040 & 0.828 & 0.723 & 2.591 & 2.400 \\
\hline 5 & 1.145 & 0.828 & 0.740 & 2.713 & 3.460 \\
\hline 7 & 1.232 & 0.810 & 0.757 & 2.799 & 4.560 \\
\hline 9 & 1.300 & 0.792 & 0.774 & 2.866 & 4.910 \\
\hline 11. & 1.322 & 0.774 & 0.757 & 2.853 & 4.940 \\
\hline 13 & 1.232 & 0.706 & 0.689 & 2.627 & 4.740 \\
\hline 15 & 1.124 & 0.624 & 0.608 & 2.356 & 4.020 \\
\hline 17 & 0.941 & 0.533 & 0.533 & 2.007 & 3.550 \\
\hline 19 & 0.722 & 0.435 & 0.436 & 1.593 & 2.560 \\
\hline 21 & 0.476 & 0.360 & 0.348 & 1.184 & 1.750 \\
\hline 23 & 0.313 & 0.291 & 0.281 & 0.885 & 1.060 \\
\hline 25 & 0.203 & 0.240 & 0.230 & 0.673 & 0.660 \\
\hline 27 & 0.115 & 0.194 & 0.185 & 0.494 & 0.420 \\
\hline 29 & 0.078 & 0.160 & 0.152 & 0.390 & 0.170 \\
\hline 31 & 0.050 & 0.130 & 0.137 & 0.317 & 0.070 \\
\hline
\end{tabular}


TABLE D.2

THIRD ORDER VELOCITY CORRELATIONS IN THE WAKE

\begin{tabular}{|c|c|c|c|c|}
\hline $\begin{array}{l}Y \\
{[\mathrm{~mm}]}\end{array}$ & $\frac{\overline{v^{2}}}{U_{0}{ }^{3}} \times 10^{3}$ & $\frac{\overline{v^{3}}}{U_{0}{ }^{3}} \times 10^{3}$ & $\frac{\overline{\mathrm{VW}^{2}}}{\mathrm{U}_{0}{ }^{3}} \times 10^{3}$ & $\frac{\overline{v^{2}}}{U_{0}{ }^{3}} \times 10^{3}$ \\
\hline 0.0 & -0.10 & +0.48 & 0.00 & +0.38 \\
\hline 1.0 & +0.82 & +0.32 & +1.43 & +2.57 \\
\hline 3.0 & +2.13 & -0.16 & +2.22 & +4.19 \\
\hline 5.0 & +2.67 & -0.88 & +2.09 & +3.88 \\
\hline 7.0 & +1.85 & -2.24 & +1.49 & +1.10 \\
\hline 9.0 & -0.48 & -3.44 & +0.29 & -3.63 \\
\hline 11.0 & -3.64 & -5.28 & -1.18 & $-10 \cdot 10$ \\
\hline 13.0 & -6.51 & -6.45 & -2.37 & -15.33 \\
\hline 15.0 & -8.71 & -7.12 & -3.23 & -19.06 \\
\hline 17.0 & -9.61 & -7.39 & -3.86 & -20.86 \\
\hline 19.0 & -8.72 & -6.61 & -3.44 & -18.77 \\
\hline 21.0 & -6.97 & -5.54 & -2.34 & -14.85 \\
\hline 23.0 & -5.05 & -4.24 & -1.57 & -10.86 \\
\hline 25.0 & -3.18 & -3.04 & -0.78 & -7.00 \\
\hline 27.0 & -1.72 & -2.02 & -0.42 & -4.16 \\
\hline 29.0 & -0.77 & -1.21 & -0.06 & -2.04 \\
\hline 31.0 & -0.21 & -0.68 & -0.00 & -0.89 \\
\hline 33.0 & -0.15 & -0.35 & +0.08 & -0.42 \\
\hline
\end{tabular}


TABLE E.I.I

$\overline{u^{2}}$-SPECTRA OBTAINED WITH WIRE 1

$\begin{array}{llll}Y & =0 & {[\mathrm{~mm}]} & \eta=0.0 \\ U=6.34 & {\left[\mathrm{~ms}^{-1}\right]} & \overline{\mathrm{u}^{2}}=1.0898 \mathrm{E}-2\left[\mathrm{~m}^{2} \mathrm{~s}^{-2}\right] \\ T=26 & {\left[{ }^{\circ} \mathrm{C}\right]} & P=732.1 & {[\mathrm{~mm} \mathrm{Hg}]} \\ E_{K}=2400 & {[\mathrm{~Hz}]} & \nu=1.62 \mathrm{E}-5 & {\left[\mathrm{~m}^{2} \mathrm{~s}^{-1}\right]}\end{array}$

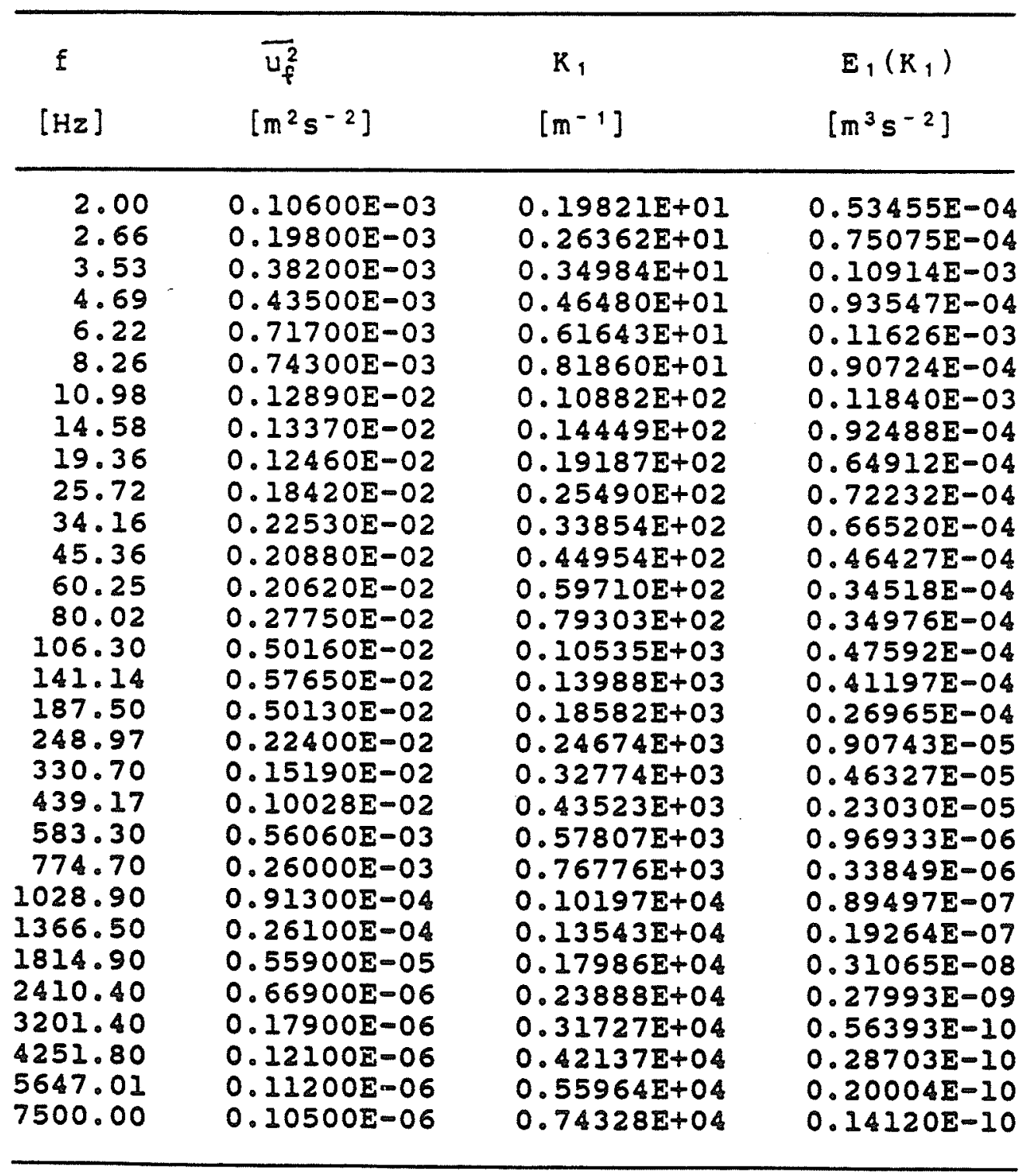


TABLE E.I.2

$\overline{U^{2}}$-SPECTRA OBTAINED WITH WIRE 1

$\begin{array}{llll}\mathrm{Y}=4 & {[\mathrm{~mm}]} & \eta=0.307 & \\ \mathrm{U}=6.39 & {[\mathrm{~ms}-1]} & \overline{\mathrm{u}^{2}}=1.1537 \mathrm{E}-2\left[\mathrm{~m}^{2} \mathrm{~s}^{-2}\right] \\ \mathrm{T}=26 & {\left[{ }^{\circ} \mathrm{C}\right]} & \mathrm{P}=732.1 & {[\mathrm{~mm} \mathrm{Hg}]} \\ E_{K}=2500 & {[\mathrm{~Hz}]} & \nu=1.62 \mathrm{E}-5 & {\left[\mathrm{~m}^{2} \mathrm{~s}^{-1}\right]}\end{array}$

\begin{tabular}{|c|c|c|c|}
\hline $\begin{array}{c}E \\
{[\mathrm{~Hz}]}\end{array}$ & $\begin{array}{l}\overline{u_{f}^{2}} \\
{\left[m^{2} s^{-2}\right]}\end{array}$ & $\begin{array}{c}K_{1} \\
{\left[m^{-1}\right]}\end{array}$ & $\begin{array}{c}E_{1}\left(K_{1}\right) \\
{\left[m^{3} s^{-2}\right]}\end{array}$ \\
\hline $\begin{array}{r}2.00 \\
2.66 \\
3.53 \\
4.69 \\
6.22 \\
8.26 \\
10.98 \\
14.58 \\
19.36 \\
25.72 \\
34.16 \\
45.36 \\
60.25 \\
80.02 \\
106.30 \\
141.14 \\
187.50 \\
248.97 \\
330.70 \\
439.17 \\
583.30 \\
774.70 \\
1028.90 \\
1366.50 \\
1814.90 \\
2410.40 \\
3201.40 \\
4251.80 \\
5647.01 \\
7500.00\end{array}$ & $\begin{array}{l}0.10030 E-03 \\
0.39400 E-03 \\
0.53200 E-03 \\
0.81200 E-03 \\
0.80700 E-03 \\
0.10004 E-02 \\
0.11190 E-02 \\
0.14590 E-02 \\
0.22400 E-02 \\
0.21240 E-02 \\
0.21380 E-02 \\
0.23430 E-02 \\
0.33038 E-02 \\
0.32700 E-02 \\
0.35820 E-02 \\
0.41160 E-02 \\
0.53240 E-02 \\
0.23220 E-02 \\
0.15530 E-02 \\
0.10680 E-02 \\
0.58200 E-03 \\
0.30900 E-03 \\
0.10750 E-03 \\
0.33100 E-04 \\
0.53900 E-05 \\
0.70600 E-06 \\
0.18600 E-06 \\
0.12500 E-06 \\
0.11400 E-06 \\
0.10200 E-06\end{array}$ & $\begin{array}{l}0.19666 \mathrm{E}+01 \\
0.26155 \mathrm{E}+01 \\
0.34710 \mathrm{E}+01 \\
0.46116 \mathrm{E}+01 \\
0.61160 \mathrm{O}+01 \\
0.81219 \mathrm{E}+01 \\
0.10796 \mathrm{E}+02 \\
0.14336 \mathrm{E}+02 \\
0.19036 \mathrm{E}+02 \\
0.25290 \mathrm{E}+02 \\
0.33589 \mathrm{E}+02 \\
0.44602 \mathrm{E}+02 \\
0.59243 \mathrm{E}+02 \\
0.78682 \mathrm{E}+02 \\
0.10452 \mathrm{E}+03 \\
0.13878 \mathrm{E}+03 \\
0.18437 \mathrm{E}+03 \\
0.24481 \mathrm{E}+03 \\
0.32517 \mathrm{E}+03 \\
0.43183 \mathrm{E}+03 \\
0.57355 \mathrm{E}+03 \\
0.76175 \mathrm{E}+03 \\
0.10117 \mathrm{E}+04 \\
0.13437 \mathrm{E}+04 \\
0.17846 \mathrm{E}+04 \\
0.23701 \mathrm{E}+04 \\
0.31479 \mathrm{E}+04 \\
0.41807 \mathrm{E}+04 \\
0.55526 \mathrm{E}+04 \\
0.73746 \mathrm{E}+04\end{array}$ & $\begin{array}{l}0.51967 E-04 \\
0.15349 E-03 \\
0.15617 E-03 \\
0.17941 E-03 \\
0.13444 E-03 \\
0.12550 E-03 \\
0.10561 E-03 \\
0.10369 E-03 \\
0.11990 E-03 \\
0.85574 E-04 \\
0.64856 E-04 \\
0.53525 E-04 \\
0.56822 E-04 \\
0.42346 E-04 \\
0.34918 E-04 \\
0.30219 E-04 \\
0.29424 E-04 \\
0.96644 E-05 \\
0.48663 E-05 \\
0.25200 E-05 \\
0.10339 E-05 \\
0.41332 E-06 \\
0.10827 E-06 \\
0.25100 E-07 \\
0.30775 E-08 \\
0.30351 E-09 \\
0.60205 E-10 \\
0.30465 E-10 \\
0.20919 E-10 \\
0.14093 E-10\end{array}$ \\
\hline
\end{tabular}


TABLE E.1.3

$\overline{u^{2}}$-SPECTRA OBTAINED WITH WIRE 1

$$
\begin{aligned}
& y=8 \quad[\mathrm{~mm}] \quad \eta=0.614 \\
& U=6.44\left[\mathrm{~ms}^{-1}\right] \quad \overline{u^{2}}=1.3254 \mathrm{E}-2\left[\mathrm{~m}^{2} \mathrm{~s}^{-2}\right] \\
& T=26 \quad\left[{ }^{\circ} \mathrm{C}\right] \quad P=732.1 \quad[\mathrm{~mm} \mathrm{Hg}] \\
& f_{k}=2500[\mathrm{~Hz}] \quad \nu=1.62 \mathrm{E}-5 \quad\left[\mathrm{~m}^{2} \mathrm{~s}^{-1}\right]
\end{aligned}
$$

\begin{tabular}{|c|c|c|c|}
\hline$[\mathrm{Hz}]$ & $\begin{array}{l}\overline{u_{f}^{2}} \\
{\left[m^{2} s^{-2}\right]}\end{array}$ & $\begin{array}{c}k_{1} \\
{\left[m^{-1}\right]}\end{array}$ & $\begin{array}{c}E_{1}\left(K_{1}\right) \\
{\left[m^{3} s^{-2}\right]}\end{array}$ \\
\hline $\begin{array}{r}2.00 \\
2.66 \\
3.53 \\
4.69 \\
6.22 \\
8.26 \\
10.98 \\
14.58 \\
19.36 \\
25.72 \\
34.16 \\
45.36 \\
60.25 \\
80.02 \\
106.30 \\
141.14 \\
187.50 \\
248.97 \\
330.70 \\
439.17 \\
583.30 \\
774.70 \\
1028.90 \\
1366.50 \\
1814.90 \\
2410.40 \\
3201.40 \\
4251.80 \\
5647.01 \\
7500.00\end{array}$ & $\begin{array}{l}0.18500 E-03 \\
0.68000 E-03 \\
0.75800 E-03 \\
0.12820 E-02 \\
0.12550 E-02 \\
0.13740 E-02 \\
0.10500 E-02 \\
0.18840 E-02 \\
0.20550 E-02 \\
0.15980 E-02 \\
0.17920 E-02 \\
0.29030 E-02 \\
0.49600 E-02 \\
0.34590 E-02 \\
0.42810 E-02 \\
0.52050 E-02 \\
0.55650 E-02 \\
0.23720 E-02 \\
0.15830 E-02 \\
0.10930 E-02 \\
0.54900 E-03 \\
0.25900 E-03 \\
0.99100 E-04 \\
0.26300 E-04 \\
0.51800 E-05 \\
0.73000 E-06 \\
0.21100 E-06 \\
0.14300 E-06 \\
0.13100 E-06 \\
0.11600 E-06\end{array}$ & $\begin{array}{l}0.19513 \mathrm{E}+01 \\
0.25952 \mathrm{E}+01 \\
0.34440 \mathrm{E}+01 \\
0.45758 \mathrm{E}+01 \\
0.60685 \mathrm{E}+01 \\
0.80589 \mathrm{E}+01 \\
0.10713 \mathrm{E}+02 \\
0.14225 \mathrm{E}+02 \\
0.18889 \mathrm{E}+02 \\
0.25094 \mathrm{E}+02 \\
0.33328 \mathrm{E}+02 \\
0.44255 \mathrm{E}+02 \\
0.58783 \mathrm{E}+02 \\
0.78072 \mathrm{E}+02 \\
0.10371 \mathrm{E}+03 \\
0.13770 \mathrm{E}+03 \\
0.18293 \mathrm{E}+03 \\
0.24291 \mathrm{E}+03 \\
0.32265 \mathrm{E}+03 \\
0.42848 \mathrm{E}+03 \\
0.56910 \mathrm{E}+03 \\
0.75584 \mathrm{E}+03 \\
0.10038 \mathrm{E}+04 \\
0.13332 \mathrm{E}+04 \\
0.17707 \mathrm{E}+04 \\
0.23517 \mathrm{E}+04 \\
0.31234 \mathrm{E}+04 \\
0.41483 \mathrm{E}+04 \\
0.55095 \mathrm{E}+04 \\
0.73174 \mathrm{E}+04\end{array}$ & $\begin{array}{l}0.97300 \mathrm{E}-04 \\
0.26890 \mathrm{E}-03 \\
0.22587 \mathrm{E}-03 \\
0.28753 \mathrm{E}-03 \\
0.21224 \mathrm{E}-03 \\
0.17498 \mathrm{E}-03 \\
0.10059 \mathrm{E}-03 \\
0.13592 \mathrm{E}-03 \\
0.11165 \mathrm{E}-03 \\
0.65355 \mathrm{E}-04 \\
0.55181 \mathrm{E}-04 \\
0.67320 \mathrm{E}-04 \\
0.86596 \mathrm{E}-04 \\
0.45470 \mathrm{E}-04 \\
0.42363 \mathrm{E}-04 \\
0.38792 \mathrm{E}-04 \\
0.31220 \mathrm{E}-04 \\
0.10022 \mathrm{E}-04 \\
0.50352 \mathrm{E}-05 \\
0.26179 \mathrm{E}-05 \\
0.99004 \mathrm{E}-06 \\
0.35167 \mathrm{E}-06 \\
0.10131 \mathrm{E}-06 \\
0.20245 \mathrm{E}-07 \\
0.30023 \mathrm{E}-08 \\
0.31857 \mathrm{E}-09 \\
0.69329 \mathrm{E}-10 \\
0.35378 \mathrm{E}-10 \\
0.24402 \mathrm{E}-10 \\
0.16269 \mathrm{E}-10\end{array}$ \\
\hline
\end{tabular}


TABLE E.1.4

$\overline{u^{2}}$-SPECTRA OBTAINED WITH WIRE 1

\begin{tabular}{|c|c|c|c|c|c|}
\hline$y$ & $=12$ & {$[\mathrm{~mm}]$} & $\eta$ & $=0.921$ & \\
\hline U & $=6.50$ & {$\left[\mathrm{~ms}^{-1}\right]$} & $\overline{u^{2}}$ & $=1.3752 \mathrm{E}-2$ & {$\left[m^{2} s^{-2}\right]$} \\
\hline & $=26$ & {$\left[{ }^{\circ} \mathrm{C}\right]$} & $P$ & $=732.1$ & {$[\mathrm{~mm} \mathrm{Hg}]$} \\
\hline & $=2400$ & {$[\mathrm{~Hz}]$} & $\nu$ & $=1.62 \mathrm{E}-5$ & {$\left[m^{2} s^{-1}\right]$} \\
\hline
\end{tabular}

\begin{tabular}{|c|c|c|c|}
\hline$[\mathrm{Hz}]$ & $\begin{array}{l}\overline{u_{f}^{2}} \\
{\left[\mathrm{~m}^{2} \mathrm{~s}^{-2}\right]}\end{array}$ & $\begin{array}{c}k_{1} \\
{\left[m^{-1}\right]}\end{array}$ & $\begin{array}{c}E_{1}\left(K_{1}\right) \\
{\left[m^{3} s^{-2}\right]}\end{array}$ \\
\hline $\begin{array}{r}2.00 \\
2.66 \\
3.53 \\
4.69 \\
6.22 \\
8.26 \\
10.98 \\
14.58 \\
19.36 \\
25.72 \\
34.16 \\
45.36 \\
60.25 \\
80.02 \\
106.30 \\
141.14 \\
187.50 \\
248.97 \\
330.70 \\
439.17 \\
583.30 \\
774.70 \\
1028.90 \\
1366.50 \\
1814.90 \\
2410.40 \\
3201.40 \\
4251.80 \\
5647.01 \\
7500.00\end{array}$ & $\begin{array}{l}0.22990 E-03 \\
0.59900 E-03 \\
0.86000 E-03 \\
0.96910 E-03 \\
0.15210 E-02 \\
0.18770 E-02 \\
0.17330 E-02 \\
0.18520 E-02 \\
0.15070 E-02 \\
0.24460 E-02 \\
0.21960 E-02 \\
0.27650 E-02 \\
0.32440 E-02 \\
0.32870 E-02 \\
0.45030 E-02 \\
0.49240 E-02 \\
0.47910 E-02 \\
0.20230 E-02 \\
0.12490 E-02 \\
0.82100 E-03 \\
0.40800 E-03 \\
0.17330 E-03 \\
0.72500 E-04 \\
0.18400 E-04 \\
0.40800 E-05 \\
0.58500 E-06 \\
0.21000 E-06 \\
0.14600 E-06 \\
0.13500 E-06 \\
0.12100 E-06\end{array}$ & $\begin{array}{l}0.19333 \mathrm{E}+01 \\
0.25713 \mathrm{E}+01 \\
0.34123 \mathrm{E}+01 \\
0.45336 \mathrm{E}+01 \\
0.60125 \mathrm{E}+01 \\
0.79845 \mathrm{E}+01 \\
0.10614 \mathrm{E}+02 \\
0.14094 \mathrm{E}+02 \\
0.18714 \mathrm{E}+02 \\
0.24862 \mathrm{E}+02 \\
0.33021 \mathrm{E}+02 \\
0.43847 \mathrm{E}+02 \\
0.58240 \mathrm{E}+02 \\
0.77351 \mathrm{E}+02 \\
0.10275 \mathrm{E}+03 \\
0.13643 \mathrm{E}+03 \\
0.18125 \mathrm{E}+03 \\
0.24067 \mathrm{E}+03 \\
0.31967 \mathrm{E}+03 \\
0.42452 \mathrm{E}+03 \\
0.56384 \mathrm{E}+03 \\
0.74886 \mathrm{E}+03 \\
0.99458 \mathrm{E}+03 \\
0.13209 \mathrm{E}+04 \\
0.17544 \mathrm{E}+04 \\
0.23300 \mathrm{E}+04 \\
0.30946 \mathrm{E}+04 \\
0.41100 \mathrm{E}+04 \\
0.54586 \mathrm{E}+04 \\
0.72498 \mathrm{E}+04\end{array}$ & $\begin{array}{l}0.13142 E-03 \\
0.25745 E-03 \\
0.27853 E-03 \\
0.23624 E-03 \\
0.27957 E-03 \\
0.25980 E-03 \\
0.18045 E-03 \\
0.14522 E-03 \\
0.88994 E-04 \\
0.10873 E-03 \\
0.73496 E-04 \\
0.69690 E-04 \\
0.61557 E-04 \\
0.46963 E-04 \\
0.48431 E-04 \\
0.39886 E-04 \\
0.29213 E-04 \\
0.92897 E-05 \\
0.43180 E-05 \\
0.21373 E-05 \\
0.79969 E-06 \\
0.25575 E-06 \\
0.80559 E-07 \\
0.15394 E-07 \\
0.25702 E-08 \\
0.27747 E-09 \\
0.74995 E-10 \\
0.39258 E-10 \\
0.27332 E-10 \\
0.18445 E-10\end{array}$ \\
\hline
\end{tabular}


TABLE E.1.5

BTAINED WITH WIRE 1

\begin{tabular}{|c|c|c|c|c|c|}
\hline$y$ & $=16$ & {$[\mathrm{~mm}]$} & $\eta$ & $=1.228$ & \\
\hline $\mathrm{U}$ & $=6.56$ & {$\left[\mathrm{~ms}^{-1}\right]$} & $\overline{u^{2}}$ & $=1.1301 \mathrm{E}-2$ & {$\left[m^{2} s^{-2}\right]$} \\
\hline$T$ & $=26$ & {$\left[{ }^{\circ} \mathrm{C}\right]$} & $P$ & $=732.1$ & [mm Hg] \\
\hline & $=2200$ & {$[\mathrm{~Hz}]$} & $\nu$ & $=1.62 \mathrm{E}-5$ & {$\left[m^{2} s^{-1}\right]$} \\
\hline
\end{tabular}

\begin{tabular}{|c|c|c|c|}
\hline$[\mathrm{Hz}]$ & $\begin{array}{l}\overline{u_{f}^{2}} \\
{\left[m^{2} s^{-2}\right]}\end{array}$ & $\begin{array}{c}K_{1} \\
{\left[m^{-1}\right]}\end{array}$ & $\begin{array}{c}E_{1}\left(K_{1}\right) \\
{\left[m^{3} s^{-2}\right]}\end{array}$ \\
\hline $\begin{array}{r}2.00 \\
2.66 \\
3.53 \\
4.69 \\
6.22 \\
8.26 \\
10.98 \\
14.58 \\
19.36 \\
25.72 \\
34.16 \\
45.36 \\
60.25 \\
80.02 \\
106.30 \\
141.14 \\
187.50 \\
248.97 \\
330.70 \\
439.17 \\
583.30 \\
774.70 \\
1028.90 \\
1366.50 \\
1814.90 \\
2410.40 \\
3201.40 \\
4251.80 \\
5647.01\end{array}$ & $\begin{array}{l}0.15100 E-03 \\
0.50300 E-03 \\
0.94200 E-03 \\
0.88500 E-03 \\
0.12470 E-02 \\
0.20140 E-02 \\
0.17770 E-02 \\
0.20610 E-02 \\
0.19220 E-02 \\
0.17300 E-02 \\
0.29210 E-02 \\
0.17400 E-02 \\
0.25540 E-02 \\
0.29010 E-02 \\
0.32390 E-02 \\
0.34680 E-02 \\
0.44170 E-02 \\
0.16420 E-02 \\
0.10380 E-02 \\
0.62500 E-03 \\
0.28300 E-03 \\
0.11800 E-03 \\
0.44900 E-04 \\
0.13400 E-04 \\
0.27000 E-05 \\
0.36600 E-06 \\
0.16600 E-06 \\
0.12600 E-06 \\
0.12100 E-06\end{array}$ & $\begin{array}{l}0.19156 E+01 \\
0.25478 E+01 \\
0.33810 E+01 \\
0.44921 E+01 \\
0.59575 E+01 \\
0.79115 E+01 \\
0.10517 E+02 \\
0.13965 E+02 \\
0.18543 E+02 \\
0.24635 E+02 \\
0.32719 E+02 \\
0.43446 E+02 \\
0.57708 E+02 \\
0.76643 E+02 \\
0.10181 E+03 \\
0.13518 E+03 \\
0.17959 E+03 \\
0.23846 E+03 \\
0.31675 E+03 \\
0.42064 E+03 \\
0.55869 E+03 \\
0.74201 E+03 \\
0.98548 E+03 \\
0.13088 E+04 \\
0.17383 E+04 \\
0.23087 E+04 \\
0.30663 E+04 \\
0.40724 E+04 \\
0.54087 E+04\end{array}$ & $\begin{array}{l}0.84124 E-04 \\
0.21070 E-03 \\
0.29734 E-03 \\
0.21025 E-03 \\
0.22338 E-03 \\
0.27168 E-03 \\
0.18033 E-03 \\
0.15750 E-03 \\
0.11062 E-03 \\
0.74946 E-04 \\
0.95277 E-04 \\
0.42741 E-04 \\
0.47232 E-04 \\
0.40394 E-04 \\
0.33951 E-04 \\
0.27378 E-04 \\
0.26248 E-04 \\
0.73485 E-05 \\
0.34973 E-05 \\
0.15857 E-05 \\
0.54059 E-06 \\
0.16972 E-06 \\
0.48623 E-07 \\
0.10926 E-07 \\
0.16576 E-08 \\
0.16919 E-09 \\
0.57775 E-10 \\
0.33019 E-10 \\
0.23875 E-10\end{array}$ \\
\hline
\end{tabular}


TABLE E:1.6

$\overline{u^{2}}$-SPECTRA OBTAINED WITH WIRE 1

\begin{tabular}{|c|c|c|c|c|c|}
\hline$y$ & $=20$ & {$[\mathrm{~mm}]$} & $\eta$ & $=1.535$ & \\
\hline$U$ & $=6.63$ & {$\left[\mathrm{~ms}^{-1}\right]$} & $\overline{u^{2}}$ & $=6.7203 \mathrm{E}-3$ & {$\left[\mathrm{~m}^{2} \mathrm{~s}^{-}\right.$} \\
\hline & $=26$ & {$\left[{ }^{\circ} \mathrm{C}\right]$} & $\mathrm{P}$ & $=732.1$ & {$[\mathrm{~mm} \mathrm{H}$} \\
\hline & $=2000$ & [Hz] & $\nu$ & $=1.62 \mathrm{E}-5$ & {$\left[\mathrm{~m}^{2}\right.$} \\
\hline
\end{tabular}

\begin{tabular}{|c|c|c|c|}
\hline$[\mathrm{Hz}]$ & $\begin{array}{l}\overline{u_{f}^{2}} \\
{\left[m^{2} s^{-2}\right]}\end{array}$ & $\begin{array}{c}K_{1} \\
{\left[m^{-1}\right]}\end{array}$ & $\begin{array}{c}E_{1}\left(K_{1}\right) \\
{\left[m^{3} s^{-2}\right]}\end{array}$ \\
\hline $\begin{array}{r}2.00 \\
2.66 \\
3.53 \\
4.69 \\
6.22 \\
8.26 \\
10.98 \\
14.58 \\
19.36 \\
25.72 \\
34.16 \\
45.36 \\
60.25 \\
80.02 \\
106.30 \\
141.14 \\
187.50 \\
248.97 \\
330.70 \\
439.17 \\
583.30 \\
774.70 \\
1028.90 \\
1366.50 \\
1814.90 \\
2410.40 \\
3201.40 \\
4251.80\end{array}$ & $\begin{array}{l}0.94800 E-04 \\
0.33400 E-03 \\
0.40060 E-03 \\
0.45800 E-03 \\
0.54400 E-03 \\
0.55200 E-03 \\
0.11130 E-02 \\
0.11870 E-02 \\
0.10190 E-02 \\
0.11450 E-02 \\
0.16050 E-02 \\
0.15030 E-02 \\
0.15690 E-02 \\
0.17930 E-02 \\
0.23670 E-02 \\
0.25970 E-02 \\
0.33970 E-02 \\
0.10470 E-02 \\
0.61300 E-03 \\
0.46400 E-03 \\
0.21500 E-03 \\
0.82200 E-04 \\
0.29900 E-04 \\
0.79300 E-05 \\
0.12100 E-05 \\
0.16900 E-06 \\
0.11200 E-06 \\
0.85000 E-07\end{array}$ & $\begin{array}{l}0.18954 \mathrm{E}+01 \\
0.25209 \mathrm{E}+01 \\
0.33453 \mathrm{E}+01 \\
0.44447 \mathrm{E}+01 \\
0.58946 \mathrm{E}+01 \\
0.78279 \mathrm{E}+01 \\
0.10406 \mathrm{E}+02 \\
0.13817 \mathrm{E}+02 \\
0.18347 \mathrm{E}+02 \\
0.24375 \mathrm{E}+02 \\
0.32373 \mathrm{E}+02 \\
0.42987 \mathrm{E}+02 \\
0.57098 \mathrm{E}+02 \\
0.75834 \mathrm{E}+02 \\
0.10074 \mathrm{E}+03 \\
0.13376 \mathrm{E}+03 \\
0.17769 \mathrm{E}+03 \\
0.23595 \mathrm{E}+03 \\
0.31340 \mathrm{E}+03 \\
0.41620 \mathrm{E}+03 \\
0.55279 \mathrm{E}+03 \\
0.73418 \mathrm{E}+03 \\
0.97508 \mathrm{E}+03 \\
0.12950 \mathrm{E}+04 \\
0.17200 \mathrm{E}+04 \\
0.22843 \mathrm{E}+04 \\
0.30339 \mathrm{E}+04 \\
0.40294 \mathrm{E}+04\end{array}$ & $\begin{array}{l}0.50597 E-04 \\
0.13403 E-03 \\
0.12114 E-03 \\
0.10424 E-03 \\
0.93359 E-04 \\
0.71336 E-04 \\
0.10820 E-03 \\
0.86905 E-04 \\
0.56185 E-04 \\
0.47521 E-04 \\
0.50154 E-04 \\
0.35370 E-04 \\
0.27798 E-04 \\
0.23918 E-04 \\
0.23769 E-04 \\
0.19641 E-04 \\
0.19339 E-04 \\
0.44890 E-05 \\
0.19787 E-05 \\
0.11278 E-05 \\
0.39346 E-06 \\
0.11326 E-06 \\
0.31020 E-07 \\
0.61946 E-08 \\
0.71168 E-09 \\
0.74842 E-10 \\
0.37345 E-10 \\
0.21340 E-10\end{array}$ \\
\hline
\end{tabular}


TABLE E.1.7

$\overline{u^{2}}$-SPECTRA OBTAINED WITH WIRE 1

$\begin{array}{llll}\mathrm{y}=24 & {[\mathrm{~mm}]} & \eta=1.842 & \\ \mathrm{U}=6.66\left[\mathrm{~ms}^{-1}\right] & \overline{\mathrm{u}^{2}}=3.1134 \mathrm{E}-3\left[\mathrm{~m}^{2} \mathrm{~s}^{-2}\right] \\ \mathrm{T}=26 & {\left[{ }^{0} \mathrm{C}\right]} & \mathrm{P}=732.1 & {[\mathrm{~mm} \mathrm{Hg}]} \\ E_{K}=1700 & {[\mathrm{~Hz}]} & \nu=1.62 \mathrm{E}-5 & {\left[\mathrm{~m}^{2} \mathrm{~s}^{-1}\right]}\end{array}$

\begin{tabular}{|c|c|c|c|}
\hline $\begin{array}{c}E \\
{[\mathrm{~Hz}]}\end{array}$ & $\begin{array}{l}\overline{u_{f}^{2}} \\
{\left[m^{2} s^{-2}\right]}\end{array}$ & $\begin{array}{c}k_{1} \\
{\left[m^{-1}\right]}\end{array}$ & $\begin{array}{c}E_{1}\left(k_{1}\right) \\
{\left[m^{3} s^{-2}\right]}\end{array}$ \\
\hline $\begin{array}{r}2.00 \\
2.66 \\
3.53 \\
4.69 \\
6.22 \\
8.26 \\
10.98 \\
14.58 \\
19.36 \\
25.72 \\
34.16 \\
45.36 \\
60.25 \\
80.02 \\
106.30 \\
141.14 \\
187.50 \\
248.97 \\
330.70 \\
439.17 \\
583.30 \\
774.70 \\
1028.90 \\
1366.50 \\
1814.90 \\
2410.40 \\
3201.40 \\
4251.80\end{array}$ & $\begin{array}{l}0.38000 E-04 \\
0.14140 E-03 \\
0.19080 E-03 \\
0.19860 E-03 \\
0.18730 E-03 \\
0.26100 E-03 \\
0.32600 E-03 \\
0.37100 E-03 \\
0.40800 E-03 \\
0.54900 E-03 \\
0.64000 E-03 \\
0.85000 E-03 \\
0.76300 E-03 \\
0.81000 E-03 \\
0.10250 E-02 \\
0.12310 E-02 \\
0.14790 E-02 \\
0.66100 E-03 \\
0.38100 E-03 \\
0.24900 E-03 \\
0.11070 E-03 \\
0.50100 E-04 \\
0.18400 E-04 \\
0.38700 E-05 \\
0.33300 E-06 \\
0.64000 E-07 \\
0.53000 E-07 \\
0.40000 E-07\end{array}$ & $\begin{array}{l}0.18868 E+01 \\
0.25095 E+01 \\
0.33303 E+01 \\
0.44246 E+01 \\
0.58681 E+01 \\
0.77927 E+01 \\
0.10359 E+02 \\
0.13755 E+02 \\
0.18265 E+02 \\
0.24265 E+02 \\
0.32227 E+02 \\
0.42794 \mathrm{E}+02 \\
0.56841 \mathrm{E}+02 \\
0.75493 \mathrm{E}+02 \\
0.10029 \mathrm{E}+03 \\
0.13315 \mathrm{E}+03 \\
0.17689 \mathrm{E}+03 \\
0.23488 \mathrm{E}+03 \\
0.31199 \mathrm{E}+03 \\
0.41432 \mathrm{E}+03 \\
0.55030 \mathrm{E}+03 \\
0.73087 \mathrm{E}+03 \\
0.97069 \mathrm{E}+03 \\
0.12892 \mathrm{E}+04 \\
0.17122 \mathrm{E}+04 \\
0.22740 \mathrm{E}+04 \\
0.30203 \mathrm{E}+04 \\
0.40112 \mathrm{E}+04\end{array}$ & $\begin{array}{l}0.20333 E-04 \\
0.56886 E-04 \\
0.57842 E-04 \\
0.45315 E-04 \\
0.32224 E-04 \\
0.33814 E-04 \\
0.31773 E-04 \\
0.27230 E-04 \\
0.22552 E-04 \\
0.22842 E-04 \\
0.20049 E-04 \\
0.20053 E-04 \\
0.13552 E-04 \\
0.10832 E-04 \\
0.10319 E-04 \\
0.93335 E-05 \\
0.84412 E-05 \\
0.28411 E-05 \\
0.12329 E-05 \\
0.60674 E-06 \\
0.20309 E-06 \\
0.69206 E-07 \\
0.19137 E-07 \\
0.30307 E-08 \\
0.19635 E-09 \\
0.28414 E-10 \\
0.17716 E-10 \\
0.10068 E-10\end{array}$ \\
\hline
\end{tabular}


TABLE E.1.8

$\overline{U^{2}}$-SPECTRA OBTAINED WITH WIRE 1

$$
\begin{aligned}
& y=28 \quad[\mathrm{~mm}] \quad \eta=2.149 \\
& U=6.69\left[\mathrm{~ms}^{-1}\right] \quad \overline{u^{2}}=9.8979 \mathrm{E}-4\left[\mathrm{~m}^{2} \mathrm{~s}^{-2}\right] \\
& T=26 \quad\left[{ }^{\circ} \mathrm{C}\right] \quad P=732.1 \quad[\mathrm{~mm} \mathrm{Hg}] \\
& E_{k}=1100[\mathrm{~Hz}] \quad \nu=1.62 \mathrm{E}-5\left[\mathrm{~m}^{2} \mathrm{~s}^{-1}\right]
\end{aligned}
$$

\begin{tabular}{|c|c|c|c|}
\hline$[\mathrm{Hz}]$ & $\begin{array}{l}\overline{u_{f}^{2}} \\
{\left[m^{2} s^{-2}\right]}\end{array}$ & $\begin{array}{c}K_{1} \\
{\left[m^{-1}\right]}\end{array}$ & $\begin{array}{l}E_{1}\left(K_{1}\right) \\
{\left[m^{3} s^{-2}\right]}\end{array}$ \\
\hline $\begin{array}{r}2.00 \\
2.66 \\
3.53 \\
4.69 \\
6.22 \\
8.26 \\
10.98 \\
14.58 \\
19.36 \\
25.72 \\
34.16 \\
45.36 \\
60.25 \\
80.02 \\
106.30 \\
141.14 \\
187.50 \\
248.97 \\
330.70 \\
439.17 \\
583.30 \\
774.70 \\
1028.90 \\
1366.50 \\
1814.90 \\
2410.40 \\
3201.40\end{array}$ & $\begin{array}{l}0.99600 E-05 \\
0.26900 E-04 \\
0.33100 E-04 \\
0.39900 E-04 \\
0.66900 E-04 \\
0.69400 E-04 \\
0.93200 E-04 \\
0.10400 E-03 \\
0.12800 E-03 \\
0.11400 E-03 \\
0.16400 E-03 \\
0.19300 E-03 \\
0.15700 E-03 \\
0.27100 E-03 \\
0.36600 E-03 \\
0.49500 E-03 \\
0.49000 E-03 \\
0.24500 E-03 \\
0.15390 E-03 \\
0.91700 E-04 \\
0.46700 E-04 \\
0.18700 E-04 \\
0.56000 E-05 \\
0.25300 E-06 \\
0.31000 E-07 \\
0.25000 E-07 \\
0.25000 E-07\end{array}$ & $\begin{array}{l}0.18784 \mathrm{E}+01 \\
0.24982 \mathrm{E}+01 \\
0.33153 \mathrm{E}+01 \\
0.44048 \mathrm{E}+01 \\
0.58418 \mathrm{E}+01 \\
0.77577 \mathrm{E}+01 \\
0.10312 \mathrm{E}+02 \\
0.13693 \mathrm{E}+02 \\
0.18183 \mathrm{E}+02 \\
0.24156 \mathrm{E}+02 \\
0.32083 \mathrm{E}+02 \\
0.42602 \mathrm{E}+02 \\
0.56586 \mathrm{E}+02 \\
0.75154 \mathrm{E}+02 \\
0.99836 \mathrm{E}+02 \\
0.13256 \mathrm{E}+03 \\
0.17610 \mathrm{E}+03 \\
0.23383 \mathrm{E}+03 \\
0.31059 \mathrm{E}+03 \\
0.41246 \mathrm{E}+03 \\
0.54783 \mathrm{E}+03 \\
0.72759 \mathrm{E}+03 \\
0.96633 \mathrm{E}+03 \\
0.12834 \mathrm{E}+04 \\
0.17045 \mathrm{E}+04 \\
0.22638 \mathrm{E}+04 \\
0.30067 \mathrm{E}+04\end{array}$ & $\begin{array}{l}0.54630 E-05 \\
0.11094 E-04 \\
0.10286 E-04 \\
0.93325 E-05 \\
0.11799 E-04 \\
0.92168 E-05 \\
0.93113 E-05 \\
0.78248 E-05 \\
0.72528 E-05 \\
0.48622 E-05 \\
0.52665 E-05 \\
0.46675 E-05 \\
0.28585 E-05 \\
0.37151 E-05 \\
0.37770 E-05 \\
0.38473 E-05 \\
0.28668 E-05 \\
0.10795 E-05 \\
0.51051 E-06 \\
0.22905 E-06 \\
0.87826 E-07 \\
0.26479 E-07 \\
0.59705 E-08 \\
0.20310 E-09 \\
0.18737 E-10 \\
0.11378 E-10 \\
0.85664 E-11\end{array}$ \\
\hline
\end{tabular}


TABLE E.2.I

$\overline{u^{2}}$-SPECTRA OBTAINED WITH WIRE 2

$$
\begin{aligned}
& y=0 \quad[\mathrm{~mm}] \quad \eta=0.0 \\
& U=6.34\left[\mathrm{~ms}^{-1}\right] \quad \overline{u^{2}}=1.1450 \mathrm{E}-2\left[\mathrm{~m}^{2} \mathrm{~s}^{-2}\right] \\
& T=24 \quad\left[{ }^{\circ} \mathrm{C}\right] \quad P=732.5 \quad[\mathrm{~mm} \mathrm{Hg}] \\
& E_{K}=2400[\mathrm{~Hz}] \quad \nu=1.60 \mathrm{E}-5 \quad\left[\mathrm{~m}^{2} \mathrm{~s}^{-1}\right]
\end{aligned}
$$

\begin{tabular}{|c|c|c|c|}
\hline$[\mathrm{Hz}]$ & $\begin{array}{l}\overline{u_{f}^{2}} \\
{\left[m^{2} s^{-2}\right]}\end{array}$ & $\begin{array}{c}K_{1} \\
{\left[m^{-1}\right]}\end{array}$ & $\begin{array}{c}E_{1}\left(K_{1}\right) \\
{\left[m^{3} s^{-2}\right]}\end{array}$ \\
\hline $\begin{array}{r}2.00 \\
2.66 \\
3.53 \\
4.69 \\
6.22 \\
8.26 \\
10.98 \\
14.58 \\
19.36 \\
25.72 \\
34.16 \\
45.36 \\
60.25 \\
80.02 \\
106.30 \\
141.14 \\
187.50 \\
248.97 \\
330.70 \\
439.17 \\
583.30 \\
774.70 \\
1028.90 \\
1366.50 \\
1814.90 \\
2410.40 \\
3201.40 \\
4251.80 \\
5647.01 \\
7500.00\end{array}$ & $\begin{array}{l}0.73400 E-04 \\
0.30600 E-03 \\
0.42100 E-03 \\
0.68400 E-03 \\
0.90300 E-03 \\
0.11340 E-02 \\
0.14080 E-02 \\
0.14790 E-02 \\
0.19860 E-02 \\
0.23310 E-02 \\
0.22190 E-02 \\
0.30020 E-02 \\
0.31750 E-02 \\
0.36770 E-02 \\
0.39290 E-02 \\
0.44460 E-02 \\
0.57570 E-02 \\
0.21470 E-02 \\
0.14660 E-02 \\
0.10300 E-02 \\
0.55600 E-03 \\
0.25800 E-03 \\
0.10200 E-03 \\
0.30500 E-04 \\
0.57000 E-05 \\
0.81100 E-06 \\
0.19600 E-06 \\
0.13500 E-06 \\
0.12500 E-06 \\
0.11100 E-06\end{array}$ & $\begin{array}{l}0.19821 E+01 \\
0.26362 E+01 \\
0.34984 E+01 \\
0.46480 E+01 \\
0.61643 E+01 \\
0.81860 E+01 \\
0.10882 E+02 \\
0.14449 E+02 \\
0.19187 E+02 \\
0.25490 E+02 \\
0.33854 E+02 \\
0.44954 E+02 \\
0.59710 E+02 \\
0.79303 E+02 \\
0.10535 E+03 \\
0.13988 E+03 \\
0.18582 E+03 \\
0.24674 E+03 \\
0.32774 E+03 \\
0.43523 E+03 \\
0.57807 E+03 \\
0.76776 E+03 \\
0.10197 E+04 \\
0.13543 E+04 \\
0.17986 E+04 \\
0.23888 E+04 \\
0.31727 E+04 \\
0.42137 E+04 \\
0.55964 E+04 \\
0.74328 E+04\end{array}$ & $\begin{array}{l}0.35567 E-04 \\
0.11149 \mathrm{E}-03 \\
0.11558 \mathrm{E}-03 \\
0.14134 \mathrm{E}-03 \\
0.14070 \mathrm{E}-03 \\
0.13305 \mathrm{E}-03 \\
0.12428 \mathrm{E}-03 \\
0.98309 \mathrm{E}-04 \\
0.99416 \mathrm{E}-04 \\
0.87833 \mathrm{E}-04 \\
0.62954 \mathrm{E}-04 \\
0.64139 \mathrm{E}-04 \\
0.51071 \mathrm{E}-04 \\
0.44533 \mathrm{E}-04 \\
0.35821 \mathrm{E}-04 \\
0.30528 \mathrm{E}-04 \\
0.29756 \mathrm{E}-04 \\
0.83574 \mathrm{E}-05 \\
0.42962 \mathrm{E}-05 \\
0.22729 \mathrm{E}-05 \\
0.92378 \mathrm{E}-06 \\
0.32275 \mathrm{E}-06 \\
0.96075 \mathrm{E}-07 \\
0.21631 \mathrm{E}-07 \\
0.30437 \mathrm{E}-08 \\
0.32607 \mathrm{E}-09 \\
0.59334 \mathrm{E}-10 \\
0.30771 \mathrm{E}-10 \\
0.21452 \mathrm{E}-10 \\
0.14343 \mathrm{E}-10\end{array}$ \\
\hline
\end{tabular}


TABLE E.2.2

$\overline{u^{2}}$-SPECTRA OBTAINED WITH WIRE 2

$$
\begin{aligned}
& y=4 \quad[\mathrm{~mm}] \quad \eta=0.307 \\
& U=6.39\left[\mathrm{~ms}^{-1}\right] \quad \overline{u^{2}}=1.2279 \mathrm{E}-2\left[\mathrm{~m}^{2} \mathrm{~s}^{-2}\right] \\
& T=24 \quad\left[{ }^{\circ} \mathrm{C}\right] \quad P=732.5[\mathrm{~mm} \mathrm{Hg}] \\
& E_{k}=2500[\mathrm{~Hz}] \quad \nu=1.60 \mathrm{E}-5 \quad\left[\mathrm{~m}^{2} \mathrm{~s}^{-1}\right]
\end{aligned}
$$

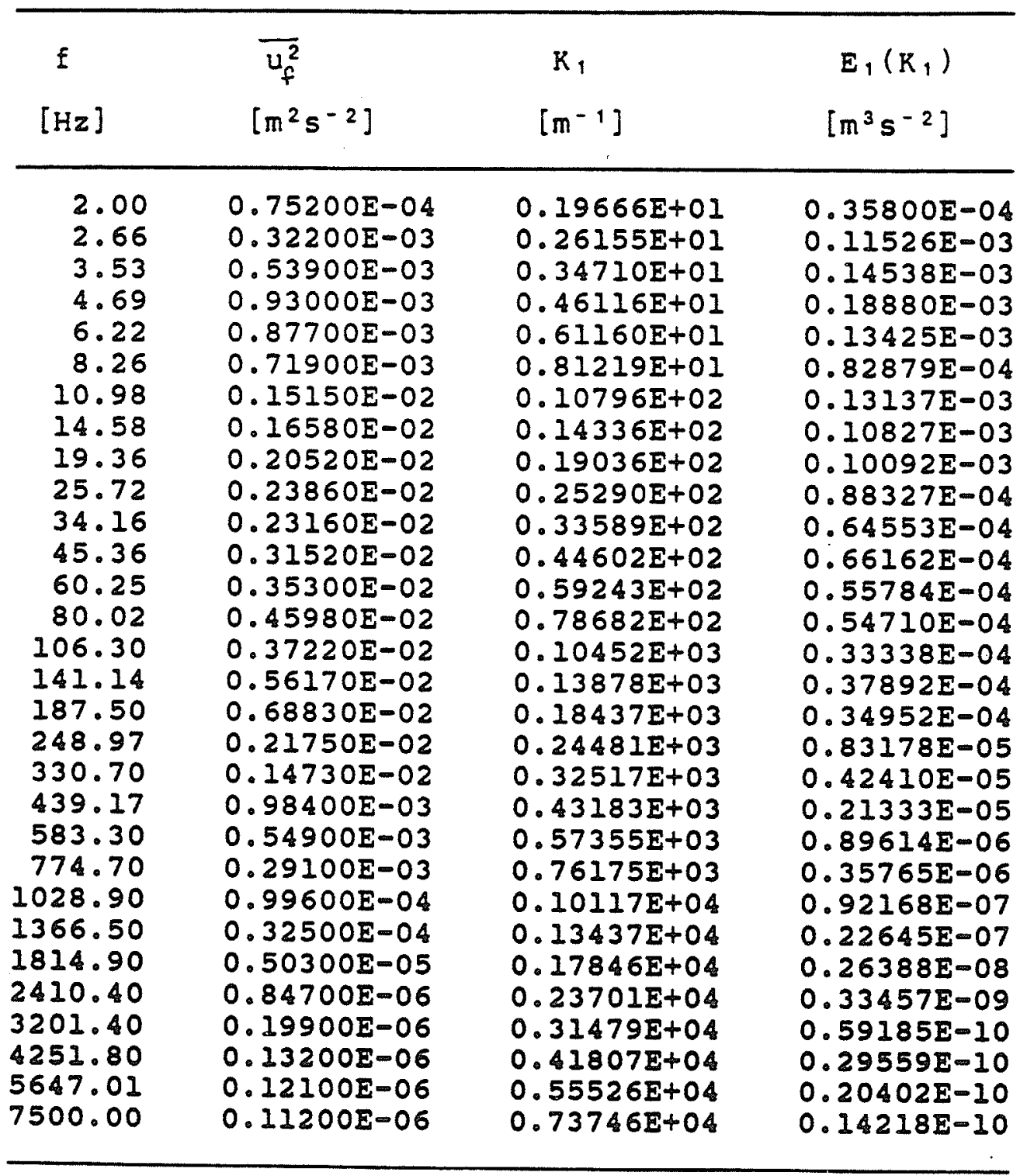


TABLE E.2.3

$\overline{u^{2}}$-SPECTRA OBTAINED WITH WIRE 2

\begin{tabular}{|c|c|c|c|c|c|}
\hline$y$ & $=8$ & {$[\mathrm{~mm}]$} & $\eta$ & $=0.614$ & \\
\hline & $=6.44$ & {$\left[\mathrm{~ms}^{-1}\right]$} & $\overline{u^{2}}$ & $=1.4226 \mathrm{E}-2$ & {$\left[m^{2} s^{-2}\right]$} \\
\hline & $=24$ & {$\left[{ }^{\circ} \mathrm{C}\right]$} & $P$ & $=732.5$ & [mm Hg] \\
\hline & $=2500$ & {$[\mathrm{~Hz}]$} & $\nu$ & $=1.60 \mathrm{E}-5$ & {$\left[m^{2} s^{-1}\right]$} \\
\hline
\end{tabular}

\begin{tabular}{|c|c|c|c|}
\hline $\begin{array}{c}f \\
{[\mathrm{~Hz}]}\end{array}$ & $\begin{array}{l}\overline{u_{f}^{2}} \\
{\left[m^{2} s^{-2}\right]}\end{array}$ & $\begin{array}{l}\mathrm{K}_{1} \\
{\left[\mathrm{~m}^{-1}\right]}\end{array}$ & $\begin{array}{c}E_{1}\left(K_{1}\right) \\
{\left[m^{3} s^{-2}\right]}\end{array}$ \\
\hline $\begin{array}{r}2.00 \\
2.66 \\
3.53 \\
4.69 \\
6.22 \\
8.26 \\
10.98 \\
14.58 \\
19.36 \\
25.72 \\
34.16 \\
45.36 \\
60.25 \\
80.02 \\
106.30 \\
141.14 \\
187.50 \\
248.97 \\
330.70 \\
439.17 \\
583.30 \\
774.70 \\
1028.90 \\
1366.50 \\
1814.90 \\
2410.40 \\
3201.40 \\
4251.80 \\
5647.01 \\
7500.00\end{array}$ & $\begin{array}{l}0.18400 E-03 \\
0.60600 E-03 \\
0.85200 E-03 \\
0.93600 E-03 \\
0.13200 E-02 \\
0.20590 E-02 \\
0.19430 E-02 \\
0.20230 E-02 \\
0.23180 E-02 \\
0.17080 E-02 \\
0.22360 E-02 \\
0.32710 E-02 \\
0.42820 E-02 \\
0.47560 E-02 \\
0.34050 E-02 \\
0.47680 E-02 \\
0.53720 E-02 \\
0.21160 E-02 \\
0.13620 E-02 \\
0.92200 E-03 \\
0.49200 E-03 \\
0.23500 E-03 \\
0.89100 E-04 \\
0.25000 E-04 \\
0.45100 E-05 \\
0.79500 E-06 \\
0.22600 E-06 \\
0.15300 E-06 \\
0.13300 E-06 \\
0.12600 E-06\end{array}$ & $\begin{array}{l}0.19513 \mathrm{E}+01 \\
0.25952 \mathrm{E}+01 \\
0.34440 \mathrm{E}+01 \\
0.45758 \mathrm{E}+01 \\
0.60685 \mathrm{E}+01 \\
0.80589 \mathrm{E}+01 \\
0.10713 \mathrm{E}+02 \\
0.14225 \mathrm{E}+02 \\
0.18889 \mathrm{E}+02 \\
0.25094 \mathrm{E}+02 \\
0.33328 \mathrm{E}+02 \\
0.44255 \mathrm{E}+02 \\
0.58783 \mathrm{E}+02 \\
0.78072 \mathrm{E}+02 \\
0.10371 \mathrm{E}+03 \\
0.13770 \mathrm{E}+03 \\
0.18293 \mathrm{E}+03 \\
0.24291 \mathrm{E}+03 \\
0.32265 \mathrm{E}+03 \\
0.42848 \mathrm{E}+03 \\
0.56910 \mathrm{E}+03 \\
0.75584 \mathrm{E}+03 \\
0.10038 \mathrm{E}+04 \\
0.13332 \mathrm{E}+04 \\
0.17707 \mathrm{E}+04 \\
0.23517 \mathrm{E}+04 \\
0.31234 \mathrm{E}+04 \\
0.41483 \mathrm{E}+04 \\
0.55095 \mathrm{E}+04 \\
0.73174 \mathrm{E}+04\end{array}$ & $\begin{array}{l}0.10033 E-03 \\
0.24845 E-03 \\
0.26321 E-03 \\
0.21764 E-03 \\
0.23144 E-03 \\
0.27185 E-03 \\
0.19298 E-03 \\
0.15132 E-03 \\
0.13057 E-03 \\
0.72421 E-04 \\
0.71384 E-04 \\
0.78642 E-04 \\
0.77506 E-04 \\
0.64817 E-04 \\
0.34932 E-04 \\
0.36841 E-04 \\
0.31245 E-04 \\
0.92686 E-05 \\
0.44915 E-05 \\
0.22895 E-05 \\
0.91985 E-06 \\
0.33081 E-06 \\
0.94439 E-07 \\
0.19952 E-07 \\
0.27100 E-08 \\
0.35969 E-09 \\
0.76986 E-10 \\
0.39243 E-10 \\
0.25685 E-10 \\
0.18321 E-10\end{array}$ \\
\hline
\end{tabular}


TABLE E.2.4

$\overline{u^{2}}$-SPECTRA OBTAINED WITH WIRE 2

$$
\begin{array}{rlrlrl}
\mathrm{Y} & =12 & {[\mathrm{~mm}]} & \eta & =0.921 \\
U & =6.50\left[\mathrm{~ms}^{-1}\right] & \overline{u^{2}} & =1.4249 \mathrm{E}-2 & {\left[\mathrm{~m}^{2} \mathrm{~s}^{-2}\right]} \\
T & =24 & {\left[{ }^{\circ} \mathrm{C}\right]} & P & =732.5 & {[\mathrm{~mm} \mathrm{Hg}]} \\
E_{K} & =2400[\mathrm{~Hz}] & \nu & =1.60 \mathrm{E}-5 & {\left[\mathrm{~m}^{2} \mathrm{~s}^{-1}\right]}
\end{array}
$$

\begin{tabular}{|c|c|c|c|}
\hline $\begin{array}{c}E \\
{[\mathrm{~Hz}]}\end{array}$ & $\begin{array}{l}\overline{u_{f}^{2}} \\
{\left[m^{2} s^{-2}\right]}\end{array}$ & $\begin{array}{c}k_{1} \\
{\left[m^{-1}\right]}\end{array}$ & $\begin{array}{c}E_{1}\left(K_{1}\right) \\
{\left[m^{3} s^{-2}\right]}\end{array}$ \\
\hline $\begin{array}{r}2.00 \\
2.66 \\
3.53 \\
4.69 \\
6.22 \\
8.26 \\
10.98 \\
14.58 \\
19.36 \\
25.72 \\
34.16 \\
45.36 \\
60.25 \\
80.02 \\
106.30 \\
141.14 \\
187.50 \\
248.97 \\
330.70 \\
439.17 \\
583.30 \\
774.70 \\
1028.90 \\
1366.50 \\
1814.90 \\
2410.40 \\
3201.40 \\
4251.80 \\
5647.01 \\
7500.00\end{array}$ & $\begin{array}{l}0.25700 E-03 \\
0.76100 E-03 \\
0.89980 E-03 \\
0.13920 E-02 \\
0.17360 E-02 \\
0.18930 E-02 \\
0.27310 E-02 \\
0.26870 E-02 \\
0.29040 E-02 \\
0.23190 E-02 \\
0.28910 E-02 \\
0.29510 E-02 \\
0.51670 E-02 \\
0.50030 E-02 \\
0.43620 E-02 \\
0.33810 E-02 \\
0.57400 E-02 \\
0.19100 E-02 \\
0.11550 E-02 \\
0.77260 E-03 \\
0.38300 E-03 \\
0.18100 E-03 \\
0.70600 E-04 \\
0.20200 E-04 \\
0.35300 E-05 \\
0.64900 E-06 \\
0.22400 E-06 \\
0.15900 E-06 \\
0.14100 E-06 \\
0.12900 E-06\end{array}$ & $\begin{array}{l}0.19333 \mathrm{E}+01 \\
0.25713 \mathrm{E}+01 \\
0.34123 \mathrm{E}+01 \\
0.45336 \mathrm{E}+01 \\
0.60125 \mathrm{E}+01 \\
0.79845 \mathrm{E}+01 \\
0.10614 \mathrm{E}+02 \\
0.14094 \mathrm{E}+02 \\
0.18714 \mathrm{E}+02 \\
0.24862 \mathrm{E}+02 \\
0.33021 \mathrm{E}+02 \\
0.43847 \mathrm{E}+02 \\
0.58240 \mathrm{E}+02 \\
0.77351 \mathrm{E}+02 \\
0.10275 \mathrm{E}+03 \\
0.13643 \mathrm{E}+03 \\
0.18125 \mathrm{E}+03 \\
0.24067 \mathrm{E}+03 \\
0.31967 \mathrm{E}+03 \\
0.42452 \mathrm{E}+03 \\
0.56384 \mathrm{E}+03 \\
0.74886 \mathrm{E}+03 \\
0.99458 \mathrm{E}+03 \\
0.13209 \mathrm{E}+04 \\
0.17544 \mathrm{E}+04 \\
0.23300 \mathrm{E}+04 \\
0.30946 \mathrm{E}+04 \\
0.41100 \mathrm{E}+04 \\
0.54586 \mathrm{E}+04 \\
0.72498 \mathrm{E}+04\end{array}$ & $\begin{array}{l}0.13401 E-03 \\
0.29836 E-03 \\
0.26583 E-03 \\
0.30953 E-03 \\
0.29107 E-03 \\
0.23900 E-03 \\
0.25939 E-03 \\
0.19219 E-03 \\
0.15643 E-03 \\
0.94029 E-04 \\
0.88259 E-04 \\
0.67846 E-04 \\
0.89436 E-04 \\
0.65202 E-04 \\
0.42794 E-04 \\
0.24982 E-04 \\
0.31926 E-04 \\
0.80005 E-05 \\
0.36423 E-05 \\
0.18346 E-05 \\
0.68476 E-06 \\
0.24366 E-06 \\
0.71559 E-07 \\
0.15416 E-07 \\
0.20284 E-08 \\
0.28079 E-09 \\
0.72969 E-10 \\
0.38999 E-10 \\
0.26039 E-10 \\
0.17937 E-10\end{array}$ \\
\hline
\end{tabular}


TABLE E.2.5

$\overline{u^{2}}$-SPECTRA OBTAINED WITH WIRE 2

$$
\begin{aligned}
& y=16 \quad[\mathrm{~mm}] \quad \eta=1.228 \\
& U=6.56\left[\mathrm{~ms}^{-1}\right] \quad \overline{u^{2}}=1.1376 \mathrm{E}-2\left[\mathrm{~m}^{2} \mathrm{~s}^{-2}\right] \\
& T=24 \quad\left[{ }^{\circ} \mathrm{C}\right] \quad P=732.5 \quad[\mathrm{~mm} \mathrm{Hg}] \\
& \mathrm{f}_{\mathrm{K}}=2200[\mathrm{~Hz}] \quad \nu=1.60 \mathrm{E}-5 \quad\left[\mathrm{~m}^{2} \mathrm{~s}^{-1}\right]
\end{aligned}
$$

\begin{tabular}{|c|c|c|c|}
\hline$[\mathrm{Hz}]$ & $\begin{array}{l}\overline{u_{f}^{2}} \\
{\left[m^{2} s^{-2}\right]}\end{array}$ & $\begin{array}{c}k_{1} \\
{\left[m^{-1}\right]}\end{array}$ & $\begin{array}{c}E_{1}\left(K_{1}\right) \\
{\left[m^{3} s^{-2}\right]}\end{array}$ \\
\hline $\begin{array}{r}2.00 \\
2.66 \\
3.53 \\
4.69 \\
6.22 \\
8.26 \\
10.98 \\
14.58 \\
19.36 \\
25.72 \\
34.16 \\
45.36 \\
60.25 \\
80.02 \\
106.30 \\
141.14 \\
187.50 \\
248.97 \\
330.70 \\
439.17 \\
583.30 \\
774.70 \\
1028.90 \\
1366.50 \\
1814.90 \\
2410.40 \\
3201.40 \\
4251.80 \\
5647.01\end{array}$ & $\begin{array}{l}0.17200 \mathrm{E}-03 \\
0.44100 \mathrm{E}-03 \\
0.77700 \mathrm{E}-03 \\
0.11650 \mathrm{E}-02 \\
0.12070 \mathrm{E}-02 \\
0.14290 \mathrm{E}-02 \\
0.15350 \mathrm{E}-02 \\
0.18420 \mathrm{E}-02 \\
0.93400 \mathrm{E}-03 \\
0.22330 \mathrm{E}-02 \\
0.21750 \mathrm{E}-02 \\
0.31050 \mathrm{E}-02 \\
0.39070 \mathrm{E}-02 \\
0.31430 \mathrm{O}-02 \\
0.39940 \mathrm{E}-02 \\
0.39160 \mathrm{E}-02 \\
0.27760 \mathrm{E}-02 \\
0.14890 \mathrm{E}-02 \\
0.89400 \mathrm{E}-03 \\
0.54100 \mathrm{E}-03 \\
0.28400 \mathrm{E}-03 \\
0.13400 \mathrm{E}-03 \\
0.49300 \mathrm{E}-04 \\
0.14600 \mathrm{E}-04 \\
0.22600 \mathrm{E}-05 \\
0.39100 \mathrm{E}-06 \\
0.18000 \mathrm{E}-06 \\
0.12600 \mathrm{E}-06 \\
0.12300 \mathrm{E}-06\end{array}$ & $\begin{array}{l}0.19156 \mathrm{E}+01 \\
0.25478 \mathrm{E}+01 \\
0.33810 \mathrm{E}+01 \\
0.44921 \mathrm{E}+01 \\
0.59575 \mathrm{E}+01 \\
0.79115 \mathrm{E}+01 \\
0.10517 \mathrm{E}+02 \\
0.13965 \mathrm{E}+02 \\
0.18543 \mathrm{E}+02 \\
0.24635 \mathrm{E}+02 \\
0.32719 \mathrm{E}+02 \\
0.43446 \mathrm{E}+02 \\
0.57708 \mathrm{E}+02 \\
0.76643 \mathrm{E}+02 \\
0.10181 \mathrm{E}+03 \\
0.13518 \mathrm{E}+03 \\
0.17959 \mathrm{E}+03 \\
0.23846 \mathrm{E}+03 \\
0.31675 \mathrm{E}+03 \\
0.42064 \mathrm{E}+03 \\
0.55869 \mathrm{E}+03 \\
0.74201 \mathrm{E}+03 \\
0.98548 \mathrm{E}+03 \\
0.13088 \mathrm{E}+04 \\
0.17383 \mathrm{E}+04 \\
0.23087 \mathrm{E}+04 \\
0.30663 \mathrm{E}+04 \\
0.40724 \mathrm{E}+04 \\
0.54087 \mathrm{E}+04\end{array}$ & $\begin{array}{l}0.93755 E-04 \\
0.18074 E-03 \\
0.23996 E-03 \\
0.27080 E-03 \\
0.21155 E-03 \\
0.18860 E-03 \\
0.15241 E-03 \\
0.13773 E-03 \\
0.52594 E-04 \\
0.94649 E-04 \\
0.69413 E-04 \\
0.74625 E-04 \\
0.70694 E-04 \\
0.42820 E-04 \\
0.40961 E-04 \\
0.30248 E-04 \\
0.16140 E-04 \\
0.65200 E-05 \\
0.29471 E-05 \\
0.13430 E-05 \\
0.53079 E-06 \\
0.18857 E-06 \\
0.52236 E-07 \\
0.11648 E-07 \\
0.13575 E-08 \\
0.17684 E-09 \\
0.61296 E-10 \\
0.32307 E-10 \\
0.23746 E-10\end{array}$ \\
\hline
\end{tabular}


TABLE E.2.6

$\overline{u^{2}}$-SPECTRA OBTAINED WITH WIRE 2

\begin{tabular}{|c|c|c|c|c|c|}
\hline$y$ & $=20$ & {$[\mathrm{~mm}]$} & $\eta$ & $=1.535$ & \\
\hline U & $=6.63$ & {$\left[\mathrm{~ms}^{-1}\right]$} & $\overline{u^{2}}$ & $=6.6363 \mathrm{E}-3$ & {$\left[m^{2} s^{-2}\right]$} \\
\hline & $=24$ & {$\left[{ }^{\circ} \mathrm{C}\right]$} & $\mathrm{P}$ & $=732.5$ & [mm Hg] \\
\hline & $=2000$ & {$[\mathrm{~Hz}]$} & $\nu$ & $=1.60 E-5$ & {$\left[m^{2} s^{-1}\right]$} \\
\hline
\end{tabular}

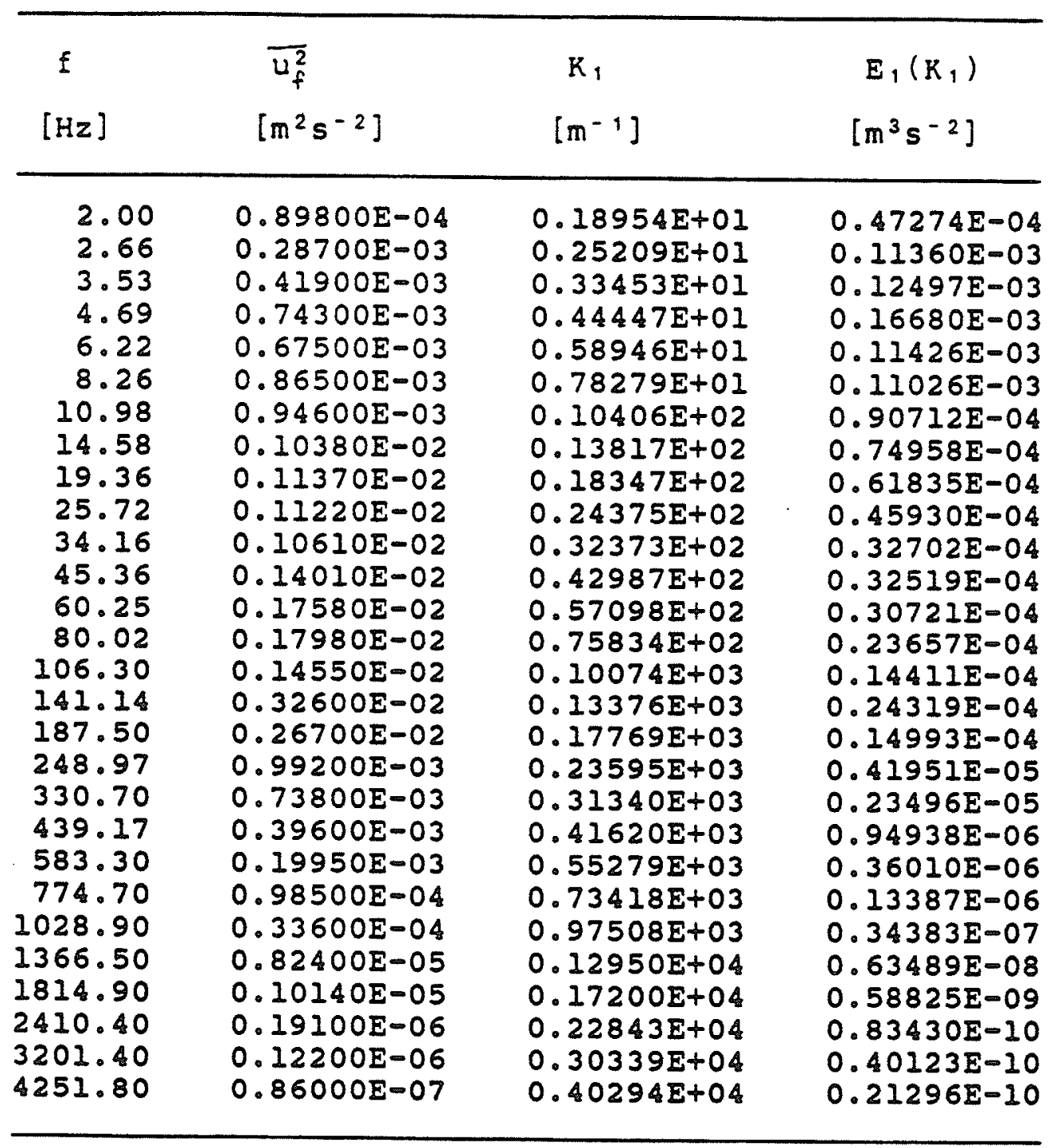


TABLE E.2.7

$\overline{U^{2}}$-SPECTRA OBTAINED WITH WIRE 2

\begin{tabular}{|c|c|c|c|c|c|}
\hline$y$ & $=24$ & {$[\mathrm{~mm}]$} & $\eta$ & $=1.842$ & \\
\hline U & $=6.66$ & {$\left[\mathrm{~ms}^{-1}\right]$} & $\overline{u^{2}}$ & $=2.9309 \mathrm{E}-3$ & {$\left[m^{2} s^{-2}\right]$} \\
\hline$T$ & $=24$ & {$\left[{ }^{\circ} \mathrm{C}\right]$} & $\mathrm{p}$ & $=732.5$ & [mm Hg] \\
\hline$f$ & $=1700$ & {$[\mathrm{~Hz}]$} & $\nu$ & $=1.60 \mathrm{E}-5$ & {$\left[m^{2} s^{-1}\right]$} \\
\hline
\end{tabular}

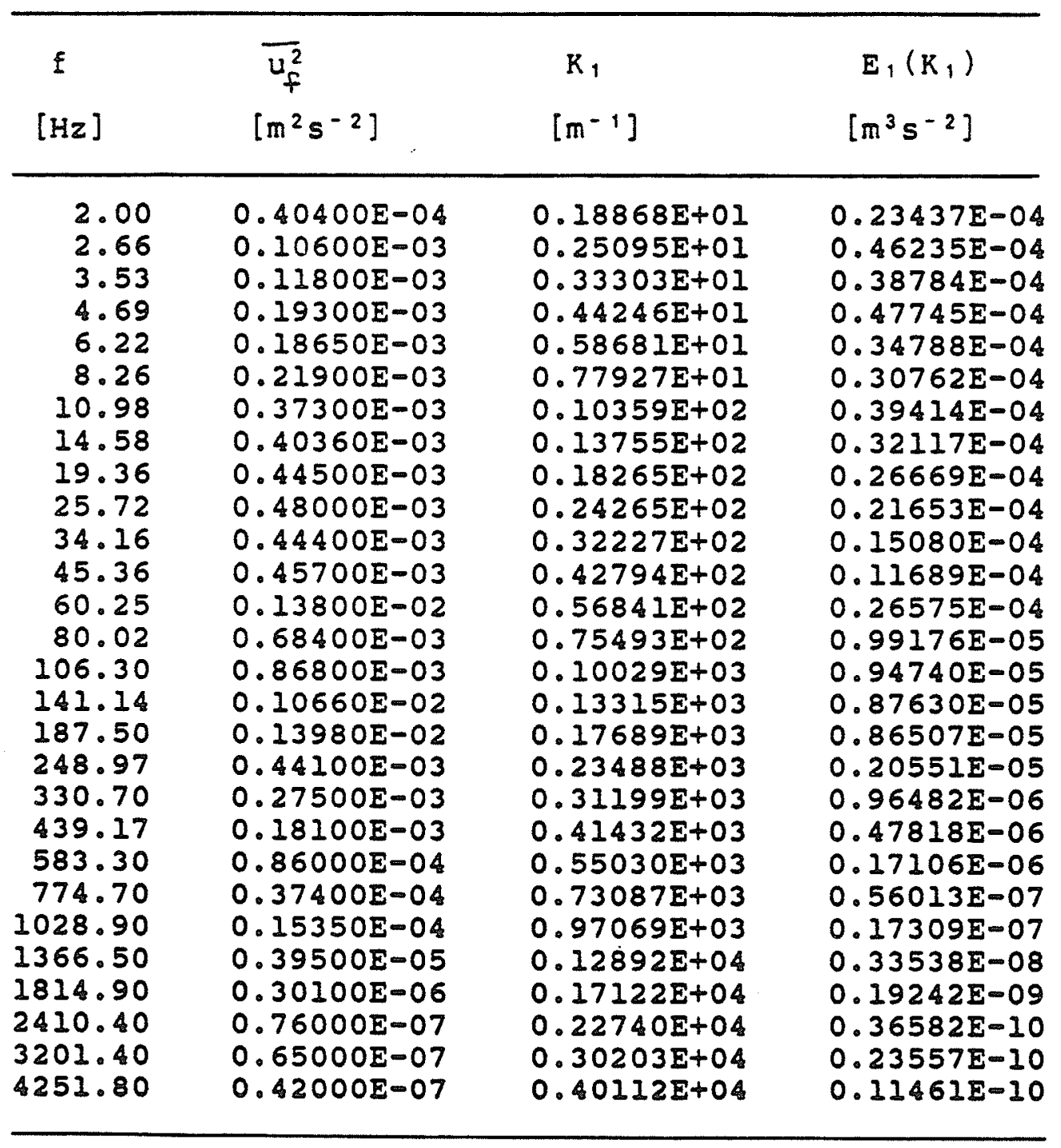


TABLE E.2.8

$\overline{u^{2}}$-SPECTRA OBTAINED WITH WIRE 2

$$
\begin{aligned}
& y=28[\mathrm{~mm}] \quad \eta=2.149 \\
& U=6.69\left[\mathrm{~ms}^{-1}\right] \quad \overline{u^{2}}=9.7744 \mathrm{E}-4\left[\mathrm{~m}^{2} \mathrm{~s}^{-2}\right] \\
& T=24 \quad\left[{ }^{\circ} \mathrm{C}\right] \quad \mathrm{P}=732.5 \quad[\mathrm{~mm} \mathrm{Hg}] \\
& E_{K}=1100[\mathrm{~Hz}] \quad \nu=1.60 \mathrm{E}-5 \quad\left[\mathrm{~m}^{2} \mathrm{~s}^{-1}\right]
\end{aligned}
$$

\begin{tabular}{|c|c|c|c|}
\hline$[\mathrm{Hz}]$ & $\begin{array}{l}\overline{u_{f}^{2}} \\
{\left[m^{2} s^{-2}\right]}\end{array}$ & {$\left[m^{-1}\right]$} & $\begin{array}{c}E_{1}\left(K_{1}\right) \\
{\left[m^{3} s^{-2}\right]}\end{array}$ \\
\hline $\begin{array}{r}2.00 \\
2.66 \\
3.53 \\
4.69 \\
6.22 \\
8.26 \\
10.98 \\
14.58 \\
19.36 \\
25.72 \\
34.16 \\
45.36 \\
60.25 \\
80.02 \\
106.30 \\
141.14 \\
187.50 \\
248.97 \\
330.70 \\
439.17 \\
583.30 \\
774.70 \\
1028.90 \\
1366.50 \\
1814.90 \\
2410.40 \\
3201.40\end{array}$ & $\begin{array}{l}0.84600 E-05 \\
0.26300 E-04 \\
0.37500 E-04 \\
0.63100 E-04 \\
0.59400 E-04 \\
0.59600 E-04 \\
0.83300 E-04 \\
0.11220 E-03 \\
0.11700 E-03 \\
0.94400 E-04 \\
0.16310 E-03 \\
0.23700 E-03 \\
0.28000 E-03 \\
0.34600 E-03 \\
0.44140 E-03 \\
0.55800 E-03 \\
0.46420 E-03 \\
0.24900 E-03 \\
0.14690 E-03 \\
0.64400 E-04 \\
0.28500 E-04 \\
0.13700 E-04 \\
0.40600 E-05 \\
0.29100 E-06 \\
0.26000 E-07 \\
0.26000 E-07 \\
0.34000 E-07\end{array}$ & $\begin{array}{l}0.18784 E+01 \\
0.24982 E+01 \\
0.33153 E+01 \\
0.44048 E+01 \\
0.58418 E+01 \\
0.77577 E+01 \\
0.10312 E+02 \\
0.13693 E+02 \\
0.18183 E+02 \\
0.24156 E+02 \\
0.32083 E+02 \\
0.42602 E+02 \\
0.56586 E+02 \\
0.75154 E+02 \\
0.99836 E+02 \\
0.13256 E+03 \\
0.17610 E+03 \\
0.23383 E+03 \\
0.31059 E+03 \\
0.41246 E+03 \\
0.54783 E+03 \\
0.72759 E+03 \\
0.96633 E+03 \\
0.12834 E+04 \\
0.17045 E+04 \\
0.22638 E+04 \\
0.30067 E+04\end{array}$ & $\begin{array}{l}0.42481 E-05 \\
0.99296 E-05 \\
0.10669 E-04 \\
0.13512 E-04 \\
0.95907 E-05 \\
0.72464 E-05 \\
0.76190 E-05 \\
0.77284 E-05 \\
0.60693 E-05 \\
0.36860 E-05 \\
0.47950 E-05 \\
0.52472 E-05 \\
0.46672 E-05 \\
0.43424 E-05 \\
0.41702 E-05 \\
0.39705 E-05 \\
0.24863 E-05 \\
0.10044 E-05 \\
0.44611 E-06 \\
0.14727 E-06 \\
0.49069 E-07 \\
0.17760 E-07 \\
0.39629 E-08 \\
0.21386 E-09 \\
0.14387 E-10 \\
0.10833 E-10 \\
0.10666 E-10\end{array}$ \\
\hline
\end{tabular}


TABLE E.3.I

$\overline{u^{2}}$-SPECTRA OBTAINED WITH WIRE 3

$$
\begin{aligned}
& y=0 \quad[\mathrm{~mm}] \quad \eta=0.0 \\
& U=6.34\left[\mathrm{~ms}^{-1}\right] \quad \overline{u^{2}}=1.0769 \mathrm{E}-2\left[\mathrm{~m}^{2} \mathrm{~s}^{-2}\right] \\
& T=26 \quad\left[{ }^{\circ} \mathrm{C}\right] \quad P=729.0 \quad[\mathrm{~mm} \mathrm{Hg}] \\
& E_{K}=2400[\mathrm{~Hz}] \quad \nu=1.63 E-5 \quad\left[\mathrm{~m}^{2} \mathrm{~s}^{-1}\right]
\end{aligned}
$$

\begin{tabular}{|c|c|c|c|}
\hline $\begin{array}{c}E \\
{[\mathrm{~Hz}]}\end{array}$ & $\begin{array}{l}\overline{u_{f}^{2}} \\
{\left[m^{2} s^{-2}\right]}\end{array}$ & $\begin{array}{c}K_{1} \\
{\left[m^{-1}\right]}\end{array}$ & $\begin{array}{c}E_{1}\left(K_{1}\right) \\
{\left[m^{3} s^{-2}\right]}\end{array}$ \\
\hline $\begin{array}{r}2.00 \\
2.66 \\
3.53 \\
4.69 \\
6.22 \\
8.26 \\
10.98 \\
14.58 \\
19.36 \\
25.72 \\
34.16 \\
45.36 \\
60.24 \\
80.02 \\
106.30 \\
141.10 \\
187.50 \\
248.97 \\
330.70 \\
439.17 \\
583.30 \\
774.70 \\
1028.90 \\
1366.50 \\
1814.90 \\
2410.40 \\
3201.40 \\
4251.80 \\
5647.01 \\
7500.00\end{array}$ & $\begin{array}{l}0.74300 E-04 \\
0.26900 E-03 \\
0.35600 E-03 \\
0.72700 E-03 \\
0.92100 E-03 \\
0.80000 E-03 \\
0.10370 E-02 \\
0.12550 E-02 \\
0.15480 E-02 \\
0.16350 E-02 \\
0.17010 E-02 \\
0.23240 E-02 \\
0.25120 E-02 \\
0.38635 E-02 \\
0.57990 E-02 \\
0.30820 E-02 \\
0.43550 E-02 \\
0.20571 E-02 \\
0.13585 E-02 \\
0.90040 E-03 \\
0.48900 E-03 \\
0.23000 E-03 \\
0.84800 E-04 \\
0.25400 E-04 \\
0.50400 E-05 \\
0.53800 E-06 \\
0.17700 E-06 \\
0.12300 E-06 \\
0.11300 E-06 \\
0.11700 E-06\end{array}$ & $\begin{array}{l}0.19821 E+01 \\
0.26362 E+01 \\
0.34984 E+01 \\
0.46480 E+01 \\
0.61643 E+01 \\
0.81860 E+01 \\
0.10882 E+02 \\
0.14449 E+02 \\
0.19187 E+02 \\
0.25490 E+02 \\
0.33854 E+02 \\
0.44954 E+02 \\
0.59700 E+02 \\
0.79303 E+02 \\
0.10535 E+03 \\
0.13984 E+03 \\
0.18582 E+03 \\
0.24674 E+03 \\
0.32774 E+03 \\
0.43523 E+03 \\
0.57807 E+03 \\
0.76776 E+03 \\
0.10197 E+04 \\
0.13543 E+04 \\
0.17986 E+04 \\
0.23888 E+04 \\
0.31727 E+04 \\
0.42137 E+04 \\
0.55964 E+04 \\
0.74328 E+04\end{array}$ & $\begin{array}{l}0.39124 E-04 \\
0.10650 E-03 \\
0.10621 E-03 \\
0.16325 E-03 \\
0.15594 E-03 \\
0.10200 E-03 \\
0.99462 E-04 \\
0.90650 E-04 \\
0.84207 E-04 \\
0.66946 E-04 \\
0.52441 E-04 \\
0.53956 E-04 \\
0.43915 E-04 \\
0.50847 E-04 \\
0.57451 E-04 \\
0.23003 E-04 \\
0.24461 E-04 \\
0.87014 E-05 \\
0.43262 E-05 \\
0.21592 E-05 \\
0.88287 E-06 \\
0.31266 E-06 \\
0.86797 E-07 \\
0.19575 E-07 \\
0.29245 E-08 \\
0.23506 E-09 \\
0.58226 E-10 \\
0.30466 E-10 \\
0.21074 E-10 \\
0.16429 E-10\end{array}$ \\
\hline
\end{tabular}


TABLE E.3.2

$\overline{u^{2}}$-SPECTRA OBTAINED WITH WIRE 3

$$
\begin{aligned}
& y=4[\mathrm{~mm}] \quad \eta=0.307 \\
& U=6.39\left[\mathrm{~ms}^{-1}\right] \quad \overline{u^{2}}=1.1159 \mathrm{E}-2\left[\mathrm{~m}^{2} \mathrm{~s}^{-2}\right] \\
& T=26 \quad\left[{ }^{\circ} \mathrm{C}\right] \quad P=729.0 \quad[\mathrm{~mm} \mathrm{Hg}] \\
& E_{K}=2500[\mathrm{~Hz}] \quad \nu=1.63 \mathrm{E}-5 \quad\left[\mathrm{~m}^{2} \mathrm{~s}^{-1}\right]
\end{aligned}
$$

\begin{tabular}{|c|c|c|c|}
\hline$[\mathrm{Hz}]$ & $\begin{array}{l}\overline{u_{f}^{2}} \\
{\left[m^{2} s^{-2}\right]}\end{array}$ & $\begin{array}{l}K_{1} \\
{\left[m^{-1}\right]}\end{array}$ & $\begin{array}{c}E_{1}\left(K_{1}\right) \\
{\left[m^{3} s^{-2}\right]}\end{array}$ \\
\hline $\begin{array}{r}2.00 \\
2.66 \\
3.53 \\
4.69 \\
6.22 \\
8.26 \\
10.98 \\
14.58 \\
19.36 \\
25.72 \\
34.16 \\
45.36 \\
60.24 \\
80.02 \\
106.30 \\
141.10 \\
187.50 \\
248.97 \\
330.70 \\
439.17 \\
583.30 \\
774.70 \\
1028.90 \\
1366.50 \\
1814.90 \\
2410.40 \\
3201.40 \\
4251.80 \\
5647.01 \\
7500.00\end{array}$ & $\begin{array}{l}0.89200 E-04 \\
0.43400 E-03 \\
0.36000 E-03 \\
0.53600 E-03 \\
0.74100 E-03 \\
0.10283 E-02 \\
0.13233 E-02 \\
0.13555 E-02 \\
0.20630 E-02 \\
0.18930 E-02 \\
0.25990 E-02 \\
0.29150 E-02 \\
0.25500 E-02 \\
0.32620 E-02 \\
0.31820 E-02 \\
0.36885 E-02 \\
0.43420 E-02 \\
0.20660 E-02 \\
0.13670 E-02 \\
0.90530 E-03 \\
0.50250 E-03 \\
0.22330 E-03 \\
0.87800 E-04 \\
0.25300 E-04 \\
0.51460 E-05 \\
0.63400 E-06 \\
0.18000 E-06 \\
0.12200 E-06 \\
0.11400 E-06 \\
0.10700 E-06\end{array}$ & $\begin{array}{l}0.19666 \mathrm{E}+01 \\
0.26155 \mathrm{E}+01 \\
0.34710 \mathrm{E}+01 \\
0.46116 \mathrm{E}+01 \\
0.61160 \mathrm{E}+01 \\
0.81219 \mathrm{E}+01 \\
0.10796 \mathrm{E}+02 \\
0.14336 \mathrm{E}+02 \\
0.19036 \mathrm{E}+02 \\
0.25290 \mathrm{E}+02 \\
0.33589 \mathrm{E}+02 \\
0.44602 \mathrm{E}+02 \\
0.59233 \mathrm{E}+02 \\
0.78682 \mathrm{E}+02 \\
0.10452 \mathrm{E}+03 \\
0.13874 \mathrm{E}+03 \\
0.18437 \mathrm{E}+03 \\
0.24481 \mathrm{E}+03 \\
0.32517 \mathrm{E}+03 \\
0.43183 \mathrm{E}+03 \\
0.57355 \mathrm{E}+03 \\
0.76175 \mathrm{E}+03 \\
0.10117 \mathrm{E}+04 \\
0.13437 \mathrm{E}+04 \\
0.17846 \mathrm{E}+04 \\
0.23701 \mathrm{E}+04 \\
0.31479 \mathrm{E}+04 \\
0.41807 \mathrm{E}+04 \\
0.55526 \mathrm{E}+04 \\
0.73746 \mathrm{E}+04\end{array}$ & $\begin{array}{l}0.47925 E-04 \\
0.17532 E-03 \\
0.10959 E-03 \\
0.12281 E-03 \\
0.12801 E-03 \\
0.13377 E-03 \\
0.12950 E-03 \\
0.99901 E-04 \\
0.11450 E-03 \\
0.79088 E-04 \\
0.81756 E-04 \\
0.69055 E-04 \\
0.45487 E-04 \\
0.43804 E-04 \\
0.32166 E-04 \\
0.28090 E-04 \\
0.24884 E-04 \\
0.89169 E-05 \\
0.44418 E-05 \\
0.22151 E-05 \\
0.92571 E-06 \\
0.30973 E-06 \\
0.91696 E-07 \\
0.19895 E-07 \\
0.30468 E-08 \\
0.28264 E-09 \\
0.60417 E-10 \\
0.30833 E-10 \\
0.21693 E-10 \\
0.15330 E-10\end{array}$ \\
\hline
\end{tabular}


TABLE E.3.3

$\overline{u^{2}}$-SPECTRA OBTAINED WITH WIRE 3

\begin{tabular}{|c|c|c|c|c|c|}
\hline$y$ & $=8$ & {$[\mathrm{~mm}]$} & $\eta$ & $=0.614$ & \\
\hline $\mathrm{U}$ & $=6.44$ & {$\left[\mathrm{~ms}^{-1}\right]$} & $\overline{u^{2}}$ & $=1.2766 \mathrm{E}-2$ & {$\left[\mathrm{~m}^{2} \mathrm{~s}^{-2}\right]$} \\
\hline $\mathrm{T}$ & $=26$ & {$\left[{ }^{\circ} \mathrm{C}\right]$} & $P$ & $=729.0$ & [mm Hg] \\
\hline & $=2500$ & {$[\mathrm{~Hz}]$} & $\nu$ & $=1.63 \mathrm{E}-5$ & {$\left[m^{2} s^{-1}\right]$} \\
\hline
\end{tabular}

\begin{tabular}{|c|c|c|c|}
\hline$[\mathrm{Hz}]$ & $\begin{array}{c}\overline{u_{f}^{2}} \\
{\left[m^{2} s^{-2}\right]}\end{array}$ & {$\left[m^{-1}\right]$} & $\begin{array}{c}E_{1}\left(K_{1}\right) \\
{\left[m^{3} s^{-2}\right]}\end{array}$ \\
\hline $\begin{array}{r}2.00 \\
2.66 \\
3.53 \\
4.69 \\
6.22 \\
8.26 \\
10.98 \\
14.58 \\
19.36 \\
25.72 \\
34.16 \\
45.36 \\
60.24 \\
80.02 \\
106.30 \\
141.10 \\
187.50 \\
248.97 \\
330.70 \\
439.17 \\
583.30 \\
774.70 \\
1028.90 \\
1366.50 \\
1814.90 \\
2410.40 \\
3201.40 \\
4251.80 \\
5647.01 \\
7500.00\end{array}$ & $\begin{array}{l}0.17650 E-03 \\
0.58900 E-03 \\
0.74300 E-03 \\
0.88200 E-03 \\
0.14950 E-02 \\
0.14470 E-02 \\
0.17860 E-02 \\
0.17290 E-02 \\
0.18030 E-02 \\
0.20230 E-02 \\
0.20610 E-02 \\
0.23060 E-02 \\
0.34980 E-02 \\
0.29770 E-02 \\
0.34970 E-02 \\
0.34320 E-02 \\
0.40630 E-02 \\
0.19950 E-02 \\
0.12870 E-02 \\
0.84000 E-03 \\
0.43500 E-03 \\
0.19500 E-03 \\
0.76300 E-04 \\
0.22200 E-04 \\
0.47860 E-05 \\
0.59100 E-06 \\
0.19500 E-06 \\
0.13400 E-06 \\
0.12200 E-06 \\
0.11300 E-06\end{array}$ & $\begin{array}{l}0.19513 E+01 \\
0.25952 E+01 \\
0.34440 E+01 \\
0.45758 E+01 \\
0.60685 E+01 \\
0.80589 E+01 \\
0.10713 E+02 \\
0.14225 E+02 \\
0.18889 E+02 \\
0.25094 E+02 \\
0.33328 E+02 \\
0.44255 E+02 \\
0.58773 E+02 \\
0.78072 E+02 \\
0.10371 E+03 \\
0.13766 E+03 \\
0.18293 E+03 \\
0.24291 E+03 \\
0.32265 E+03 \\
0.42848 E+03 \\
0.56910 E+03 \\
0.75584 E+03 \\
0.10038 E+04 \\
0.13332 E+04 \\
0.17707 E+04 \\
0.23517 E+04 \\
0.31234 E+04 \\
0.41483 E+04 \\
0.55095 E+04 \\
0.73174 E+04\end{array}$ & $\begin{array}{l}0.10575 E-03 \\
0.26535 E-03 \\
0.25223 E-03 \\
0.22536 E-03 \\
0.28803 E-03 \\
0.20993 E-03 \\
0.19492 E-03 \\
0.14211 E-03 \\
0.11160 E-03 \\
0.94256 E-04 \\
0.72301 E-04 \\
0.60922 E-04 \\
0.69586 E-04 \\
0.44583 E-04 \\
0.39423 E-04 \\
0.29148 E-04 \\
0.25968 E-04 \\
0.96024 E-05 \\
0.46637 E-05 \\
0.22921 E-05 \\
0.89368 E-06 \\
0.30164 E-06 \\
0.88866 E-07 \\
0.19468 E-07 \\
0.31601 E-08 \\
0.29382 E-09 \\
0.72993 E-10 \\
0.37767 E-10 \\
0.25890 E-10 \\
0.18055 E-10\end{array}$ \\
\hline
\end{tabular}


TABIE E.3.4

$\overline{u^{2}}$-SPECTRA OBTAINED WITH WIRE 3

$$
\begin{array}{llll}
Y & =12 & {[\mathrm{~mm}]} & \eta=0.921 \\
U=6.50 & {\left[\mathrm{~ms}^{-1}\right]} & \overline{u^{2}}=1.3241 \mathrm{E}-2\left[\mathrm{~m}^{2} \mathrm{~s}^{-2}\right] \\
T=26 & {\left[{ }^{\circ} \mathrm{C}\right]} & P=729.0 & {[\mathrm{~mm} \mathrm{Hg}]} \\
E_{K}=2400 & {[\mathrm{~Hz}]} & \nu=1.63 E-5 & {\left[\mathrm{~m}^{2} \mathrm{~s}^{-1}\right]}
\end{array}
$$

\begin{tabular}{|c|c|c|c|}
\hline$[\mathrm{Hz}]$ & $\begin{array}{l}\overline{u_{f}^{2}} \\
{\left[m^{2} s^{-2}\right]}\end{array}$ & $\begin{array}{c}K_{1} \\
{\left[m^{-1}\right]}\end{array}$ & $\begin{array}{c}E_{1}\left(K_{1}\right) \\
{\left[m^{3} s^{-2}\right]}\end{array}$ \\
\hline $\begin{array}{r}2.00 \\
2.66 \\
3.53 \\
4.69 \\
6.22 \\
8.26 \\
10.98 \\
14.58 \\
19.36 \\
25.72 \\
34.16 \\
45.36 \\
60.24 \\
80.02 \\
106.30 \\
141.10 \\
187.50 \\
248.97 \\
330.70 \\
439.17 \\
583.30 \\
774.70 \\
1028.90 \\
1366.50 \\
1814.90 \\
2410.40 \\
3201.40 \\
4251.80 \\
5647.01 \\
7500.00\end{array}$ & $\begin{array}{l}0.22300 E-03 \\
0.55300 E-03 \\
0.95600 E-03 \\
0.11390 E-02 \\
0.15930 E-02 \\
0.20110 E-02 \\
0.19150 E-02 \\
0.20250 E-02 \\
0.21120 E-02 \\
0.19050 E-02 \\
0.21940 E-02 \\
0.23920 E-02 \\
0.52020 E-02 \\
0.40090 E-02 \\
0.44720 E-02 \\
0.36300 E-02 \\
0.43010 E-02 \\
0.17380 E-02 \\
0.10940 E-02 \\
0.69200 E-03 \\
0.34700 E-03 \\
0.16200 E-03 \\
0.61000 E-04 \\
0.17700 E-04 \\
0.35700 E-05 \\
0.49300 E-06 \\
0.19700 E-06 \\
0.14400 E-06 \\
0.13400 E-06 \\
0.12500 E-06\end{array}$ & $\begin{array}{l}0.19333 E+01 \\
0.25713 E+01 \\
0.34123 E+01 \\
0.45336 E+01 \\
0.60125 E+01 \\
0.79845 E+01 \\
0.10614 E+02 \\
0.14094 E+02 \\
0.18714 E+02 \\
0.24862 E+02 \\
0.33021 E+02 \\
0.43847 E+02 \\
0.58231 E+02 \\
0.77351 E+02 \\
0.10275 E+03 \\
0.13639 E+03 \\
0.18125 E+03 \\
0.24067 E+03 \\
0.31967 E+03 \\
0.42452 E+03 \\
0.56384 E+03 \\
0.74886 E+03 \\
0.99458 E+03 \\
0.13209 E+04 \\
0.17544 E+04 \\
0.23300 E+04 \\
0.30946 E+04 \\
0.41100 E+04 \\
0.54586 E+04 \\
0.72498 E+04\end{array}$ & $\begin{array}{l}0.12436 E-03 \\
0.23188 E-03 \\
0.30207 E-03 \\
0.27087 E-03 \\
0.28566 E-03 \\
0.27155 E-03 \\
0.19453 E-03 \\
0.15491 E-03 \\
0.12168 E-03 \\
0.82612 E-04 \\
0.71637 E-04 \\
0.58817 E-04 \\
0.96317 E-04 \\
0.55880 E-04 \\
0.46923 E-04 \\
0.28694 E-04 \\
0.25585 E-04 \\
0.77861 E-05 \\
0.36898 E-05 \\
0.17575 E-05 \\
0.66352 E-06 \\
0.23324 E-06 \\
0.66126 E-07 \\
0.14447 E-07 \\
0.21940 E-08 \\
0.22813 E-09 \\
0.68635 E-10 \\
0.37775 E-10 \\
0.26467 E-10 \\
0.18589 E-10\end{array}$ \\
\hline
\end{tabular}


TABLE E.3.5

$\begin{array}{llll} & \overline{u^{2}} \text { SPECTRA } & \text { OBTAINED WITH WIRE } 3 \\ y= & 16 \quad[\mathrm{~mm}] & \eta=1.228 & \\ U=6.56 & {\left[\mathrm{~ms}^{-1}\right]} & \overline{u^{2}}=1.1120 \mathrm{E}-2\left[\mathrm{~m}^{2} \mathrm{~s}^{-2}\right] \\ T=26 & {\left[{ }^{\circ} \mathrm{C}\right]} & P=729.0 & {[\mathrm{~mm} \mathrm{Hg}]} \\ E_{K}=2200 & {[\mathrm{~Hz}]} & \nu=1.63 E-5 & {\left[\mathrm{~m}^{2} \mathrm{~s}^{-1}\right]}\end{array}$

\begin{tabular}{|c|c|c|c|}
\hline$[\mathrm{Hz}]$ & $\begin{array}{l}\overline{u^{2}} \\
f \\
{\left[m^{2} s^{-2}\right]}\end{array}$ & $\begin{array}{c}K_{1} \\
{\left[m^{-1}\right]}\end{array}$ & $\begin{array}{c}E_{1}\left(K_{1}\right) \\
{\left[m^{3} s^{-2}\right]}\end{array}$ \\
\hline $\begin{array}{r}2.00 \\
2.66 \\
3.53 \\
4.69 \\
6.22 \\
8.26 \\
10.98 \\
14.58 \\
19.36 \\
25.72 \\
34.16 \\
45.36 \\
60.24 \\
80.02 \\
106.30 \\
141.10 \\
187.50 \\
248.97 \\
330.70 \\
439.17 \\
583.30 \\
774.70 \\
1028.90 \\
1366.50 \\
1814.90 \\
2410.40 \\
3201.40 \\
4251.80 \\
5647.01\end{array}$ & $\begin{array}{l}0.22600 E-03 \\
0.71450 E-03 \\
0.71640 E-03 \\
0.97990 E-03 \\
0.11130 E-02 \\
0.14500 E-02 \\
0.16090 E-02 \\
0.29547 E-02 \\
0.19140 E-02 \\
0.19880 E-02 \\
0.24160 E-02 \\
0.24455 E-02 \\
0.44180 E-02 \\
0.30637 E-02 \\
0.48180 E-02 \\
0.40050 E-02 \\
0.32600 E-02 \\
0.14210 E-02 \\
0.85840 E-03 \\
0.52150 E-03 \\
0.27660 E-03 \\
0.12300 E-03 \\
0.47800 E-04 \\
0.13200 E-04 \\
0.24700 E-05 \\
0.32200 E-06 \\
0.15900 E-06 \\
0.12600 E-06 \\
0.11600 E-06\end{array}$ & $\begin{array}{l}0.19156 \mathrm{E}+01 \\
0.25478 \mathrm{E}+01 \\
0.33810 \mathrm{E}+01 \\
0.44921 \mathrm{E}+01 \\
0.59575 \mathrm{E}+01 \\
0.79115 \mathrm{E}+01 \\
0.10517 \mathrm{E}+02 \\
0.13965 \mathrm{E}+02 \\
0.18543 \mathrm{E}+02 \\
0.24635 \mathrm{E}+02 \\
0.32719 \mathrm{E}+02 \\
0.43446 \mathrm{E}+02 \\
0.57698 \mathrm{E}+02 \\
0.76643 \mathrm{E}+02 \\
0.10181 \mathrm{E}+03 \\
0.13515 \mathrm{E}+03 \\
0.17959 \mathrm{E}+03 \\
0.23846 \mathrm{E}+03 \\
0.31675 \mathrm{E}+03 \\
0.42064 \mathrm{E}+03 \\
0.55869 \mathrm{E}+03 \\
0.74201 \mathrm{E}+03 \\
0.98548 \mathrm{E}+03 \\
0.13088 \mathrm{E}+04 \\
0.17383 \mathrm{E}+04 \\
0.23087 \mathrm{E}+04 \\
0.30663 \mathrm{E}+04 \\
0.40724 \mathrm{E}+04 \\
0.54087 \mathrm{E}+04\end{array}$ & $\begin{array}{l}0.11382 E-03 \\
0.27056 E-03 \\
0.20442 E-03 \\
0.21045 E-03 \\
0.18024 E-03 \\
0.17682 E-03 \\
0.14760 E-03 \\
0.20413 E-03 \\
0.99582 E-04 \\
0.77856 E-04 \\
0.71240 E-04 \\
0.54305 E-04 \\
0.73873 E-04 \\
0.38565 E-04 \\
0.45654 E-04 \\
0.28590 E-04 \\
0.17513 E-04 \\
0.57490 E-05 \\
0.26146 E-05 \\
0.11961 E-05 \\
0.47765 E-06 \\
0.15993 E-06 \\
0.46795 E-07 \\
0.97299 E-08 \\
0.13709 E-08 \\
0.13456 E-09 \\
0.50027 E-10 \\
0.29850 E-10 \\
0.20691 E-10\end{array}$ \\
\hline
\end{tabular}


TABLE E.3.6

$\overline{u^{2}}$-SPECTRA OBTAINED WITH WIRE 3

$\begin{array}{llll}y=20 & {[\mathrm{~mm}]} & \eta=1.535 \\ U=6.63\left[\mathrm{~ms}^{-1}\right] & \overline{u^{2}}=6.9959 \mathrm{E}-3\left[\mathrm{~m}^{2} \mathrm{~s}^{-2}\right] \\ T=26 & {\left[{ }^{\circ} \mathrm{C}\right]} & P=729.0 & {[\mathrm{~mm} \mathrm{Hg}]} \\ E_{K}=2000[\mathrm{~Hz}] & \nu=1.63 \mathrm{E}-5 & {\left[\mathrm{~m}^{2} \mathrm{~s}^{-1}\right]}\end{array}$

\begin{tabular}{|c|c|c|c|}
\hline $\begin{array}{c}f \\
{[\mathrm{~Hz}]}\end{array}$ & $\begin{array}{l}\overline{u^{2}} \\
{\left[m^{2} s^{-2}\right]}\end{array}$ & $\begin{array}{c}K_{1} \\
{\left[m^{-1}\right]}\end{array}$ & $\begin{array}{c}E_{1}\left(K_{1}\right) \\
{\left[m^{3} s^{-2}\right]}\end{array}$ \\
\hline $\begin{array}{r}2.00 \\
2.66 \\
3.53 \\
4.69 \\
6.22 \\
8.26 \\
10.98 \\
14.58 \\
19.36 \\
25.72 \\
34.16 \\
45.36 \\
60.24 \\
80.02 \\
106.30 \\
141.10 \\
187.50 \\
248.97 \\
330.70 \\
439.17 \\
583.30 \\
774.70 \\
1028.90 \\
1366.50 \\
1814.90 \\
2410.40 \\
3201.40 \\
4251.80\end{array}$ & $\begin{array}{l}0.10100 E-03 \\
0.27300 E-03 \\
0.58800 E-03 \\
0.48500 E-03 \\
0.54200 E-03 \\
0.99400 E-03 \\
0.89800 E-03 \\
0.85100 E-03 \\
0.10080 E-02 \\
0.11780 E-02 \\
0.14560 E-02 \\
0.16750 E-02 \\
0.21923 E-02 \\
0.15903 E-02 \\
0.23260 E-02 \\
0.18140 E-02 \\
0.20310 E-02 \\
0.92000 E-03 \\
0.56700 E-03 \\
0.35400 E-03 \\
0.17800 E-03 \\
0.80400 E-04 \\
0.29100 E-04 \\
0.79400 E-05 \\
0.12600 E-05 \\
0.17500 E-06 \\
0.10600 E-06 \\
0.86000 E-07\end{array}$ & $\begin{array}{l}0.18954 E+01 \\
0.25209 E+01 \\
0.33453 E+01 \\
0.44447 E+01 \\
0.58946 E+01 \\
0.78279 E+01 \\
0.10406 E+02 \\
0.13817 E+02 \\
0.18347 E+02 \\
0.24375 E+02 \\
0.32373 E+02 \\
0.42987 E+02 \\
0.57089 E+02 \\
0.75834 E+02 \\
0.10074 E+03 \\
0.13372 E+03 \\
0.17769 E+03 \\
0.23595 E+03 \\
0.31340 E+03 \\
0.41620 E+03 \\
0.55279 E+03 \\
0.73418 E+03 \\
0.97508 E+03 \\
0.12950 E+04 \\
0.17200 E+04 \\
0.22843 E+04 \\
0.30339 E+04 \\
0.40294 E+04\end{array}$ & $\begin{array}{l}0.60982 E-04 \\
0.12394 E-03 \\
0.20115 E-03 \\
0.12488 E-03 \\
0.10523 E-03 \\
0.14532 E-03 \\
0.98761 E-04 \\
0.70483 E-04 \\
0.62874 E-04 \\
0.55308 E-04 \\
0.51470 E-04 \\
0.44592 E-04 \\
0.43947 E-04 \\
0.23999 E-04 \\
0.26423 E-04 \\
0.15525 E-04 \\
0.13080 E-04 \\
0.44623 E-05 \\
0.20704 E-05 \\
0.97338 E-06 \\
0.36850 E-06 \\
0.12532 E-06 \\
0.34153 E-07 \\
0.70166 E-08 \\
0.83836 E-09 \\
0.87672 E-10 \\
0.39983 E-10 \\
0.24425 E-10\end{array}$ \\
\hline
\end{tabular}


TABLE E.3.7

$\overline{U^{2}}$-SPECTRA OBTAINED WITH WIRE 3

\begin{tabular}{|c|c|c|c|c|c|}
\hline y & $=24$ & {$[\mathrm{~mm}]$} & $\eta$ & $=1.842$ & \\
\hline$U$ & $=6.66$ & {$\left[\mathrm{~ms}^{-1}\right]$} & $\overline{u^{2}}$ & $=3.2953 \mathrm{E}-3$ & {$\left[m^{2} s^{-2}\right]$} \\
\hline$T$ & $=26$ & {$\left[{ }^{\circ} \mathrm{C}\right]$} & $P$ & $=729.0$ & [mm $\mathrm{Hg}]$ \\
\hline$f_{k}$ & $=1700$ & {$[\mathrm{~Hz}]$} & $\nu$ & $=1.63 E-5$ & {$\left[\mathrm{~m}^{2} \mathrm{~s}^{-1}\right]$} \\
\hline
\end{tabular}

\begin{tabular}{|c|c|c|c|}
\hline$[\mathrm{Hz}]$ & $\begin{array}{l}\overline{u_{f}^{2}} \\
{\left[m^{2} s^{-2}\right]}\end{array}$ & {$\left[m^{-1}\right]$} & {$\left[m^{3} s^{-2}\right]$} \\
\hline $\begin{array}{r}2.00 \\
2.66 \\
3.53 \\
4.69 \\
6.22 \\
8.26 \\
10.98 \\
14.58 \\
19.36 \\
25.72 \\
34.16 \\
45.36 \\
60.24 \\
80.02 \\
106.30 \\
141.10 \\
187.50 \\
248.97 \\
330.70 \\
439.17 \\
583.30 \\
774.70 \\
1028.90 \\
1366.50 \\
1814.90 \\
2410.40 \\
3201.40 \\
4251.80\end{array}$ & $\begin{array}{l}0.33200 E-04 \\
0.12640 E-03 \\
0.21600 E-03 \\
0.24700 E-03 \\
0.24200 E-03 \\
0.32800 E-03 \\
0.43800 E-03 \\
0.48000 E-03 \\
0.41800 E-03 \\
0.45800 E-03 \\
0.60800 E-03 \\
0.66200 E-03 \\
0.18660 E-02 \\
0.10810 E-02 \\
0.89800 E-03 \\
0.11110 E-02 \\
0.14730 E-02 \\
0.49800 E-03 \\
0.29700 E-03 \\
0.18030 E-03 \\
0.91000 E-04 \\
0.41700 E-04 \\
0.15400 E-04 \\
0.39200 E-05 \\
0.33500 E-06 \\
0.68000 E-07 \\
0.51000 E-07 \\
0.44000 E-07\end{array}$ & $\begin{array}{l}0.18868 \mathrm{E}+01 \\
0.25095 \mathrm{E}+01 \\
0.33303 \mathrm{E}+01 \\
0.44246 \mathrm{E}+01 \\
0.58681 \mathrm{E}+01 \\
0.77927 \mathrm{E}+01 \\
0.10359 \mathrm{E}+02 \\
0.13755 \mathrm{E}+02 \\
0.18265 \mathrm{E}+02 \\
0.24265 \mathrm{E}+02 \\
0.32227 \mathrm{E}+02 \\
0.42794 \mathrm{E}+02 \\
0.56832 \mathrm{E}+02 \\
0.75493 \mathrm{E}+02 \\
0.10029 \mathrm{E}+03 \\
0.13312 \mathrm{E}+03 \\
0.17689 \mathrm{E}+03 \\
0.23488 \mathrm{E}+03 \\
0.31199 \mathrm{E}+03 \\
0.41432 \mathrm{E}+03 \\
0.55030 \mathrm{E}+03 \\
0.73087 \mathrm{E}+03 \\
0.97069 \mathrm{E}+03 \\
0.12892 \mathrm{E}+04 \\
0.17122 \mathrm{E}+04 \\
0.22740 \mathrm{E}+04 \\
0.30203 \mathrm{E}+04 \\
0.40112 \mathrm{E}+04\end{array}$ & $\begin{array}{l}0.18013 E-04 \\
0.51565 E-04 \\
0.66400 E-04 \\
0.57150 E-04 \\
0.42220 E-04 \\
0.43091 E-04 \\
0.43287 E-04 \\
0.35725 E-04 \\
0.23429 E-04 \\
0.19323 E-04 \\
0.19314 E-04 \\
0.15837 E-04 \\
0.33614 E-04 \\
0.14659 E-04 \\
0.91671 E-05 \\
0.85443 E-05 \\
0.85249 E-05 \\
0.21706 E-05 \\
0.97457 E-06 \\
0.44550 E-06 \\
0.16929 E-06 \\
0.58411 E-07 \\
0.16242 E-07 \\
0.31129 E-08 \\
0.20030 E-09 \\
0.30613 E-10 \\
0.17287 E-10 \\
0.11230 E-10\end{array}$ \\
\hline
\end{tabular}


TABLE E.3.8

$\overline{u^{2}}$-SPECTRA OBTAINED WITH WIRE 3

$$
\begin{aligned}
& y=28 \quad[\mathrm{~mm}] \quad \eta=2.149 \\
& U=6.69\left[\mathrm{~ms}^{-1}\right] \quad \overline{u^{2}}=1.1967 \mathrm{E}-3\left[\mathrm{~m}^{2} \mathrm{~s}^{-2}\right] \\
& T=26 \quad\left[{ }^{\circ} \mathrm{C}\right] \quad P=729.0 \quad[\mathrm{~mm} \mathrm{Hg}] \\
& E_{K}=1100[\mathrm{~Hz}] \quad \nu=1.63 E-5 \quad\left[\mathrm{~m}^{2} \mathrm{~s}^{-1}\right]
\end{aligned}
$$

\begin{tabular}{|c|c|c|c|}
\hline $\begin{array}{c}E \\
{[\mathrm{~Hz}]}\end{array}$ & $\begin{array}{l}\overline{u^{2}} \\
f \\
{\left[m^{2} s^{-2}\right]}\end{array}$ & $\begin{array}{c}\mathrm{K}_{1} \\
{\left[\mathrm{~m}^{-1}\right]}\end{array}$ & $\begin{array}{c}E_{1}\left(K_{1}\right) \\
{\left[m^{3} s^{-2}\right]}\end{array}$ \\
\hline $\begin{array}{r}2.00 \\
2.66 \\
3.53 \\
4.69 \\
6.22 \\
8.26 \\
10.98 \\
14.58 \\
19.36 \\
25.72 \\
34.16 \\
45.36 \\
60.24 \\
80.02 \\
106.30 \\
141.10 \\
187.50 \\
248.97 \\
330.70 \\
439.17 \\
583.30 \\
774.70 \\
1028.90 \\
1366.50 \\
1814.90 \\
2410.40 \\
3201.40\end{array}$ & $\begin{array}{l}0.98600 E-05 \\
0.33370 E-04 \\
0.56420 E-04 \\
0.49010 E-04 \\
0.75350 E-04 \\
0.11120 E-03 \\
0.10800 E-03 \\
0.14540 E-03 \\
0.14770 E-03 \\
0.18190 E-03 \\
0.20640 E-03 \\
0.24240 E-03 \\
0.71200 E-03 \\
0.45100 E-03 \\
0.32870 E-03 \\
0.44680 E-03 \\
0.40150 E-03 \\
0.20580 E-03 \\
0.12230 E-03 \\
0.74200 E-04 \\
0.36900 E-04 \\
0.15900 E-04 \\
0.44000 E-05 \\
0.28600 E-06 \\
0.32000 E-07 \\
0.25000 E-07 \\
0.22000 E-07\end{array}$ & $\begin{array}{l}0.18784 \mathrm{E}+01 \\
0.24982 \mathrm{E}+01 \\
0.33153 \mathrm{E}+01 \\
0.44048 \mathrm{E}+01 \\
0.58418 \mathrm{E}+01 \\
0.77577 \mathrm{E}+01 \\
0.10312 \mathrm{E}+02 \\
0.13693 \mathrm{E}+02 \\
0.18183 \mathrm{E}+02 \\
0.24156 \mathrm{E}+02 \\
0.32083 \mathrm{E}+02 \\
0.42602 \mathrm{E}+02 \\
0.56577 \mathrm{E}+02 \\
0.75154 \mathrm{E}+02 \\
0.99836 \mathrm{E}+02 \\
0.13252 \mathrm{E}+03 \\
0.17610 \mathrm{E}+03 \\
0.23383 \mathrm{E}+03 \\
0.31059 \mathrm{E}+03 \\
0.41246 \mathrm{E}+03 \\
0.54783 \mathrm{E}+03 \\
0.72759 \mathrm{E}+03 \\
0.96633 \mathrm{E}+03 \\
0.12834 \mathrm{E}+04 \\
0.17045 \mathrm{E}+04 \\
0.22638 \mathrm{E}+04 \\
0.30067 \mathrm{E}+04\end{array}$ & $\begin{array}{l}0.54261 E-05 \\
0.13808 E-04 \\
0.17592 E-04 \\
0.11502 E-04 \\
0.13333 E-04 \\
0.14817 E-04 \\
0.10826 E-04 \\
0.10976 E-04 \\
0.83969 E-05 \\
0.77841 E-05 \\
0.66502 E-05 \\
0.58817 E-05 \\
0.13009 E-04 \\
0.62033 E-05 \\
0.34034 E-05 \\
0.34852 E-05 \\
0.23568 E-05 \\
0.90979 E-06 \\
0.40704 E-06 \\
0.18596 E-06 \\
0.69627 E-07 \\
0.22590 E-07 \\
0.47068 E-08 \\
0.23036 E-09 \\
0.19406 E-10 \\
0.11416 E-10 \\
0.75636 E-111\end{array}$ \\
\hline
\end{tabular}


TABLE E.4.I

$\overline{u^{2}}$-SPECTRA OBTAINED WITH WIRE 4

\begin{tabular}{|c|c|c|c|c|c|}
\hline$y$ & $=0$ & {$[\mathrm{~mm}]$} & $\eta$ & $=0.0$ & \\
\hline U & $=6.34$ & {$\left[\mathrm{~ms}^{-1}\right]$} & $\overline{u^{2}}$ & $=1.0175 E-2$ & {$\left[m^{2} s^{-2}\right]$} \\
\hline $\mathrm{T}$ & $=24$ & {$\left[{ }^{\circ} \mathrm{C}\right]$} & $\mathrm{P}$ & $=737.7$ & [mm Hg] \\
\hline$E_{K}$ & $=2400$ & {$[\mathrm{~Hz}]$} & $\nu$ & $=1.59 E-5$ & {$\left[m^{2} s^{-1}\right]$} \\
\hline
\end{tabular}

\begin{tabular}{|c|c|c|c|}
\hline $\begin{array}{c}f \\
{[\mathrm{~Hz}]}\end{array}$ & $\begin{array}{l}\overline{u^{2}} \\
{\left[m^{2} s^{-2}\right]}\end{array}$ & $\begin{array}{c}K_{1} \\
{\left[m^{-1}\right]}\end{array}$ & $\begin{array}{c}E_{1}\left(k_{1}\right) \\
{\left[m^{3} s^{-2}\right]}\end{array}$ \\
\hline $\begin{array}{r}2.00 \\
2.66 \\
3.53 \\
4.69 \\
6.22 \\
8.26 \\
10.98 \\
14.58 \\
19.36 \\
25.72 \\
34.16 \\
45.36 \\
60.25 \\
80.02 \\
106.30 \\
141.14 \\
187.50 \\
248.97 \\
330.70 \\
439.17 \\
583.30 \\
774.70 \\
1028.90 \\
1366.50 \\
1814.90 \\
2410.40 \\
3201.40 \\
4251.80 \\
5647.01 \\
7500.00\end{array}$ & $\begin{array}{l}0.67980 E-04 \\
0.25500 E-03 \\
0.33700 E-03 \\
0.55000 E-03 \\
0.54800 E-03 \\
0.80300 E-03 \\
0.92500 E-03 \\
0.11220 E-02 \\
0.16180 E-02 \\
0.22070 E-02 \\
0.17530 E-02 \\
0.28200 E-02 \\
0.24540 E-02 \\
0.32550 E-02 \\
0.38950 E-02 \\
0.41620 E-02 \\
0.49180 E-02 \\
0.18960 E-02 \\
0.13300 E-02 \\
0.89300 E-03 \\
0.46500 E-03 \\
0.22000 E-03 \\
0.86900 E-04 \\
0.24200 E-04 \\
0.51000 E-05 \\
0.57900 E-06 \\
0.15200 E-06 \\
0.11500 E-06 \\
0.10600 E-06 \\
0.97000 E-07\end{array}$ & $\begin{array}{l}0.19821 \mathrm{E}+01 \\
0.26362 \mathrm{E}+01 \\
0.34984 \mathrm{E}+01 \\
0.46480 \mathrm{E}+01 \\
0.61643 \mathrm{E}+01 \\
0.81860 \mathrm{E}+01 \\
0.10882 \mathrm{E}+02 \\
0.14449 \mathrm{E}+02 \\
0.19187 \mathrm{E}+02 \\
0.25490 \mathrm{E}+02 \\
0.33854 \mathrm{E}+02 \\
0.44954 \mathrm{E}+02 \\
0.59710 \mathrm{E}+02 \\
0.79303 \mathrm{E}+02 \\
0.10535 \mathrm{E}+03 \\
0.13988 \mathrm{E}+03 \\
0.18582 \mathrm{E}+03 \\
0.24674 \mathrm{E}+03 \\
0.32774 \mathrm{E}+03 \\
0.43523 \mathrm{E}+03 \\
0.57807 \mathrm{E}+03 \\
0.76776 \mathrm{E}+03 \\
0.10197 \mathrm{E}+04 \\
0.13543 \mathrm{E}+04 \\
0.17986 \mathrm{E}+04 \\
0.23888 \mathrm{E}+04 \\
0.31727 \mathrm{E}+04 \\
0.42137 \mathrm{E}+04 \\
0.55964 \mathrm{E}+04 \\
0.74328 \mathrm{E}+04\end{array}$ & $\begin{array}{l}0.33670 E-04 \\
0.94961 E-04 \\
0.94567 E-04 \\
0.11617 E-03 \\
0.87272 E-04 \\
0.96299 E-04 \\
0.83450 E-04 \\
0.76229 E-04 \\
0.82786 E-04 \\
0.85000 E-04 \\
0.50833 E-04 \\
0.61583 E-04 \\
0.40346 E-04 \\
0.40294 E-04 \\
0.36296 E-04 \\
0.29210 E-04 \\
0.25982 E-04 \\
0.75436 E-05 \\
0.39839 E-05 \\
0.20142 E-05 \\
0.78967 E-06 \\
0.28130 E-06 \\
0.83663 E-07 \\
0.17543 E-07 \\
0.27836 E-08 \\
0.23794 E-09 \\
0.47032 E-10 \\
0.26792 E-10 \\
0.18594 E-10 \\
0.12811 E-10\end{array}$ \\
\hline
\end{tabular}


TABLE E.4.2

$\overline{u^{2}}$-SPECTRA OBTAINED WITH WIRE 4

$$
\begin{array}{lllll}
y & =4 & {[\mathrm{~mm}]} & \eta=0.307 & \\
U=6.39 & {\left[\mathrm{~ms}^{-1}\right]} & \overline{U^{2}}=1.0719 \mathrm{E}-2\left[\mathrm{~m}^{2} \mathrm{~s}^{-2}\right] \\
T=24 & {\left[{ }^{\circ} \mathrm{C}\right]} & P=737.7 & {[\mathrm{~mm} \mathrm{Hg}]} \\
E_{K}=2500 & {[\mathrm{~Hz}]} & \nu=1.59 E-5 & {\left[\mathrm{~m}^{2} \mathrm{~s}^{-1}\right]}
\end{array}
$$

\begin{tabular}{|c|c|c|c|}
\hline $\begin{array}{c}E \\
{[\mathrm{~Hz}]}\end{array}$ & $\begin{array}{c}\overline{u_{f}^{2}} \\
{\left[m^{2} s^{-2}\right]}\end{array}$ & $\begin{array}{c}k_{1} \\
{\left[m^{-1}\right]}\end{array}$ & $\begin{array}{c}E_{1}\left(K_{1}\right) \\
{\left[m^{3} s^{-2}\right]}\end{array}$ \\
\hline $\begin{array}{r}2.00 \\
2.66 \\
3.53 \\
4.69 \\
6.22 \\
8.26 \\
10.98 \\
14.58 \\
19.36 \\
25.72 \\
34.16 \\
45.36 \\
60.25 \\
80.02 \\
106.30 \\
141.14 \\
187.50 \\
248.97 \\
330.70 \\
439.17 \\
583.30 \\
774.70 \\
1028.90 \\
1366.50 \\
1814.90 \\
2410.40 \\
3201.40 \\
4251.80 \\
5647.01 \\
7500.00\end{array}$ & 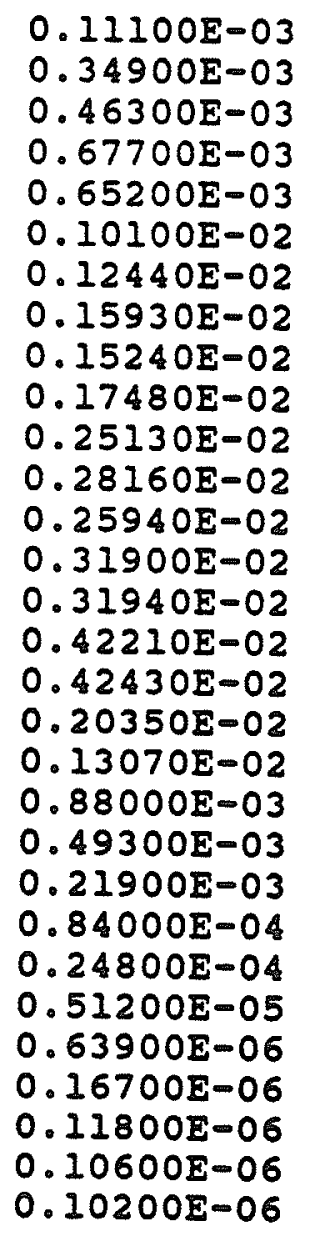 & $\begin{array}{l}0.19666 \mathrm{E}+01 \\
0.26155 \mathrm{E}+01 \\
0.34710 \mathrm{E}+01 \\
0.46116 \mathrm{I}+01 \\
0.61160 \mathrm{E}+01 \\
0.81219 \mathrm{E}+01 \\
0.10796 \mathrm{E}+02 \\
0.14336 \mathrm{E}+02 \\
0.19036 \mathrm{E}+02 \\
0.25290 \mathrm{E}+02 \\
0.33589 \mathrm{E}+02 \\
0.44602 \mathrm{E}+02 \\
0.59243 \mathrm{E}+02 \\
0.78682 \mathrm{E}+02 \\
0.10452 \mathrm{E}+03 \\
0.13878 \mathrm{E}+03 \\
0.18437 \mathrm{E}+03 \\
0.24481 \mathrm{E}+03 \\
0.32517 \mathrm{E}+03 \\
0.43183 \mathrm{E}+03 \\
0.57355 \mathrm{E}+03 \\
0.76175 \mathrm{E}+03 \\
0.10117 \mathrm{E}+04 \\
0.13437 \mathrm{E}+04 \\
0.17846 \mathrm{E}+04 \\
0.23701 \mathrm{E}+04 \\
0.31479 \mathrm{E}+04 \\
0.41807 \mathrm{E}+04 \\
0.55526 \mathrm{E}+04 \\
0.73746 \mathrm{E}+04\end{array}$ & $\begin{array}{l}0.57209 E-04 \\
0.13524 E-03 \\
0.13520 E-03 \\
0.14880 E-03 \\
0.10805 E-03 \\
0.12604 E-03 \\
0.11679 E-03 \\
0.11262 E-03 \\
0.81144 E-04 \\
0.70056 E-04 \\
0.75831 E-04 \\
0.63993 E-04 \\
0.44380 E-04 \\
0.41093 E-04 \\
0.30972 E-04 \\
0.30828 E-04 \\
0.23326 E-04 \\
0.84254 E-05 \\
0.40740 E-05 \\
0.20655 E-05 \\
0.87122 E-06 \\
0.29140 E-06 \\
0.84155 E-07 \\
0.18708 E-07 \\
0.29080 E-08 \\
0.27327 E-09 \\
0.53771 E-10 \\
0.28608 E-10 \\
0.19349 E-10 \\
0.14019 E-10\end{array}$ \\
\hline
\end{tabular}


TABLE E.4.3

$\overline{u^{2}}$-SPECTRA OBTAINED WITH WIRE 4

\begin{tabular}{|c|c|c|c|c|c|}
\hline$y$ & $=8$ & {$[\mathrm{~mm}]$} & $\eta$ & $=0.614$ & \\
\hline $\mathrm{U}$ & $=6.48$ & {$\left[\mathrm{~ms}^{-1}\right]$} & $\overline{u^{2}}$ & $=1.2640 \mathrm{E}-2$ & {$\left[m^{2} s^{-2}\right]$} \\
\hline$T$ & $=24$ & {$\left[{ }^{\circ} \mathrm{C}\right]$} & $P$ & $=737.7$ & {$[\mathrm{~mm} \mathrm{Hg}]$} \\
\hline$E_{K}$ & $=2500$ & {$[\mathrm{~Hz}]$} & $\nu$ & $=1.59 E-5$ & {$\left[m^{2} s^{-1}\right]$} \\
\hline
\end{tabular}

\begin{tabular}{|c|c|c|c|}
\hline $\begin{array}{c}f \\
{[\mathrm{~Hz}]}\end{array}$ & $\begin{array}{l}\overline{u_{f}^{2}} \\
{\left[m^{2} s^{-2}\right]}\end{array}$ & $\begin{array}{c}k_{1} \\
{\left[m^{-1}\right]}\end{array}$ & $\begin{array}{c}E_{1}\left(K_{1}\right) \\
{\left[m^{3} s^{-2}\right]}\end{array}$ \\
\hline $\begin{array}{r}2.00 \\
2.66 \\
3.53 \\
4.69 \\
6.22 \\
8.26 \\
10.98 \\
14.58 \\
19.36 \\
25.72 \\
34.16 \\
45.36 \\
60.25 \\
80.02 \\
106.30 \\
141.14 \\
187.50 \\
248.97 \\
330.70 \\
439.17 \\
583.30 \\
774.70 \\
1028.90 \\
1366.50 \\
1814.90 \\
2410.40 \\
3201.40 \\
4251.80 \\
5647.01 \\
7500.00\end{array}$ & $\begin{array}{l}0.19500 E-03 \\
0.61100 E-03 \\
0.66700 E-03 \\
0.75400 E-03 \\
0.11180 E-02 \\
0.18640 E-02 \\
0.18900 E-02 \\
0.21940 E-02 \\
0.21160 E-02 \\
0.22200 E-02 \\
0.23430 E-02 \\
0.29830 E-02 \\
0.37820 E-02 \\
0.39270 E-02 \\
0.45530 E-02 \\
0.33650 E-02 \\
0.58080 E-02 \\
0.19480 E-02 \\
0.12450 E-02 \\
0.81000 E-03 \\
0.44400 E-03 \\
0.19800 E-03 \\
0.76000 E-04 \\
0.22700 E-04 \\
0.51400 E-05 \\
0.68300 E-06 \\
0.19600 E-06 \\
0.13800 E-06 \\
0.12700 E-06 \\
0.11500 E-06\end{array}$ & $\begin{array}{l}0.19513 E+01 \\
0.25952 \mathrm{E}+01 \\
0.34440 \mathrm{E}+01 \\
0.45758 \mathrm{E}+01 \\
0.60685 \mathrm{E}+01 \\
0.80589 \mathrm{E}+01 \\
0.10713 \mathrm{E}+02 \\
0.14225 \mathrm{E}+02 \\
0.18889 \mathrm{E}+02 \\
0.25094 \mathrm{E}+02 \\
0.33328 \mathrm{E}+02 \\
0.44255 \mathrm{E}+02 \\
0.58783 \mathrm{E}+02 \\
0.78072 \mathrm{E}+02 \\
0.10371 \mathrm{E}+03 \\
0.13770 \mathrm{E}+03 \\
0.18293 \mathrm{E}+03 \\
0.24291 \mathrm{E}+03 \\
0.32265 \mathrm{E}+03 \\
0.42848 \mathrm{E}+03 \\
0.56910 \mathrm{E}+03 \\
0.75584 \mathrm{E}+03 \\
0.10038 \mathrm{E}+04 \\
0.13332 \mathrm{E}+04 \\
0.17707 \mathrm{E}+04 \\
0.23517 \mathrm{E}+04 \\
0.31234 \mathrm{E}+04 \\
0.41483 \mathrm{E}+04 \\
0.55095 \mathrm{E}+04 \\
0.73174 \mathrm{E}+04\end{array}$ & $\begin{array}{l}0.10126 E-03 \\
0.23856 E-03 \\
0.19624 E-03 \\
0.16697 E-03 \\
0.18668 E-03 \\
0.23437 E-03 \\
0.17877 E-03 \\
0.15628 E-03 \\
0.11351 E-03 \\
0.89643 E-04 \\
0.71235 E-04 \\
0.68299 E-04 \\
0.65193 E-04 \\
0.50968 E-04 \\
0.44484 E-04 \\
0.24761 E-04 \\
0.32171 E-04 \\
0.81260 E-05 \\
0.39100 E-05 \\
0.19155 E-05 \\
0.79055 E-06 \\
0.26544 E-06 \\
0.76714 E-07 \\
0.17253 E-07 \\
0.29414 E-08 \\
0.29428 E-09 \\
0.63585 E-10 \\
0.33709 E-10 \\
0.23357 E-10 \\
0.15925 E-10\end{array}$ \\
\hline
\end{tabular}


TABLE E.4.4

$$
\overline{u^{2}} \text {-SPECTRA OBTAINED WITH WIRE } 4
$$

$$
\begin{array}{rlrlrl}
\mathrm{Y} & =12 & {[\mathrm{~mm}]} & \eta & =0.921 \\
\mathrm{U} & =6.50 & {\left[\mathrm{~ms}^{-1}\right]} & \overline{\mathrm{u}^{2}} & =1.2722 \mathrm{E}-2 & {\left[\mathrm{~m}^{2} \mathrm{~s}^{-2}\right]} \\
\mathrm{T} & =24 & {\left[{ }^{0} \mathrm{C}\right]} & \mathrm{P} & =737.7 & {[\mathrm{~mm} \mathrm{Hg}]} \\
E_{\mathrm{K}}=2400 & {[\mathrm{~Hz}]} & \nu & =1.59 \mathrm{E}-5 & {\left[\mathrm{~m}^{2} \mathrm{~s}^{-1}\right]}
\end{array}
$$

\begin{tabular}{|c|c|c|c|}
\hline $\begin{array}{c}\mathrm{E} \\
{[\mathrm{Hz}]}\end{array}$ & $\begin{array}{c}\overline{u_{f}^{2}} \\
{\left[m^{2} s^{-2}\right]}\end{array}$ & $\begin{array}{c}k_{1} \\
{\left[m^{-1}\right]}\end{array}$ & $\begin{array}{c}E_{1}\left(K_{1}\right) \\
{\left[m^{3} s^{-2}\right]}\end{array}$ \\
\hline $\begin{array}{r}2.00 \\
2.66 \\
3.53 \\
4.69 \\
6.22 \\
8.26 \\
10.98 \\
14.58 \\
19.36 \\
25.72 \\
34.16 \\
45.36 \\
60.25 \\
80.02 \\
106.30 \\
141.14 \\
187.50 \\
248.97 \\
330.70 \\
439.17 \\
583.30 \\
774.70 \\
1028.90 \\
1366.50 \\
1814.90 \\
2410.40 \\
3201.40 \\
4251.80 \\
5647.01 \\
7500.00\end{array}$ & $\begin{array}{l}0.17800 E-03 \\
0.51000 E-03 \\
0.76660 E-03 \\
0.12320 E-02 \\
0.15770 E-02 \\
0.18800 E-02 \\
0.25270 E-02 \\
0.27650 E-02 \\
0.21240 E-02 \\
0.27660 E-02 \\
0.21610 E-02 \\
0.24270 E-02 \\
0.44990 E-02 \\
0.37750 E-02 \\
0.34890 E-02 \\
0.44950 E-02 \\
0.32010 E-02 \\
0.16910 E-02 \\
0.10590 E-02 \\
0.67300 E-03 \\
0.35900 E-03 \\
0.15900 E-03 \\
0.61800 E-04 \\
0.17300 E-04 \\
0.38100 E-05 \\
0.51300 E-06 \\
0.18200 E-06 \\
0.13600 E-06 \\
0.12800 E-06 \\
0.11500 E-06\end{array}$ & $\begin{array}{l}0.19333 E+01 \\
0.25713 E+01 \\
0.34123 E+01 \\
0.45336 E+01 \\
0.60125 E+01 \\
0.79845 E+01 \\
0.10614 E+02 \\
0.14094 E+02 \\
0.18714 E+02 \\
0.24862 E+02 \\
0.33021 E+02 \\
0.43847 E+02 \\
0.58240 E+02 \\
0.77351 E+02 \\
0.10275 E+03 \\
0.13643 E+03 \\
0.18125 E+03 \\
0.24067 E+03 \\
0.31967 E+03 \\
0.42452 E+03 \\
0.56384 E+03 \\
0.74886 E+03 \\
0.99458 E+03 \\
0.13209 E+04 \\
0.17544 E+04 \\
0.23300 E+04 \\
0.30946 E+04 \\
0.41100 E+04 \\
0.54586 E+04 \\
0.72498 E+04\end{array}$ & $\begin{array}{l}0.93039 E-04 \\
0.20043 E-03 \\
0.22702 E-03 \\
0.27461 E-03 \\
0.26504 E-03 \\
0.23793 E-03 \\
0.24059 E-03 \\
0.19825 E-03 \\
0.11469 E-03 \\
0.11242 E-03 \\
0.66132 E-04 \\
0.55933 E-04 \\
0.78061 E-04 \\
0.49317 E-04 \\
0.34312 E-04 \\
0.33293 E-04 \\
0.17847 E-04 \\
0.71002 E-05 \\
0.33476 E-05 \\
0.16020 E-05 \\
0.64339 E-06 \\
0.21455 E-06 \\
0.62790 E-07 \\
0.13235 E-07 \\
0.21946 E-08 \\
0.22249 E-09 \\
0.59430 E-10 \\
0.33438 E-10 \\
0.23695 E-10 \\
0.16029 E-10\end{array}$ \\
\hline
\end{tabular}


TABLE E. 4.5

$\overline{u^{2}}$-SPECTRA OBTAINED WITH WIRE $\&$

\begin{tabular}{|c|c|c|c|c|c|}
\hline$y$ & $=16$ & {$[\mathrm{~mm}]$} & $\eta$ & $=1.228$ & \\
\hline & $=6.56$ & {$\left[\mathrm{~ms}^{-1}\right]$} & $\overline{u^{2}}$ & $=9.8650 \mathrm{E}-3$ & {$\left[\mathrm{~m}^{2} \mathrm{~s}^{-2}\right]$} \\
\hline & $=24$ & {$\left[{ }^{\circ} \mathrm{C}\right]$} & $P$ & $=737.7$ & {$[\mathrm{~mm} \mathrm{Hg}]$} \\
\hline & $=2200$ & {$[\mathrm{~Hz}]$} & $\nu$ & $=1.59 \mathrm{E}-5$ & {$\left[\mathrm{~m}^{2} \mathrm{~s}^{-1}\right]$} \\
\hline
\end{tabular}

\begin{tabular}{|c|c|c|c|}
\hline$[\mathrm{Hz}]$ & $\begin{array}{c}\overline{u_{f}^{2}} \\
{\left[m^{2} s^{-2}\right]}\end{array}$ & {$\left[m^{-1}\right]$} & $\begin{array}{c}E_{1}\left(K_{1}\right) \\
{\left[m^{3} s^{-2}\right]}\end{array}$ \\
\hline $\begin{array}{r}2.00 \\
2.66 \\
3.53 \\
4.69 \\
6.22 \\
8.26 \\
10.98 \\
14.58 \\
19.36 \\
25.72 \\
34.16 \\
45.36 \\
60.25 \\
80.02 \\
106.30 \\
141.14 \\
187.50 \\
248.97 \\
330.70 \\
439.17 \\
583.30 \\
774.70 \\
1028.90 \\
1366.50 \\
1814.90 \\
2410.40 \\
3201.40 \\
4251.80 \\
5647.01\end{array}$ & $\begin{array}{l}0.15840 E-03 \\
0.44500 E-03 \\
0.51500 E-03 \\
0.79600 E-03 \\
0.75500 E-03 \\
0.13070 E-02 \\
0.15730 E-02 \\
0.15720 E-02 \\
0.15440 E-02 \\
0.24550 E-02 \\
0.21830 E-02 \\
0.23950 E-02 \\
0.35710 E-02 \\
0.27520 E-02 \\
0.33970 E-02 \\
0.31130 E-02 \\
0.24170 E-02 \\
0.13080 E-02 \\
0.76500 E-03 \\
0.45100 E-03 \\
0.20700 E-03 \\
0.91000 E-04 \\
0.38600 E-04 \\
0.92000 E-05 \\
0.22900 E-05 \\
0.30700 E-06 \\
0.14300 E-06 \\
0.11400 E-06 \\
0.10900 E-06\end{array}$ & $\begin{array}{l}0.19156 E+01 \\
0.25478 E+01 \\
0.33810 E+01 \\
0.44921 E+01 \\
0.59575 E+01 \\
0.79115 E+01 \\
0.10517 E+02 \\
0.13965 E+02 \\
0.18543 E+02 \\
0.24635 E+02 \\
0.32719 E+02 \\
0.43446 E+02 \\
0.57708 E+02 \\
0.76643 E+02 \\
0.10181 E+03 \\
0.13518 E+03 \\
0.17959 E+03 \\
0.23846 E+03 \\
0.31675 E+03 \\
0.42064 E+03 \\
0.55869 E+03 \\
0.74201 E+03 \\
0.98548 E+03 \\
0.13088 E+04 \\
0.17383 E+04 \\
0.23087 E+04 \\
0.30663 E+04 \\
0.40724 E+04 \\
0.54087 E+04\end{array}$ & $\begin{array}{l}0.85185 E-04 \\
0.17994 E-03 \\
0.15692 \mathrm{E}-03 \\
0.18255 \mathrm{E}-03 \\
0.13056 \mathrm{E}-03 \\
0.17019 \mathrm{E}-03 \\
0.15409 \mathrm{E}-03 \\
0.11597 \mathrm{E}-03 \\
0.85779 \mathrm{E}-04 \\
0.10266 \mathrm{E}-03 \\
0.68735 \mathrm{E}-04 \\
0.56790 \mathrm{E}-04 \\
0.63749 \mathrm{E}-04 \\
0.36990 \mathrm{E}-04 \\
0.34372 \mathrm{E}-04 \\
0.23723 \mathrm{E}-04 \\
0.13865 \mathrm{E}-04 \\
0.56507 \mathrm{E}-05 \\
0.24881 \mathrm{E}-05 \\
0.11045 \mathrm{E}-05 \\
0.38170 \mathrm{E}-06 \\
0.12634 \mathrm{E}-06 \\
0.40351 \mathrm{E}-07 \\
0.72413 \mathrm{E}-08 \\
0.13571 \mathrm{E}-08 \\
0.13699 \mathrm{E}-09 \\
0.48044 \mathrm{E}-10 \\
0.28838 \mathrm{E}-10 \\
0.20761 \mathrm{E}-10\end{array}$ \\
\hline
\end{tabular}


TABLE E.4.6

$\overline{u^{2}}$-SPECTRA OBTAINED WITH WIRE 4

\begin{tabular}{|c|c|c|c|c|c|}
\hline$y$ & $=20$ & {$[\mathrm{~mm}]$} & $\eta$ & $=1.535$ & \\
\hline$U$ & $=6.63$ & {$\left[\mathrm{~ms}^{-1}\right]$} & $\overline{u^{2}}$ & $=6.0286 \mathrm{E}-3$ & {$\left[m^{2} s^{-2}\right]$} \\
\hline $\mathrm{T}$ & $=24$ & {$\left[{ }^{\circ} \mathrm{C}\right]$} & $P$ & $=737.7$ & {$[\mathrm{~mm} \mathrm{Hg}]$} \\
\hline$E_{K}$ & $=2000$ & {$[\mathrm{~Hz}]$} & $\nu$ & $=1.59 E-5$ & {$\left[m^{2} s^{-1}\right]$} \\
\hline
\end{tabular}

\begin{tabular}{|c|c|c|c|}
\hline$[\mathrm{Hz}]$ & $\begin{array}{l}\overline{u^{2}} \\
f \\
{\left[m^{2} s^{-2}\right]}\end{array}$ & $\begin{array}{c}k_{1} \\
{\left[m^{-1}\right]}\end{array}$ & $\begin{array}{c}E_{1}\left(K_{1}\right) \\
{\left[m^{3} s^{-2}\right]}\end{array}$ \\
\hline $\begin{array}{r}2.00 \\
2.66 \\
3.53 \\
4.69 \\
6.22 \\
8.26 \\
10.98 \\
14.58 \\
19.36 \\
25.72 \\
34.16 \\
45.36 \\
60.25 \\
80.02 \\
106.30 \\
141.14 \\
187.50 \\
248.97 \\
330.70 \\
439.17 \\
583.30 \\
774.70 \\
1028.90 \\
1366.50 \\
1814.90 \\
2410.40 \\
3201.40 \\
4251.80\end{array}$ & $\begin{array}{l}0.85100 \mathrm{E}-04 \\
0.26500 \mathrm{E}-03 \\
0.38600 \mathrm{E}-03 \\
0.39540 \mathrm{E}-03 \\
0.63900 \mathrm{E}-03 \\
0.72900 \mathrm{E}-03 \\
0.85000 \mathrm{E}-03 \\
0.86500 \mathrm{E}-03 \\
0.10880 \mathrm{E}-02 \\
0.16840 \mathrm{E}-02 \\
0.11930 \mathrm{E}-02 \\
0.13570 \mathrm{E}-02 \\
0.22570 \mathrm{E}-02 \\
0.16380 \mathrm{E}-02 \\
0.20780 \mathrm{E}-02 \\
0.21300 \mathrm{E}-02 \\
0.20260 \mathrm{E}-02 \\
0.85300 \mathrm{E}-03 \\
0.49900 \mathrm{E}-03 \\
0.31600 \mathrm{E}-03 \\
0.15200 \mathrm{E}-03 \\
0.72800 \mathrm{E}-04 \\
0.26000 \mathrm{E}-04 \\
0.75000 \mathrm{E}-05 \\
0.11000 \mathrm{E}-05 \\
0.14700 \mathrm{E}-06 \\
0.91000 \mathrm{E}-07 \\
0.77000 \mathrm{E}-07\end{array}$ & $\begin{array}{l}0.18954 E+01 \\
0.25209 E+01 \\
0.33453 E+01 \\
0.44447 E+01 \\
0.58946 E+01 \\
0.78279 E+01 \\
0.10406 E+02 \\
0.13817 E+02 \\
0.18347 E+02 \\
0.24375 E+02 \\
0.32373 E+02 \\
0.42987 E+02 \\
0.57098 E+02 \\
0.75834 E+02 \\
0.10074 E+03 \\
0.13376 E+03 \\
0.17769 E+03 \\
0.23595 E+03 \\
0.31340 E+03 \\
0.41620 E+03 \\
0.55279 E+03 \\
0.73418 E+03 \\
0.97508 E+03 \\
0.12950 E+04 \\
0.17200 E+04 \\
0.22843 E+04 \\
0.30339 E+04 \\
0.40294 E+04\end{array}$ & $\begin{array}{l}0.44902 E-04 \\
0.10513 E-03 \\
0.11539 E-03 \\
0.88968 E-04 \\
0.10841 E-03 \\
0.93136 E-04 \\
0.81693 E-04 \\
0.62608 E-04 \\
0.59305 E-04 \\
0.69094 E-04 \\
0.36855 E-04 \\
0.31570 E-04 \\
0.39531 E-04 \\
0.21602 E-04 \\
0.20629 E-04 \\
0.15926 E-04 \\
0.11403 E-04 \\
0.36155 E-05 \\
0.15923 E-05 \\
0.75932 E-06 \\
0.27499 E-06 \\
0.99167 E-07 \\
0.26667 E-07 \\
0.57919 E-08 \\
0.63960 E-09 \\
0.64357 E-10 \\
0.29996 E-10 \\
0.19111 E-10\end{array}$ \\
\hline
\end{tabular}


TABLE E. 4.7

$\overline{u^{2}}$-SPECTRA OBTAINED WITH WIRE 4

$\begin{array}{rlrlrl}y & =24 & {[\mathrm{~mm}]} & \eta & =1.842 & \\ U & =6.66 & {[\mathrm{~ms}-1]} & \overline{\mathrm{u}^{2}} & =2.6923 \mathrm{E}-3\left[\mathrm{~m}^{2} \mathrm{~s}^{-2}\right] \\ T & =24 & {\left[{ }^{\circ} \mathrm{C}\right]} & P & =737.7 & {[\mathrm{~mm} \mathrm{Hg}]} \\ E_{K}=1700 & {[\mathrm{~Hz}]} & \nu & =1.59 \mathrm{E}-5 & {\left[\mathrm{~m}^{2} \mathrm{~s}^{-1}\right]}\end{array}$

\begin{tabular}{|c|c|c|c|}
\hline $\begin{array}{c}E \\
{[\mathrm{~Hz}]}\end{array}$ & $\begin{array}{l}\overline{u_{f}^{2}} \\
{\left[m^{2} s^{-2}\right]}\end{array}$ & $\begin{array}{c}\mathrm{K}_{1} \\
{\left[\mathrm{~m}^{-1}\right]}\end{array}$ & $\begin{array}{c}E_{1}\left(K_{1}\right) \\
{\left[m^{3} s^{-2}\right]}\end{array}$ \\
\hline $\begin{array}{r}2.00 \\
2.66 \\
3.53 \\
4.69 \\
6.22 \\
8.26 \\
10.98 \\
14.58 \\
19.36 \\
25.72 \\
34.16 \\
45.36 \\
60.25 \\
80.02 \\
106.30 \\
141.14 \\
187.50 \\
248.97 \\
330.70 \\
439.17 \\
583.30 \\
774.70 \\
1028.90 \\
1366.50 \\
1814.90 \\
2410.40 \\
3201.40 \\
4251.80\end{array}$ & $\begin{array}{l}0.28700 E-04 \\
0.11000 E-03 \\
0.12700 E-03 \\
0.10600 E-03 \\
0.21600 E-03 \\
0.33300 E-03 \\
0.25300 E-03 \\
0.47800 E-03 \\
0.38200 E-03 \\
0.55300 E-03 \\
0.53700 E-03 \\
0.84800 E-03 \\
0.12550 E-02 \\
0.59400 E-03 \\
0.97200 E-03 \\
0.12610 E-02 \\
0.85700 E-03 \\
0.40800 E-03 \\
0.25500 E-03 \\
0.16400 E-03 \\
0.72000 E-04 \\
0.34000 E-04 \\
0.12500 E-04 \\
0.31200 E-05 \\
0.30000 E-06 \\
0.56000 E-07 \\
0.42000 E-07 \\
0.39000 E-07\end{array}$ & $\begin{array}{l}0.18868 E+01 \\
0.25095 E+01 \\
0.33303 E+01 \\
0.44246 E+01 \\
0.58681 E+01 \\
0.77927 E+01 \\
0.10359 E+02 \\
0.13755 E+02 \\
0.18265 E+02 \\
0.24265 E+02 \\
0.32227 E+02 \\
0.42794 E+02 \\
0.56841 E+02 \\
0.75493 E+02 \\
0.10029 E+03 \\
0.13315 E+03 \\
0.17689 E+03 \\
0.23488 E+03 \\
0.31199 E+03 \\
0.41432 E+03 \\
0.55030 E+03 \\
0.73087 E+03 \\
0.97069 E+03 \\
0.12892 E+04 \\
0.17122 E+04 \\
0.22740 E+04 \\
0.30203 E+04 \\
0.40112 E+04\end{array}$ & $\begin{array}{l}0.14688 E-04 \\
0.42328 E-04 \\
0.36825 E-04 \\
0.23134 E-04 \\
0.35545 E-04 \\
0.41265 E-04 \\
0.23585 E-04 \\
0.33557 E-04 \\
0.20196 E-04 \\
0.22007 E-04 \\
0.16091 E-04 \\
0.19135 E-04 \\
0.21321 E-04 \\
0.75980 E-05 \\
0.93594 E-05 \\
0.91449 E-05 \\
0.46784 E-05 \\
0.16774 E-05 \\
0.78926 E-06 \\
0.38223 E-06 \\
0.12634 E-06 \\
0.44922 E-07 \\
0.12435 E-07 \\
0.23370 E-08 \\
0.16919 E-09 \\
0.23780 E-10 \\
0.13428 E-10 \\
0.93887 E-11\end{array}$ \\
\hline
\end{tabular}


TABLE E.4.8

$u^{2}-S P E C T R A$ OBTAINED WITH WIRE 4

$$
\begin{aligned}
& y=28 \quad[\mathrm{~mm}] \quad \eta=2.149 \\
& \mathrm{U}=6.69\left[\mathrm{~ms}^{-1}\right] \quad \overline{\mathrm{u}^{2}}=9.3007 \mathrm{E}-4\left[\mathrm{~m}^{2} \mathrm{~s}^{-2}\right] \\
& T=24 \quad\left[{ }^{\circ} \mathrm{C}\right] \quad P=737.7 \quad[\mathrm{~mm} \mathrm{Hg}] \\
& E_{K}=1100[\mathrm{~Hz}] \quad \nu=1.59 E-5 \quad\left[\mathrm{~m}^{2} \mathrm{~s}^{-1}\right]
\end{aligned}
$$

\begin{tabular}{|c|c|c|c|}
\hline $\begin{array}{c}E \\
{[\mathrm{~Hz}]}\end{array}$ & $\begin{array}{l}\overline{u_{f}^{2}} \\
{\left[m^{2} s^{-2}\right]}\end{array}$ & $\begin{array}{l}\mathrm{K}_{1} \\
{[\mathrm{~m}-1]}\end{array}$ & $\begin{array}{c}E_{1}\left(K_{1}\right) \\
{\left[m^{3} s^{-2}\right]}\end{array}$ \\
\hline $\begin{array}{r}2.00 \\
2.66 \\
3.53 \\
4.69 \\
6.22 \\
8.26 \\
10.98 \\
14.58 \\
19.36 \\
25.72 \\
34.16 \\
45.36 \\
60.25 \\
80.02 \\
106.30 \\
141.14 \\
187.50 \\
248.97 \\
330.70 \\
439.17 \\
583.30 \\
774.70 \\
1028.90 \\
1366.50 \\
1814.90 \\
2410.40 \\
3201.40\end{array}$ & $\begin{array}{l}0.76300 E-05 \\
0.25000 E-04 \\
0.35300 E-04 \\
0.45000 E-04 \\
0.62300 E-04 \\
0.87700 E-04 \\
0.10310 E-03 \\
0.81200 E-04 \\
0.18280 E-03 \\
0.18200 E-03 \\
0.24900 E-03 \\
0.18500 E-03 \\
0.57200 E-03 \\
0.28900 E-03 \\
0.33400 E-03 \\
0.38200 E-03 \\
0.34900 E-03 \\
0.13800 E-03 \\
0.90000 E-04 \\
0.53700 E-04 \\
0.28700 E-04 \\
0.12200 E-04 \\
0.32000 E-05 \\
0.22900 E-06 \\
0.35000 E-07 \\
0.26000 E-07 \\
0.22000 E-07\end{array}$ & $\begin{array}{l}0.18784 \mathrm{E}+01 \\
0.24982 \mathrm{E}+01 \\
0.33153 \mathrm{E}+01 \\
0.44048 \mathrm{E}+01 \\
0.58418 \mathrm{E}+01 \\
0.77577 \mathrm{E}+01 \\
0.10312 \mathrm{E}+02 \\
0.13693 \mathrm{E}+02 \\
0.18183 \mathrm{E}+02 \\
0.24156 \mathrm{E}+02 \\
0.32083 \mathrm{E}+02 \\
0.42602 \mathrm{E}+02 \\
0.56586 \mathrm{E}+02 \\
0.75154 \mathrm{E}+02 \\
0.99836 \mathrm{E}+02 \\
0.13256 \mathrm{E}+03 \\
0.17610 \mathrm{E}+03 \\
0.23383 \mathrm{E}+03 \\
0.31059 \mathrm{E}+03 \\
0.41246 \mathrm{E}+03 \\
0.54783 \mathrm{E}+03 \\
0.72759 \mathrm{E}+03 \\
0.96633 \mathrm{E}+03 \\
0.12834 \mathrm{E}+04 \\
0.17045 \mathrm{E}+04 \\
0.22638 \mathrm{E}+04 \\
0.30067 \mathrm{E}+04\end{array}$ & $\begin{array}{l}0.40137 E-05 \\
0.98880 E-05 \\
0.10521 E-04 \\
0.10095 E-04 \\
0.10538 E-04 \\
0.11170 E-04 \\
0.98789 E-05 \\
0.58593 E-05 \\
0.99339 E-05 \\
0.74448 E-05 \\
0.76689 E-05 \\
0.42909 E-05 \\
0.99883 E-05 \\
0.37997 E-05 \\
0.33057 E-05 \\
0.28475 E-05 \\
0.19583 E-05 \\
0.58315 E-06 \\
0.28632 E-06 \\
0.12864 E-06 \\
0.51766 E-07 \\
0.16568 E-07 \\
0.32721 E-08 \\
0.17631 E-09 \\
0.20289 E-10 \\
0.11348 E-10 \\
0.72299 E-11\end{array}$ \\
\hline
\end{tabular}


TABLE E.5.1

$\overline{u^{2}}$-SPECTRA OBTAINED WITH WIRE 5

$$
\begin{aligned}
& y=0 \quad[\mathrm{~mm}] \quad \eta=0.0 \\
& U=6.34\left[\mathrm{~ms}^{-1}\right] \quad \overline{u^{2}}=9.8089 \mathrm{E}-3\left[\mathrm{~m}^{2} \mathrm{~s}^{-2}\right] \\
& T=20 \quad\left[{ }^{\circ} \mathrm{C}\right] \quad P=782.7 \quad[\mathrm{~mm} \mathrm{Hg}] \\
& E_{K}=2400[\mathrm{~Hz}] \quad \nu=1.54 \mathrm{E}-5 \quad\left[\mathrm{~m}^{2} \mathrm{~s}^{-1}\right]
\end{aligned}
$$

\begin{tabular}{|c|c|c|c|}
\hline$[\mathrm{Hz}]$ & $\begin{array}{l}\bar{u}_{f}^{2} \\
{\left[m^{2} s^{-2}\right]}\end{array}$ & {$\left[m^{-1}\right]$} & $\begin{array}{c}E_{1}\left(K_{1}\right) \\
{\left[m^{3} s^{-2}\right]}\end{array}$ \\
\hline $\begin{array}{r}2.00 \\
2.66 \\
3.53 \\
4.69 \\
6.22 \\
8.26 \\
10.98 \\
14.58 \\
19.36 \\
25.72 \\
34.16 \\
45.36 \\
60.25 \\
80.02 \\
106.30 \\
141.14 \\
187.50 \\
248.97 \\
330.70 \\
439.17 \\
583.30 \\
774.70 \\
1028.90 \\
1366.50 \\
1814.90 \\
2410.40 \\
3201.40 \\
4251.80 \\
5647.01 \\
7500.00\end{array}$ & $\begin{array}{l}0.11200 E-03 \\
0.25800 E-03 \\
0.45700 E-03 \\
0.55000 E-03 \\
0.68500 E-03 \\
0.10520 E-02 \\
0.10650 E-02 \\
0.11870 E-02 \\
0.14070 E-02 \\
0.21080 E-02 \\
0.20070 E-02 \\
0.18000 E-02 \\
0.25600 E-02 \\
0.31660 E-02 \\
0.34570 E-02 \\
0.48560 E-02 \\
0.35200 E-02 \\
0.18630 E-02 \\
0.12880 E-02 \\
0.84500 E-03 \\
0.47100 E-03 \\
0.20900 E-03 \\
0.83900 E-04 \\
0.23890 E-04 \\
0.47360 E-05 \\
0.55300 E-06 \\
0.15200 E-06 \\
0.11200 E-06 \\
0.10800 E-06 \\
0.99000 E-07\end{array}$ & $\begin{array}{l}0.19821 \mathrm{E}+01 \\
0.26362 \mathrm{E}+01 \\
0.34984 \mathrm{E}+01 \\
0.46480 \mathrm{E}+01 \\
0.61643 \mathrm{E}+01 \\
0.81860 \mathrm{E}+01 \\
0.10882 \mathrm{E}+02 \\
0.14449 \mathrm{E}+02 \\
0.19187 \mathrm{E}+02 \\
0.25490 \mathrm{E}+02 \\
0.33854 \mathrm{E}+02 \\
0.44954 \mathrm{E}+02 \\
0.59710 \mathrm{E}+02 \\
0.79303 \mathrm{E}+02 \\
0.10535 \mathrm{E}+03 \\
0.13988 \mathrm{E}+03 \\
0.18582 \mathrm{E}+03 \\
0.24674 \mathrm{E}+03 \\
0.32774 \mathrm{E}+03 \\
0.43523 \mathrm{E}+03 \\
0.57807 \mathrm{E}+03 \\
0.76776 \mathrm{E}+03 \\
0.10197 \mathrm{E}+04 \\
0.13543 \mathrm{E}+04 \\
0.17986 \mathrm{E}+04 \\
0.23888 \mathrm{E}+04 \\
0.31727 \mathrm{E}+04 \\
0.42137 \mathrm{E}+04 \\
0.55964 \mathrm{E}+04 \\
0.74328 \mathrm{E}+04\end{array}$ & $\begin{array}{l}0.55384 E-04 \\
0.95926 E-04 \\
0.12804 E-03 \\
0.11598 E-03 \\
0.10892 E-03 \\
0.12596 E-03 \\
0.95928 E-04 \\
0.80518 E-04 \\
0.71876 E-04 \\
0.81058 E-04 \\
0.58107 E-04 \\
0.39246 E-04 \\
0.42022 E-04 \\
0.39130 E-04 \\
0.32164 E-04 \\
0.34027 E-04 \\
0.18567 E-04 \\
0.74005 E-05 \\
0.38519 E-05 \\
0.19029 E-05 \\
0.79860 E-06 \\
0.26682 E-06 \\
0.80647 E-07 \\
0.17290 E-07 \\
0.25808 E-08 \\
0.22690 E-09 \\
0.46957 E-10 \\
0.26052 E-10 \\
0.18915 E-10 \\
0.13055 E-10\end{array}$ \\
\hline
\end{tabular}


TABLE E.5.2

$\overline{u^{2}}$-SPECTRA OBTAINED WITH WIRE 5

\begin{tabular}{|c|c|c|c|c|c|}
\hline y & $=4$ & {$[\mathrm{~mm}]$} & $\eta$ & $=0.307$ & \\
\hline$U$ & $=6.39$ & {$\left[\mathrm{~ms}^{-1}\right]$} & $\overline{u^{2}}$ & $=1.0260 E-2$ & {$\left[m^{2} s^{-2}\right]$} \\
\hline $\mathrm{T}$ & $=20$ & {$\left[{ }^{\circ} \mathrm{C}\right]$} & $\mathrm{P}$ & $=742.7$ & [mm Hg] \\
\hline$\xi_{k}$ & $=2500$ & {$[\mathrm{~Hz}]$} & $\nu$ & $=1.54 \mathrm{E}-5$ & {$\left[m^{2} s^{-1}\right]$} \\
\hline
\end{tabular}

\begin{tabular}{|c|c|c|c|}
\hline$[\mathrm{Hz}]$ & $\begin{array}{l}\vec{u}_{f}^{2} \\
{\left[m^{2} s^{-2}\right]}\end{array}$ & $\begin{array}{c}\mathrm{K}_{1} \\
{\left[\mathrm{~m}^{-1}\right]}\end{array}$ & $\begin{array}{c}E_{1}\left(K_{1}\right) \\
{\left[m^{3} s^{-2}\right]}\end{array}$ \\
\hline $\begin{array}{r}2.00 \\
2.66 \\
3.53 \\
4.69 \\
6.22 \\
8.26 \\
10.98 \\
14.58 \\
19.36 \\
25.72 \\
34.16 \\
45.36 \\
60.25 \\
80.02 \\
106.30 \\
141.14 \\
187.50 \\
248.97 \\
330.70 \\
439.17 \\
583.30 \\
774.70 \\
1028.90 \\
1366.50 \\
1814.90 \\
2410.40 \\
3201.40 \\
4251.80 \\
5647.01 \\
7500.00\end{array}$ & $\begin{array}{l}0.12000 \mathrm{E}-03 \\
0.37500 \mathrm{E}-03 \\
0.39240 \mathrm{E}-03 \\
0.64100 \mathrm{E}-03 \\
0.85200 \mathrm{E}-03 \\
0.98200 \mathrm{E}-03 \\
0.11050 \mathrm{E}-02 \\
0.14010 \mathrm{E}-02 \\
0.13350 \mathrm{E}-02 \\
0.19490 \mathrm{E}-02 \\
0.21160 \mathrm{E}-02 \\
0.26660 \mathrm{E}-02 \\
0.25510 \mathrm{E}-02 \\
0.37120 \mathrm{E}-02 \\
0.35390 \mathrm{E}-02 \\
0.31620 \mathrm{E}-02 \\
0.36200 \mathrm{E}-02 \\
0.19160 \mathrm{E}-02 \\
0.13270 \mathrm{E}-02 \\
0.85200 \mathrm{E}-03 \\
0.46300 \mathrm{E}-03 \\
0.20600 \mathrm{E}-03 \\
0.82200 \mathrm{E}-04 \\
0.23800 \mathrm{E}-04 \\
0.47400 \mathrm{E}-05 \\
0.62700 \mathrm{E}-06 \\
0.16600 \mathrm{E}-06 \\
0.11800 \mathrm{E}-06 \\
0.11100 \mathrm{E}-06 \\
0.10400 \mathrm{E}-06\end{array}$ & $\begin{array}{l}0.19666 \mathrm{E}+01 \\
0.26155 \mathrm{E}+01 \\
0.34710 \mathrm{E}+01 \\
0.46116 \mathrm{E}+01 \\
0.61160 \mathrm{E}+01 \\
0.81219 \mathrm{E}+01 \\
0.10796 \mathrm{E}+02 \\
0.14336 \mathrm{E}+02 \\
0.19036 \mathrm{E}+02 \\
0.25290 \mathrm{E}+02 \\
0.33589 \mathrm{E}+02 \\
0.44602 \mathrm{E}+02 \\
0.59243 \mathrm{E}+02 \\
0.78682 \mathrm{E}+02 \\
0.10452 \mathrm{E}+03 \\
0.13878 \mathrm{E}+03 \\
0.18437 \mathrm{E}+03 \\
0.24481 \mathrm{E}+03 \\
0.32517 \mathrm{E}+03 \\
0.43183 \mathrm{E}+03 \\
0.57355 \mathrm{E}+03 \\
0.76175 \mathrm{E}+03 \\
0.10117 \mathrm{E}+04 \\
0.13437 \mathrm{E}+04 \\
0.17846 \mathrm{E}+04 \\
0.23701 \mathrm{E}+04 \\
0.31479 \mathrm{E}+04 \\
0.41807 \mathrm{E}+04 \\
0.55526 \mathrm{E}+04 \\
0.73746 \mathrm{E}+04\end{array}$ & $\begin{array}{l}0.62183 E-04 \\
0.14611 E-03 \\
0.11521 E-03 \\
0.14165 E-03 \\
0.14196 E-03 \\
0.12321 E-03 \\
0.10430 E-03 \\
0.99587 E-04 \\
0.71465 E-04 \\
0.78535 E-04 \\
0.64198 E-04 \\
0.60913 E-04 \\
0.43881 E-04 \\
0.48076 E-04 \\
0.34504 E-04 \\
0.23218 E-04 \\
0.20009 E-04 \\
0.79757 E-05 \\
0.41587 E-05 \\
0.20106 E-05 \\
0.82264 E-06 \\
0.27558 E-06 \\
0.82798 E-07 \\
0.18050 E-07 \\
0.27067 E-08 \\
0.26959 E-09 \\
0.53739 E-10 \\
0.28763 E-10 \\
0.20372 E-10 \\
0.14371 E-10\end{array}$ \\
\hline
\end{tabular}


TABLE E.5.3

$\bar{u}^{2}$-SPECTRA OBTAINED WITH WIRE 5

\begin{tabular}{|c|c|c|c|c|c|}
\hline$y$ & $=8$ & {$[\mathrm{~mm}]$} & $\pi$ & $=0.614$ & \\
\hline$U$ & $=6.44$ & {$\left[\mathrm{~ms}^{-1}\right]$} & $\overline{u^{2}}$ & $=1.1776 \mathrm{E}-2$ & {$\left[m^{2} s^{-2}\right]$} \\
\hline$T$ & $=20$ & {$\left[{ }^{\circ} \mathrm{C}\right]$} & $P$ & $=742.7$ & [ $\mathrm{mm} \mathrm{Hg}]$ \\
\hline$\xi$ & $=2500$ & {$[\mathrm{~Hz}]$} & $\nu$ & $=1.54 \mathrm{E}-5$ & {$\left[m^{2} s^{-1}\right]$} \\
\hline
\end{tabular}

\begin{tabular}{|c|c|c|c|}
\hline$[\mathrm{Hz}]$ & $\begin{array}{c}\overline{u_{f}^{2}} \\
{\left[m^{2} s^{-2}\right]}\end{array}$ & $\begin{array}{c}K_{1} \\
{\left[m^{-1}\right]}\end{array}$ & $\begin{array}{r}E_{1}\left(k_{1}\right) \\
{\left[m^{3} s^{-2}\right]}\end{array}$ \\
\hline $\begin{array}{r}2.00 \\
2.66 \\
3.53 \\
4.69 \\
6.22 \\
8.26 \\
10.98 \\
14.58 \\
19.36 \\
25.72 \\
34.16 \\
45.36 \\
60.25 \\
80.02 \\
106.30 \\
141.14 \\
187.50 \\
248.97 \\
330.70 \\
439.17 \\
583.30 \\
774.70 \\
1028.90 \\
1366.50 \\
1814.90 \\
2410.40 \\
3201.40 \\
4251.80 \\
5647.01 \\
7500.00\end{array}$ & $\begin{array}{l}0.15400 E-03 \\
0.44000 E-03 \\
0.70100 E-03 \\
0.73800 E-03 \\
0.10480 E-02 \\
0.14070 E-02 \\
0.18580 E-02 \\
0.18570 E-02 \\
0.17240 E-02 \\
0.20950 E-02 \\
0.27430 E-02 \\
0.27480 E-02 \\
0.42520 E-02 \\
0.37290 E-02 \\
0.41880 E-02 \\
0.37620 E-02 \\
0.39100 E-02 \\
0.17470 E-02 \\
0.11940 E-02 \\
0.76500 E-03 \\
0.42700 E-03 \\
0.18600 E-03 \\
0.74700 E-04 \\
0.20400 E-04 \\
0.46200 E-05 \\
0.63700 E-06 \\
0.19800 E-06 \\
0.13800 E-06 \\
0.12800 E-06 \\
0.12000 E-06\end{array}$ & $\begin{array}{l}0.19513 \mathrm{E}+01 \\
0.25952 \mathrm{E}+01 \\
0.34440 \mathrm{E}+01 \\
0.45758 \mathrm{E}+01 \\
0.60685 \mathrm{E}+01 \\
0.80589 \mathrm{E}+01 \\
0.10713 \mathrm{E}+02 \\
0.14225 \mathrm{E}+02 \\
0.18889 \mathrm{E}+02 \\
0.25094 \mathrm{E}+02 \\
0.33328 \mathrm{E}+02 \\
0.44255 \mathrm{E}+02 \\
0.58783 \mathrm{E}+02 \\
0.78072 \mathrm{E}+02 \\
0.10371 \mathrm{E}+03 \\
0.13770 \mathrm{E}+03 \\
0.18293 \mathrm{E}+03 \\
0.24291 \mathrm{E}+03 \\
0.32265 \mathrm{E}+03 \\
0.42848 \mathrm{E}+03 \\
0.56910 \mathrm{E}+03 \\
0.75584 \mathrm{E}+03 \\
0.10038 \mathrm{E}+04 \\
0.13332 \mathrm{E}+04 \\
0.17707 \mathrm{E}+04 \\
0.23517 \mathrm{E}+04 \\
0.31234 \mathrm{E}+04 \\
0.41483 \mathrm{E}+04 \\
0.55095 \mathrm{E}+04 \\
0.73174 \mathrm{E}+04\end{array}$ & $\begin{array}{l}0.80278 E-04 \\
0.17246 E-03 \\
0.20704 E-03 \\
0.16405 E-03 \\
0.17566 E-03 \\
0.17759 E-03 \\
0.17642 E-03 \\
0.13279 E-03 \\
0.92841 E-04 \\
0.84922 E-04 \\
0.83717 E-04 \\
0.63161 E-04 \\
0.73577 E-04 \\
0.48585 E-04 \\
0.41075 E-04 \\
0.27789 E-04 \\
0.21741 E-04 \\
0.73156 E-05 \\
0.37642 E-05 \\
0.18161 E-05 \\
0.76321 E-06 \\
0.25031 E-06 \\
0.75693 E-07 \\
0.15564 E-07 \\
0.26540 E-08 \\
0.27552 E-09 \\
0.64481 E-10 \\
0.33839 E-10 \\
0.23632 E-10 \\
0.16681 E-10\end{array}$ \\
\hline
\end{tabular}


TABLE E.5.4

$\overline{u^{2}}$-SPECTRA OBTAINED WITH WIRE 5

$\begin{array}{llll}Y=12 & {[\mathrm{~mm}]} & \eta=0.921 & \\ U=6.50 & {[\mathrm{~ms}-1]} & \overrightarrow{u^{2}}=1.2345 \mathrm{E}-2\left[\mathrm{~m}^{2} \mathrm{~s}^{-2}\right] \\ T=20 & {\left[{ }^{\circ} \mathrm{C}\right]} & \mathrm{P}=742.7 & {[\mathrm{~mm} \mathrm{Hg}]} \\ E_{K}=2400 & {[\mathrm{~Hz}]} & \nu=1.54 \mathrm{E}-5 & {\left[\mathrm{~m}^{2} \mathrm{~s}^{-1}\right]}\end{array}$

\begin{tabular}{|c|c|c|c|}
\hline $\begin{array}{c}f \\
{[\mathrm{~Hz}]}\end{array}$ & $\begin{array}{c}\overline{u^{2}} \\
f \\
{\left[m^{2} s^{-2}\right]}\end{array}$ & $\begin{array}{c}K_{1} \\
{\left[m^{-1}\right]}\end{array}$ & $\begin{array}{r}E_{1}\left(k_{1}\right) \\
{\left[m^{3} s^{-2}\right]}\end{array}$ \\
\hline $\begin{array}{r}2.00 \\
2.66 \\
3.53 \\
4.69 \\
6.22 \\
8.26 \\
10.98 \\
14.58 \\
19.36 \\
25.72 \\
34.16 \\
45.36 \\
60.25 \\
80.02 \\
106.30 \\
141.14 \\
187.50 \\
248.97 \\
330.70 \\
439.17 \\
583.30 \\
774.70 \\
1028.90 \\
1366.50 \\
1814.90 \\
2410.40 \\
3201.40 \\
4251.80 \\
5647.01 \\
7500.00\end{array}$ & $\begin{array}{l}0.22100 E-03 \\
0.65200 E-03 \\
0.74400 E-03 \\
0.14360 E-02 \\
0.13460 E-02 \\
0.15420 E-02 \\
0.14450 E-02 \\
0.19710 E-02 \\
0.25130 E-02 \\
0.28490 E-02 \\
0.29890 E-02 \\
0.30250 E-02 \\
0.40200 E-02 \\
0.49060 E-02 \\
0.45450 E-02 \\
0.30130 E-02 \\
0.33670 E-02 \\
0.17140 E-02 \\
0.10170 E-02 \\
0.67700 E-03 \\
0.34600 E-03 \\
0.15300 E-03 \\
0.60700 E-04 \\
0.17000 E-04 \\
0.35700 E-05 \\
0.53100 E-06 \\
0.18700 E-06 \\
0.14400 E-06 \\
0.13100 E-06 \\
0.12100 E-06\end{array}$ & $\begin{array}{l}0.19333 \mathrm{E}+01 \\
0.25713 \mathrm{E}+01 \\
0.34123 \mathrm{E}+01 \\
0.45336 \mathrm{E}+01 \\
0.60125 \mathrm{E}+01 \\
0.79845 \mathrm{E}+01 \\
0.10614 \mathrm{E}+02 \\
0.14094 \mathrm{E}+02 \\
0.18714 \mathrm{E}+02 \\
0.24862 \mathrm{E}+02 \\
0.33021 \mathrm{E}+02 \\
0.43847 \mathrm{E}+02 \\
0.58240 \mathrm{E}+02 \\
0.77351 \mathrm{E}+02 \\
0.10275 \mathrm{E}+03 \\
0.13643 \mathrm{E}+03 \\
0.18125 \mathrm{E}+03 \\
0.24067 \mathrm{E}+03 \\
0.31967 \mathrm{E}+03 \\
0.42452 \mathrm{E}+03 \\
0.56384 \mathrm{E}+03 \\
0.74886 \mathrm{E}+03 \\
0.99458 \mathrm{E}+03 \\
0.13209 \mathrm{E}+04 \\
0.17544 \mathrm{E}+04 \\
0.23300 \mathrm{E}+04 \\
0.30946 \mathrm{E}+04 \\
0.41100 \mathrm{E}+04 \\
0.54586 \mathrm{E}+04 \\
0.72498 \mathrm{E}+04\end{array}$ & $\begin{array}{l}0.11230 E-03 \\
0.24912 E-03 \\
0.21421 E-03 \\
0.31118 E-03 \\
0.21993 E-03 \\
0.18973 E-03 \\
0.13375 E-03 \\
0.13739 E-03 \\
0.13192 E-03 \\
0.11258 E-03 \\
0.88929 E-04 \\
0.67778 E-04 \\
0.67812 E-04 \\
0.62311 E-04 \\
0.43455 E-04 \\
0.21696 E-04 \\
0.18251 E-04 \\
0.69968 E-05 \\
0.31255 E-05 \\
0.15667 E-05 \\
0.60287 E-06 \\
0.20072 E-06 \\
0.59959 E-07 \\
0.12644 E-07 \\
0.19992 E-08 \\
0.22389 E-09 \\
0.59366 E-10 \\
0.34421 E-10 \\
0.23577 E-10 \\
0.16397 E-10\end{array}$ \\
\hline
\end{tabular}


TABLE E.5.5

$\overline{u^{2}}$-SPECTRA OBTAINED WITH WIRE 5

\begin{tabular}{|c|c|c|c|c|c|}
\hline$y$ & $=16$ & {$[\mathrm{~mm}]$} & $\eta$ & $=1.228$ & \\
\hline$U$ & $=6.56$ & {$\left[\mathrm{~ms}^{-1}\right]$} & $\overline{u^{2}}$ & $=1.0008 \mathrm{E}-2$ & {$\left[m^{2} s^{-2}\right]$} \\
\hline $\mathrm{T}$ & $=20$ & {$\left[{ }^{\circ} \mathrm{C}\right]$} & $\mathrm{P}$ & $=742.7$ & [mm $\mathrm{Hg}]$ \\
\hline$E_{K}$ & $=2200$ & {$[\mathrm{~Hz}]$} & $\nu$ & $=1.54 \mathrm{E}-5$ & {$\left[m^{2} s^{-1}\right]$} \\
\hline
\end{tabular}

\begin{tabular}{|c|c|c|c|}
\hline $\begin{array}{c}f \\
{[\mathrm{~Hz}]}\end{array}$ & $\begin{array}{c}\overline{u^{2}} \\
f \\
{\left[m^{2} s^{-2}\right]}\end{array}$ & $\begin{array}{c}\mathrm{K}_{1} \\
{\left[\mathrm{~m}^{-1}\right]}\end{array}$ & $\begin{array}{c}E_{1}\left(K_{1}\right) \\
{\left[m^{3} s^{-2}\right]}\end{array}$ \\
\hline $\begin{array}{r}2.00 \\
2.66 \\
3.53 \\
4.69 \\
6.22 \\
8.26 \\
10.98 \\
14.58 \\
19.36 \\
25.72 \\
34.16 \\
45.36 \\
60.25 \\
80.02 \\
106.30 \\
141.14 \\
187.50 \\
248.97 \\
330.70 \\
439.17 \\
583.30 \\
774.70 \\
1028.90 \\
1366.50 \\
1814.90 \\
2410.40 \\
3201.40 \\
4251.80 \\
5647.01\end{array}$ & $\begin{array}{l}0.19900 \mathrm{E}-03 \\
0.50600 \mathrm{E}-03 \\
0.58300 \mathrm{E}-03 \\
0.91700 \mathrm{E}-03 \\
0.11590 \mathrm{E}-02 \\
0.16190 \mathrm{E}-02 \\
0.14040 \mathrm{E}-02 \\
0.15020 \mathrm{E}-02 \\
0.21500 \mathrm{E}-02 \\
0.20610 \mathrm{E}-02 \\
0.27460 \mathrm{E}-02 \\
0.2955 \mathrm{E}-02 \\
0.29980 \mathrm{E}-02 \\
0.30200 \mathrm{E}-02 \\
0.34320 \mathrm{E}-02 \\
0.34110 \mathrm{E}-02 \\
0.22410 \mathrm{O}-02 \\
0.13360 \mathrm{E}-02 \\
0.77900 \mathrm{E}-03 \\
0.42700 \mathrm{E}-03 \\
0.20500 \mathrm{E}-03 \\
0.10400 \mathrm{E}-03 \\
0.32900 \mathrm{E}-04 \\
0.82000 \mathrm{E}-05 \\
0.23300 \mathrm{E}-05 \\
0.30500 \mathrm{E}-06 \\
0.14400 \mathrm{E}-06 \\
0.11300 \mathrm{E}-06 \\
0.10800 \mathrm{E}-06\end{array}$ & $\begin{array}{l}0.19156 \mathrm{E}+01 \\
0.25478 \mathrm{E}+01 \\
0.33810 \mathrm{E}+01 \\
0.44921 \mathrm{E}+01 \\
0.59575 \mathrm{E}+01 \\
0.79115 \mathrm{E}+01 \\
0.10517 \mathrm{E}+02 \\
0.13965 \mathrm{E}+02 \\
0.18543 \mathrm{E}+02 \\
0.24635 \mathrm{E}+02 \\
0.32719 \mathrm{E}+02 \\
0.43446 \mathrm{E}+02 \\
0.57708 \mathrm{E}+02 \\
0.76643 \mathrm{E}+02 \\
0.10181 \mathrm{E}+03 \\
0.13518 \mathrm{E}+03 \\
0.17959 \mathrm{E}+03 \\
0.23846 \mathrm{E}+03 \\
0.31675 \mathrm{E}+03 \\
0.42064 \mathrm{E}+03 \\
0.55869 \mathrm{E}+03 \\
0.74201 \mathrm{E}+03 \\
0.98548 \mathrm{E}+03 \\
0.13088 \mathrm{E}+04 \\
0.17383 \mathrm{E}+04 \\
0.23087 \mathrm{E}+04 \\
0.30663 \mathrm{E}+04 \\
0.40724 \mathrm{E}+04 \\
0.54087 \mathrm{E}+04\end{array}$ & $\begin{array}{l}0.10257 \mathrm{E}-03 \\
0.19610 \mathrm{E}-03 \\
0.17025 \mathrm{E}-03 \\
0.20156 \mathrm{E}-03 \\
0.19209 \mathrm{E}-03 \\
0.20205 \mathrm{E}-03 \\
0.13182 \mathrm{E}-03 \\
0.10620 \mathrm{E}-03 \\
0.11448 \mathrm{E}-03 \\
0.82605 \mathrm{E}-04 \\
0.82868 \mathrm{E}-04 \\
0.67156 \mathrm{E}-04 \\
0.51295 \mathrm{E}-04 \\
0.38905 \mathrm{E}-04 \\
0.33282 \mathrm{E}-04 \\
0.24913 \mathrm{E}-04 \\
0.12321 \mathrm{E}-04 \\
0.55317 \mathrm{E}-05 \\
0.24283 \mathrm{E}-05 \\
0.10023 \mathrm{E}-05 \\
0.36230 \mathrm{E}-06 \\
0.13839 \mathrm{E}-06 \\
0.32963 \mathrm{E}-07 \\
0.61859 \mathrm{E}-08 \\
0.13234 \mathrm{E}-08 \\
0.13044 \mathrm{E}-09 \\
0.46369 \mathrm{E}-10 \\
0.27397 \mathrm{E}-10 \\
0.19715 \mathrm{E}-10\end{array}$ \\
\hline
\end{tabular}


TABLE E.5.6

$\overline{u^{2}}$-SPECTRA OBTAINED WITH WIRE 5

$$
\begin{aligned}
& y=20 \quad[\mathrm{~mm}] \quad \eta=1.535 \\
& U=6.63\left[\mathrm{~ms}^{-1}\right] \quad \overline{\mathrm{u}^{2}}=6.4336 \mathrm{E}-3\left[\mathrm{~m}^{2} \mathrm{~s}^{-2}\right] \\
& T=20 \quad\left[{ }^{\circ} \mathrm{C}\right] \quad P=742.7 \quad[\mathrm{~mm} \mathrm{Hg}] \\
& f_{K}=2000[\mathrm{~Hz}] \quad \nu=1.54 \mathrm{E}-5 \quad\left[\mathrm{~m}^{2} \mathrm{~s}^{-1}\right]
\end{aligned}
$$

\begin{tabular}{|c|c|c|c|}
\hline$[\mathrm{Hz}]$ & $\begin{array}{l}\overline{u_{f}^{2}} \\
{\left[m^{2} s^{-2}\right]}\end{array}$ & $\begin{array}{c}K_{1} \\
{\left[m^{-1}\right]}\end{array}$ & $\begin{array}{c}E_{1}\left(k_{1}\right) \\
{\left[m^{3} s^{-2}\right]}\end{array}$ \\
\hline $\begin{array}{r}2.00 \\
2.66 \\
3.53 \\
4.69 \\
6.22 \\
8.26 \\
10.98 \\
14.58 \\
19.36 \\
25.72 \\
34.16 \\
45.36 \\
60.25 \\
80.02 \\
106.30 \\
141.14 \\
187.50 \\
248.97 \\
330.70 \\
439.17 \\
583.30 \\
774.70 \\
1028.90 \\
1366.50 \\
1814.90 \\
2410.40 \\
3201.40 \\
4251.80\end{array}$ & $\begin{array}{l}0.11000 E-03 \\
0.27500 E-03 \\
0.32400 E-03 \\
0.49800 E-03 \\
0.72900 E-03 \\
0.78600 E-03 \\
0.83700 E-03 \\
0.11610 E-02 \\
0.12710 E-02 \\
0.14320 E-02 \\
0.18510 E-02 \\
0.20310 E-02 \\
0.23270 E-02 \\
0.20360 E-02 \\
0.23040 E-02 \\
0.20130 E-02 \\
0.19560 E-02 \\
0.80600 E-03 \\
0.46100 E-03 \\
0.30600 E-03 \\
0.12500 E-03 \\
0.72800 E-04 \\
0.23600 E-04 \\
0.72400 E-05 \\
0.11900 E-05 \\
0.15600 E-06 \\
0.11000 E-06 \\
0.79000 E-07\end{array}$ & $\begin{array}{l}0.18954 \mathrm{E}+01 \\
0.25209 \mathrm{E}+01 \\
0.33453 \mathrm{E}+01 \\
0.44447 \mathrm{E}+01 \\
0.58946 \mathrm{E}+01 \\
0.78279 \mathrm{E}+01 \\
0.10406 \mathrm{E}+02 \\
0.13817 \mathrm{E}+02 \\
0.18347 \mathrm{E}+02 \\
0.24375 \mathrm{E}+02 \\
0.32373 \mathrm{E}+02 \\
0.42987 \mathrm{E}+02 \\
0.57098 \mathrm{E}+02 \\
0.75834 \mathrm{E}+02 \\
0.10074 \mathrm{E}+03 \\
0.13376 \mathrm{E}+03 \\
0.17769 \mathrm{E}+03 \\
0.23595 \mathrm{E}+03 \\
0.31340 \mathrm{E}+03 \\
0.41620 \mathrm{E}+03 \\
0.55279 \mathrm{E}+03 \\
0.73418 \mathrm{E}+03 \\
0.97508 \mathrm{E}+03 \\
0.12950 \mathrm{E}+04 \\
0.17200 \mathrm{E}+04 \\
0.22843 \mathrm{E}+04 \\
0.30339 \mathrm{E}+04 \\
0.40294 \mathrm{E}+04\end{array}$ & $\begin{array}{l}0.56208 E-04 \\
0.10565 E-03 \\
0.93800 E-04 \\
0.10851 E-03 \\
0.11978 E-03 \\
0.97247 E-04 \\
0.77903 E-04 \\
0.81378 E-04 \\
0.67092 E-04 \\
0.56899 E-04 \\
0.55376 E-04 \\
0.45758 E-04 \\
0.39470 E-04 \\
0.26002 E-04 \\
0.22150 E-04 \\
0.14576 E-04 \\
0.10661 E-04 \\
0.33084 E-05 \\
0.14246 E-05 \\
0.71207 E-06 \\
0.21900 E-06 \\
0.96035 E-07 \\
0.23441 E-07 \\
0.54145 E-08 \\
0.67008 E-09 \\
0.66141 E-10 \\
0.35114 E-10 \\
0.18988 E-10\end{array}$ \\
\hline
\end{tabular}


TABLE E.5.7

$\overline{u^{2}}$-SPECTRA OBTAINED WITH WIRE 5

\begin{tabular}{|c|c|c|c|c|c|}
\hline$y$ & $=24$ & {$[\mathrm{~mm}]$} & $\eta$ & $=1.842$ & \\
\hline U & $=6.66$ & {$\left[\mathrm{~ms}^{-1}\right]$} & $\overline{u^{2}}$ & $=2.4487 \mathrm{E}-3$ & {$\left[\mathrm{~m}^{2} \mathrm{~s}^{-2}\right]$} \\
\hline$T$ & $=20$ & {$\left[{ }^{\circ} \mathrm{C}\right]$} & $\mathrm{P}$ & $=742.7$ & [mm $\mathrm{Hg}]$ \\
\hline$E_{K}$ & $=1700$ & {$[\mathrm{~Hz}]$} & $\nu$ & $=1.54 \mathrm{E}-5$ & {$\left[m^{2} s^{-1}\right]$} \\
\hline
\end{tabular}

\begin{tabular}{|c|c|c|c|}
\hline$[\mathrm{Hz}]$ & $\begin{array}{l}\overline{u_{f}^{2}} \\
{\left[m^{2} s^{-2}\right]}\end{array}$ & {$\left[m^{-1}\right]$} & $\begin{array}{c}E_{1}\left(K_{1}\right) \\
{\left[m^{3} s^{-2}\right]}\end{array}$ \\
\hline $\begin{array}{r}2.00 \\
2.66 \\
3.53 \\
4.69 \\
6.22 \\
8.26 \\
10.98 \\
14.58 \\
19.36 \\
25.72 \\
34.16 \\
45.36 \\
60.25 \\
80.02 \\
106.30 \\
141.14 \\
187.50 \\
248.97 \\
330.70 \\
439.17 \\
583.30 \\
774.70 \\
1028.90 \\
1366.50 \\
1814.90 \\
2410.40 \\
3201.40 \\
4251.80\end{array}$ & 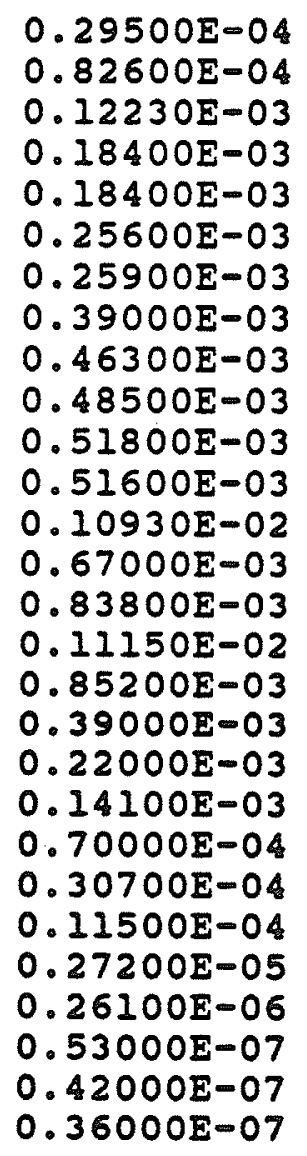 & $\begin{array}{l}0.18868 E+01 \\
0.25095 \mathrm{E}+01 \\
0.33303 \mathrm{E}+01 \\
0.44246 \mathrm{E}+01 \\
0.58681 \mathrm{I}+01 \\
0.77927 \mathrm{E}+01 \\
0.10359 \mathrm{I}+02 \\
0.13755 \mathrm{E}+02 \\
0.18265 \mathrm{E}+02 \\
0.24265 \mathrm{E}+02 \\
0.32227 \mathrm{E}+02 \\
0.42794 \mathrm{E}+02 \\
0.56841 \mathrm{E}+02 \\
0.75493 \mathrm{E}+02 \\
0.10029 \mathrm{E}+03 \\
0.13315 \mathrm{E}+03 \\
0.17689 \mathrm{E}+03 \\
0.23488 \mathrm{E}+03 \\
0.31199 \mathrm{E}+03 \\
0.41432 \mathrm{E}+03 \\
0.55030 \mathrm{E}+03 \\
0.73087 \mathrm{E}+03 \\
0.97069 \mathrm{E}+03 \\
0.12892 \mathrm{E}+04 \\
0.17122 \mathrm{E}+04 \\
0.22740 \mathrm{E}+04 \\
0.30203 \mathrm{E}+04 \\
0.40112 \mathrm{E}+04\end{array}$ & $\begin{array}{l}0.15363 E-04 \\
0.32343 E-04 \\
0.36086 E-04 \\
0.40863 E-04 \\
0.30812 E-04 \\
0.32281 E-04 \\
0.24569 E-04 \\
0.27861 E-04 \\
0.24909 E-04 \\
0.19641 E-04 \\
0.15794 E-04 \\
0.11848 E-04 \\
0.18895 E-04 \\
0.87209 E-05 \\
0.82110 E-05 \\
0.82283 E-05 \\
0.47329 E-05 \\
0.16316 E-05 \\
0.69291 E-06 \\
0.33441 E-06 \\
0.12500 E-06 \\
0.41275 E-07 \\
0.11642 E-07 \\
0.20732 E-08 \\
0.14979 E-09 \\
0.22902 E-10 \\
0.13665 E-10 \\
0.88189 E-111\end{array}$ \\
\hline
\end{tabular}


TABLE E.5.8

$\overline{u^{2}}$-SPECTRA OBTAINED WITH WIRE 5

\begin{tabular}{|c|c|c|c|c|c|}
\hline$y$ & $=28$ & {$[\mathrm{~mm}]$} & $\eta$ & $=2.149$ & \\
\hline $\mathrm{U}$ & $=6.69$ & {$\left[\mathrm{~ms}^{-1}\right]$} & $\overline{\mathrm{u}^{2}}$ & $=8.3222 \mathrm{E}-4$ & {$\left[m^{2} s^{-2}\right]$} \\
\hline$T$ & $=20$ & {$\left[{ }^{\circ} \mathrm{C}\right]$} & $\mathrm{P}$ & $=742.7$ & [mm $\mathrm{Hg}]$ \\
\hline$E_{k}$ & $=1100$ & {$[\mathrm{~Hz}]$} & $\nu$ & $=1.54 E-5$ & {$\left[m^{2} s^{-1}\right]$} \\
\hline
\end{tabular}

\begin{tabular}{|c|c|c|c|}
\hline $\begin{array}{c}£ \\
{[\mathrm{~Hz}]}\end{array}$ & $\begin{array}{l}\overline{u_{f}^{2}} \\
{\left[m^{2} s^{-2}\right]}\end{array}$ & $\begin{array}{c}K_{1} \\
{\left[m^{-1}\right]}\end{array}$ & $\begin{array}{c}E_{1}\left(K_{1}\right) \\
{\left[m^{3} s^{-2}\right]}\end{array}$ \\
\hline $\begin{array}{r}2.00 \\
2.66 \\
3.53 \\
4.69 \\
6.22 \\
8.26 \\
10.98 \\
14.58 \\
19.36 \\
25.72 \\
34.16 \\
45.36 \\
60.25 \\
80.02 \\
106.30 \\
141.14 \\
187.50 \\
248.97 \\
330.70 \\
439.17 \\
583.30 \\
774.70 \\
1028.90 \\
1366.50 \\
1814.90 \\
2410.40 \\
3201.40\end{array}$ & $\begin{array}{l}0.52100 E-05 \\
0.20400 E-04 \\
0.30400 E-04 \\
0.37700 E-04 \\
0.37100 E-04 \\
0.40700 E-04 \\
0.61200 E-04 \\
0.98900 E-04 \\
0.16930 E-03 \\
0.13060 E-03 \\
0.16780 E-03 \\
0.18800 E-03 \\
0.53300 E-03 \\
0.24100 E-03 \\
0.34700 E-03 \\
0.35600 E-03 \\
0.28000 E-03 \\
0.12300 E-03 \\
0.82000 E-04 \\
0.52200 E-04 \\
0.25100 E-04 \\
0.10000 E-04 \\
0.28000 E-05 \\
0.20000 E-06 \\
0.28000 E-07 \\
0.23000 E-07 \\
0.21000 E-07\end{array}$ & $\begin{array}{l}0.18784 E+01 \\
0.24982 E+01 \\
0.33153 E+01 \\
0.44048 E+01 \\
0.58418 E+01 \\
0.77577 E+01 \\
0.10312 E+02 \\
0.13693 E+02 \\
0.18183 E+02 \\
0.24156 E+02 \\
0.32083 E+02 \\
0.42602 E+02 \\
0.56586 E+02 \\
0.75154 E+02 \\
0.99836 E+02 \\
0.13256 E+03 \\
0.17610 E+03 \\
0.23383 E+03 \\
0.31059 E+03 \\
0.41246 E+03 \\
0.54783 E+03 \\
0.72759 E+03 \\
0.96633 E+03 \\
0.12834 E+04 \\
0.17045 E+04 \\
0.22638 E+04 \\
0.30067 E+04\end{array}$ & $\begin{array}{l}0.28141 E-05 \\
0.82847 E-05 \\
0.93031 E-05 \\
0.86836 E-05 \\
0.64434 E-05 \\
0.53229 E-05 \\
0.60211 E-05 \\
0.73277 E-05 \\
0.94467 E-05 \\
0.54853 E-05 \\
0.53065 E-05 \\
0.44773 E-05 \\
0.95565 E-05 \\
0.32535 E-05 \\
0.35264 E-05 \\
0.27248 E-05 \\
0.16132 E-05 \\
0.53369 E-06 \\
0.26786 E-06 \\
0.12840 E-06 \\
0.46485 E-07 \\
0.13944 E-07 \\
0.29398 E-08 \\
0.15811 E-09 \\
0.16666 E-10 \\
0.10308 E-10 \\
0.70861 E-111\end{array}$ \\
\hline
\end{tabular}


TABLE F

DISSIPATION OBTAINED WITH DIFFERENT WIRES AND THE CORRESPONDING ZERO-LENGTH EXTRAPOLATED VALUES

All values normalized by $L / U_{0}{ }^{3}$

\begin{tabular}{|c|c|c|c|c|c|c|}
\hline $\begin{array}{l}Y \\
{[\mathrm{~mm}]}\end{array}$ & $\begin{array}{c}\text { Wire } \\
\epsilon_{1}\end{array}$ & $\begin{array}{c}\text { Wire } \\
\epsilon_{2}\end{array}$ & $\begin{array}{c}\text { Wire } 3 \\
\epsilon_{3}\end{array}$ & $\begin{array}{c}\text { Wire } \\
\epsilon_{4}\end{array}$ & $\begin{array}{c}\text { Wire } \\
\epsilon_{5}\end{array}$ & $\begin{array}{c}\text { Zero - } \\
\text { length } \\
\epsilon\end{array}$ \\
\hline 0 & 0.02620 & 0.02490 & 0.02430 & 0.02200 & 0.02040 & 0.02860 \\
\hline 4 & 0.02748 & 0.02535 & 0.02410 & 0.02220 & 0.02030 & 0.03000 \\
\hline 8 & 0.02700 & 0.02510 & 0.02420 & 0.02130 & 0.01910 & 0.03020 \\
\hline 12 & 0.02270 & 0.02005 & 0.01970 & 0.01750 & 0.01600 & 0.02490 \\
\hline 16 & 0.01637 & 0.01510 & 0.01410 & 0.01190 & 0.01100 & 0.01860 \\
\hline 20 & 0.01060 & 0.01020 & 0.00990 & 0.00796 & 0.00724 & 0.01230 \\
\hline 24 & 0.00560 & 0.00470 & 0.00480 & 0.00372 & 0.00333 & 0.00640 \\
\hline 28 & 0.00203 & 0.00160 & 0.00180 & 0.00127 & 0.00110 & 0.00235 \\
\hline
\end{tabular}


TABLE G

AVERAGE TURBULENT KINETIC ENERGY BUDGET IN THE WAKE

All terms normalized by $\mathrm{L} / \mathrm{U}_{0}{ }^{3}$

\begin{tabular}{|c|c|c|c|c|c|}
\hline $\begin{array}{l}y \\
{[\mathrm{~mm}]}\end{array}$ & Production & $\begin{array}{l}\text { Diffusion } \\
\text { of } q_{2}\end{array}$ & Advection & Dissipation & $\begin{array}{l}\text { Pressure } \\
\text { diffusion }\end{array}$ \\
\hline 0 & 0.00000 & +0.01530 & +0.01522 & -0.02860 & -0.00190 \\
\hline 2 & +0.00230 & +0.00530 & +0.01546 & -0.02920 & +0.00614 \\
\hline 4 & +0.00840 & -0.00100 & +0.01626 & -0.03000 & +0.00634 \\
\hline 6 & +0.01600 & -0.00910 & +0.01736 & -0.03040 & +0.00614 \\
\hline 8 & +0.02260 & -0.01540 & +0.01813 & -0.03020 & +0.00487 \\
\hline 10 & +0.02650 & -0.02110 & +0.01805 & -0.02780 & +0.00435 \\
\hline 12 & +0.02660 & -0.01700 & +0.01565 & -0.02490 & -0.00035 \\
\hline 14 & +0.02370 & -0.01220 & +0.01116 & -0.02170 & -0.00096 \\
\hline 16 & +0.01910 & -0.00590 & +0.00636 & -0.01860 & -0.00096 \\
\hline 18 & +0.01390 & +0.00680 & +0.00164 & -0.01560 & -0.00674 \\
\hline 20 & +0.00930 & +0.01280 & -0.00355 & -0.01230 & -0.00625 \\
\hline 22 & +0.00570 & +0.01300 & -0.00643 & -0.00870 & -0.00357 \\
\hline 24 & +0.00330 & +0.01260 & -0.00628 & -0.00640 & -0.00322 \\
\hline 26 & +0.00170 & +0.00930 & -0.00538 & -0.00400 & -0.00162 \\
\hline 28 & +0.00080 & +0.00690 & -0.00446 & -0.00235 & -0.00089 \\
\hline 30 & +0.00040 & +0.00370 & -0.00306 & -0.00100 & -0.00004 \\
\hline
\end{tabular}


TABLE H

VALUES OF THE FACTOR J ACROSS THE WAKE

\begin{tabular}{lccccc}
\hline $\mathrm{y}$ & $\left(\overline{\mathrm{u}^{2}}\right)^{3 / 2}$ & $\mathrm{E}_{1}(0)$ & $\mathrm{L}_{f}$ & $\begin{array}{c}\epsilon \\
\text { zero- } \\
\text { length })\end{array}$ & $\mathrm{J}$ \\
{$[\mathrm{mm}]$} & {$\left[\mathrm{m}^{3} \mathrm{~s}^{-3}\right]$} & {$\left[\mathrm{m}^{3} \mathrm{~s}^{-2}\right]$} & {$[\mathrm{m}]$} & $\left.\mathrm{m}^{2} \mathrm{~s}^{-3}\right]$ & \\
\hline 0 & 0.001118 & $0.107 \mathrm{E}-3$ & 0.015607 & 0.10241 & 1.43 \\
4 & 0.001179 & $0.133 \mathrm{E}-3$ & 0.018722 & 0.10742 & 1.70 \\
8 & 0.001442 & $0.225 \mathrm{E}-3$ & 0.027680 & 0.10814 & 2.07 \\
12 & 0.001524 & $0.286 \mathrm{E}-3$ & 0.033930 & 0.08916 & 1.98 \\
16 & 0.001173 & $0.190 \mathrm{E}-3$ & 0.026840 & 0.06660 & 1.52 \\
20 & 0.000585 & $0.124 \mathrm{E}-3$ & 0.027840 & 0.04404 & 2.09 \\
24 & 0.000189 & $0.515 \mathrm{E}-4$ & 0.024550 & 0.02292 & 2.97 \\
& 0.000041 & $0.132 \mathrm{E}-4$ & 0.017320 & 0.00841 & 3.55 \\
\hline & & & & & \\
\hline
\end{tabular}



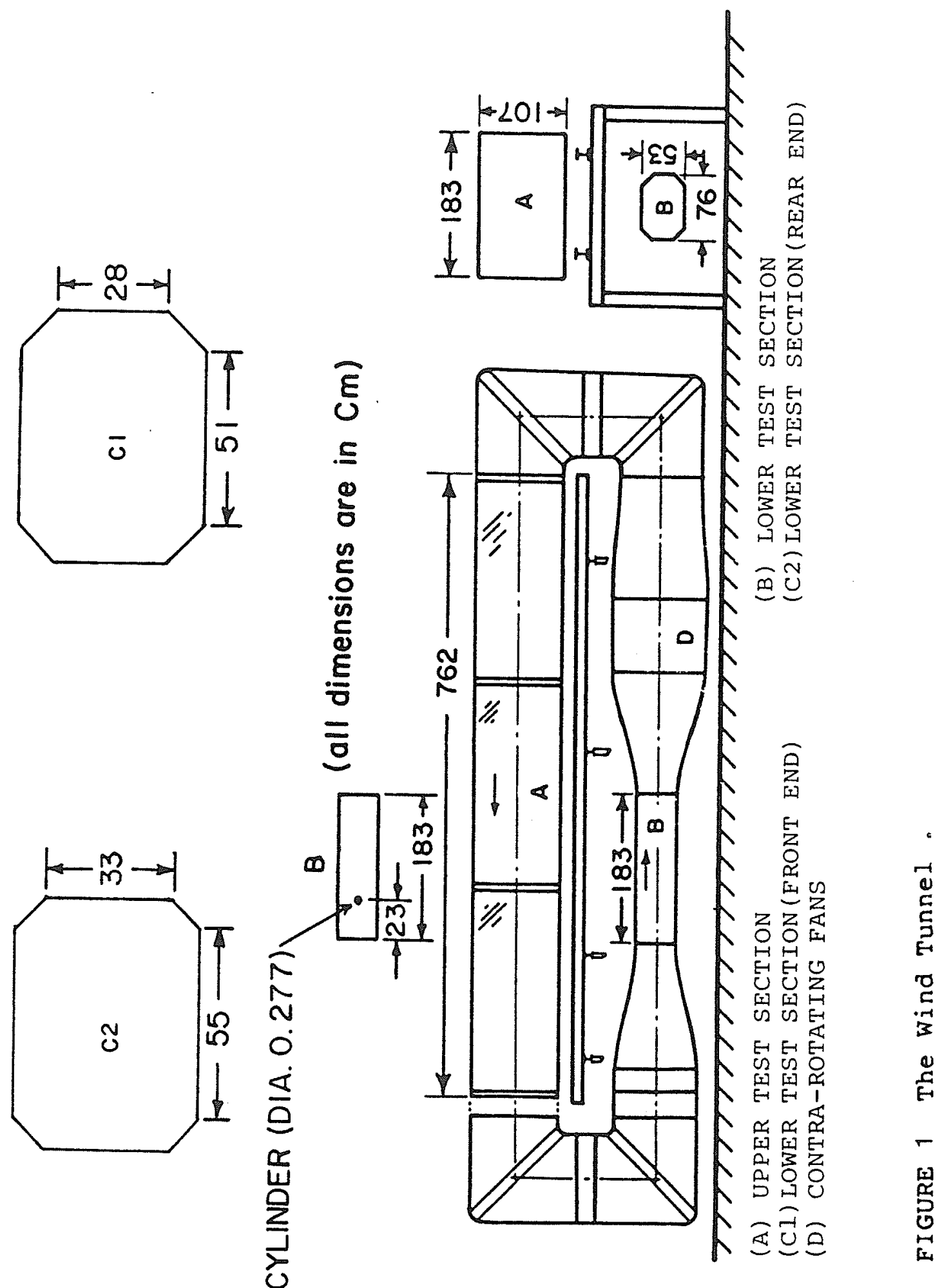


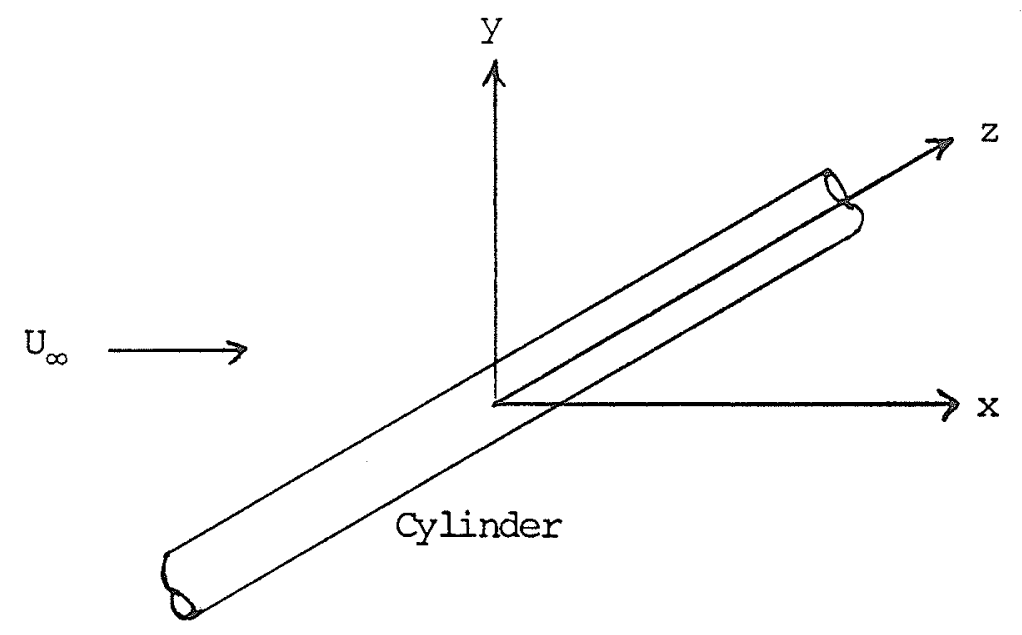

Figure 2(a) The coordinate system.

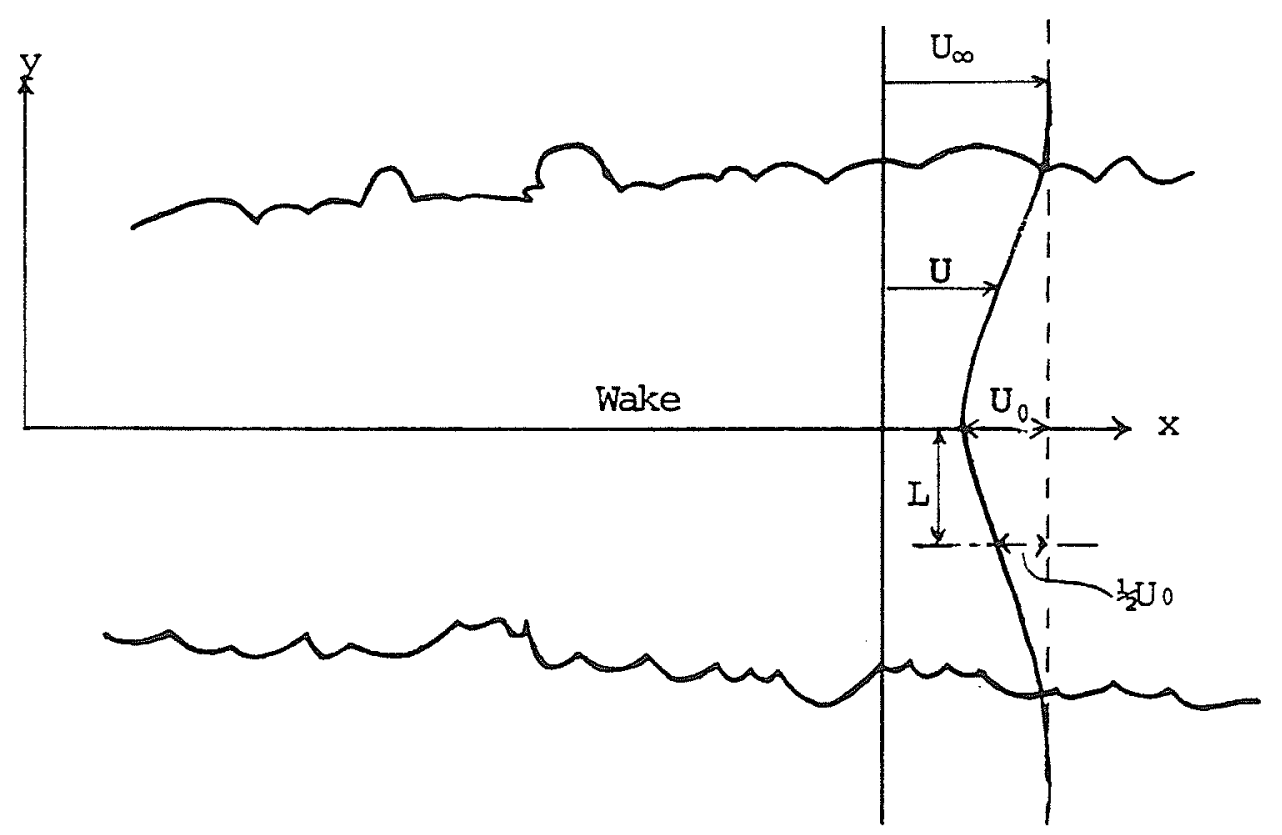

Figure 2 (b) Sketch of a plane turbulent wake. 


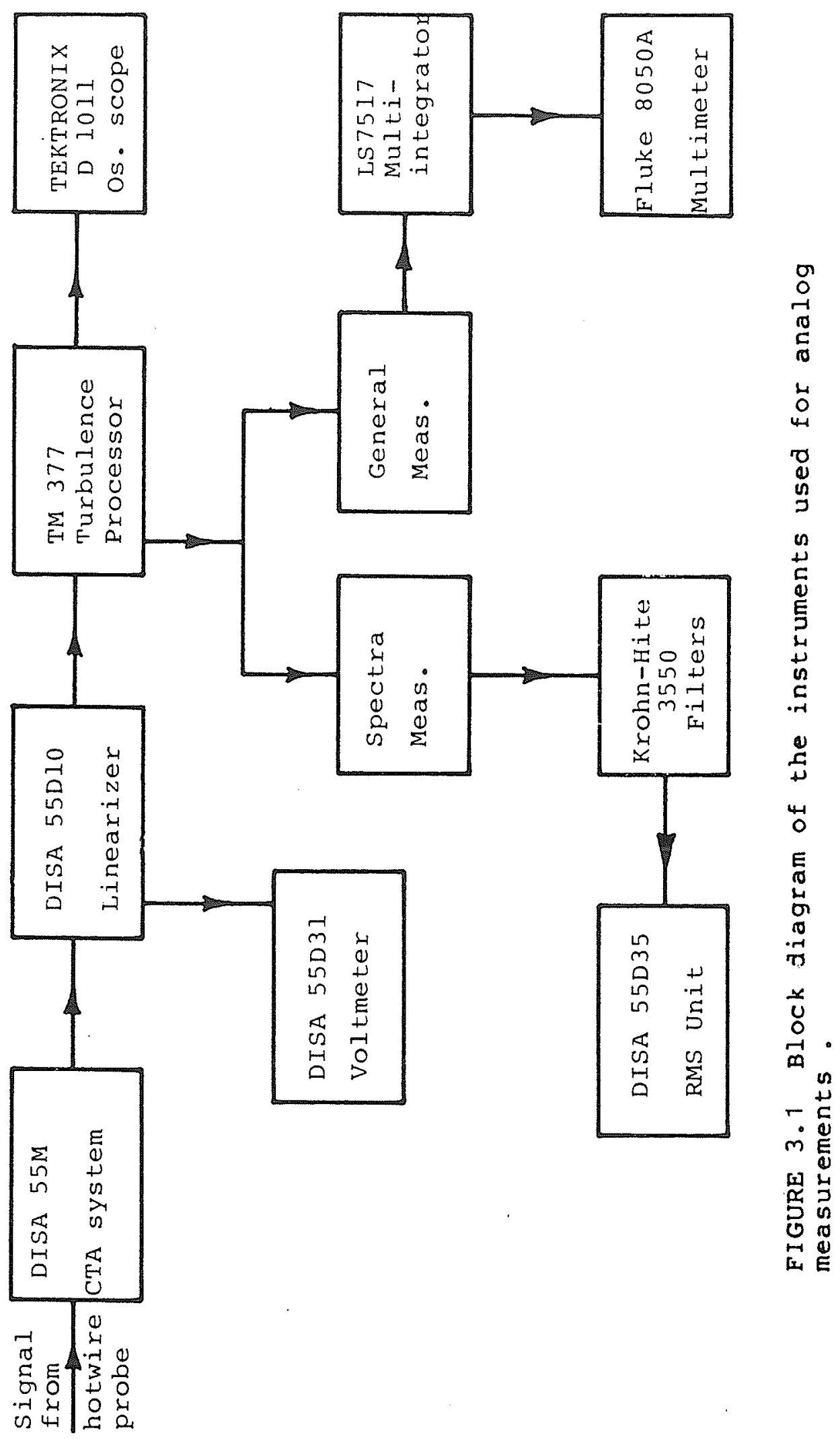




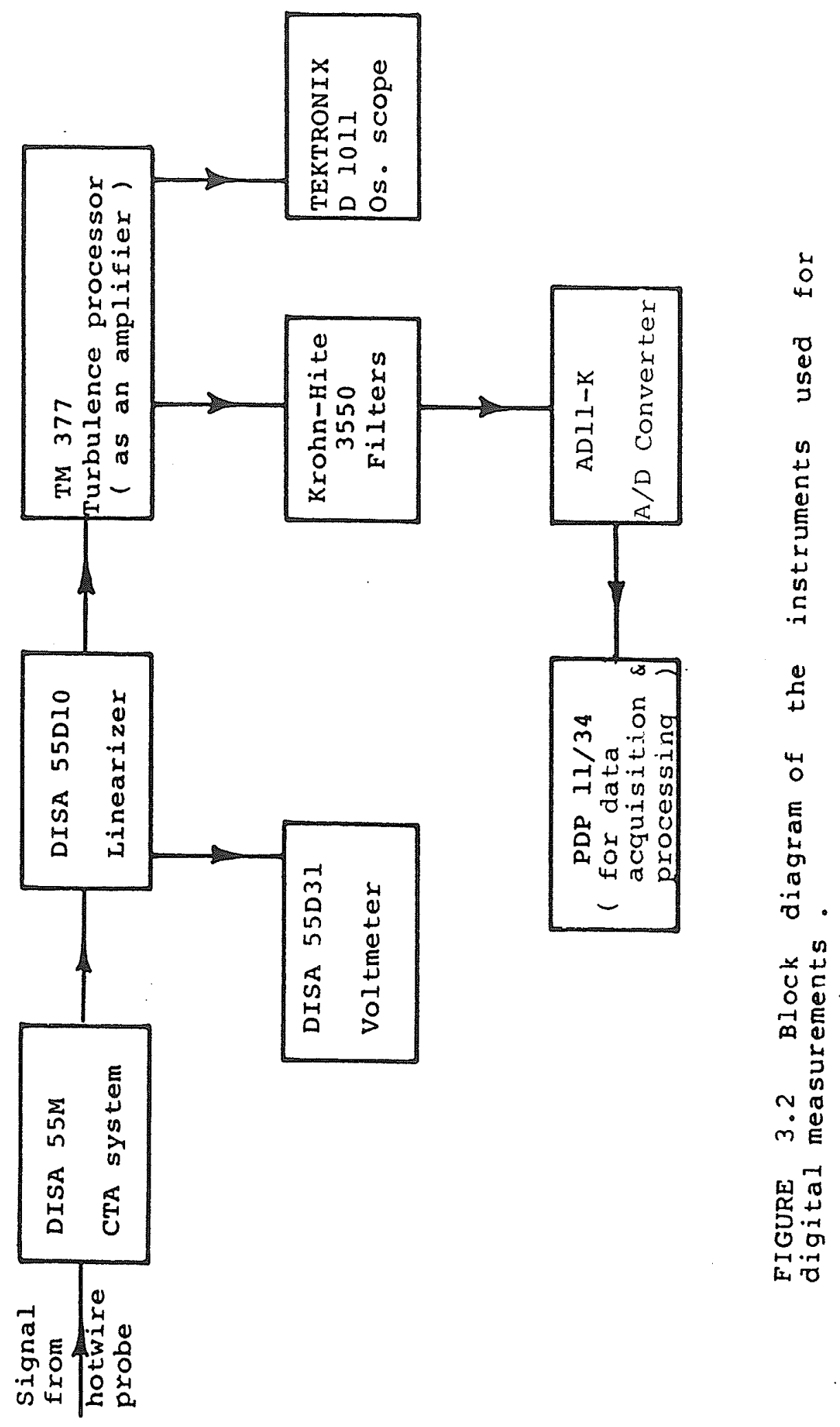




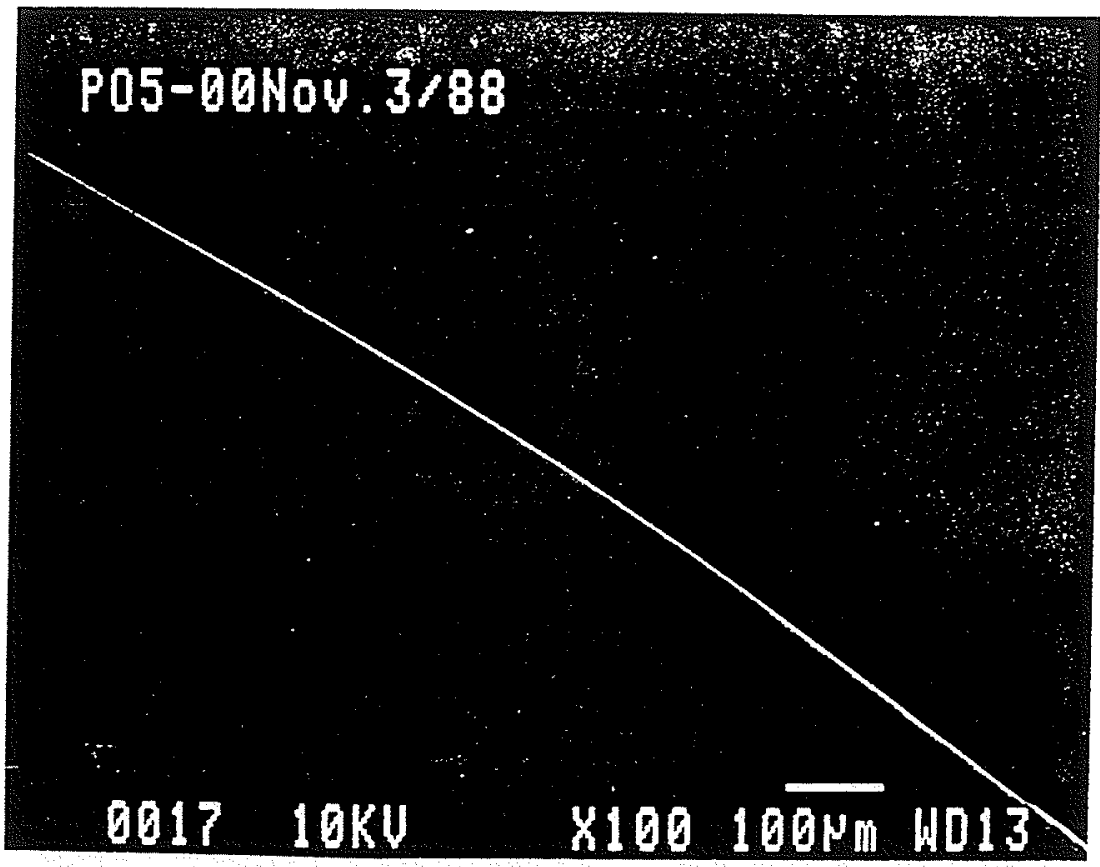

(a)

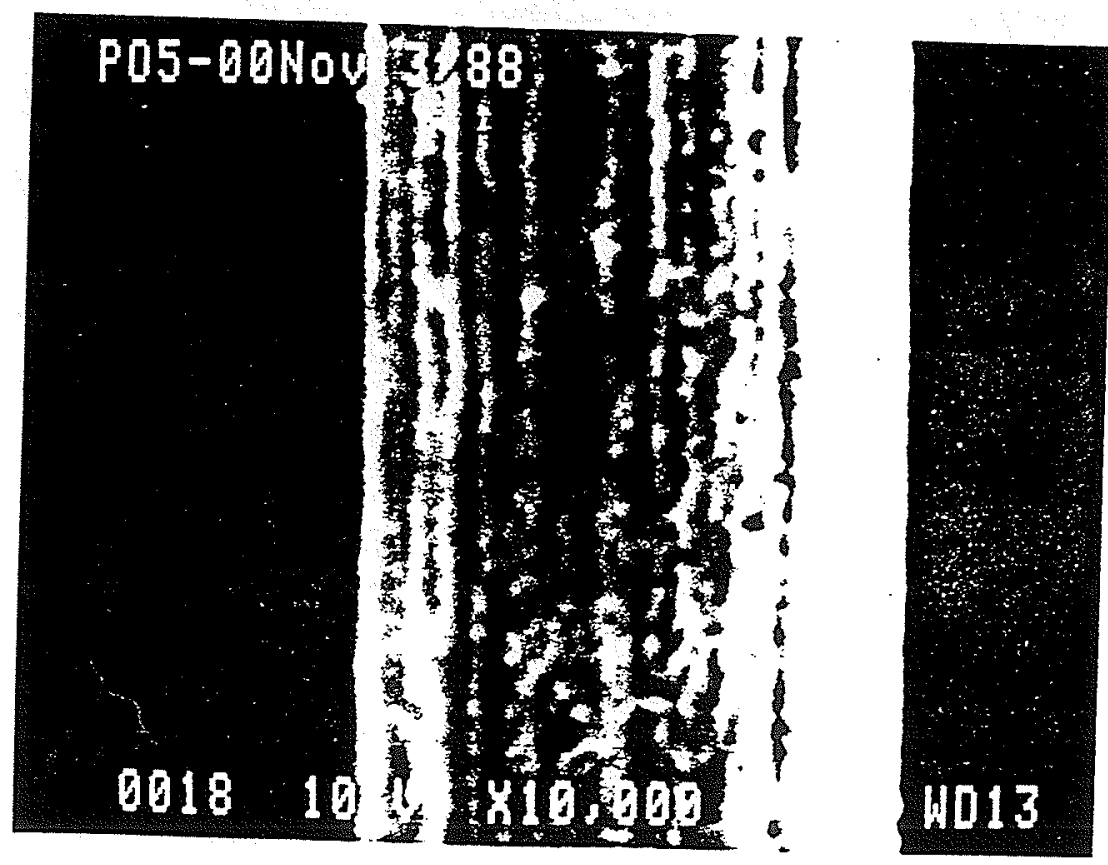

(b)

FIGURE 4 Electron microscope photographs of a typical hotwire, showing, (a) the length of the wire and (b) the diameter of the wire. 


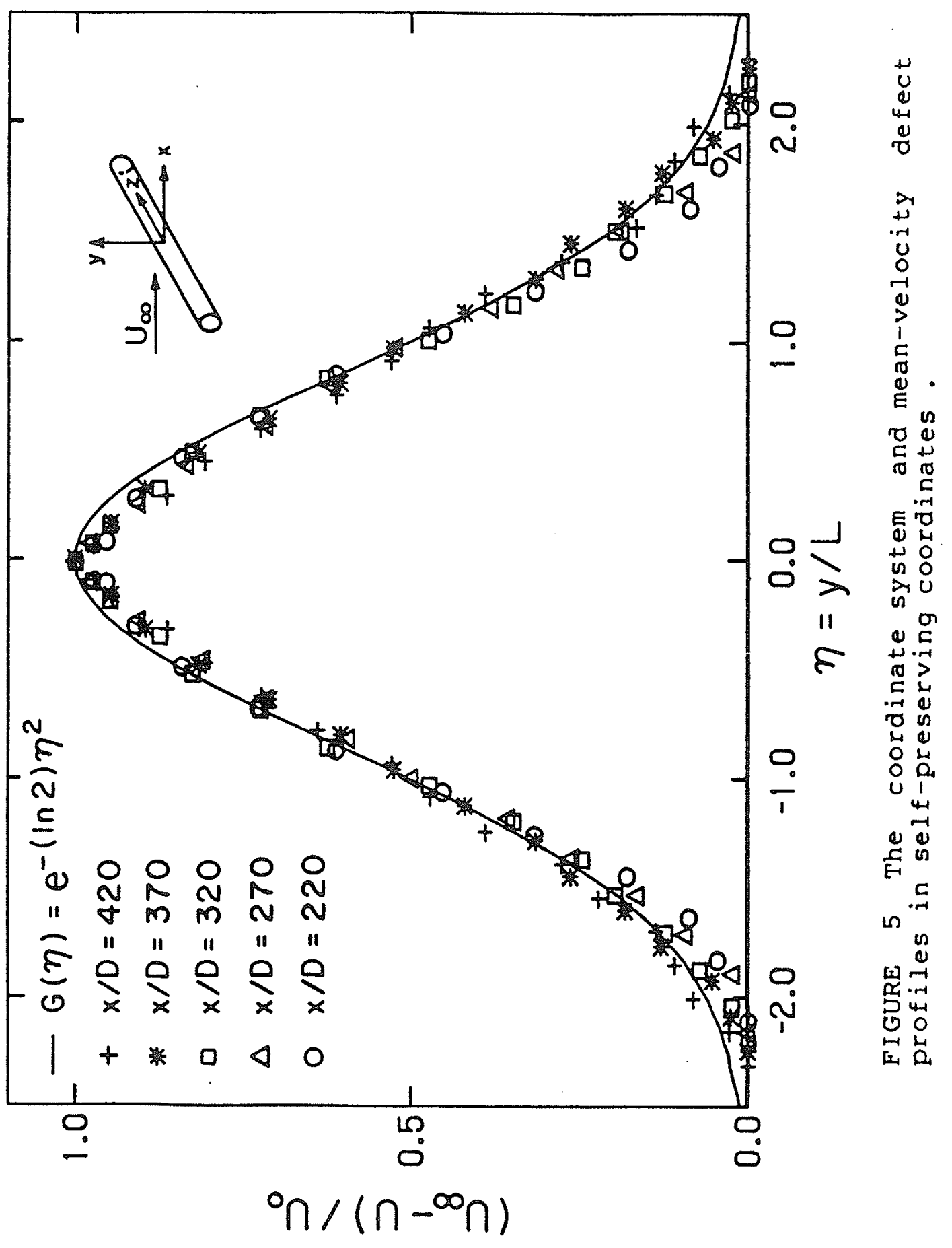




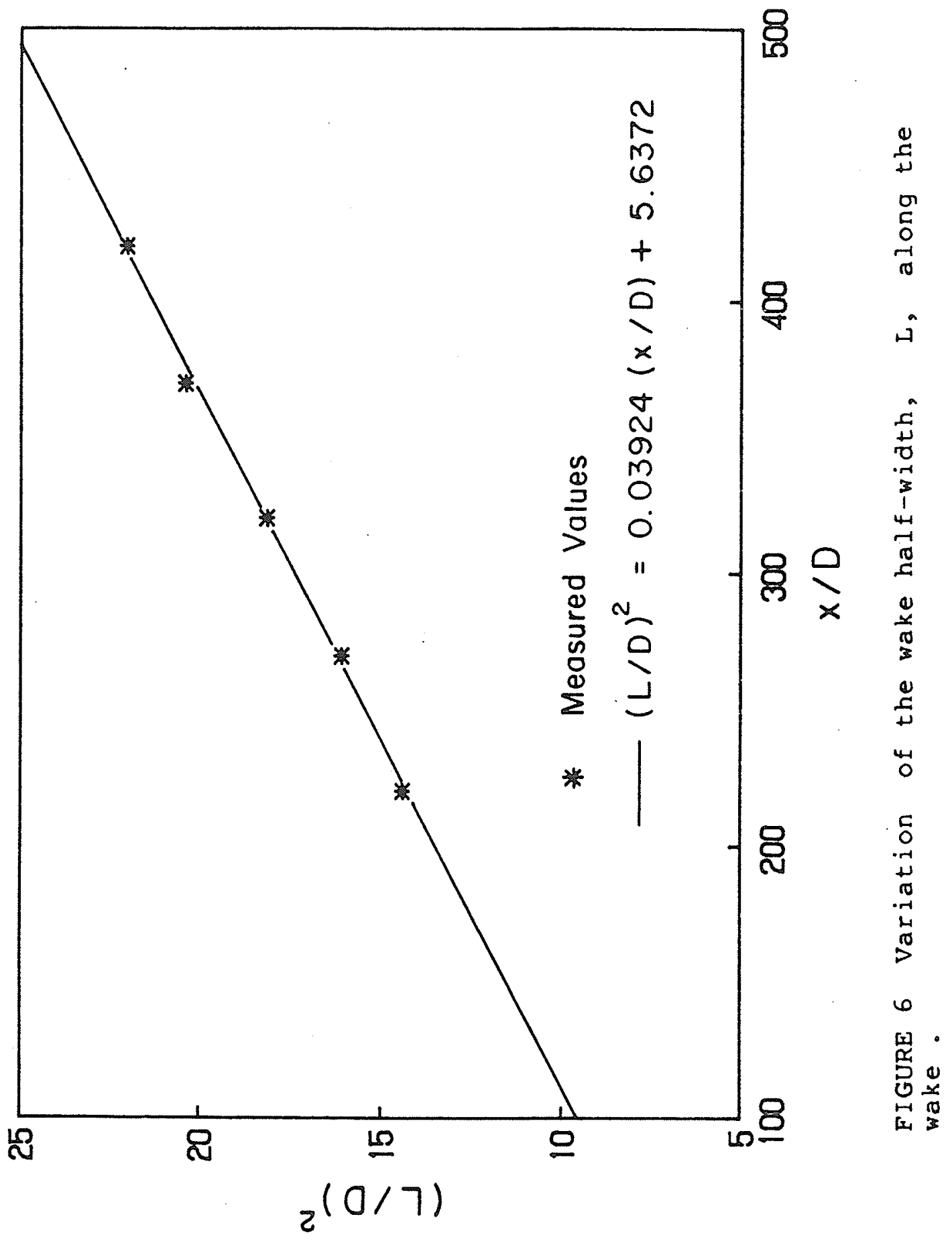




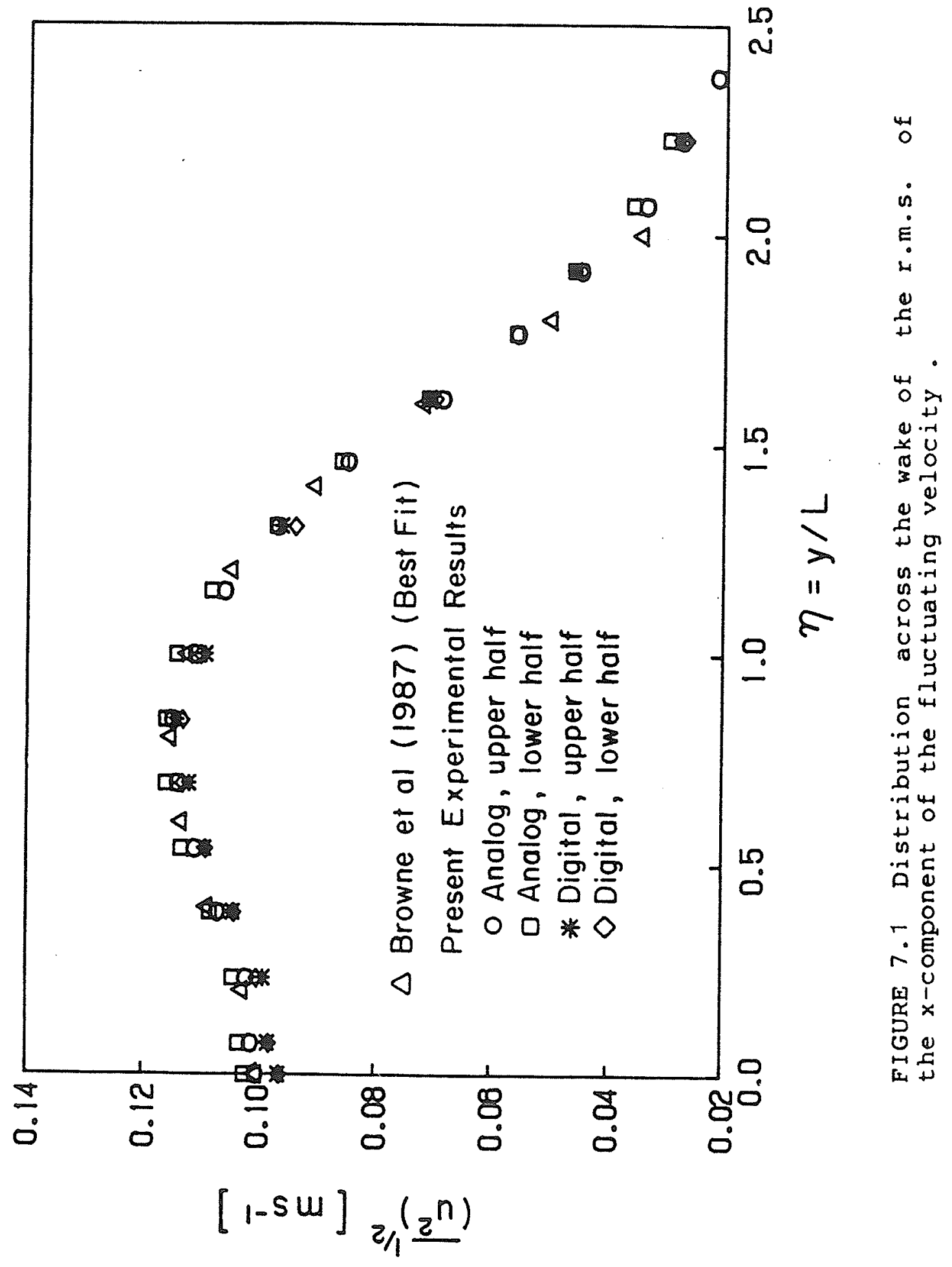




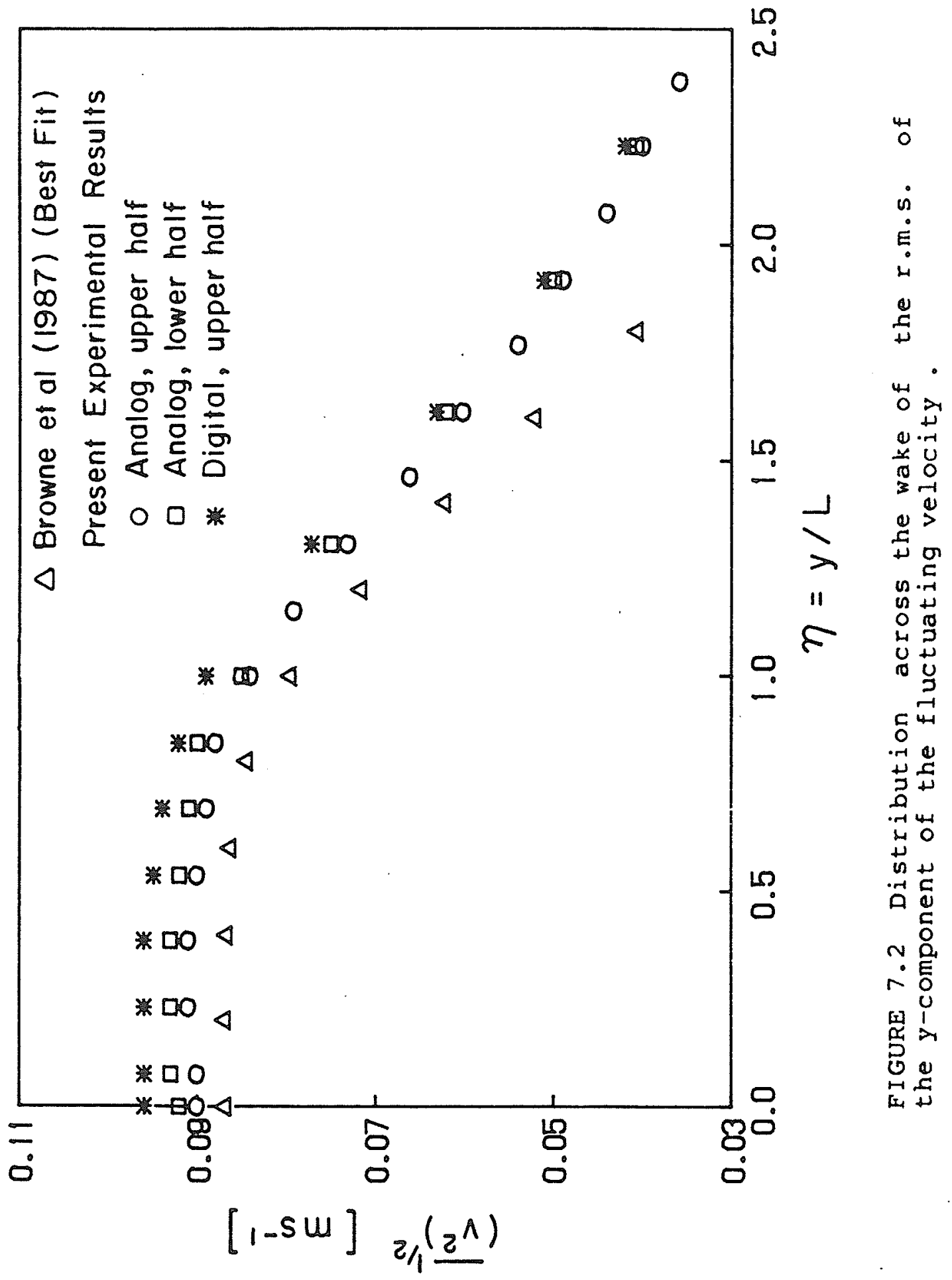




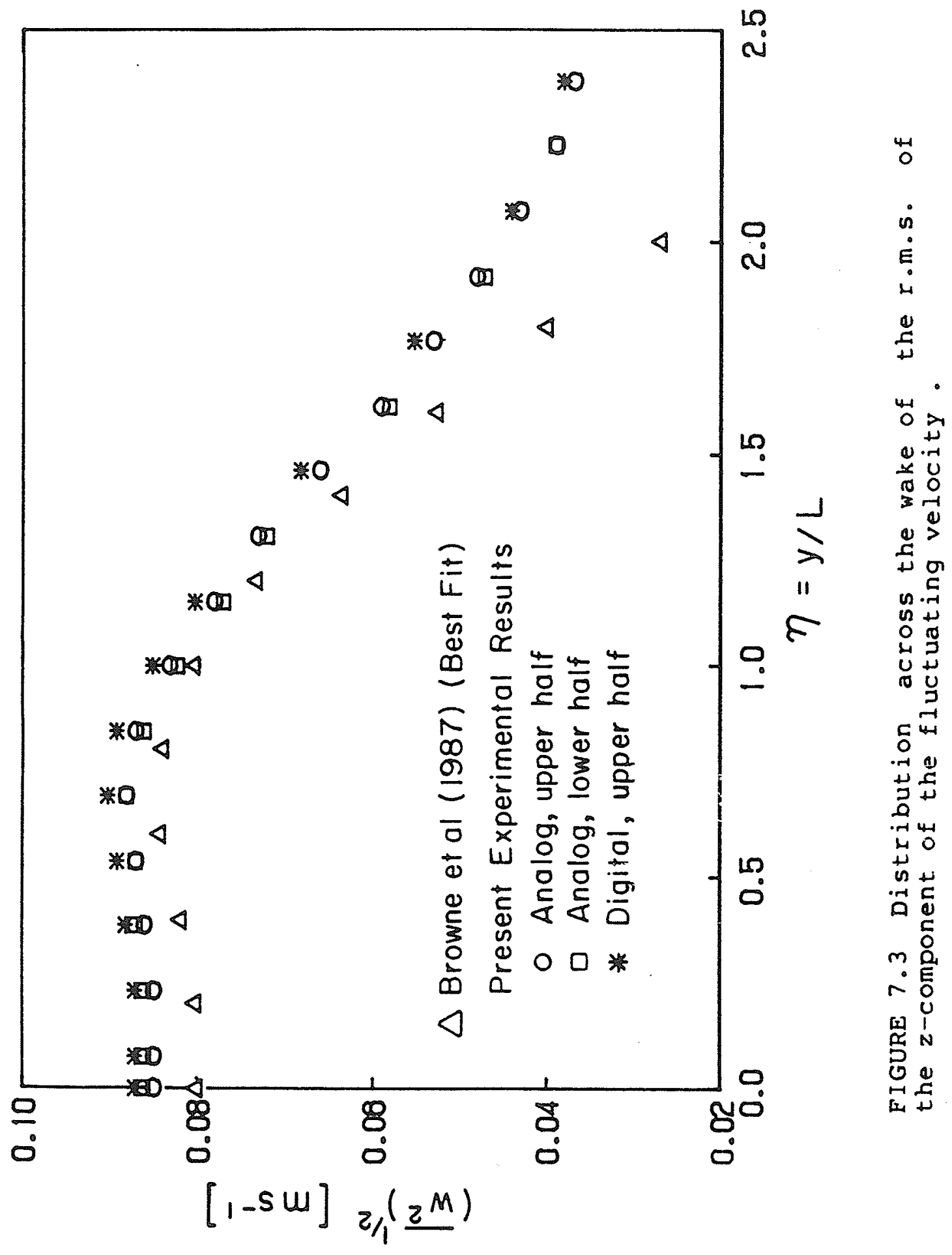




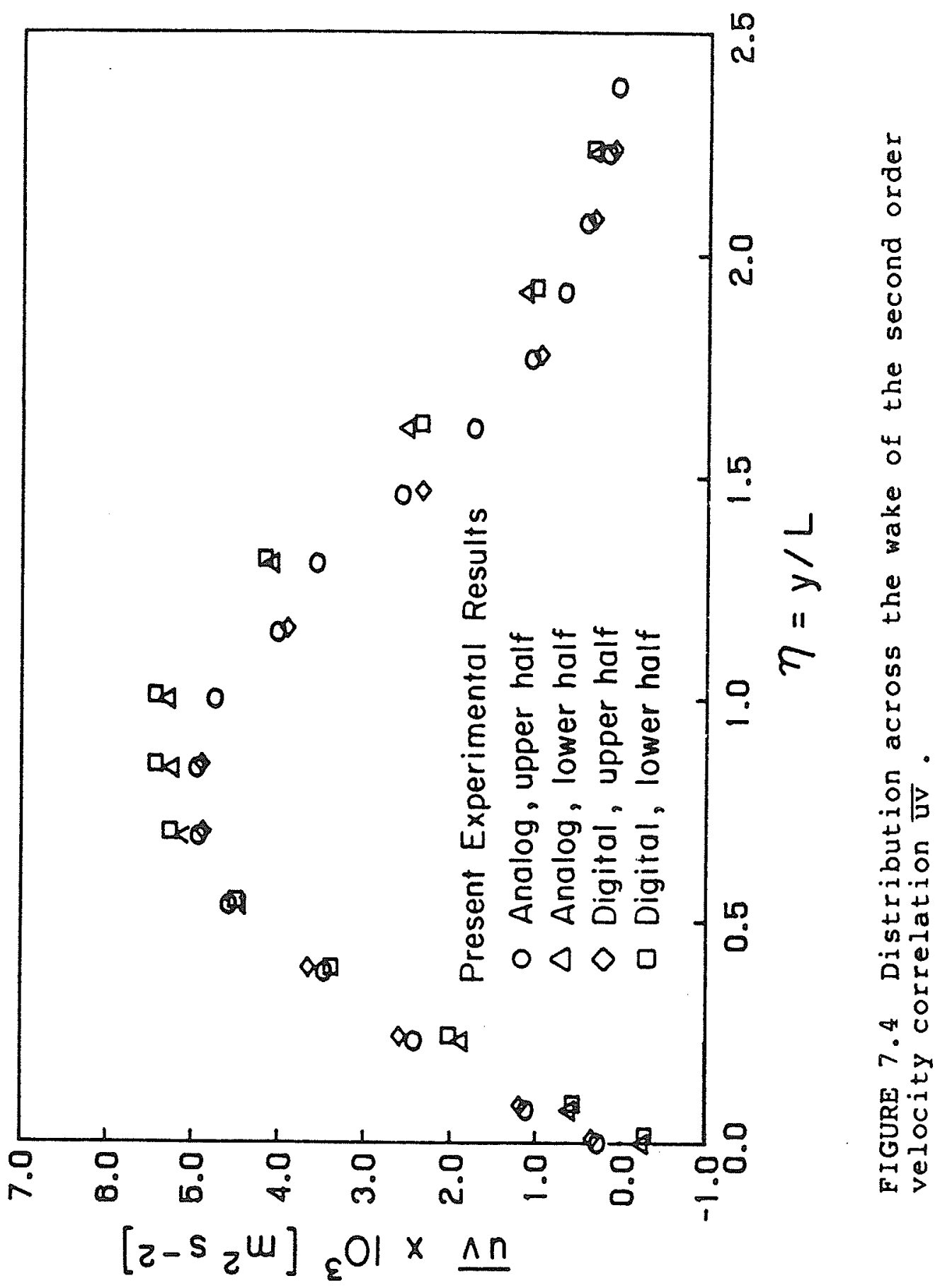




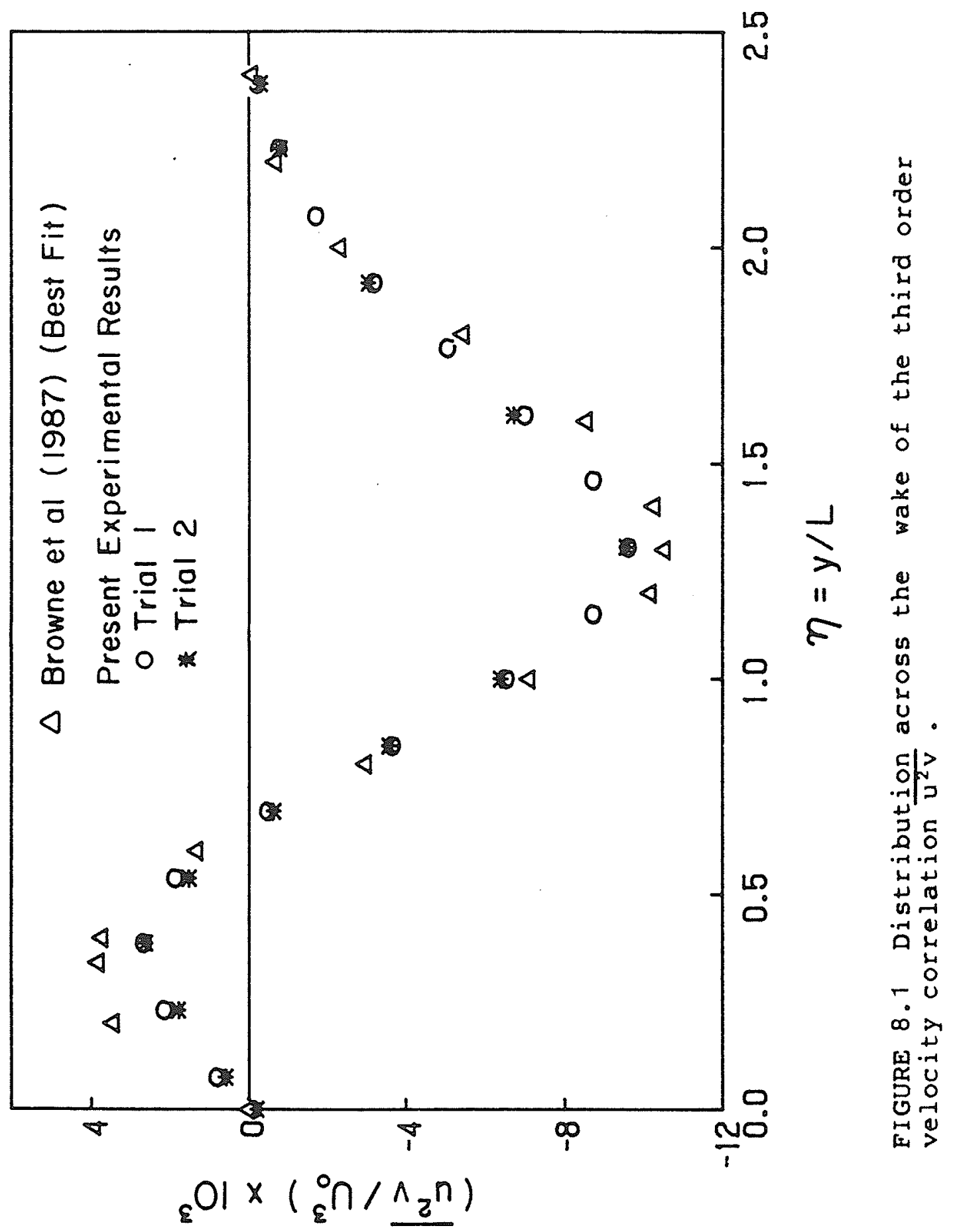




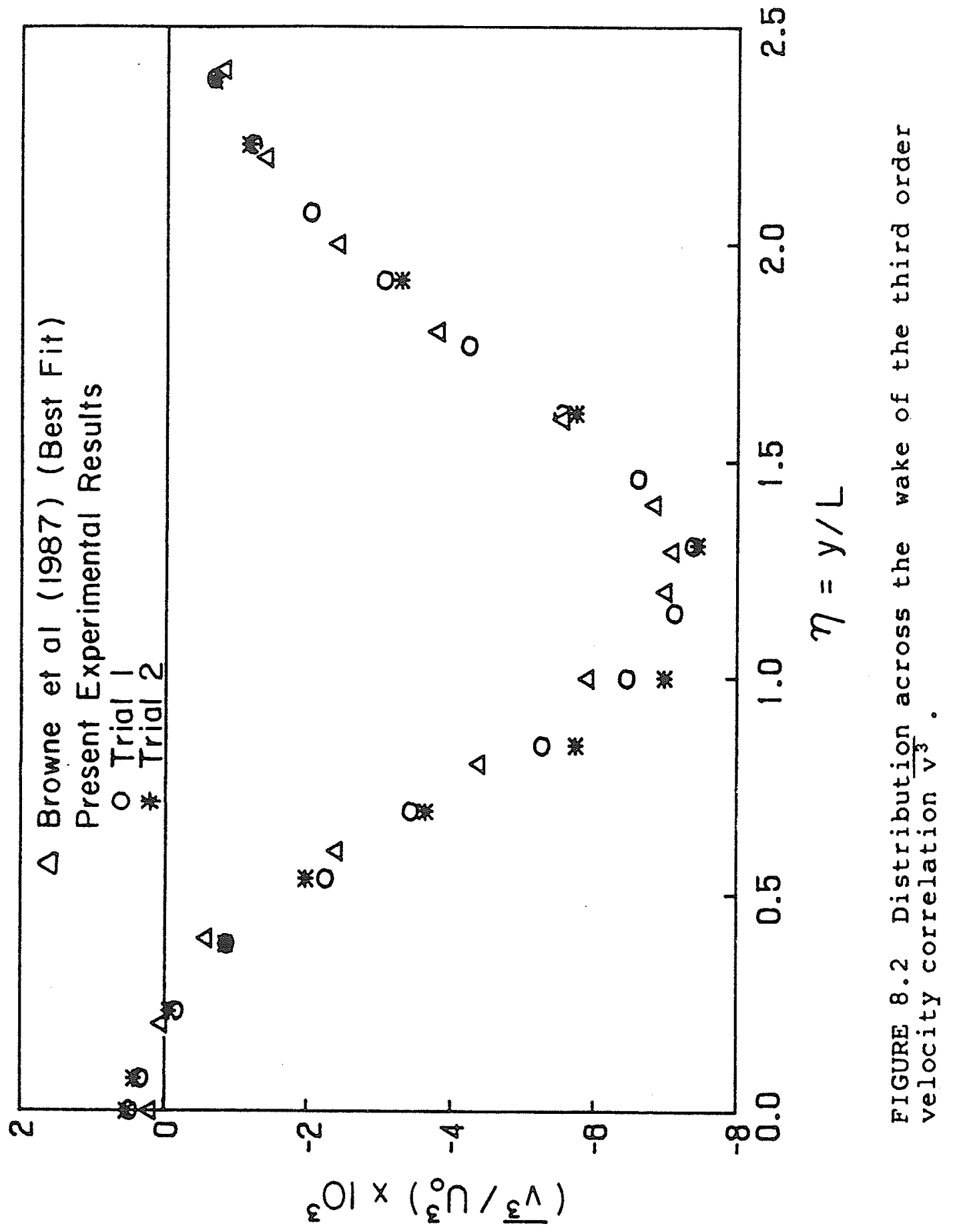




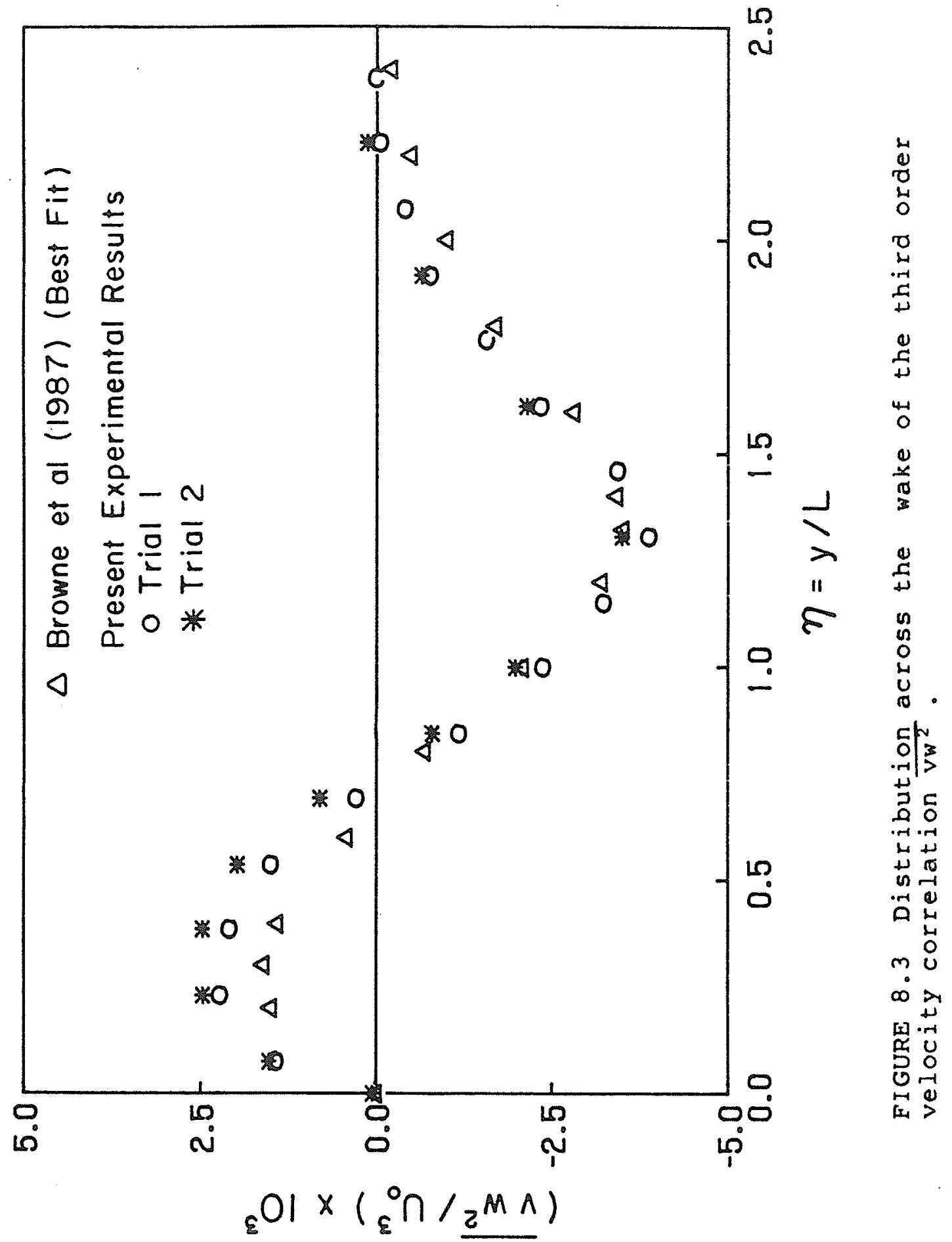




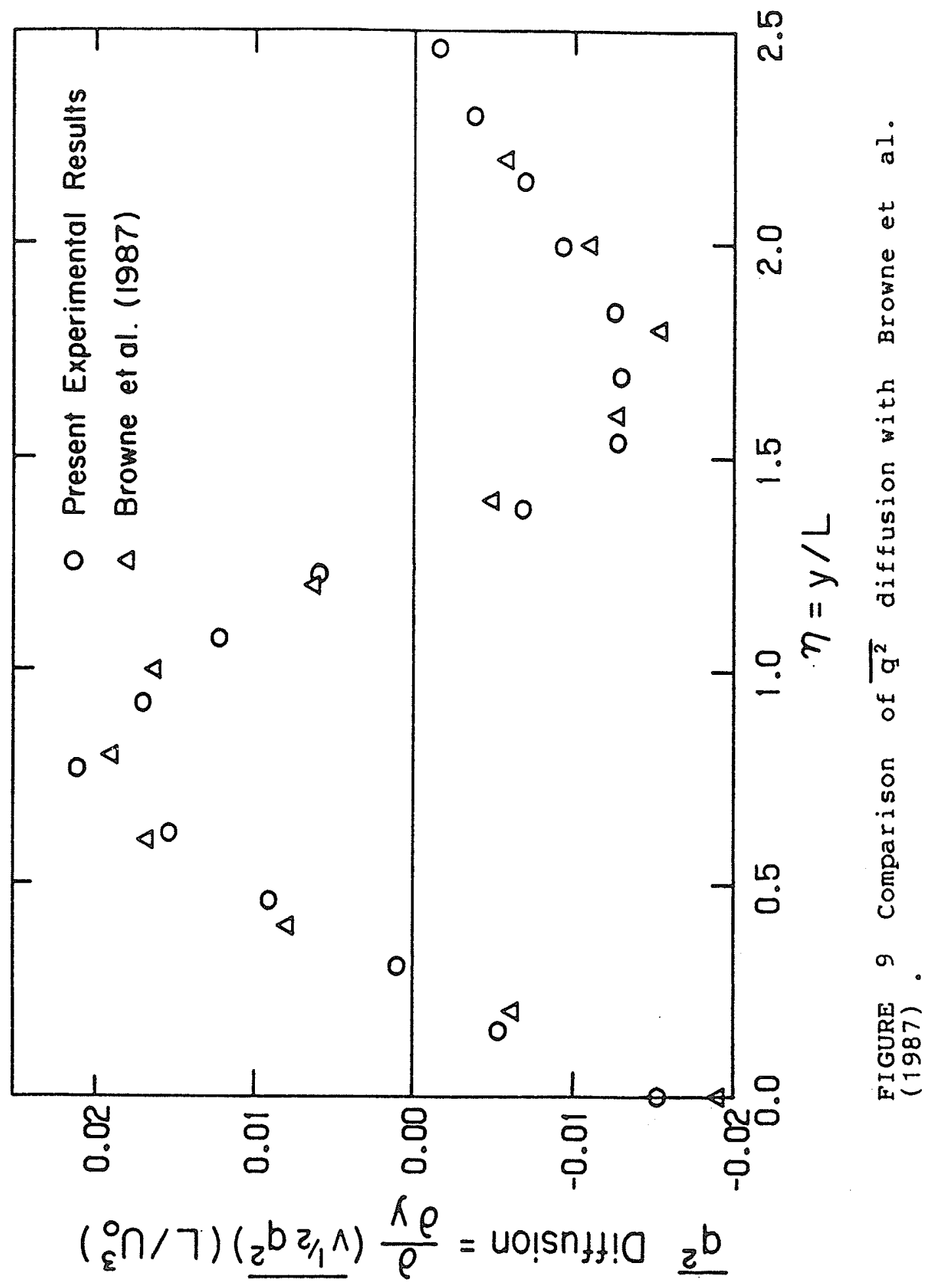




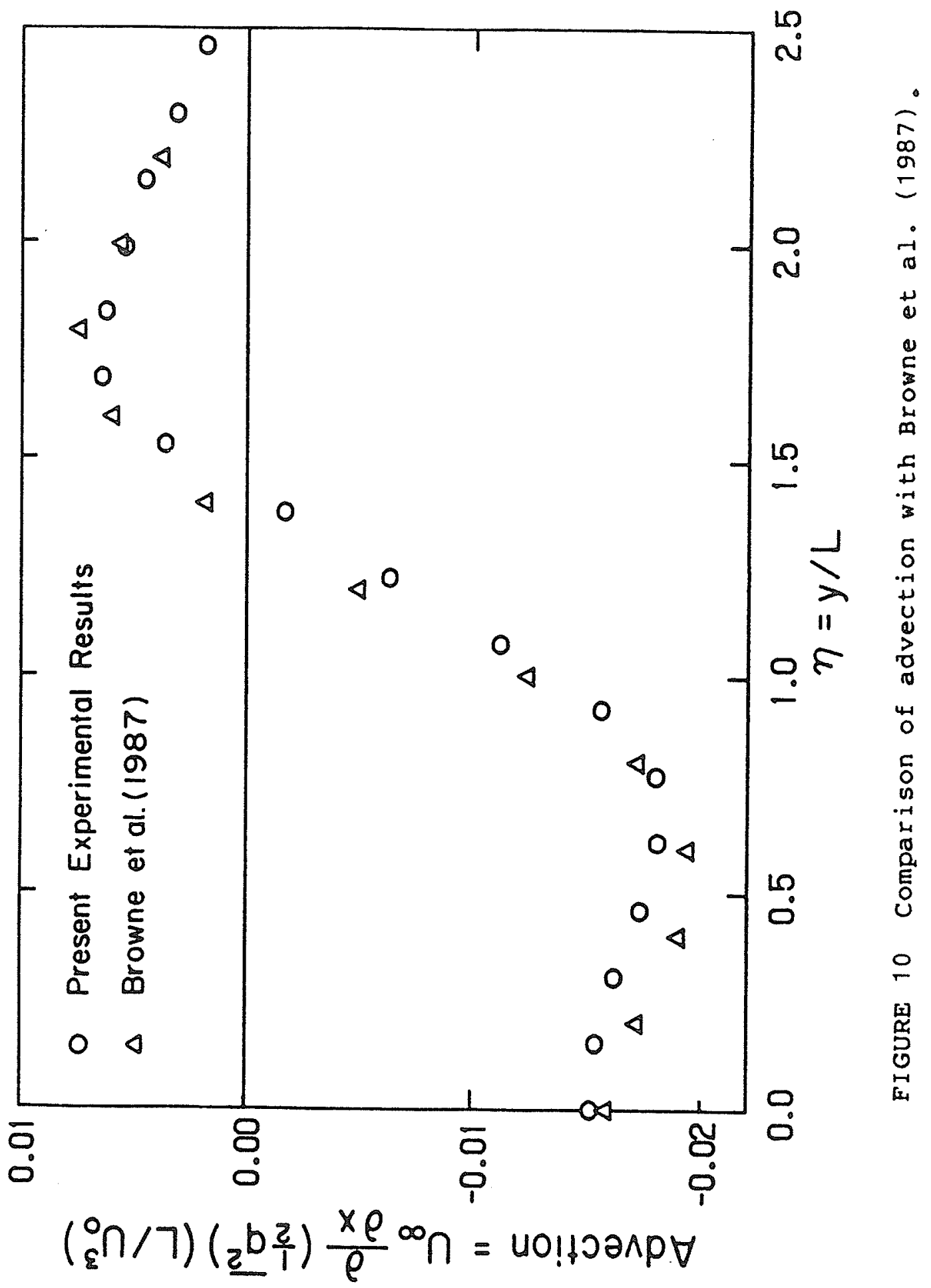




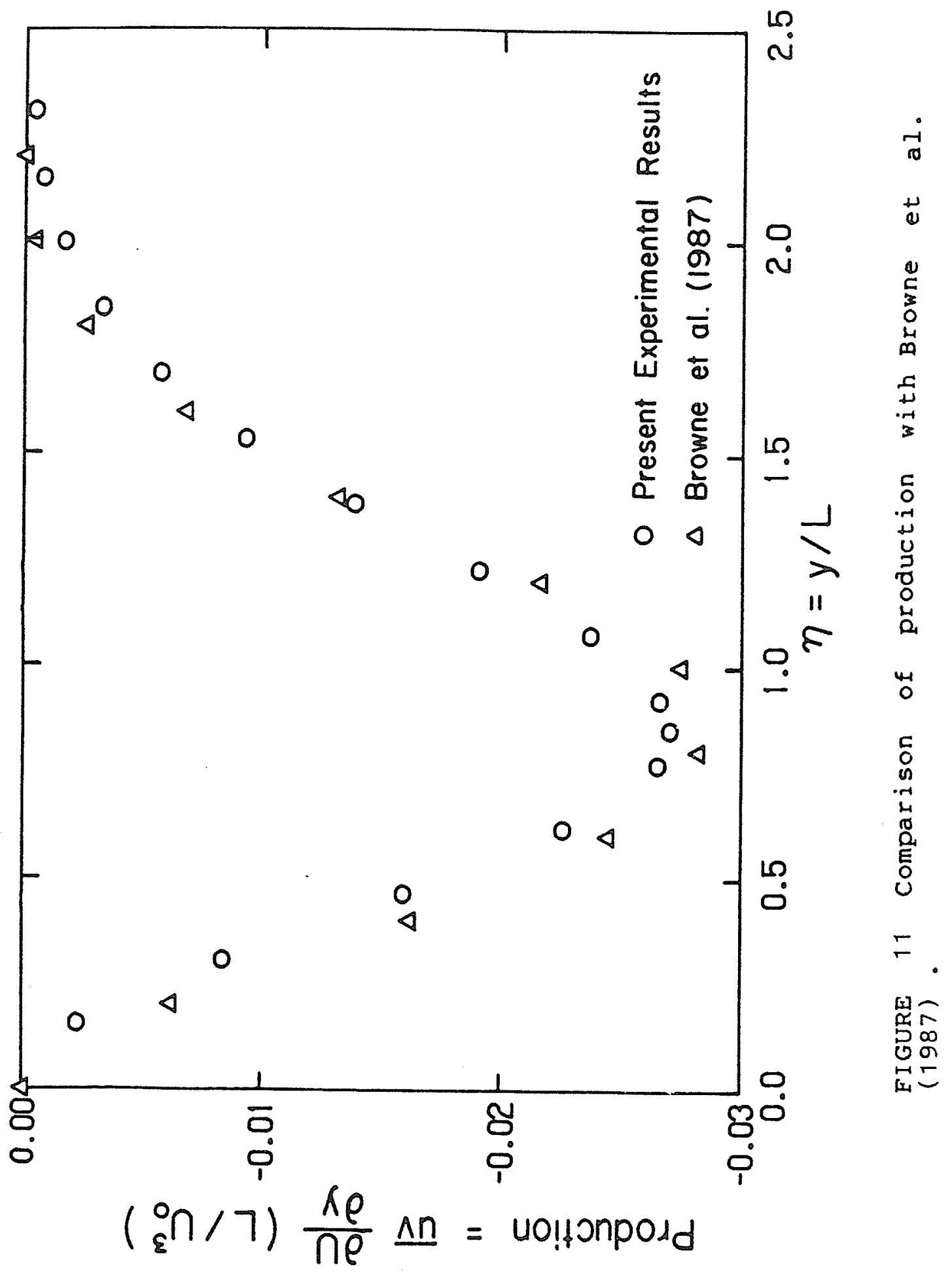




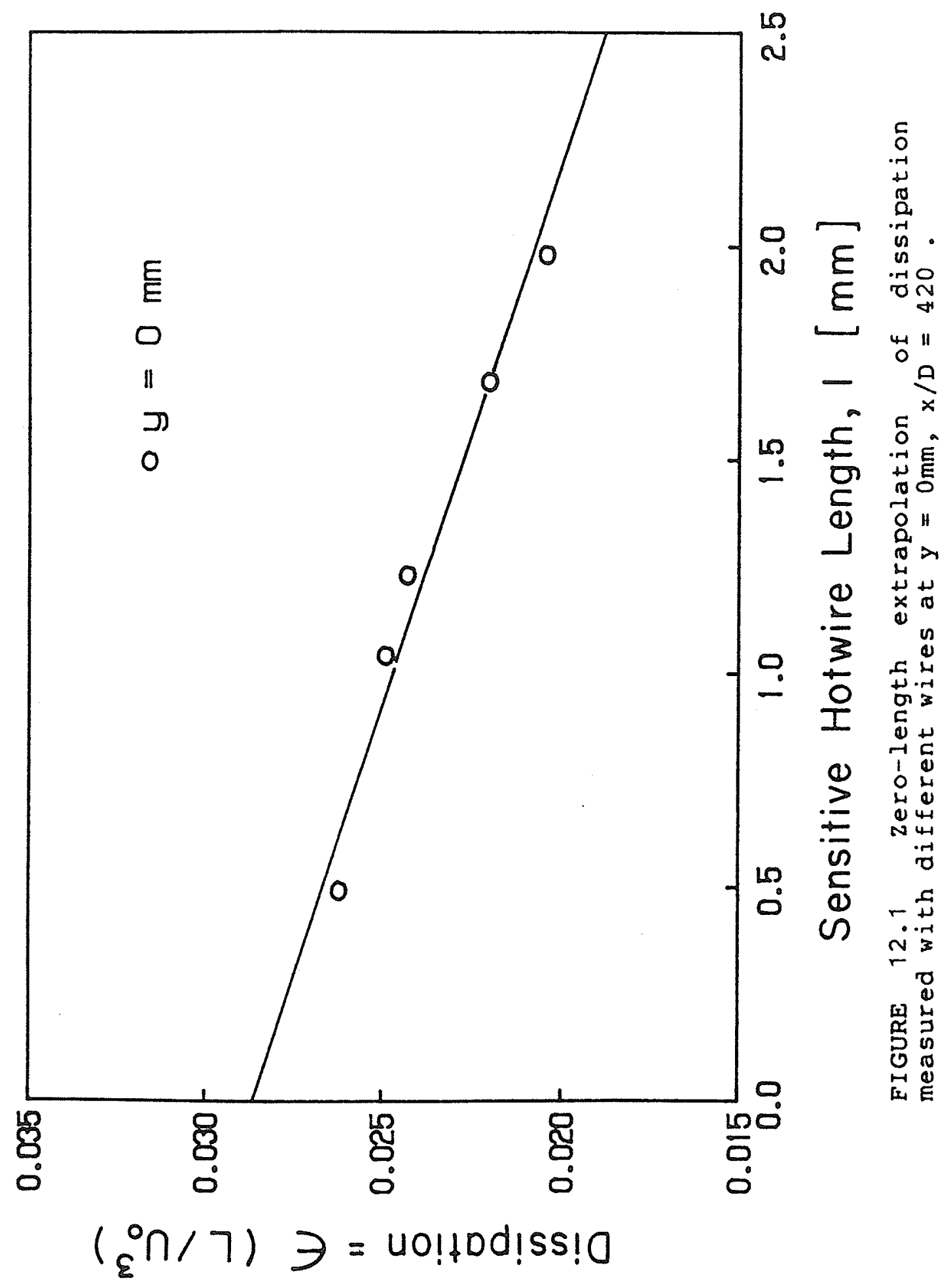




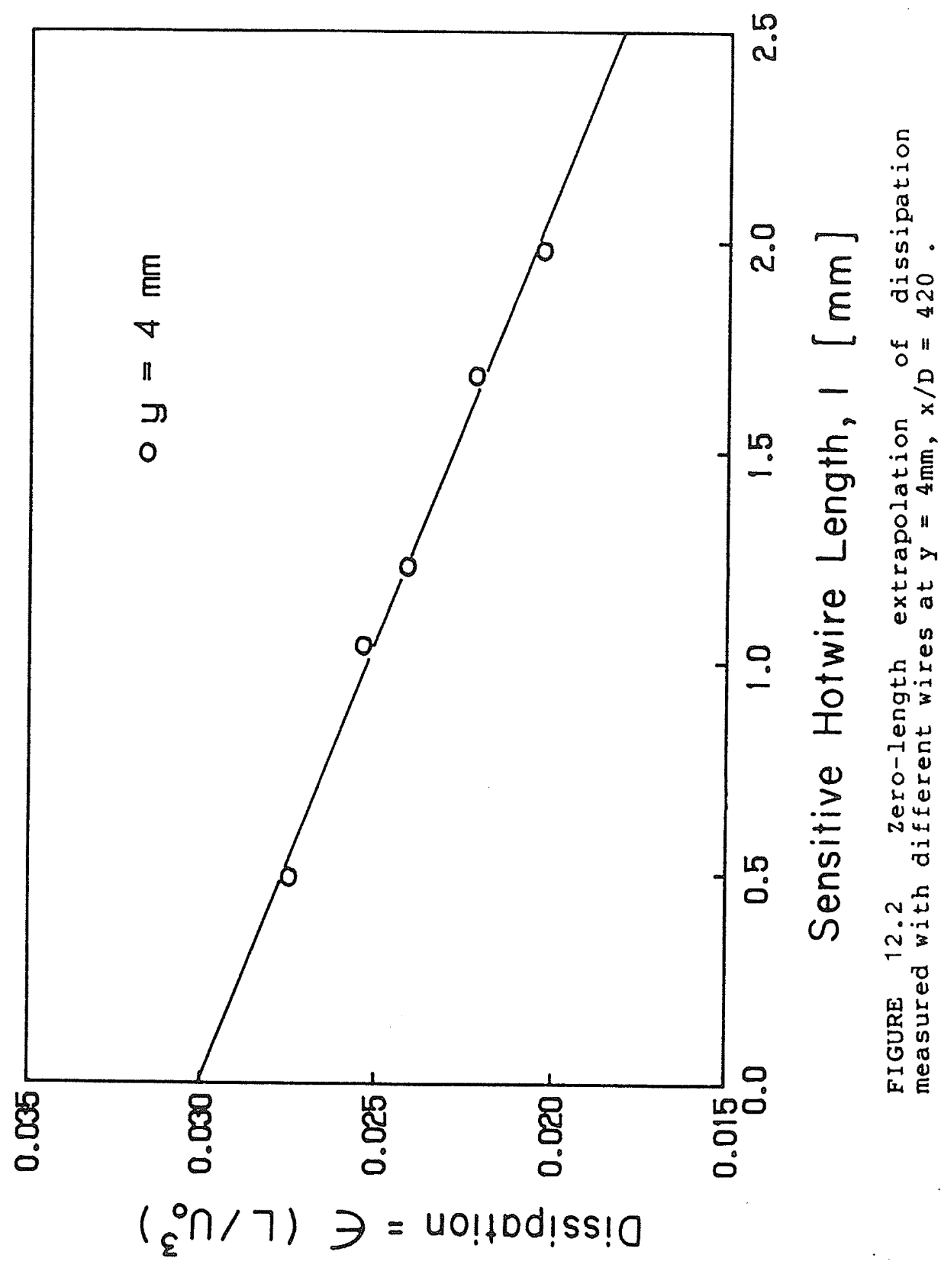




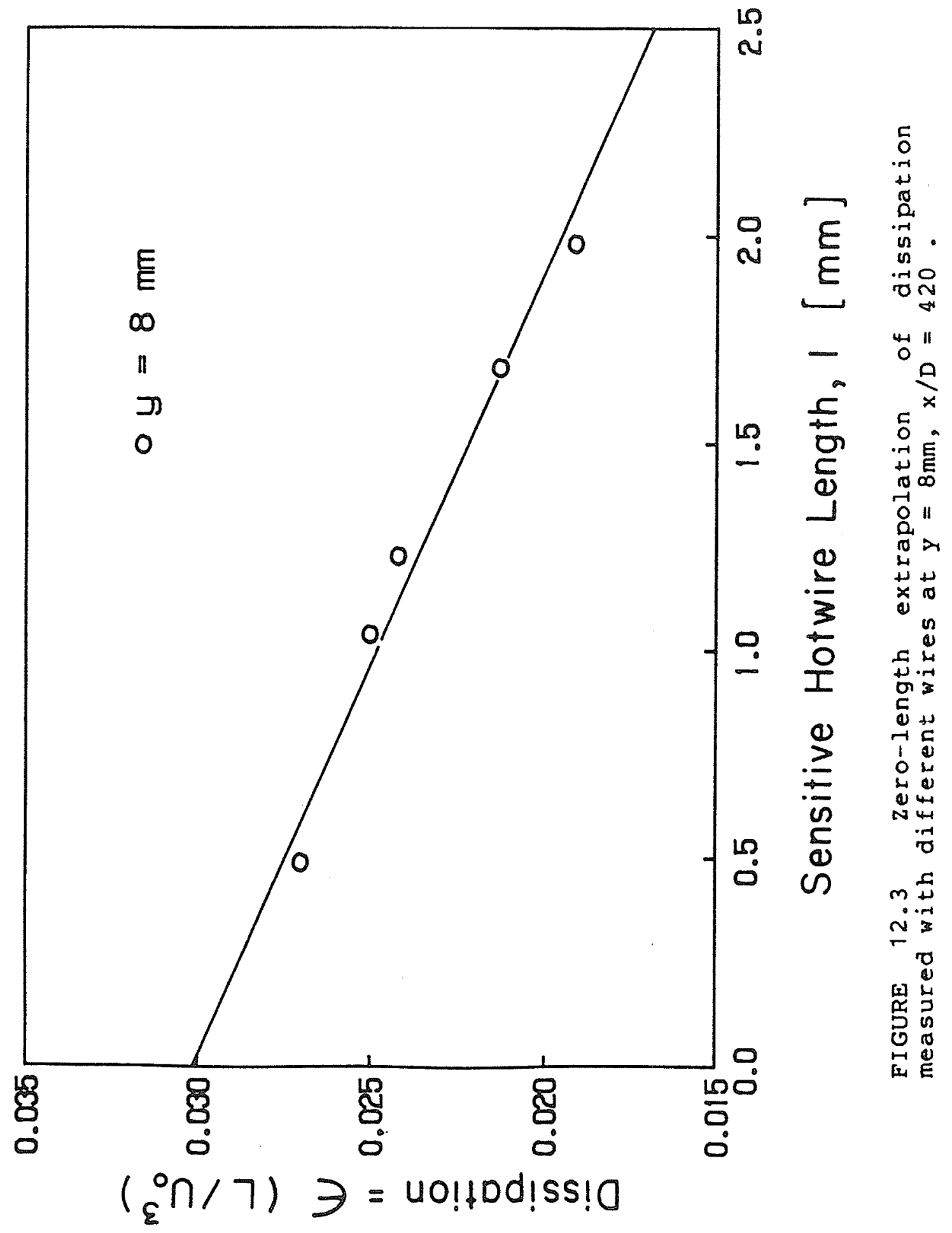




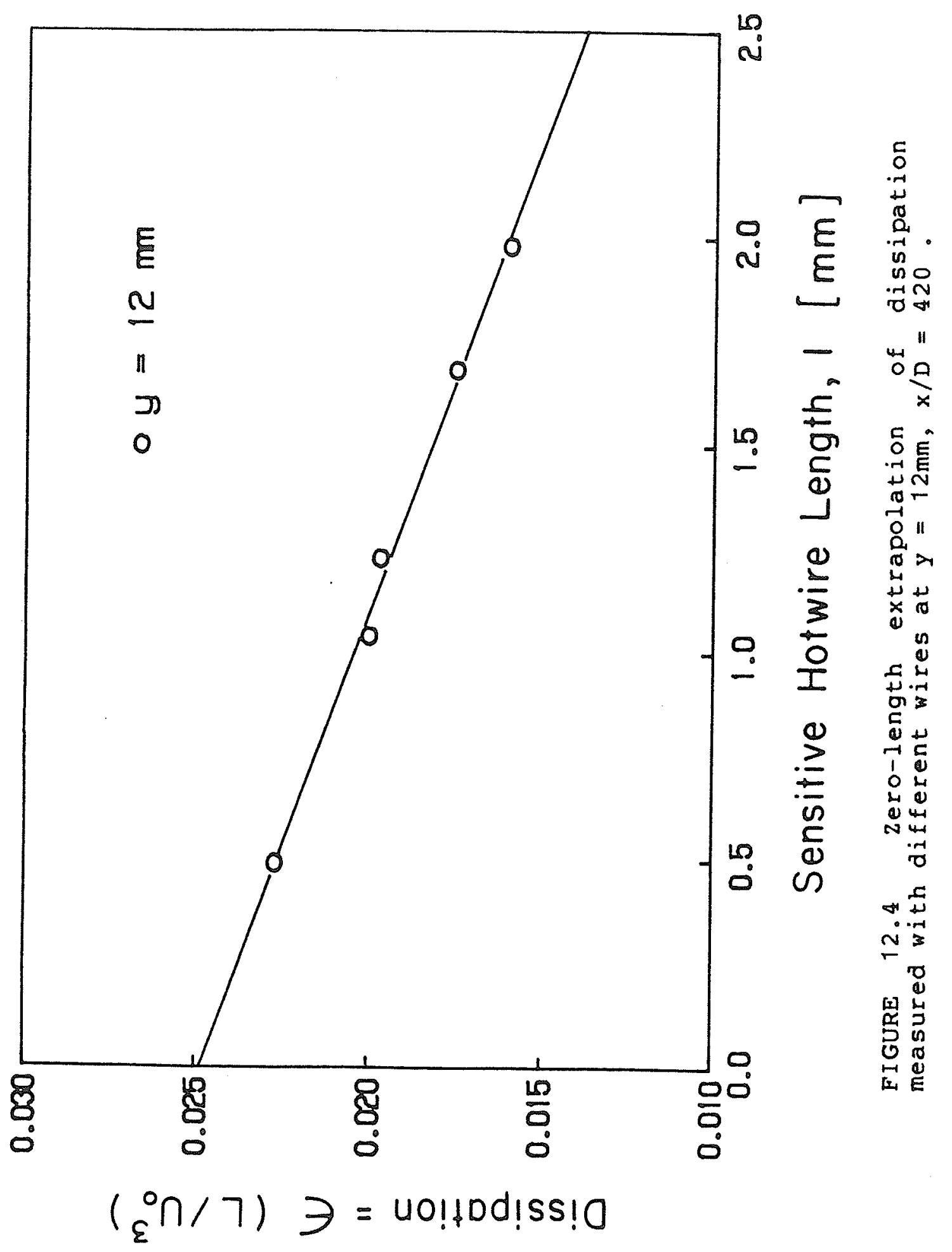




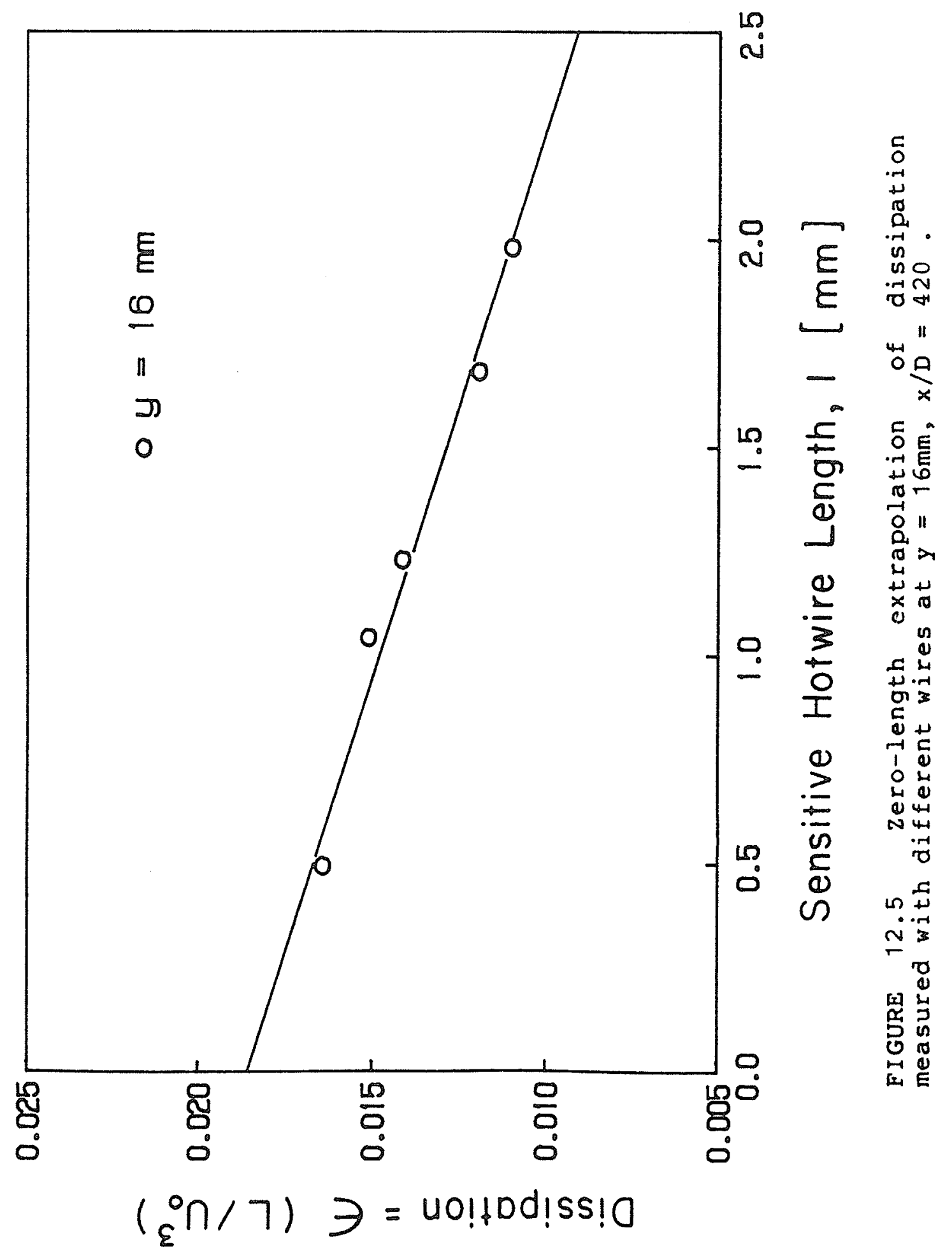




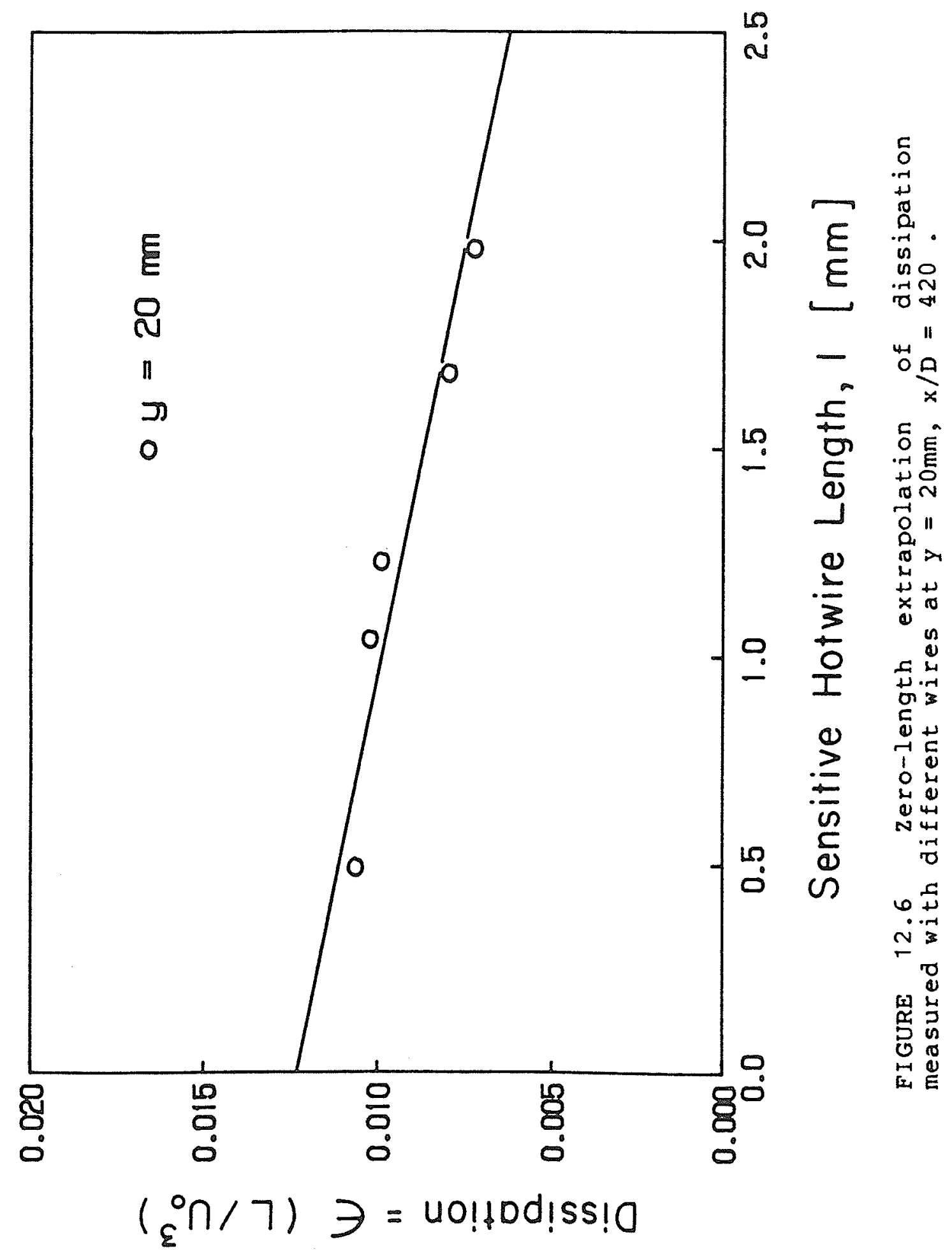




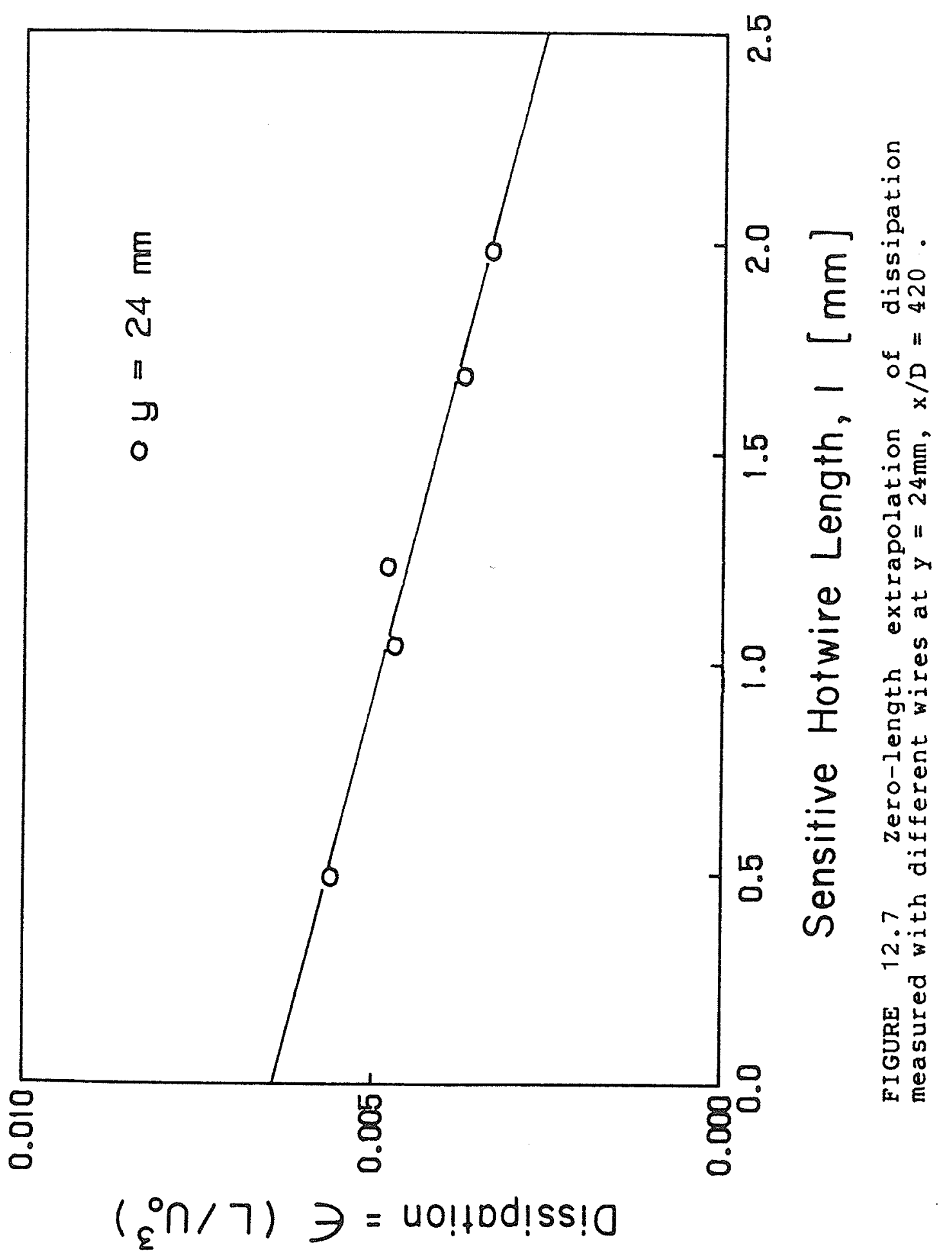




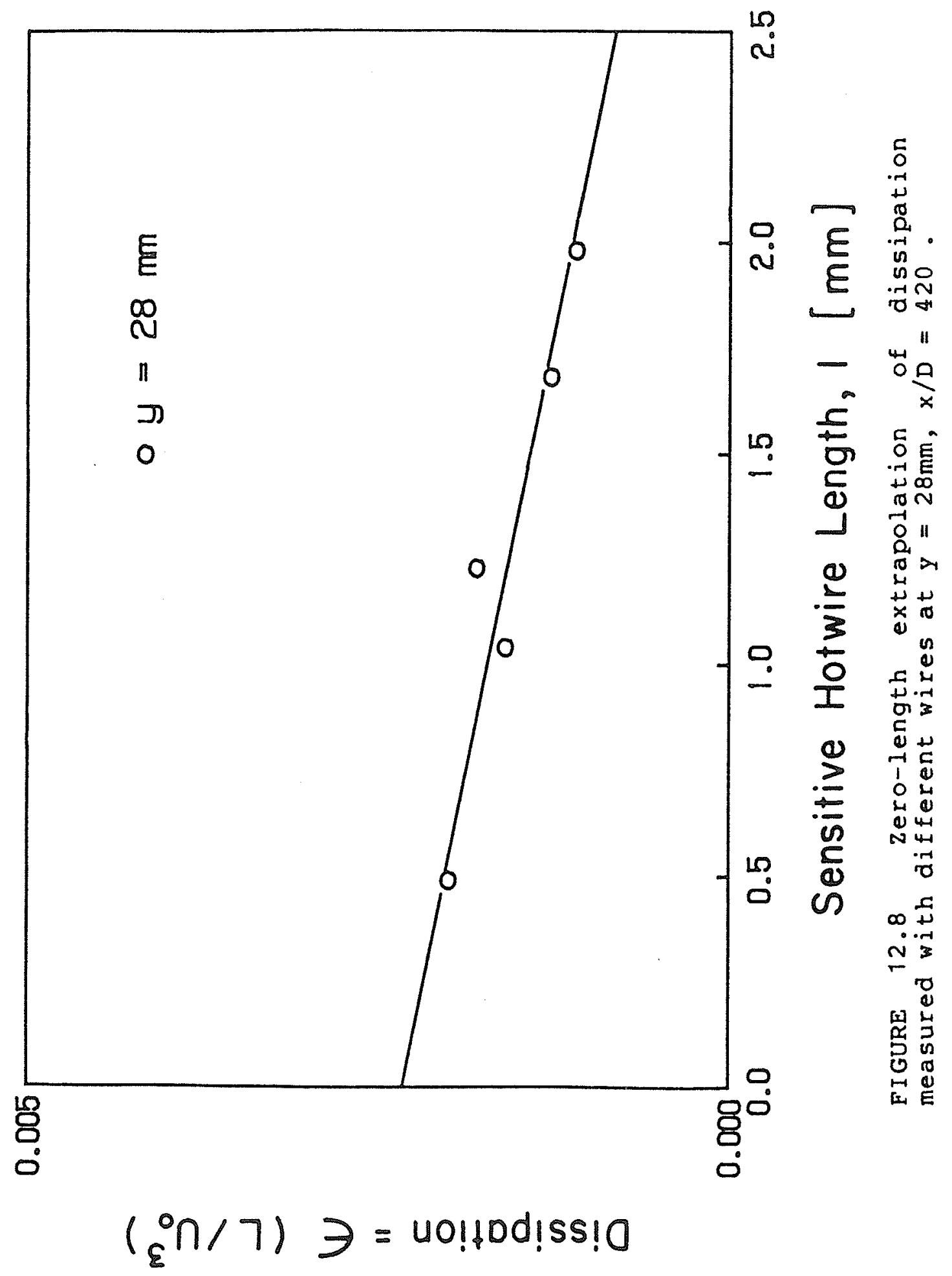




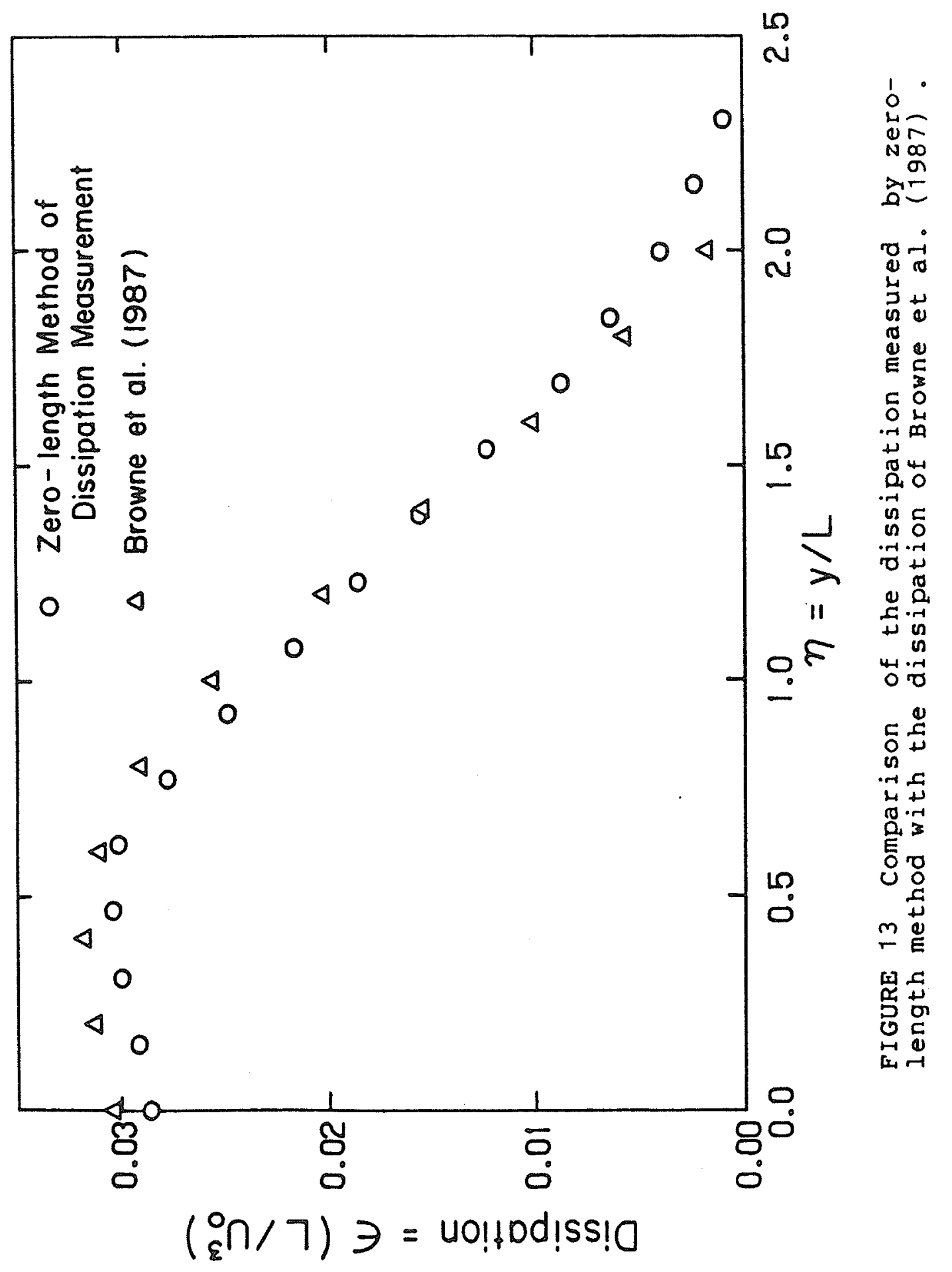




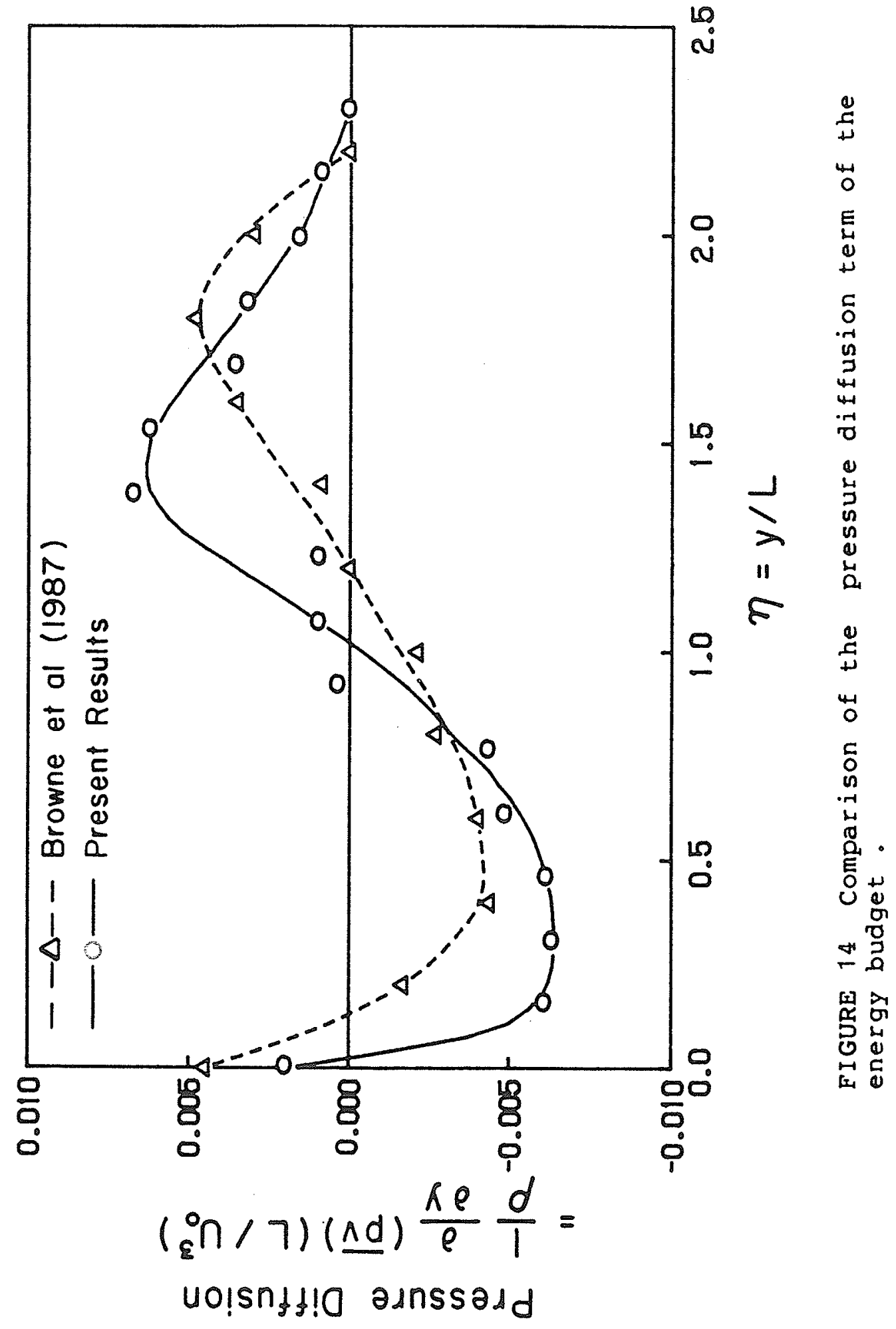




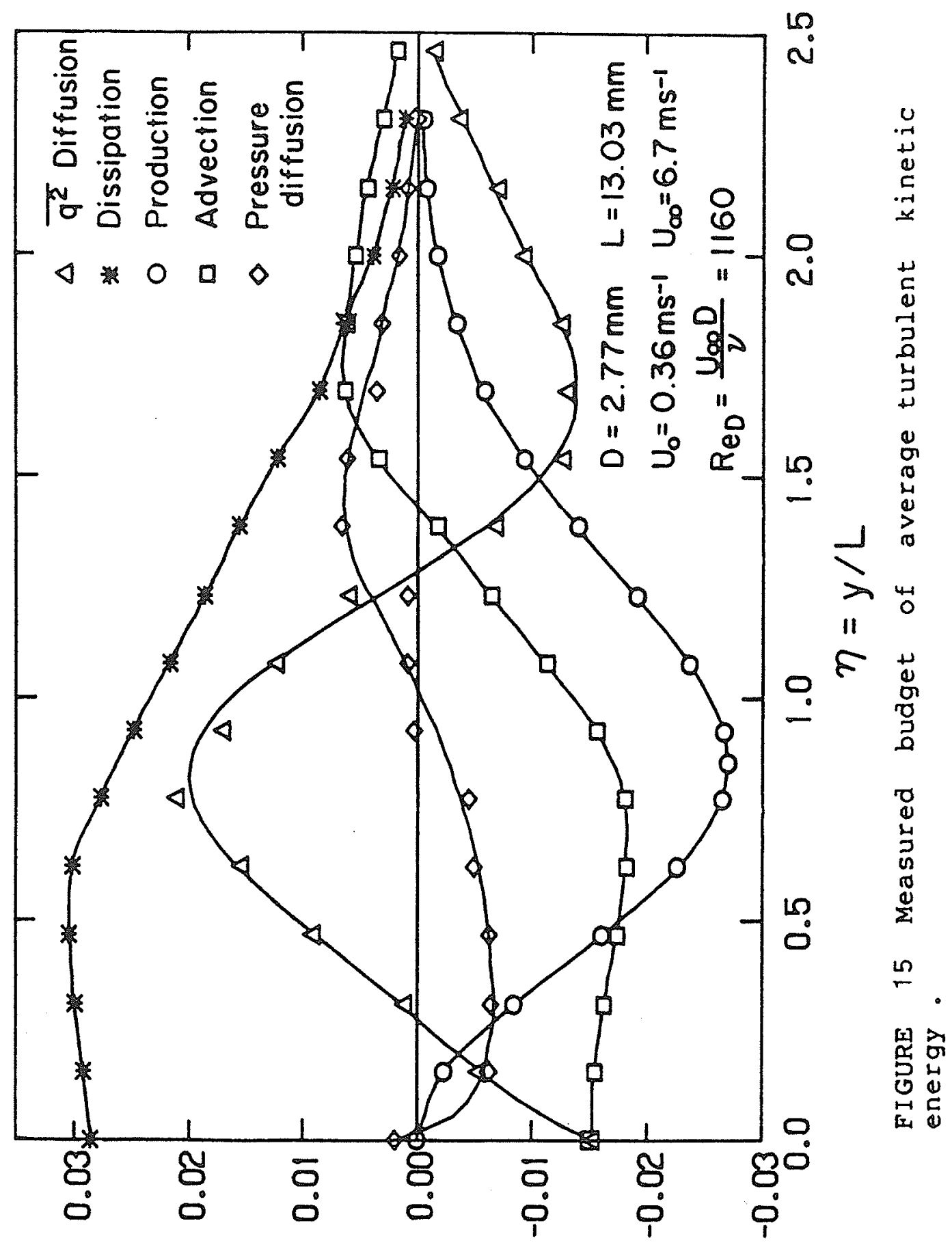




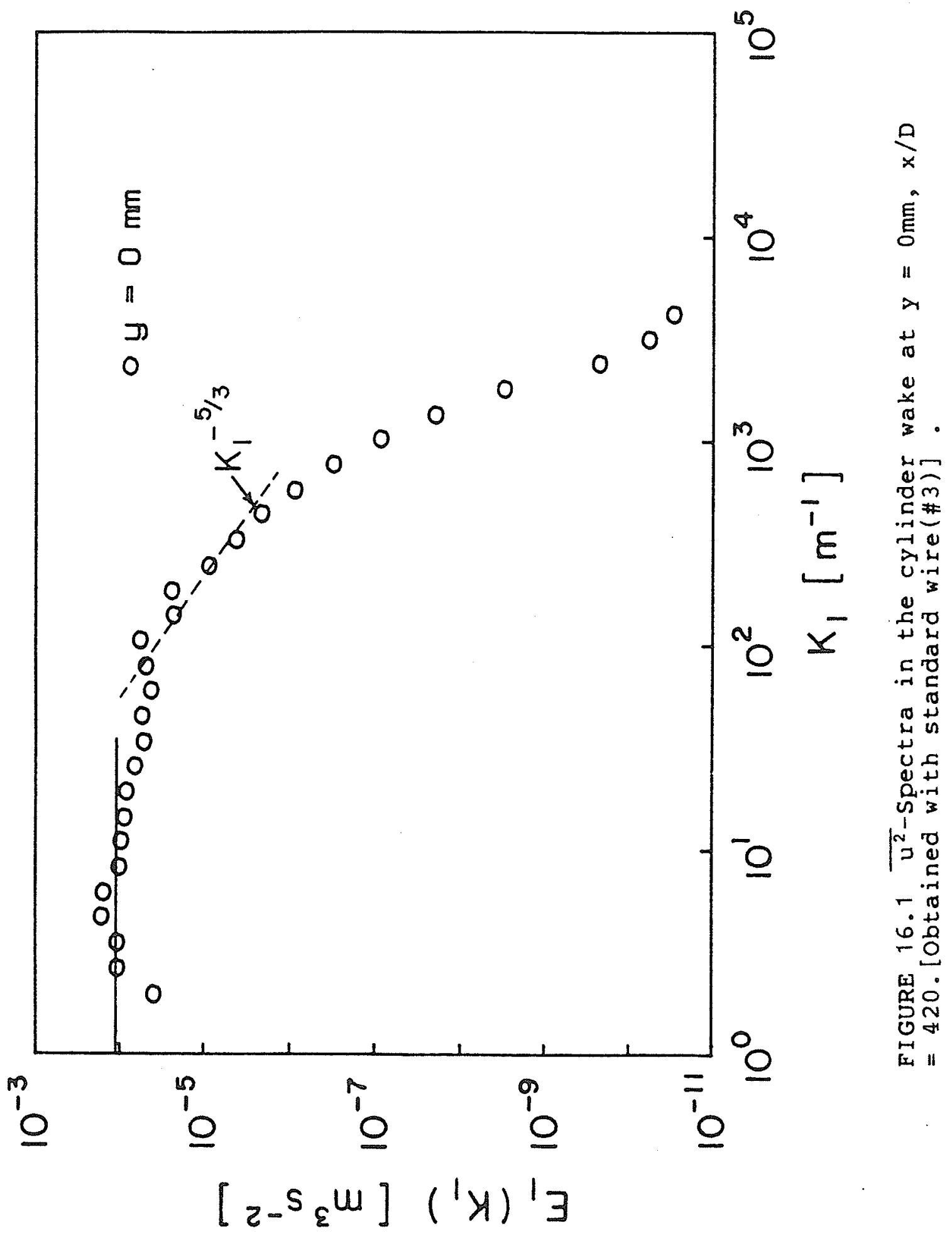




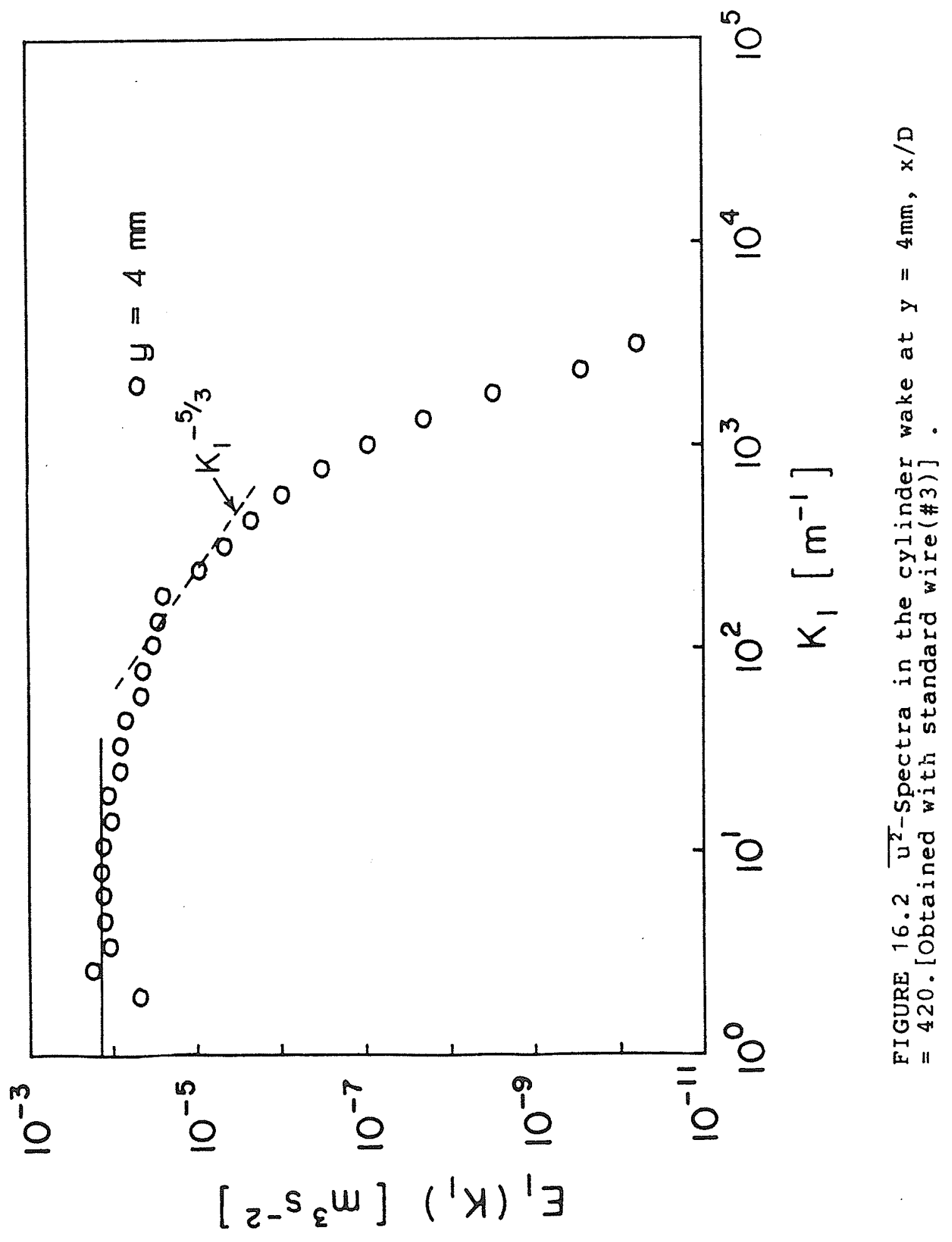




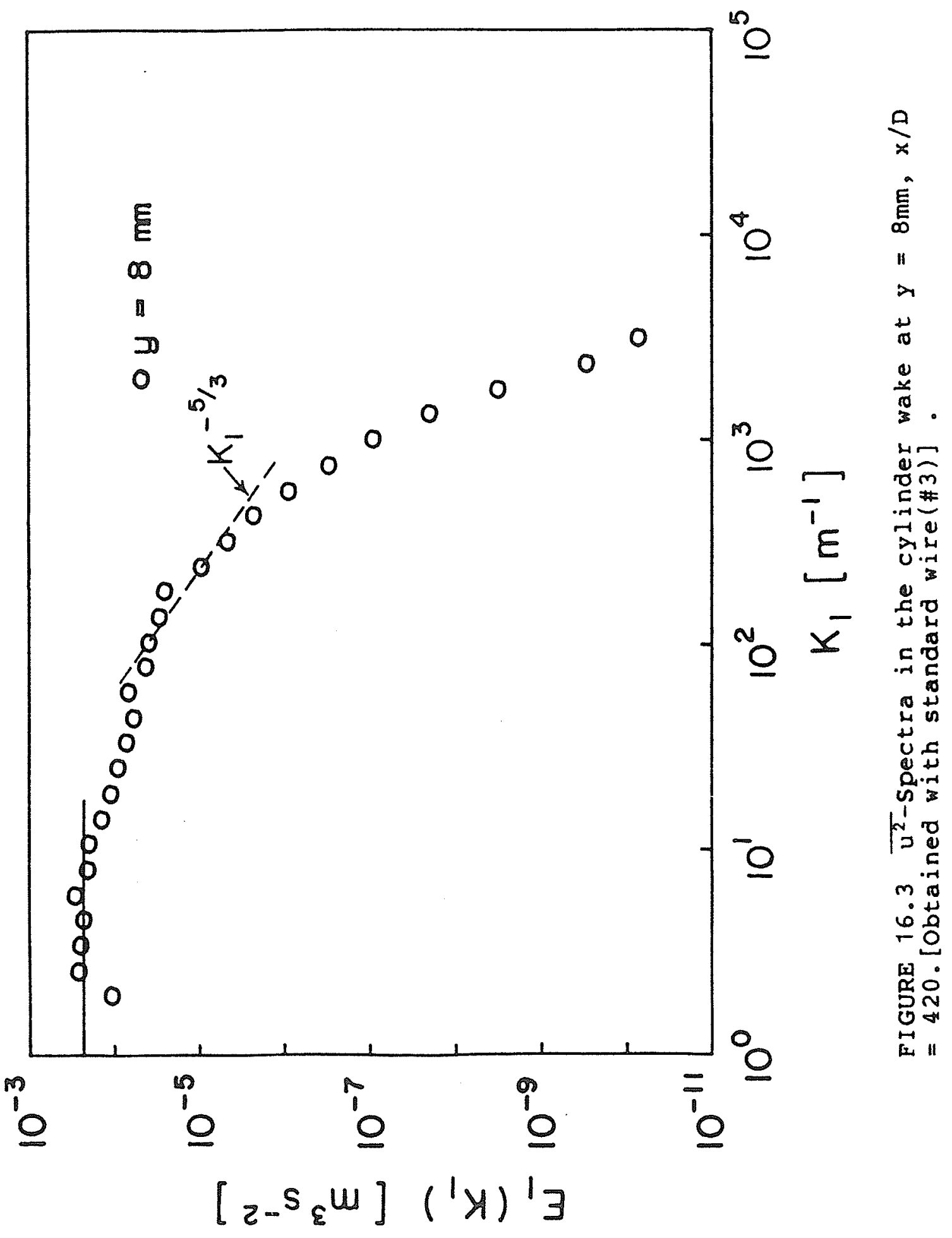




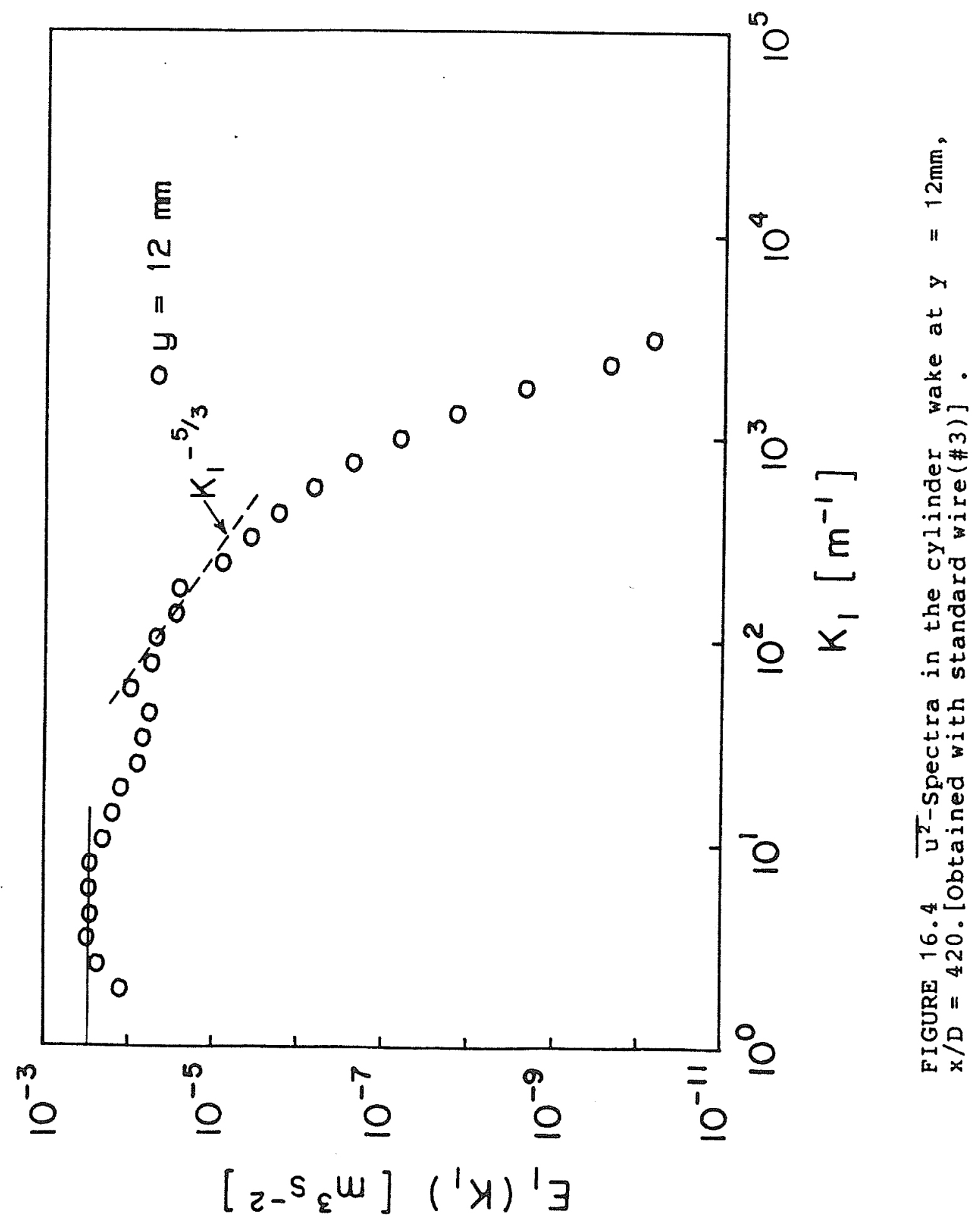




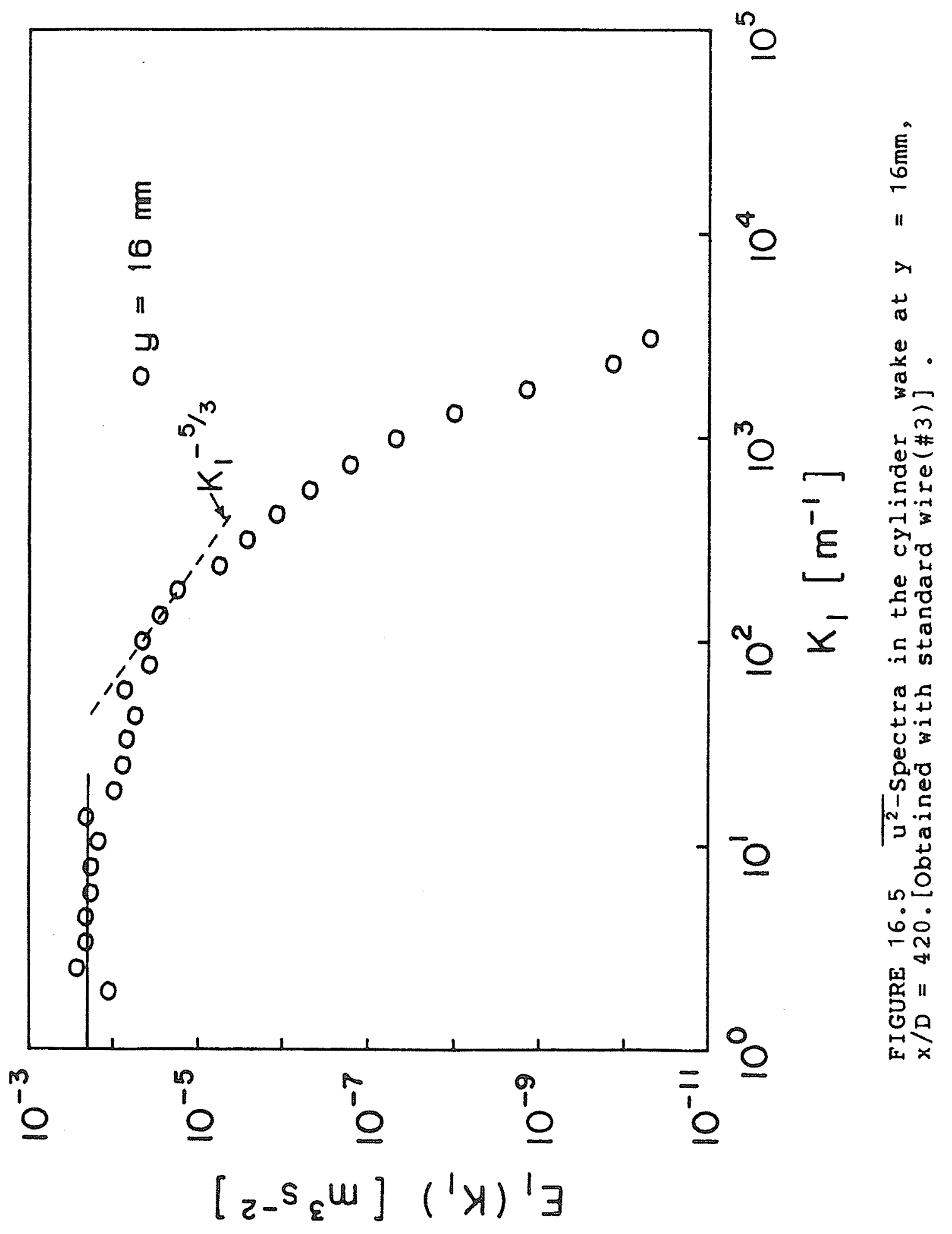




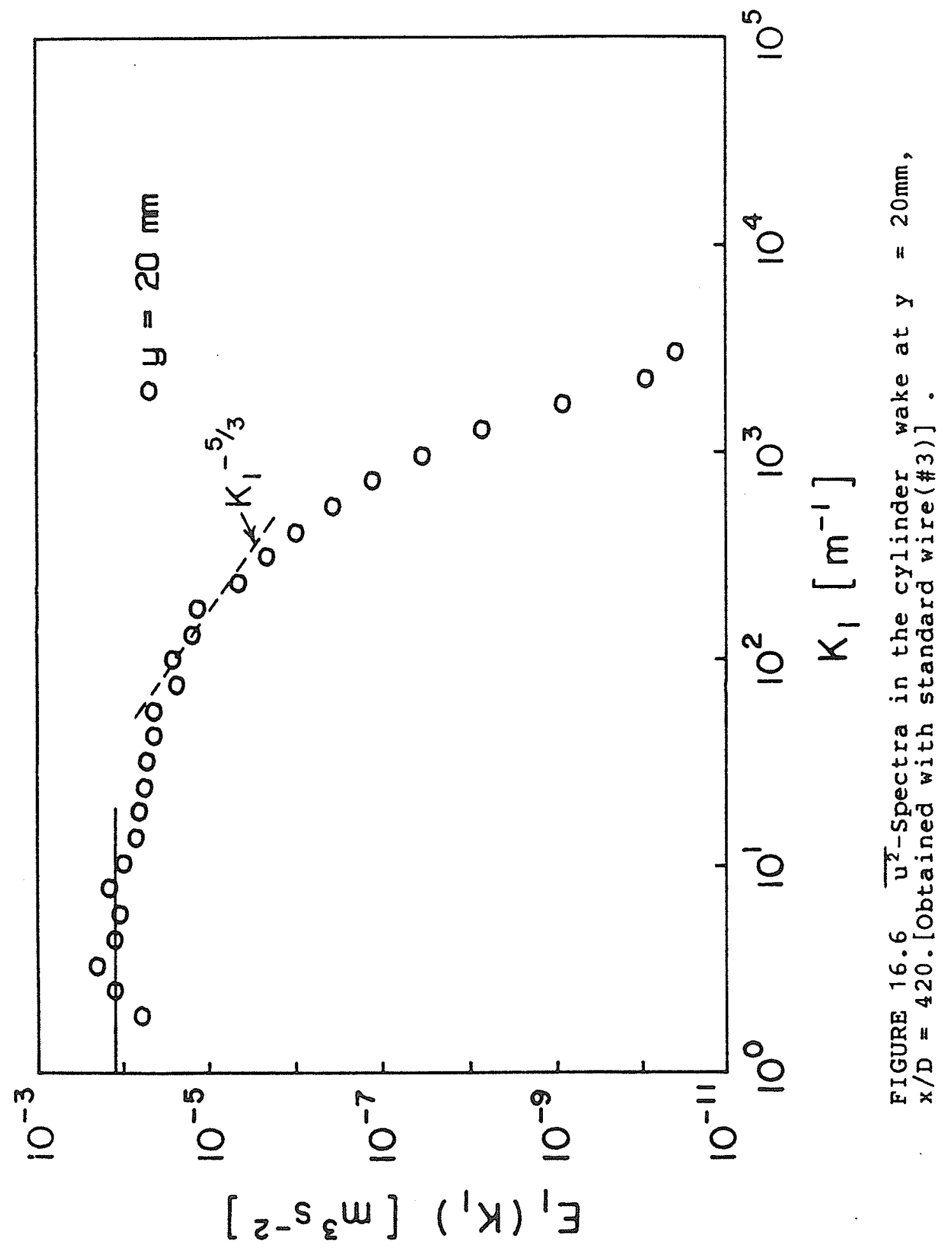




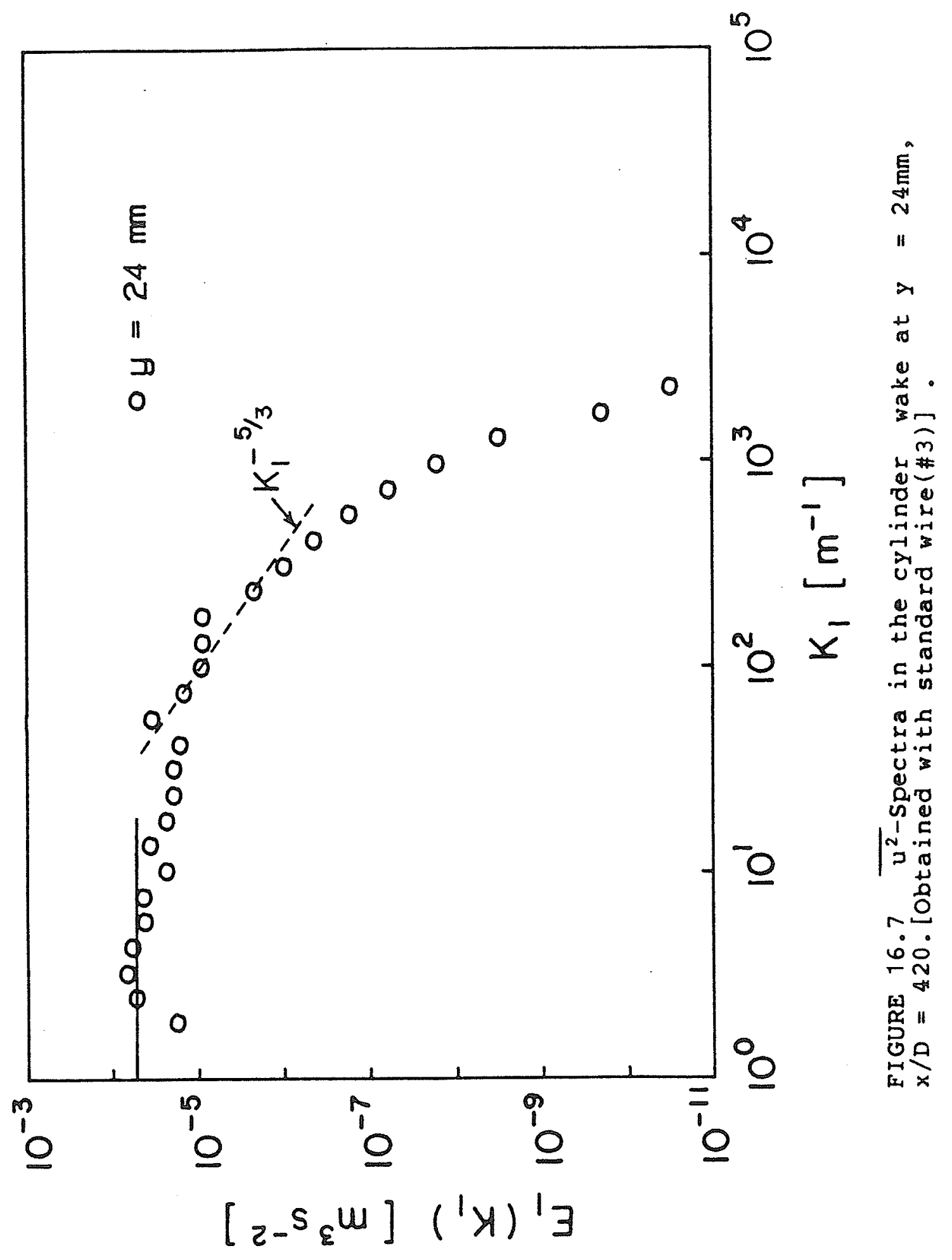




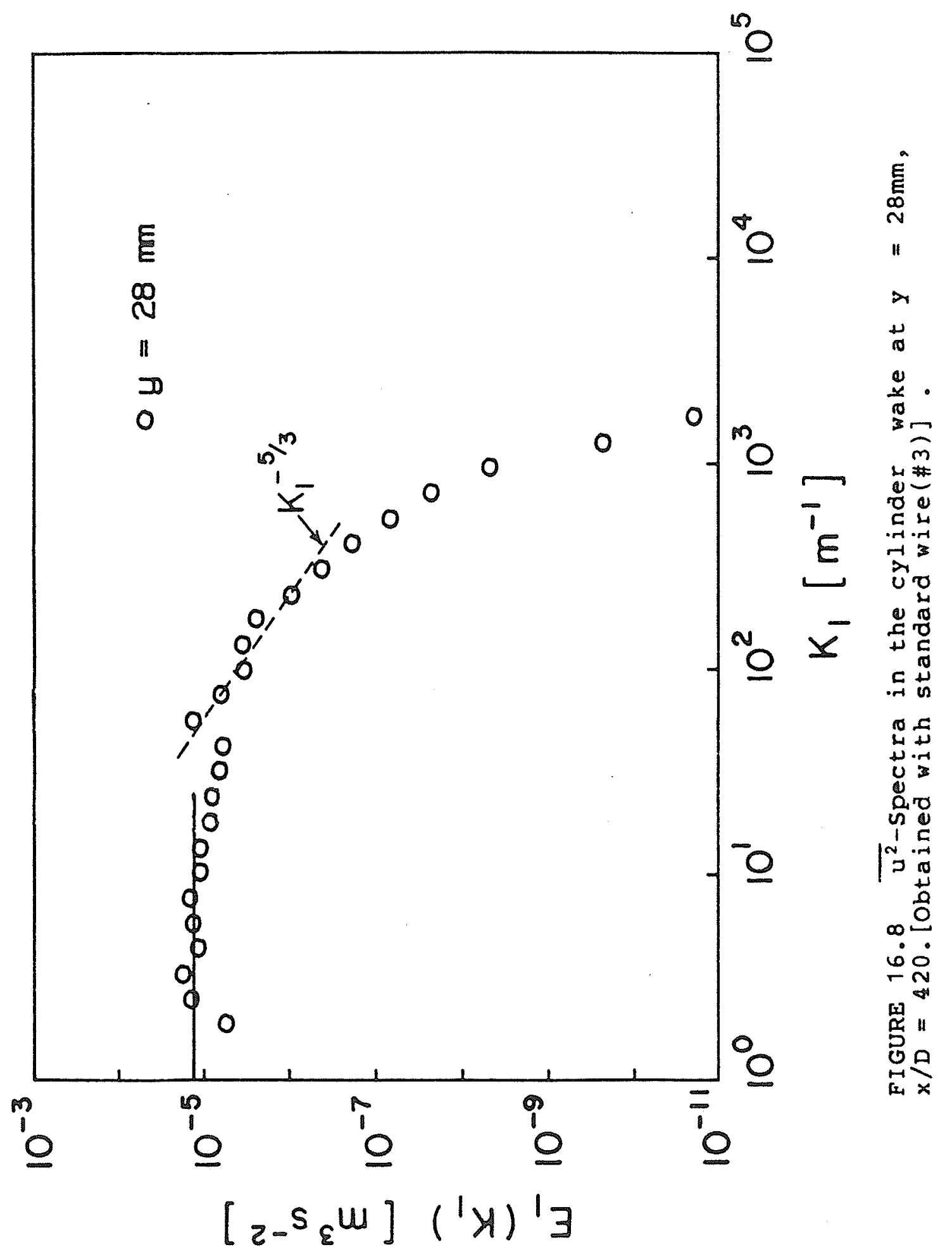




\section{APPENDIX A}

The derivation of the shear stress uv.

The shear stress per unit mass can be obtained from the $x$-momentum equation in a far wake as:

$$
-\overline{u v}=\int_{0}^{y} U_{\infty} \frac{\partial U}{\partial x} d y-v \frac{\partial U}{\partial y}
$$

The various terms of this equation are obtained separately as follows:-

Equation (11) can be written in the form:

$$
U_{\infty}-U=U_{0} \cdot G(n)=U_{0} \cdot e^{-(\ln 2) n^{2}}
$$

Differentiating the above with respect to $x$ gives,

$$
\frac{\partial U}{\partial x}=-G(\eta) \frac{\partial U}{\partial x} 0-\frac{\partial G(\eta)}{\partial \eta} \cdot \frac{\partial \eta}{\partial I} \cdot \frac{\partial L}{\partial x} \cdot U_{0}
$$

Each quantity in equation (A.2) is obtained as follows:From equation ( 9 ) we get,

$$
\frac{\partial U}{\partial x} 0=-1.28 * \frac{U_{\infty}}{2 D}\left(\frac{x}{D}+144\right)^{-3 / 2}
$$

Differentiating equation (11) with respect to $\eta$ yields,

$$
\frac{\partial G}{\partial \eta}=-2 n(\ln 2) e^{-(\ln 2) n^{2}}=2 n(\ln 2) G(n)
$$


Differentiting the relation $\eta=y / L$ with respect to $L$ we get,

$$
\frac{\partial n}{\partial L}=-\frac{y}{L^{2}}=-\frac{n}{L}
$$

By differentiating equation ( 8 ) with respect to $x$ we get,

$$
\frac{\partial L}{\partial x}=\frac{0.198}{2}\left(\frac{x}{D}+144\right)^{-1 / 2}
$$

The term du/dy can be obtained by differentiating equation (11) with respect to $y$.

$$
\begin{aligned}
& \mathrm{U}_{\infty}-\mathrm{U}=\mathrm{U}_{0} \mathrm{e}^{-(\ln 2) n^{2}} \\
& \therefore-\frac{\partial U}{\partial y}=U_{0} \frac{\partial}{\partial \eta}\left[e^{-(\ln 2) \eta^{2}}\right] \frac{\partial \eta}{\partial y} \\
& =U_{0}(-\ln 2) 2 n e^{-(\ln 2) \eta^{2}} \cdot \frac{I}{I} \\
& =-\left[\frac{2 U_{0} \ln 2}{L}\right] n G(n) \\
& \text { or } \quad \frac{\partial U}{\partial y}=\left[\frac{2 U_{0} \ln 2}{L}\right] \eta G(\eta) \text {. }
\end{aligned}
$$

Hence, the various terms of equation ( $A .1$ ), including $\partial u / \partial y$ are known. By substituting these terms back in equation (A.1) we can obtain the value of the shear stress $\overline{u v}$. 